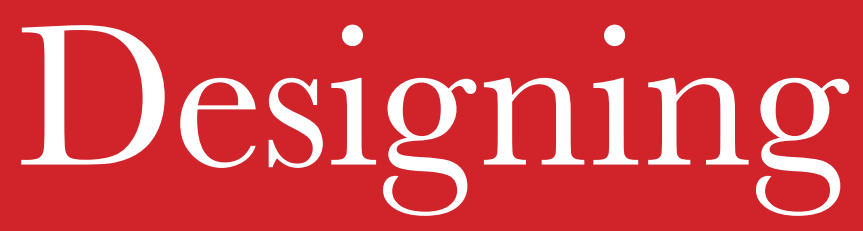

Prostitution

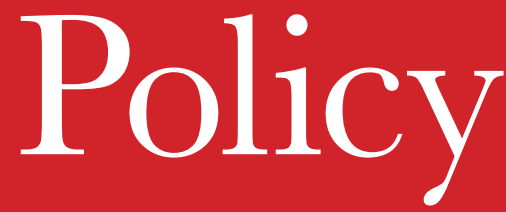

Intention and Reality in Regulating the Sex Trade

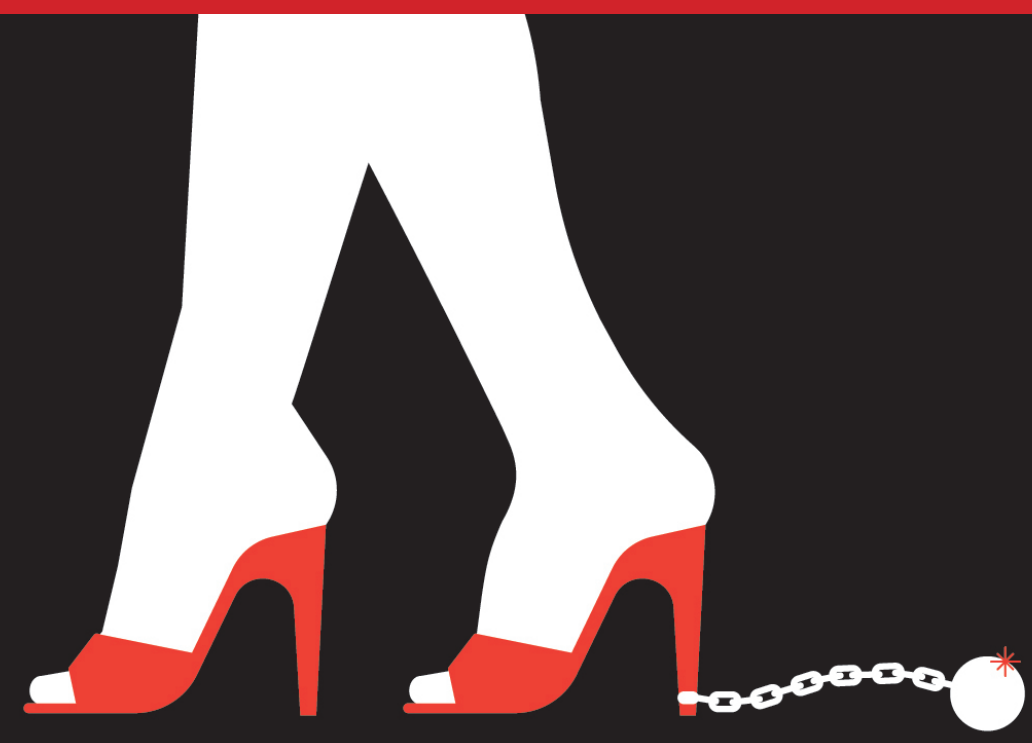

Hendrik Wagenaar, Helga Amesberger \& Sietske Altink 


\section{DESIGNING PROSTITUTION POLICY \\ Intention and reality in regulating the sex trade}

Hendrik Wagenaar, Helga Amesberger

and Sietske Altink 
Policy Press

University of Bristol

1-9 Old Park Hill

Bristol

BS2 8BB

UK

t: +44 (0)117954 5940

pp-info@bristol.ac.uk

www.policypress.co.uk
North America office:

Policy Press

c/o The University of Chicago Press

1427 East 60th Street

Chicago, IL 60637, USA

t: +17737027700

f: +1 773-702-9756

sales@press.uchicago.edu

www.press.uchicago.edu

(C) Policy Press 2017

(C) Cover image: Andrew De Loba

The digital PDF version of this title [978-1-4473-2426-3] is available Open Access and distributed under the terms of the Creative Commons Attribution-NonCommercial 4.0 license (http://creativecommons.org/

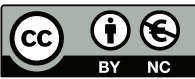
licenses/by-nc/4.0/) which permits adaptation, alteration, reproduction and distribution for non-commercial use, without further permission provided the original work is attributed. The derivative works do not need to be licensed on the same terms.

An electronic version of this book [978-1-4473-2426-3] is freely available, thanks to the support of libraries working with Knowledge Unlatched. KU is a collaborative initiative designed to make high quality books Open Access for the public good. More information about the initiative and links to the Open Access version can be found at www.knowledgeunlatched.org.

RU Knowledge Unlatched

British Library Cataloguing in Publication Data

A catalogue record for this book is available from the British Library

Library of Congress Cataloging-in-Publication Data

A catalog record for this book has been requested

ISBN 978-1-4473-2424-9 hardcover

ISBN 978-1-4473-3519-1 ePub

ISBN 978-1-4473-3520-7 Mobi

ISBN 978-1-4473-2426-3 ePdf

The right of Hendrik Wagenaar, Helga Amesberger and Sietske Altink to be identified as authors of this work has been asserted by them in accordance with the Copyright, Designs and Patents Act 1988.

All rights reserved: no part of this publication may be reproduced, stored in a retrieval system, or transmitted in any form or by any means, electronic, mechanical, photocopying, recording, or otherwise without the prior permission of Policy Press.

The statements and opinions contained within this publication are solely those of the authors and not of the University of Bristol or Policy Press. The University of Bristol and Policy Press disclaim responsibility for any injury to persons or property resulting from any material published in this publication.

Policy Press works to counter discrimination on grounds of gender, race, disability, age and sexuality.

Cover design by Hayes Design

Front cover image: Andrew De Loba

Printed and bound in Great Britain by CPI Group (UK) Ltd, Croydon, CR0 4YY

Policy Press uses environmentally responsible print partners

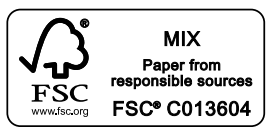




\section{Contents}

Acknowledgements $\quad$ v

one Introduction 1

Dora's story 1

The primacy of policy in prostitution $\quad 5$

The goals of the book $\quad 21$

A reader's guide to the book 23

$\begin{array}{lll}\text { two } & \text { Challenges of prostitution policy } & 27\end{array}$

The stigma of prostitution and the paradox of control 29

Prostitution politics as morality politics 33

Paradoxes of immigration 49

Obstacles to obtaining reliable numbers about $\quad 54$

prostitution and sex workers

The ineluctable importance of the local in 61

prostitution policy

Analysing prostitution policy $\quad 68$

three The local governance of prostitution: regulatory 71

drift and implementation capture

Policy implementation as policy formulation with $\quad 71$

different means

Policy design and policy instruments $\quad 79$

Local policymaking in the Netherlands $\quad 87$

Local policymaking in Vienna $\quad 117$

Conclusion: policy implementation, morality politics 135

and the corrosive effects of discourse

four The national governance of prostitution: 145

political rationality and the politics of discourse

Introduction: policy subsystems and policy streams $\quad 145$

National policy in the Netherlands $\quad 147$

National policy in Austria $\quad 170$

Conclusion 187 
five Understanding the policy field: migration,

prostitution, trafficking and exploitation

Introduction: prostitution as a complex policy field 195

Migration, prostitution and coercion 200

How immigration and labour law shape the 208

'modern slavery' problem

Prostitution and exploitation $\quad 212$

Prostitution, trafficking and exploitation: 218

an alternative framework

six Prostitution policy beyond trafficking: collaborative 227

governance in prostitution

The challenges of prostitution policy revisited:

harnessing a complex policy field

Introducing collaborative rationality in prostitution

governance

Sex worker advocacy and the state

Governance capacity and collaborative governance

Is collaborative governance in prostitution policy possible? 249

seven Summary and conclusion

Appendix: research design and methodology

Goals of the project

Research questions

Design of the study

Partnered research

Data collection 


\section{Acknowledgements}

Prostitution is a complex, contested, sensitive and fast-moving field, and this is a large and comprehensive book. It could not have been written without the generous support of a number of people. We thank Joyce Outshoorn and the anonymous reviewer of Policy Press for their extensive and constructive comments on the manuscript. They urged us to restructure the design of the book and to rethink some of our arguments. Without them the message of the book would have been considerably less focused. Agata Dziuban and Licia Brussa were kind enough to read on short notice Chapter Five, the chapter on trafficking, immigration and exploitation. This is an exceedingly difficult topic and their extensive knowledge and experience in this area prevented us from many errors and misjudgements in our discussion of these topics. As always whatever errors remain in the book are ours.

The research that forms the basis for this book would not have been possible without the generous participation and support of a large number of people. First, the members of the consortium group, officials from the cities of Rotterdam, Utrecht and The Hague, and later from the Women's Department of the City of Vienna (in particular Marion Gebhard and Alina Zachar), who were entrusted with the design and implementation of prostitution policy in their cities, and spent countless hours throughout the course of the research with the research team discussing research questions, research design, data, the interpretation of data, and the content of the various reports we produced. They were generous in providing us with insights into the everyday details of their practice, and they might like to hear that we learned a lot about the craft of policymaking in prostitution from them. We know that they will disagree with many of our conclusions in this book, but that does not detract from the fact that they were invaluable for the realisation of the research. We also need to thank Jos Koffijberg and Lydia Sterrenberg, who were the Platform 31 officers assigned to our project (Platform 31 calls itself a knowledge and network organisation in the field of urban policy. It brings together government, social organisations and businesses in addressing urban problems). Their professionalism and enthusiasm helped us sustain the project through sometimes rocky political moments. Wim Hafkamp, the then director of Platform 31, has been unwavering in his support for the project. Sylvia Bokelman conducted interviews, engaged in ethnographic observation, kept a diary and generously shared her insights and experience of the sex trade with us. Throughout the research Susanne Dodillet and Petra 
Östergren were our expert guides through the mirror palace of Swedish prostitution policy. Hendrik Wagenaar is exceedingly grateful to Catherine Healy and Calum Bennacchie of the New Zealand Prostitutes' Collective who on two occasions organised a series of meetings and interviews with key actors in New Zealand prostitution policy. He thanks them not only for their help in organising his field work and for the way they welcomed him in the sex worker advocacy community, but above all for the friendship they offered him and his wife. Hendrik is also deeply grateful to Mariska Majoor, erstwhile chair of the Dutch sex worker advocacy organisation PROUD, who, over many hours of coffee and homemade soup at the Prostitution Information Centre in Amsterdam, acted as an informal mentor and consultant on sex work. Without the wisdom of Catherine, Calum and Mariska this would have been a lesser book.

Research cannot be conducted without the willingness of a large number of experts and practitioners to take time out from their busy jobs to talk to a researcher. We realise that for them this is a onesided effort where the benefits mostly accrue to the researcher. We therefore want to thank the many officials, politicians, professionals and police officers who were kind enough to answer all our questions and to patiently explain the intricacies of their work to us. Thanks also to Marie-Theres Prantner from the Austrian federal Ministry of Health and Women's Affairs and chair of the federal working group on prostitution. Helga Amesberger became a member of the transprofessional work group, which provided her with valuable and rich insights about politics in practice. Our special thanks also go to the interviewers from the Austrian non-governmental organisations LEFÖ and maiz. Not only did they conduct many interviews with sex workers in Vienna and Upper Austria, but their discussions about the interview guidelines and the outcomes definitely contributed to better knowledge production and understanding. Finally we want to thank all the anonymous sex workers who trusted us sufficiently to share their experiences of sex work with us. We can only hope that the book is an accurate reflection of those experiences.

Hendrik Wagenaar thanks his wife Barbara Prainsack for being with him throughout the course of this project. Her love, critical understanding and unwavering support were essential in its design and completion. 


\section{ONE}

\section{Introduction}

\section{Dora's story}

Dora is Romanian. She came to Austria at the age of 20 to work in prostitution. She says she had a normal youth. She finished school at the age of 19. Her mother always pushed her hard: "Learn, learn, learn. My mother was obsessed by it." She wanted some quiet now. She says that perhaps "she had it too good".

Her entry into sex work "just happened" ("war einfach so"). She didn't have much experience as a young woman in Romania. She had had sex 10 times perhaps, and she detested blowjobs: "With this mouth I kiss the pictures of saints in church!" A woman in Austria who was a friend of the father of her school friend explained to her what sex work entailed. She also had little experience with alcohol. The night before she left for Austria she got drunk on gin and tonics for the first time in her life. She had to throw up. She is grateful that she hasn't become an alcoholic.

She travelled to Austria with a girlfriend from school and the father of the girlfriend. Later three more women joined them. The father agreed with the women that they would give him their earnings. He would save these for them and when they stopped working he would give them the savings. Dora says she trusted him, but in hindsight she concludes: "He said one thing and what really happened was something quite different." One of the women had been with this man much longer. One evening she drank too much and said in tears that the man had lied and that he would never return their earnings. Dora tells that the evening before his arrest the man fought with his son. His son accused him of treating the women badly. The son's girlfriend also worked for the man.

The women decided to jointly file a complaint against the man for pimping, rape and physical abuse. Dora only filed a complaint for pimping; she said he never beat or raped her. The man received two years. The witness testimonies in court were not anonymous. The man is now free and lives in Germany. Although he is her neighbour in her hometown in Romania, she says she doesn't fear him: "These people often threaten but they don't do anything; although you're never sure." After she accused him the police guarded her parental home for a while. 
Dora went to work in the establishment in Wels where she works now. She initially worked there from 2003 to 2006. After a change in Austrian immigration law, she had to leave the country in 2006. She didn't want to go back to Romania so she and her partner (who is also a sex worker) decided to go to Italy. They worked in Italy for six months. "It was very difficult. The work is illegal there, you don't know anybody, you live with someone, and you don't even know what papers you have." Dora and her partner worked as dancers, but they had few clients. She never did escort work because she was too afraid of that. She got to know a man. They got into a fight over money. He wanted $€ 100$ a month from the couple. She asked him if he was out of his mind and offered him a one-time payment of $€ 200$. After that he damaged the couple's car all the time, so that Dora had to have it repaired constantly.

Dora, her partner and two other women were arrested at work. "The police were funny. I started flirting with them." The police took them into another room and asked if the women would show their breasts. Dora said: "No problem." She thinks she was lucky because she had nice breasts. She was able to get all the women released. However, they were on the street now, without house or car, as the car was in the garage because of the damage inflicted by the man she had argued with. At the station they got to know some Romanian people, who, when they heard of the couple's hopeless situation, invited them to stay with them. Dora thought that one of the men wanted to have sex with her, but when he came to her in the middle of the night he just put a blanket over her. It turned out that he was from Interpol, but he had no information on them and when he checked that the car was indeed in the garage, they were free to go, but they had to leave Italy.

Dora and her partner decided to go to Spain. Romania was not yet part of the European Union (EU) and they had overshot the legal period of stay in the EU by then. They were once more illegal. They were arrested when the police raided the club where Dora worked. She spent 28 months in a detention centre waiting to be extradited. She had the right to engage a lawyer, but the lawyers said, and the other inmates confirmed this, that their case was hopeless. The couple then opted for voluntary return to Romania. The living circumstances in the detention centre were tough. There were women there who had been in prison who said that prison was better. The guards were all "arseholes". While Dora was awaiting her trial, she and her partner were put in a cell with men. She was handcuffed to an older man and the guards made fun of them. The food was terrible: "In Romania that food would only be good for pigs." They mostly ate bread. When she later asked to be locked up in one cell with her partner, the guards deliberately separated them. She cried a lot in those days. She and her partner wrote to each other every day; that made it easier. She still has the letters. A client who liked her 
visited her sometimes in "prison" and brought them some of their possessions. When she was at last deported to Romania, all her belongings were returned to her, including her money.

Dora is happy to work in Austria again because sex work is legal there. She says that working illegally in Italy and Spain caused her much stress: "You always have to be careful whom you talk to, which clients you take, when there would be police controls. It burdened me a lot. I have done enough illegal sex work. I never want to do that anymore." However, in Austria, "You go to sleep with one law and wake up with another. Things are very uncertain here." (Here Dora is referring to the abolishment of the so-called prostitution visa in 2006; that is why she had to leave Austria for Italy.)

She says that her legal position is nevertheless far from ideal in Austria: "I am powerless here. I don't get a wage slip. I can't take out any credit or loans. I can't lease a car. I pay the tax office, I pay social security, but I won't get a pension. I don't get anything. I also don't get unemployment benefits. I don't need them because in this profession you always find work easily. I can't do anything in my name." She adds that she needs a work permit for gainful employment, although she has already lived in Austria for a long time and pays taxes and social insurance.

We begin this book with Dora's story because it presents the face of prostitution in Europe today. It is representative of the stories of many sex workers that we encountered in the course of our research. What does Dora's story tell us? What lessons does it contain about prostitution in contemporary Europe? And how does it speak to the challenges of regulating prostitution in a just and effective manner? First, the rule of law is crucial for the position of sex workers. In the contemporary, fierce debates about the best 'policy regime' for sex work, this basic fact is often overlooked. Even imperfect forms of regulation are better for the human rights of sex workers than the illegality that automatically comes with the outright prohibition of prostitution. Dora's story suggests that illegality is inextricably bound up with arbitrary behaviour of state officials, police corruption, and living in constant fear of being arrested (Kempadoo, 2012b, p 252). One argument that we will develop in this book is that policy choices have consequences. What looks good and morally just on paper has concrete, real-world consequences once policy is operationalised and implemented. It is every nation's sovereign right to prohibit or legalise sex work, but in the final analysis such policies come as 'packages' of beliefs about and attitudes towards women, laws, rules, agencies, 
professionals, policy instruments, practices and consequences, both intended and unintended. Whenever we talk of policy, what we should have in mind is the totality of what policy entails in the real world.

Second, sex work is an occupation that is dominated by immigrants. Over 90 per cent of female sex workers in Austria and about 70 per cent in the Netherlands are immigrants; in this these two countries are representative of the other countries of north-western Europe. Sex work requires no diplomas or entry requirements, earnings are immediate, it is a cash economy, it requires minimal language skills, and it allows for high mobility. This makes it attractive to new immigrants, people 'not from the privileged class, gender or race' (Chew, 2012, p 74), who attempt to exercise their freedom of movement in seeking better economic opportunities and, an often overlooked motivation, less oppressive gender relations. Sex work is not the only 'entry occupation' for immigrants as we will see, but the migratory nature of sex work has profound implications for the position of sex workers. One of those implications is that their position as single migrant women in a foreign country, and the criminalisation of their work environment, makes them vulnerable to exploitation (Chew, 2012, $\mathrm{p}$ 79). This is in addition to prostitution's intrinsic vulnerability as a stigmatised occupation. Another implication is that the same qualities that make prostitution attractive to immigrants make it an exceedingly difficult 'object' for public administration and legal regulation. We argue in Chapter Five that the relationship between migration, prostitution and public policy is riddled with complexities. In Chapter Six we make suggestions for how to acknowledge these complexities in a constructive way.

The third lesson is the opposite of the first: legal rules and regulations can make life very difficult for sex workers. In many countries the laws regulating immigration and those regulating sex work are deeply intertwined. The same goes for the national discourse on immigration and prostitution (Vance, 2011; Kempadoo, 2012a). Restricting the possibilities for lawful migration increases the demand for third-party assistance of the migrant (Gallagher, 2001, p 977; Chuang, 2010). Once they are settled in the arrival country migrant sex workers struggle with arcane and constantly changing rules that regulate the conditions for legal stay or work in the country. As Dora puts it trenchantly: "You go to sleep with one law and wake up with another." Examples abound. In Dora's case she had to leave the country after the law changed. In the Netherlands an overnight change in the rules prohibited Romanian and Bulgarian sex workers to make use of a special tax arrangement that allowed them to work independently. The result was that many of the 
women to whom this change applied became dependent on proprietors or marital partners for finding a job or staying in the country. Female asylum seekers who are awaiting a visa decision can, according to Austrian law, de facto only work in prostitution. Non-EU women can only stay in the country for a few months at the time and have to leave temporarily to avoid becoming illegal. And for those migrant women who have lived and worked in the country for many years and have paid income tax and social security benefits, it is inexplicable that they do not have the same rights as other citizens, or at a minimum the right to work as an employee.

Finally, Dora's story is the story of trafficking. An older male acquaintance takes advantage of these young women's vaguely articulated urge to leave Romania and try their luck in one the affluent countries of north-western Europe. Yet the story also shows ambivalences that complicate the straightforward trafficking story. Dora is well educated and can hardly be called naive. She is vague about her entry into sex work ("It just happened"), but it is not a story of deception or violent initiation. After the Romanian trafficker was convicted Dora goes back to sex work. She says that the proprietor's take amounts to about 45 per cent of her earnings, that she works eight hours a day (and at most 48 hours a week) and can more or less set her own hours, can decide herself which sexual activities she want to engage in and complains about the lack of hygiene in the club. She says she earns enough to live off, and regularly sends money home - "as every girl does", she adds. Her legal situation in Austria is tenuous. Dora doesn't complain, but from the perspective of what is considered legally and normatively acceptable in Austria, Dora's work situation is one of labour exploitation. And although Dora can be seen as a victim, she does not behave like one. Instead she displays initiative in making a better life in another country and shows to be plucky and resourceful in difficult situations. Contrary to the pervasive narrative of sex workers as 'victims', Dora demonstrates considerable agency in organising and managing her life (Ditmore, 2012, p 110). Prostitution, far from 'enslaving' her, is in fact a self-chosen means for social and personal betterment.

\section{The primacy of policy in prostitution}

In contemporary societies prostitution as a social phenomenon cannot be seen apart from the efforts of authorities to prohibit, contain or regulate it. The different ways in which prostitution manifests itself - as streets of softly red glowing windows with scantily clad women 
behind them, as groups of women huddled on the sidewalk of a city street, as discrete clubs whose advertisements greet you at the airport, as the woman who asks guests if they want to share a drink with her in a hotel bar, as the Thai masseuse who offers a "happy end' for an additional fee - are the joint outcome of autonomous social-economic forces, government intervention and civil society reactions. Prostitution, in all its manifestations, is deeply entangled with the state. While trade liberalisation and the ensuing structural adjustments, poverty, migration trends, education and employment possibilities, and global connectedness through the internet influence the 'supply' of sex workers, an array of government interventions shapes the nature, organisation and location of prostitution markets. Zoning laws determine which urban spaces are designated for prostitution purposes; national laws determine the legal position and civil rights of sex workers, while the mandate, skills and expertise of professionals and administrators influence the health and work conditions of sex workers, police procedure affects the security situation of sex workers; and, as we saw in the interview with Dora, immigration laws influence sex workers' mobility. Also, for reasons that we will explain in the next chapter, in most western countries, prostitution is considered a matter of considerable moral urgency. Policy makers and the media award it substantial amounts of their attention. No matter how policy towards prostitution is formulated, in every country it leaves its imprint on the market for sexual services.

Public policy is a woolly concept that has different meanings in different cultures. It is little wonder then that the literature provides dozens of definitions of public policy, but, with differences in emphasis, most of them contain the following elements: public policy comprises an expression of intent, often, but not exclusively, by one or another agency of government, that is translated into specific proposals, resulting in an authoritative decision (such as legislation or formal regulation) that in turn is implemented through the allocation of funding and staffing and the selection and application of appropriate policy instruments (Cairney, 2012, pp 23-24). Policy implies therefore a distinct moral and teleological relationship between the state and society. From the perspective of the state, policy formulated in a particular societal domain defines its values and aspirations regarding this domain, its responsibilities towards its citizens and the obligations of these citizens towards the state and each other, its preferred imagery of its citizens, and 
its economic, cultural and moral position in the international world. ${ }^{1}$ From the perspective of citizens, policy is at the same time a focal point for their needs, values, ideals, aspirations, meanings, self-image and identity, and a set of constraints and opportunities imposed on the way they organise their daily life. Policies are a practical and lexical space in which political struggles over needs, claims, understandings, values and opinion are acted out - struggles between citizens and societal organisations on the one hand and the state on the other (Hajer, 2003). Thus, in most domains of life, such as work, housing, health, education, adult care, safety, immigration, energy, urban space, or the natural environment, public policy is a key platform for the ongoing interaction between state and society. This is recognised in the many subdivisions of the policy literature that deal with sectorspecific policies. Yet, despite the central importance of policy in shaping and articulating societal domains and individual destinies, relatively little attention has been paid to prostitution policy in the literature on prostitution. Or, more precisely, much of the literature prefers to discuss prostitution either in non-policy terms or to reduce public policy towards prostitution to only one element of the policy process. Each academic field develops its own traditions; its own preferred foci of attention, problem definitions, and styles of writing. More specifically, in the academic literature, prostitution is predominantly discussed as shaped by society-wide extraneous influences, as broad (national) policy regimes, in terms of international governance regimes and human rights, as discourse, and as the outcome of broad shifts in governmentality.

Extraneous forces. Several scholars argue that the shape of the sex trade is not so much influenced by public policy as by external determinants such as 'rapid and large-scale economic and cultural transformations' (Bernstein, 2007, p 168; Agustín, 2008). These authors urge us to see prostitution as 'sex labour' and thereby as one manifestation of profound changes in the nature, diversity and spatial location of service work in general. These changes then lead to 'new configurations of intimate life as well as in new erotic dispositions' (Bernstein, 2007, p 28). These larger economic and cultural transformations are deemed to be so powerful that national responses to prostitution are hardly more than the enactment of this 'post-industrial' sociological script. Against the inexorable forces of these socio-cultural tectonic shifts policy

This is a simplified image of public policy. In contemporary society policy denotes a complex triangular relationship between state, civil society and the corporate world. 
is considered as largely ineffectual. Analysts argue for example that policies as antithetical as the Swedish attempt at client criminalisation and the Dutch attempt at legalisation of sex facilities result in the same outcomes: the banishment of outdoor sex work from gentrified city centres and the proliferation of venues of sex work for a more affluent clientele (Bernstein, 2007, pp 168-9; Scoular, 2010).

An important variant of the extraneous forces approach is the 'transnational feminist' approach. This is the label for an important perspective on prostitution that explicitly situates the sex trade in large migration trends. These trends are the result of changes in the postcolonial global political economy, or, as Kempadoo puts it, in a formulation typical for this type of approach, of 'hegemonic and local patriarchies, globalized capitalism, and the widening gaps in income and wealth, as well as by reconfigurations of empire under late twentiethcentury globalization that reinscribed international hierarchies around notions of racial, religious and national difference' (Kempadoo, 2012a, $\mathrm{p}$ xix). Prostitution is thus part of a set of strategies of migrant men and women, often, but not exclusively, from developing countries, to improve their position and life perspective in the global economy. And although these men and women are vulnerable to deception, coercion and exploitation, they are 'agents in their own right, with complex identities and subjectivities' (Kempadoo, 2102a, p xix; see also Sassen, 2002). Despite the focus on global trends, the transnational feminist approach is explicitly grounded in the everyday experiences of sex workers. Research in this tradition foregrounds the voice of the individuals who work in the sex trade to enable scholars to redefine the dominant intellectual and ideological frameworks around prostitution. The 'transnational feminist' approach contains many important insights for a deeper understanding of an effective and humane prostitution policy, yet it does not draw these implications itself. It usually restricts itself to presenting a critical postcolonial alternative to traditional approaches to prostitution, emphasising that prostitution is not an isolated phenomenon in the urban landscape but instead a symptom of larger trends in the changing global political economy and the ensuing struggles for identity, recognition, human rights and citizenship that flow from it. In the remainder of this book, particularly in Chapter Five, we will draw on insights from the transnational feminist perspective in our analysis of prostitution policy.

Policy regimes. The distinction between different policy regimes is a common trope in the literature on prostitution policy. In the policy literature the term 'policy regime' expresses a certain coherence and continuity of design and execution in a policy field. These derive from 
the way a problem is formulated, the actors and organisations that are involved and make decisions, and the kind of instruments and solutions that are favoured. Howlett and colleagues say, for example:

The term 'policy regime' attempts to capture how policy institutions, actors, and ideas tend to congeal into relatively long-term, institutionalized patterns of interaction that combine to keep public policy contents and processes more or less constant over time. (2009, p 86)

The concept thus refers to a recognisable and stable policy style that is the aggregate of organisational routines, habitual interactions and shared values and understandings among key actors. In the prostitution literature the concept of a policy regime is taken in a somewhat narrower sense. Outshoorn, for example, defines a regime as 'sets of laws and practices governing prostitution that shape prostitution in their respective jurisdictions in distinctive ways' (Outshoorn, 2004a, p 6, but see also Bernstein, 2007; Abel et al, 2010; Chuang, 2010; Weitzer, 2012). As this definition illustrates, prostitution policy regimes are thought to coincide with national borders and consider laws the main vehicle for policymaking. This perspective on prostitution policy is borne out for example in Outshoorn's analysis of the national parliamentary debates that resulted in the decision to legalise the commercial exploitation of prostitution in the Netherlands, and her subsequent analysis of the changes that resulted in a proposal for, and subsequent defeat of, a new repressive national prostitution law of 2010 (Outshoorn, 2004a; 2012). There is considerable debate about the type and proper nomenclature of the different regimes (Agustín, 2008; Phoenix, 2009; Abel et al, 2010; Chuang, 2010; Scoular, 2010), but that need not concern us here.

A different approach to policy regimes consists of the continuing efforts of transnational organisations such as the International Labour Organization or the United Nations to design international protocols and agreements on prostitution, trafficking, labour exploitation or organised crime. The 2000 UN Protocol to Prevent, Suppress and Punish Trafficking in Persons, Especially Women and Children is the most familiar and influential example in the prostitution literature. Similar to the policy regime approach, its attraction resides in a certain authority that follows from its generalised character - from the very circumstance, in other words, that broad moral end-point indications are not disturbed by potentially controversial details of execution. The UN protocol not only provides the definition of trafficking for states 
that have signed up to it, but more surreptitiously, it imposes - and legitimises - a criminal justice approach to trafficking with an emphasis on prosecution of both traffickers and (migrant) victims instead of human rights and service provision (Chuang, 2010, p 1663; Smith, 2011; Vance, 2011; Kempadoo, 2012a). It is less important in this respect that the protocol has been deliberately formulated in such a way that it allows states considerable leeway in formulating or continuing their own national policy approaches (Ditmore, 2012, p 115). Or, differently put, global governance regimes such as the UN protocol also require further specification to be able to function as effective forms of policy regulation.

One of the reasons for the popularity of the regime concept is that it neatly coincides with the popular debate on prostitution. Opponents of prostitution argue for its prohibition or for client criminalisation; pragmatists for whom prostitution is an ineradicable element of human society argue for its regulation; and those who consider prostitution an occupation as any other argue for the legalisation or decriminalisation of the sex trade. These moral positions on prostitution, particularly the abolitionist framework, restrict themselves to broad-brush regime indications, generalised end-point indications, without much specification of how such regimes are to be implemented, sustained and evaluated.

Regime typologies have been criticised on several grounds. They do not necessarily coincide with national borders, they are insufficiently consistent as more than one regime can be discerned in the same country or even in one policy programme, and they ignore the complex and multi-level character of prostitution policy (Phoenix, 2009; Skilbrei and Holmström, 2013; Wagenaar et al, 2013). Does that mean that the policy regimes in the prostitution literature must be seen as convenient shorthand for a complex set of processes, institutions and actors, somewhat as Howlett and colleagues' definition implies, and that scholars can be trusted to be careful enough to elaborate when they analyse prostitution policy? In the hands of scholars such as Chuang, this is how the regime indications are indeed used. In her article she carefully reconstructs the legal regimes that underlie the different regime types (Chuang, 2010). But there is a darker side to the regime labels, as the uptake by popular discourse betrays. Regime labels are not just innocent summaries of complex policy processes. They tend to have a performative character. Not only do they function as banners under which proponents of different moral positions towards prostitution unite, but they also refer to ideal types - not in the usual Weberian sense of the word, but in the way that poststructuralists use 
the term (Glynos and Howarth, 2007). Regime labels are instances of the fantasmatic in public policy. They highlight the crucial role of fantasy and utopian thinking in the design of policy, a fantasy that serves to fill uncomfortable cognitive gaps. We will encounter the importance of fantasy in prostitution policy later in this book, in particular in Chapter Two, where we discuss morality politics.

Discourse analysis. Another common form of academic writing about prostitution focuses on discourse. Authors in this tradition usually explain the shape a policy has obtained in a particular country by referring to the national discourse about prostitution (Outshoorn, 2004b, 2012; Sauer, 2004), or they explain how the issue of trafficking has come to dominate the (inter)national debate on prostitution (Chuang, 2010; Doezema, 2010; Sanghere, 2012). Discourse analysis comes in two forms. The first analyses broad national debates about prostitution and how these influence political decision making. Outshoorn's analysis of the outcome of the Dutch parliamentary deliberations on the legalisation of the commercial exploitation of prostitution is an example (Outshoorn, 2004b; 2014). The underlying premise is that the way prostitution is represented in the national media, in policy reports and in speeches before parliament has consequences for the design of public policy. Outshoorn carefully traces how different actors have contributed to the shaping of a multi-site debate on the nature of prostitution in the Netherlands and how these imageries predispose to certain preferred solutions. This form of discourse analysis is good at explaining changes in prostitution policy. Outshoorn's book is also a fine example of the way that discourse analysis can be used in a comparative way. Chuang's analysis of the impact of the trafficking discourse on US prostitution and foreign policy is another outstanding example of this type of discourse analysis. Chuang argues that radical feminists in the US managed to capture the debate on prostitution and usher in a hegemonic 'neo-abolitionist' policy approach to prostitution (Chuang, 2010). ${ }^{2}$

2 A note on terminology: 'neo-abolitionism' is the term that is often used in the literature to indicate the current dominant movement to eradicate or suppress prostitution in society by applying criminal law to clients and third parties. As Chuang sates: '(I)n their (the neo-abolitionists) opinion, pimps, brothel owners and managers, clients and any third parties who assist women to travel and work in the sex industry should be prosecuted for rape, trafficking or both' (2010, $\mathrm{p}$ 1669). In this ideological framework sex workers are victims of male patriarchy who should be 'rescued', although in reality, because of the criminalisation of their work environment, they become more vulnerable. As there can be no such thing as non-coerced prostitution, broad anti-trafficking laws and repressive enforcement 
The second form of discourse analysis is more radically social constructivist. The central concepts in such analysis are myth, meaning and power. The purpose of constructivist discourse analysis is not so much to confront certain myths about prostitution (in particular the myth about trafficking as an epidemic worldwide phenomenon) with the reality of sex workers' lives or the utter lack of reliable data, but to trace the origins (or genealogy) of these images, and how they succeed in convincing the larger world of their truth claims (Walkowitz, 1980; Doezema, 2010, p 10). By placing the discourse on trafficking in an historical perspective, the analyst discerns larger patterns of meaning making and the coalitions and mechanisms (such as funding decisions, organisational design, media attention) that fuel those meanings and succeed in imposing them on the wider public. Constructivist discourse analysis is particularly strong in its analysis of the role of experts who put forward authoritative truths about prostitution and trafficking. It explains the naturalisation of certain images and understandings through the repeated use of certain narrative tropes that are owned and supported by political, academic and moral authorities.

Discourse analysis is an important but ultimately limited way of analysing prostitution policy. It mostly contributes to explaining the agenda-setting phase of the policy process where it demarcates how common metaphors and tropes suggest policy solutions and determine the limits of what is possible and permissible to say. In able hands, constructivist discourse analysis shows how ideology becomes embedded in laws, regulations and policy programs, and how, inversely these policy schemes bestow legitimacy on the reigning discourse (Walkowitz 1980; Corbin, 1990). Discourse analysis is particularly strong in tracing the ramifications of power and authority in a particular political-administrative domain and the decisive role that professionals and academic experts play in this. For example, through their careful and detailed analysis of 19th century arrangements for regulating prostitution, historians who work in this Foucauldian tradition have provided suggestive insights into contemporary policymaking. However, a similarly detailed, similarly comprehensive "history of the present' of prostitution policy has not been written yet. While discourse

schemes are the logical approach to prostitution (Chuang, 2010, p 1669). The label abolitionism explicitly refers to the 19th-century movement to abolish the transatlantic slave trade and the subsequent early 20th-century feminist movement to fight 'white slavery', or licensed prostitution. Neo-abolitionism is particularly strong in the Anglo-Saxon world, although its expression in public policy - client criminalisation and use of law as a pedagogical tool - was designed in Sweden. In this book we use the label abolitionism to refer to this ideology. 
analysis is particularly well suited to drawing the different positions, it is much less adept at explaining how discursive constructions of prostitution are related to policy design. One of the purposes of this book is to do just that: to use discourse analysis to explain policy formulation and implementation in Austria and the Netherlands (Chapters Three and Four). We will see there that discourse itself is not sufficient as an explanation for policy change. We require the introduction of veto points for example to explain why the repeal of the brothel ban was first rejected by Dutch parliament, albeit passed a few years later.

Human rights and international governance. The human rights literature is largely concerned with international governance regimes in prostitution, in particular the UN Protocol to Prevent, Suppress and Punish Trafficking in Persons, Especially Women and Children, as adopted in Palermo in 1999. Much of the literature attempts to assess to what extent the international governance of prostitution is driven by human rights or by a concern over security issues surrounding migration, generally concluding that the first takes a back seat to the second. Gallagher concludes, for example, that national states tend to focus on repressive measures against illegal migration and organized crime, rather than on strengthening migrants' human rights (Gallagher, 2001, p 994). Other recurrent topics are the exact interpretation of the various clauses of and definitions in the protocol, how the bitter conflicts between prohibitionist and legalisation camps have affected the wording of the protocol (Gallagher, 2001; Ditmore and Wijers, 2003; Ditmore, 2012), the effectiveness of the protocol, and the importance of focusing on labour and criminal justice policies to strengthen the human rights of sex workers (Chew, 2012, pp 75-78). In its foregrounding of human rights and its tentative acknowledgements that trafficking includes other industries besides prostitution, most authors are guardedly optimistic about the protocol, noticing that it represents an improvement over the more repressive 1949 Convention for the Suppression of the Traffick in Persons and of the Exploitation of the Prostitution of Others. However, little or no attention is paid to the translation of the UN protocol into national policy. In fact, as some authors argue, the protocol has been kept deliberatively vague to accommodate almost opposing policies towards prostitution by the signatory nations (Ditmore, 2012, p 115). We will see that the effect of the protocol on national policy is often not felicitous, and that it has been used to legitimise repressive prostitution measures in which concerns over immigration overrule the human and civil rights of sex workers. 
Governmentality. Finally, there is a group of scholars that is interested in changes in governmentality (Scoular and O'Neill, 2007). The term governmentality depicts a style of governing in which all aspects of public life and individual conduct are in principle subject to regulation. The process of governing should not be seen as the expression of a monolithic power centre or grand ideology, but instead as the accumulation of a myriad of micro-practices within local programmes such as schools, prisons, welfare agencies, corporations and disability programmes, that sustain, modify and even generate what we perceive and experience as the institutions of the state (Foucault, 1991, p 102). These regimes of government are made possible because state agencies rely on, and implicate, communities, neighbourhoods private businesses, professionals and citizens to achieve their ends (Dean, 1999, p 70). In a rather jargon-infested phrase, Walters summarises governmentality as 'multiply constituted, polytemporal and recombinatory' (Walters, 2012, p 40). Governmentality is aimed at regulating populations instead of territories and it does that, almost surreptitiously, through weaving a web of techniques, tactics and vocabularies - 'a relatively durable network of heterogeneous elements (discourses, law, architectures, institutions, administrative practices and so on)' (Walters, 2012, p 36) - that aims to create a shared consciousness, particular identities and desired practices among the population. Rose and Miller have famously argued that governmentality operates along two channels of activity: political rationalities and governing techniques (Rose and Miller, 1992). The first refers to the way that programmes of government are formulated within broad discourses of collective truth, proper ruling and moral justification. ${ }^{3}$ The second refers to a plethora of techniques that are deployed to put governmental rationalities into effect. Rose and Miller describe these technologies as the 'complex of mundane programmes, calculations, techniques, apparatuses, documents and procedures that act on the subjects of governance, to coerce, persuade, cajole, suggest, or goad them to behave in certain preferred ways' (1992, p 175).

Scoular and O'Neill's 2007 article is a good example of the governmentality approach to prostitution. The authors observe a movement in prostitution policy from " "enforcement" (punishment) to "multi-agency" (regulatory) responses designed to exit women from the sex trade' (Scoular and O'Neill, 2007, p 764). This is part of a broader

3 The governmentality approach is in effect another form of discourse analysis, except that it takes discourse in a much wider, more ontological, sense (Wagenaar, 2011, ch 6). 
historical trend in the regulation of prostitution that proceeds from 'regulationism' via 'suppression' to the current neoliberal 'welfarism'. The 'welfarism' approach is characterised by two elements: a reliance on expert knowledge and the implication that the subjects are to be controlled through appeals to moral responsibility. As the authors put it: "Often termed "progressive governance", these new matrices of power are increasingly organized around forms of specialist and expert knowledge which seek to manage crime prevention and control through strategies of self-governance and responsibilization' (2007, p 76). Prior and colleagues use the governmentality framework to explain the distribution of the sex trade in urban spaces. Their conclusion is that seemingly neutral planning instruments such as zoning procedures in fact impose moral categories regarding prostitution and 'good sexuality' on the spatial layout of the city (Prior et al, 2013, p 354). Or, as the authors phrase it: '[T] hese geographies are reinforced through a range of legal and administrative techniques enacted by state agents such as the police, the judiciary, medical officials, planners, and licensing officers', establishing so-called 'moral geographies' (Prior et al, 2013, p 355). These analyses have a distinct critical flavour; their aim is to expose the surreptitious working of power in what superficially looks like a benign or technically neutral approach to prostitution. However, the appeal to sex workers to take charge of their lives is not optional and the planning instruments are far from dispassionate. The underlying moral position of 'responsibilisation' strategies is that prostitution is a moral wrong and should be banished to carefully contained vice zones, while those sex workers who persist in their work and refuse to take part in exit programmes are to be subjected to a punitive regime of custody and rehabilitation (Scoular and O'Neill, 2007, p 773).

Discussion. Each of these five approaches provides important insights into prostitution and its regulation. Yet, they also fall short of providing a convincing account of prostitution policy and how it affects the actors in the sex trade and the wider public. First, the exogenous forces and governmentality approach to prostitution amount to an exaggerated claim as an explanation of change and variation in the sex trade (John, 2012, p 98). Without a careful specification of the causal or interpretive factors that link wider developments in property, land and labour markets or in regimes of regulation to the place and manifestation of a social phenomenon such as prostitution, or even more elusive 'intimate life', in society, the argument begs the question. In fact, in both cases the argument is based on very thin empirical evidence indeed. Exhibit number one, the banishment of outdoor prostitution from many city centres in the western world, does not 
hold up to closer scrutiny. There is indeed a remarkable convergence in the disappearance of street prostitution in many, but not all, cities in north-western Europe (Tampep International Foundation, 2009), but on closer scrutiny the motivation for these measures is quite diverse. In the Netherlands, for example, the tolerance zones that were set up in the late 1990s for vulnerable, addicted sex workers began to attract large numbers of young eastern European women, many of whom were believed to be victims of trafficking (interviews, service providers, The Hague). Service providers and municipal authorities felt increasingly uncomfortable with what they saw as abetting exploitation, and closed down the tolerance zones. In Vienna, street prostitution has been displaced to the periphery of the city because of a sustained campaign by residents, supported by a strident right-wing press and the capture of policy implementation by the police. And in Italy, the crackdown on street work was part of a populist law-and-order campaign of the Berlusconi government (Crowhurst, 2012). It could very well be that in all these cases urban development, gentrification and changes in the market for service labour are the 'real' drivers behind these processes, but this has to be demonstrated, otherwise it simply beggars belief that all these different actors in different national cultures were all marching in synch to the same supranational script. Even the argument that these different approaches to outdoor sex work can all be subsumed under an overarching movement to a 'welfarist' regulatory approach disintegrates under closer scrutiny. Exit programmes make up a small, almost negligible, part of prostitution policy in most countries. As we will see later, repressive policy measures have made a comeback in many countries, although admittedly, mixed in with social servicebased approaches. Moreover, both approaches lack a sufficiently finegrained description of the effects of policies, or of large-scale trends, on the target group, outdoor sex workers, and tend to lump dissimilar cases under similar theoretical categories. In the Netherlands sex workers who were banished from the tolerance zones were offered ample social services (Vos and Wagenaar, 2014). In Vienna outdoor sex workers ended up on the outskirts of the city in a risky, degrading environment without any amenities, and after being moved around by city authorities, lost their workplace altogether (see Chapter Three). In Italy, outdoor sex workers de facto lost their rights and were frequent victims of abuse by the police (Crowhurst, 2012). These examples demonstrate that an adequate understanding of the nature of, and changes in, national and local prostitution markets requires the detailed analysis of prostitution policy. The exogenous forces and governmentality approach are important sociological descriptions of 
the wider social-economic and regulatory environment of prostitution; as explanations of policy and its effects, they fall short.

Second, all five approaches to a greater or lesser extent deny agency to the actors involved in the sex trade; both the agency of political actors and officials as well as that of sex workers, brothel owners, clients and others who are involved in prostitution. Actors tend to act on the way they understand social and political phenomena. The reigning trope in much of the prostitution literature is to posit large overarching constructs - political-economic forces, discourse, governmentality, global governance regimes - that somehow explain the size, manifestation and geographical distribution of prostitution. However, these constructs are not linear representations of objects 'out there' in the world, which then compellingly determine people's behaviour. Rather, actors in the context of their own (working) life interpret large socioeconomic developments, trends in government regulation, shifts in public opinion, or, more generally, situations in their own life circumstances. For example, Dora, in the example above, was exploited by a neighbour, but decided to file a complaint against him, because she knew that "These people often threaten but they don't do anything." As Bevir and Rhodes put it: 'Social facts are cultural in that they exist only because of the meaning and beliefs of the relevant actors' (2008, p 2). Because actors operate within steady practices and belief systems, 'traditions' in the vocabulary of Bevir and Rhodes, much of social and political life is relatively stable. However, every now and then actors face a disruption of their routines. How they react to such dislocations always contains an element of contingency (Bevir and Rhodes, 2010). For example, if we take the agency of actors seriously, it is likely that policy acts both as a reaction to, and as a mediating force between, political-economic shifts and changes in the nature, composition and location of the sex trade. As John puts it: '[E]xogenous economic approaches do not offer an all-encompassing theory of political action - they suggest a set of constraints on action that impact on policy choices depending on the circumstances that policy makers face' (2012, p 99). The analyst faces the essentially hermeneutic task here of explaining macro-events in terms of micro-practices and vice versa (Geertz, 1973; Wagenaar, 2011, ch 2). In Chapters Three and Four by reconstructing the shifts in the implementation and formulation of prostitution policy and by situating these in the wider societal and political context of Austria and the Netherlands, we do just that to explain the course that public policy took in these countries. 
With the exception of the global governance regime approach, a related objection to the above approaches to policy analysis in prostitution is that they downplay the possibilities for government interventions to have a positive or negative impact on the position of sex workers. Such an assumption would fly in the face of credibility about the ameliorative or harmful power of governments. We have already seen in Dora's story how important the rule of law is for the rights and position of sex workers, and how the prohibition of prostitution creates opportunities for corruption and inhumane treatment of sex workers by the police. We have also seen how immigration laws induce unwanted mobility, tie workers to their employer, or force sex workers to give up independent employment and find a brothel to work in. There are at least three reasons why the study of policy in prostitution is important. First, every country, for better or worse, has a policy towards prostitution. Similar to sectors such as health, education, or housing, a range of different collective reactions towards prostitution exists across countries. This variation in itself is something that requires explanation (Cairney, 2012, p 3). Second, it is undeniable that there are considerable differences in the human rights and work conditions of sex workers across countries. Even if we are willing to entertain the hypothesis that government intervention has no effect at all on the sex trade in all of these countries, in other words that these differences can be attributed solely to the influence of large exogenous forces or to shifts in discursive formations, then this also requires explanation. Such a hypothesis would be so counterintuitive, among other things in the light of the well-established impact of public policy in areas such as health, education and housing (established through international comparative research among other things), that the burden rests on those who implicitly or explicitly entertain such a presumption to support it with convincing evidence. Instead of following this barely credible position we hold the position that public policy has a considerable, but not exhaustive, impact on the sex trade.

Third, to entertain the hypothesis that public policy is ineffectual in influencing prostitution and the position of sex workers robs the analyst of any possibility to advise public officials. Dora's story suggests that policy measures have unintended negative consequences for sex workers. As we will see in later chapters, many municipalities, under the influence of abolitionist discourses on prostitution, design and implement policies with the express intent to restrict the sex trade. Such measures usually have negative consequences for the labour and human rights of sex workers. The analyst's task is, at the very least, to 
point this out and suggest ways for a better balance between the rights of the community and those of sex workers.

Anyone who discusses the subject of public policy in an international context immediately encounters semantic problems. The concept of 'policy' has different meanings in different countries. ${ }^{4}$ For this reason it is important to state that we largely follow the Anglo-Saxon meaning of the terms 'policy' and 'politics'. The term 'policy' attempts 'to capture the idea that policy-making is a techno-political process of defining and matching goals and means among constrained actors' (Howlett et al, 2009, p 4). Howlett et al argue that policy has two dimensions. The first is a technical one that seeks 'to identify the optimal relationship between goals and tools'. This is generally seen as the business of state agencies whose task it is to manage public problems (Ansell, 2011, $\mathrm{p} 4$ ). The second dimension of public policy is a political one 'since not all actors typically agree on what constitutes a policy problem or an appropriate "solution"' (Ansell, 2011, p 4). Politics is thus society's way of dealing with the deep pluralism, the inevitable conflicts of belief, religion, value and interest that characterise all societies (Wagenaar, 2011, ch 10). It refers to practices and institutions that 'seek to establish a certain order and organize human coexistence in conditions that are always potentially conflictual' (Mouffe, 2000, p 101). These institutions are the executive and parliament that bargain, negotiate and deliberate over policy goals and broadly defined courses of action. ${ }^{5}$ In democratic

4 In the Anglo-Saxon world it is common to make a distinction between politics and policy. The latter roughly refers to the executive arm of government, the public agencies that manage societal problems, and the former to the decision-making process by elected officials. In the German-speaking world there is no term for policy; policy, polity and politics are all referred to as 'Politik'. There is a separate term for public administration ('Verwaltung') that strictly refers to the executive branch of government. In the Netherlands there is a distinction between 'politiek' (the activities of elected officials), 'bestuur' (the management of societal sectors by both elected officials and civil servants, usually by 'bestuursorganen' such as city councils, umbrella organisations, corporatist bodies and so on) and 'beleid' (which involves all public agencies, including those that have been privatised, such as housing corporations.) In Norway 'politikk' covers both policy and politics (oral communication, May-Len Skilbrei). In Italy there is no word for policy; everything is politics (oral communication, David Nelken). To make things even more complicated: nowadays the concept of 'policy' has fallen out of favor as being too statist and is being replaced with the term 'governance', signifying the decentred nature of contemporary policymaking.

5 The implicit normative principle is that there is a division of labour between the executive and public agencies in the management of public problems. While the first is at all times democratically accountable, the latter operates in relative freedom, albeit under a strict political mandate, to design and implement public programmes. 
terms, policymaking as a technical process of managing public problems is at the 'tail end' of the representative chain that starts with election campaigns and parliamentary debate (Ansell, 2011, p 4).

Public policy is the provenance of government. In the past two decades policy theorists have urged us however to shy away from the overly state-centred fixation of the term policy and adopt instead the broader term 'governance'. There are different reasons for this shift in the conceptualisation of the process of governing in contemporary society. Policy analysts have become more sensitive to the demands of citizens and other stakeholders to have a say in the policy process. On the other hand, three decades of public sector reform, fuelled by a powerful neoliberal ideology, have irrevocably altered the administrative landscape (Hood and Dixon, 2015). The privatisation of services that were formerly provided by the state and the reorganisation of government according to corporate principles have resulted in a fragmented, decentred public sector where many different actors are involved in the delivery of vital public services and where responsibility, accountability and transparency are opaque.

The concept of governance has different meanings (Rhodes, 1996, $\mathrm{p}$ 653), but in the context of policymaking it is generally taken as selforganising networks (Rhodes, 1996; Sørensen and Torfing, 2008). A networked system of governance consists of public and private sector organisations (government agencies, third sector organisations, nongovernmental organisations [NGOs], representative bodies, activists, citizen groups) that deliberate, negotiate, and sometimes implement, public policy. These organisations are bound by mutual dependency; they exchange information, material resources and legitimacy. Stable policy networks develop their own rules and culture, and may achieve considerable autonomy from the state. In the early 2000 s, for example, the city of The Hague initiated a policy network of brothel owners, municipal agencies, judicial officials and the police, for the purpose of

\footnotetext{
In this way politics and administration are more or less kept separate. The key argument is that this allows specialised technical expertise to inform the design and implementation of policy programmes. In fact, as Manin (1997) argues, a cadre of specialised experts, wedged in between elected officials and the people, and who design and execute solutions to politically identified issues, is one of the key characteristics of liberal electoral democracy. However, in practice the normative boundary between politics and administration is highly permeable. Politicians regularly ignore or intervene in administrative processes, and in an increasingly plural, complex and adversarial society public agencies have to engage in complex negotiations with stakeholders to attain a modicum of effectiveness (Ansell, 2011, p 4; Wagenaar, 2011, ch 10).
} 
designing and implementing the newly adopted law that legalised sex facilities. It made use of the relationships between police, city officials and proprietors that had developed in the preceding decade of regulated tolerance (Brants, 1998). The goals of the network were to coordinate the many activities of the various officials and agencies, to inculcate a number of shared values, and to create sufficient support for the licensing system that was to be introduced in a field that initially resisted any government intervention (Wagenaar, 2006). This example demonstrates the main rationales for the emergence of policy networks in which different stakeholders participate in policy design and implementation. First, many policy arenas are so complex, diversified and dynamic that they overwhelm the capacities of the state to govern effectively, resulting in situations of 'pluralised ungovernability' (Warren, 2014; see also Wagenaar, 2007, 2014). Second, target groups often actively resist policy measures, or at the very least find accommodations that allow them to render policy measures 'harmless' or deflect their original purpose (Wagenaar, 1995). We will encounter many examples in this book of the 'pluralised ungovernability' and policy resistance of the prostitution sector. In Chapter Six we will make suggestions about how to harness this ungovernability.

\section{The goals of the book}

Thus, the basic premise of this book is that in trying to understand the place of prostitution in society it is important to understand prostitution policy. Policy shapes the different manifestations of prostitution: the places where it is practised, the type of prostitution that is prevalent in a society, and the position and rights of sex workers. In its turn prostitution policy both shapes and is shaped by the public's attitudes towards prostitution and sex workers. Prostitution policy expresses other, wider, social attitudes towards women, immigrants and sexuality. Policy is constrained and influenced by broader social and economic developments, and often struggles to absorb, channel or ameliorate such influences. Policy, as we will argue below, is a polyvalent, multidimensional concept. It involves laws, procedures, institutions, ideas, networks of actors, interest groups and power. All of these elements influence the formulation and implementation of public policy.

The purpose of this book is threefold: first, it provides an overview and critique of how prostitution policy has been analysed to this point (see the previous section); second, it provides a policy analytical approach that both recognises the particular challenges of the field and 
brings the concepts and tools of public policy analysis to bear; and third, it provides suggestions for how policy makers can move forward in establishing a fairer and more humane policy. Policy analysis is an established discipline that has been largely ignored in understanding prostitution policy. It is an important aim of the book to relate the insights of policy theory to prostitution policy. However, the discipline of policy studies proceeds through the analysis of concrete policy issues. For this reason, the empirical basis of the book is a three-year comparative study of prostitution policy in Austria and the Netherlands (see the Appendix for a description and justification of the design of the study).

Both countries make interesting objects of analysis. Contrary to the US, where from around 2000 onwards prostitution policy was dictated by neo-abolitionism (Chuang, 2010), most western European countries followed a more or less pragmatic approach to regulating prostitution. When the Netherlands decriminalised brothels in 1999 it was widely regarded (and roundly criticised in radical feminist circles) as a vanguard of progressivism. Austria, although less in the limelight, has always had a tradition of societal acceptance, women's rights and administrative ethos when it comes to regulating prostitution. Yet, as we will see in the following chapters, a fine-grained analysis of the formulation and implementation of prostitution policy in both countries reveals that under the surface the political forces opposing prostitution have found ways to undermine and eventually undo progressive policies. We think the analysis in this book leads to two important conclusions. First, prostitution policy is fragile. Legitimisation and decriminalisation are easily reversed, and revert back to criminalisation and heavy-handed regulation and control. This is a complex process that largely occurs at the local level, thereby deviating from, and even undoing, national policymaking. Second, without a detailed exposition and analysis of the design and implementation of prostitution policy at different scales of governance, statements about its nature or outcomes remain necessarily at the surface and are at worst misleading

In the course of using the ideas and insights from policy theory to make sense of prostitution policy in Austria and the Netherlands we realised that we were making an original contribution to three general topics in the discipline of policy analysis: moral policy (Chapter Two and its application throughout the book), the importance of domainspecific challenges to policy formation (Chapter Two), and the concept of a complex policy field (Chapters Five and Six). For two reasons we have chosen to present a discussion of the relevant 'chapters' in policy theory in some detail in this book. First, to comprehend our 
analysis of prostitution policy we need to discuss the relevant topics in policy with some exactness. We take care, however, to ensure that our account of general theoretical insights remains relevant to the topic at hand. We underscore this by illustrating our theoretical exposition with ample examples from our empirical work. Second, as we stated above, our application of policy theory to prostitution policy results in insights in and reformulations of the first that constitute a contribution to the policy literature. As domain-specific and general insights are closely interconnected it would be implausible to only report on the first and ignore the latter. Finally, we take a pragmatic approach to policy theory in this book. In explaining the formulation, development and outcomes of prostitution policy, we take as much as possible the perspective of the policy maker. Differently put, our analysis and our use of the insights of policy theory is guided by the question: What does the world look like from the perspective of the official?

Taken together the book's three goals, its foundation in policy studies, and its pragmatic stance result in an intricate and comprehensive argument that brings together empirical facts and normative arguments, aggregate trends and individual experiences, different scales of policymaking, and an array of conceptual insights in policy theory. We will argue that a broad, synoptic grasp of these disparate elements is required to arrive at an analysis of prostitution policy that does justice to its many challenges, intricacies and sensitivities. An explanation of the structure of the book is therefore in order.

\section{A reader's guide to the book}

In Chapter Two we discuss five challenges to formulating, designing and implementing an effective, fair and humane prostitution policy, challenges that every policy maker in the domain of prostitution has to reckon with. These challenges are the pervasive stigma on prostitution, the deeply moral nature of prostitution policy, its confluence with immigration policy, the lack of reliable and precise data, and the inherently local character of prostitution policy. Chapters Three, Four and Five are devoted to the analysis of prostitution policy in Austria and the Netherlands. In ascending order the chapters represent the different scales of governance: local, national and transnational. However, this triptych of chapters will also illustrate the extent to which the three scales of governance are interrelated; Chapters Three and Four demonstrate the continuity of local and national policy, while Chapter Five illustrates how large global trends affect local policy. For reasons we will explain later, we begin our analysis with the implementation of 
prostitution policy. Chapter Three begins with an account of the theory of policy implementation. We then demonstrate that the aggregation of numerous local measures in effect add up to an expedient, wholesale change (Netherlands) or modification (Austria) of national legislation. In Chapter Four we discuss national policymaking. Here we will see that national policy formulation takes place in networks of policy actors who contribute to, and are influenced by, evolving national discourses on prostitution. But, important as national discourse is in shaping the collective beliefs about and understandings of the sex trade, these actors, as we will argue, need access to decision-making arenas and procedures - so-called veto points - to effectuate legislative change. We will also demonstrate the importance of ancillary law for prostitution policy; labour, fiscal, immigration, social welfare and even data protection law are mobilised by policy makers to regulate prostitution. Chapter Five discusses the wider global trends in low-wage feminised labour, migration, labour exploitation and immigration law, and how these influence both the shape of and the policy reactions to the sex trade in the affluent countries of north-western Europe. The debate on migration and trafficking in prostitution suffers from exaggerated rhetoric and the widespread distortion of evidence. To counterbalance these trends, we illustrate the insights in this chapter with excerpts from our interviews with migrant sex workers. We suggest replacing the morally charged and ineffective concept of 'trafficking' with the more useful concept of 'labour exploitation'.

In Chapter Six we present an alternative to current policymaking: collaborative governance. We argue that the inclusion of the voice of sex workers in the design and implementation of prostitution policy will result in a form of policymaking that is more realistic, more effective and more just. To put this argument forward we draw on the theory and practice of collaborative governance and on concrete examples of collaborative governance in prostitution. The book closes with a summary of its argument and its main conclusions. The Appendix contains a description of the research project that forms the empirical basis for this book.

The book is aimed at two types of reader. Those whose main interest is in prostitution policy can follow the following path: Chapters One and Two; the final three sections of Chapter Three; the sections on national policy in the Netherlands and Austria in Chapter Four, and its conclusion; Chapter Five (excluding the introduction); and Chapters Six and Seven. Those who have an interest in policy theory and only want to glance at the details of how the regulation of prostitution unfolded in the two countries are advised to read Chapters One and 
Two; the first three sections and the conclusion of Chapter Three; the introduction and conclusion of Chapter Four; the introduction to Chapter Five; the first two sections of Chapter Six; and Chapter Seven. 



\section{Challenges of prostitution policy}

The wider context of this book is the rapidly changing nature of commercial sex, and the international, national and local policy responses this has generated, particularly in the past three decades. We increasingly see a spatially and technologically mobile population of actors buying and selling sex in different venues (streets, massage parlours, hotels, flats, windows, clubs, saunas and private homes) and through different media (mobile phone, internet and via thirdparty brokering). At the same time prostitution manifests itself most urgently at the local level, putting pressures on neighbourhoods and municipal administrations and conflicting with evolving ideals of public spaces held by citizens and policy elites. The drivers for these changes include migration, transformations in attitudes towards sexuality and gender, the widening income gap and the stagnation in wages, the mass tourism industry, the ensuing development and gentrification of inner cities, and an increasing emphasis on the competing demands of equality and human rights alongside concerns about security and social control in migration and prostitution, particularly related to cross-border prostitution and human trafficking.

National policy responses have been diverse, varying, as we have seen, from prohibition, client criminalisation and increased regulation to the decriminalisation of prostitution. Local policy responses have diversified in response to these pressures, tending either towards regulation or repression, especially of street prostitution. The media pays considerable attention to prostitution, with an emphasis on violence, coercion and trafficking. In the current climate of economic austerity migrants are regarded with increasing distrust, and we witness a resurgence of anti-immigration sentiments that directly affects national and local attitudes towards prostitution. As in Dora's story, in many countries this has led to the violation of the democratic rights of a vulnerable group. Prostitution as a social domain thus presents policy makers and policy analysts with a number of challenges, both general and specific, which make the design and implementation of public policy exceedingly difficult.

There are many definitions of public policy, but in a general sense it is a purposive course of action, authorised, though not necessarily initiated or implemented, by government, to deal with a problem or 
matter of concern (Anderson, 1984, p 3; Howlett and Ramesh, 2003, $\mathrm{p} 7)$. All public policy faces certain general challenges, or key tasks that need to observed to realise a policy, any policy. Think of the challenge of setting a policy agenda and creating support for it (Kingdon, 2011), addressing the intractable nature of the problem (Rittel and Webber, 1973), moving a bill through parliament, translating policy intentions into policy design and implementation (Howlett, 2011), and navigating networks of policy actors at different scalar levels (Rhodes, 1996; Hooghe and Marks, 2003). These general challenges can best be seen as the generic tasks that policy makers face and the requisite skills that experienced policy makers need to possess to successfully formulate, design and implement public policy. In Chapter Six we will return to these generic challenges and frame them as dealing with complexity. Understanding how such intrinsic imperatives shape public policymaking is one of the central tasks of the policy analyst.

In addition, to prepare for our analysis of prostitution policy in Austria and the Netherlands, we will need to get a grasp of the domain-specific challenges in prostitution policy. A domain-specific challenge is a circumstance or characteristic of a specific policy field that heavily influences the nature of and possibilities for concerted action in that field. For example, the actors involved in policymaking, the balance between agency and dependency, the availability of data and the salience of the issue are all determined by the specific challenges of a policy domain. Domain-specific challenges affect every phase and level of policymaking, and policy makers and policy analysts ignore them at their peril. For two reasons we present the challenges specific to prostitution policy in some detail. First, instead of it being merely a preparation for an informed analysis of prostitution policy, the presentation of challenges to prostitution policy is itself a form of policy analysis. Our discussions of the challenges contain important insights into the specific nature of prostitution policy. Second, policy analysis usually proceeds through the in-depth study of specific cases or domains, yet the explication of domain-specific obstacles to policymaking and analysis remains more often than not implicit. Some analysts distinguish between types of public policy that affect the nature or discretionary feasibilities of, for example, policy formulation or implementation (Lowi, 1972; Howlett et al, 2009). However, such typologies are hardly supported by empirical evidence and more often than not are too indiscriminating to be of much help in explaining either the specific characteristics or the possibilities and limits of policymaking in a specific domain. We discern five major domain-specific challenges to prostitution policy: prostitution suffers 
from a pervasive social stigma; prostitution policy is a paradigmatic example of morality politics; precise and reliable data are hard if not impossible to obtain; prostitution policy has merged with policies aimed at containing immigrants; and, although prostitution policy, like most policy, is multilevel, local policy plays a decisive role when it comes to implementation. Any analysis of prostitution policy needs to take these five domain-specific challenges into account.

\section{The stigma of prostitution and the paradox of control}

'Man bludgeons woman to death and stabs prostitute' (Headline in Dutch newspaper, October 2015)

Whorephobia can be defined as the fear or the hate of sex workers. Sex workers like me would argue that it also embraces paternalistic attitudes that deem us a public nuisance, spreaders of disease, offenders against decency or unskilled victims who don't know what is good for them and who need to be rescued. (Thierry Schaffauser, The Guardian, 23 October 2010)

It is a truism that prostitution labours under a pervasive and near universal stigma. It is more interesting and important to trace the effects of this fact on sex workers and on public policy. We argue in this section that the effects of the prostitution stigma are widespread. Stigma, deliberately and surreptitiously, shapes laws, regulations, practices, institutions and policies, it undermines the effectiveness and fairness of the regulation of prostitution, and, in general, it results in the social marginalisation of sex workers.

In her classic treatment of the topic, Pheterson argues that the prostitution stigma centres on a deep-seated, socially shared anxiety about and condemnation of unrestrained, unbridled female sexuality, or what Pheterson calls 'unchastity' (1996, p 12; see also Nussbaum, 1998). It is probably correct to say that the prostitution stigma centres on the social organisation of sexuality and sexual expression, thereby implicitly defying deeply embedded, naturalised gender roles and hierarchies (ICRSE, 2015, p 2). And although it explicitly targets female sex workers, it implicitly controls all women. According to Pheterson the condemnation and prohibition of unrestrained female sexuality reflects gender asymmetries in the regulation of male-female relationships in four key areas: obligatory heterosexuality, marriage, reproduction and prostitution. In each of these four areas men strive 
to control women through regulation, subjugation or violence (1996, $\mathrm{p}$ 14). This gender asymmetry is expressed in laws regulating work, wages, taxes, parenting and, of course, prostitution, as well as in discourses representing sexuality, female behaviour and identity, and, again, prostitution. The prostitution stigma is thus a flashpoint for a widespread social-legal-political complex that regulates the (sexual) behaviour and position of women in society.

As the newspaper headline at the beginning of this section makes clear, one powerful expression of the prostitution stigma is that it is an identity ascription. That is, while men who visit sex workers are accused of disreputable behaviour, the women who provides the sexual services to the man is accused of being a prostitute. As Pheterson puts it: 'She is bad for who she is, he is bad for what he does' (1996, p 48). ${ }^{6}$ This identity ascription has wide and deep consequences for sex workers. The first is that prostitution is not regarded as work but as an aberration. Because it is an identity, 'all the way down', to the core of the woman's personality, it cannot be a rational, considered, albeit misguided, choice. ${ }^{7}$ Instead of a transgression or lack of judgement, prostitution is a form of deviancy, a fall from grace, and inexplicable within the regular discourse on work, body and sexuality. One of the most common reactions to prostitution is the perplexed and visceral protestation: 'But how can someone sell her body?' Because prostitution is inexplicable it is deemed insidious and dangerous, a 'menace to the social order and legitimate social norms' (ICRSE, 2015, p 2).

6 Corbin, in his magisterial study of the regulation of prostitution in 19th-century France, gives many examples of the essentialisation of the personality of the prostitute (Corbin, 1990). She is considered intemperate, lazy, wasteful, disorganised and of course, lascivious. To be a prostitute is to have a personality disorder. Zola immortalised the archetypical prostitute in his depiction of the courtesan Nana. By way of a footnote, in our times the Swedish government has made a concerted attempt to transform the occasional act of visiting a sex worker into a personality disorder (Kulick, 2005).

7 This explains both the common search for the 'causes' of becoming a prostitute, such as hidden psychological wounds in childhood or the wholesale loss of agency through addiction or criminal coercion, and the widespread dismissal of (selfreported) economic explanations for the choice of prostitution as an occupation. From here it is but a few short steps to common statements by those proclaiming the abolition of prostitution, that all, or the large majority of sex workers, are 'forced'. As Pheterson summarises it: 'Examples abound of research designs which persistently treat the variable "prostitute" as a fixed identity rather than as a contingent social status, thus assuming prostitution to be a female trait or destiny removed from the dynamic realities of group relations and political power' (1996, pp 9-10), and, we add, the realities of economic circumstances and life perspective. 
Throughout history the prostitute has been associated with contagion - the physical contagion of sexually transmitted disease (STD), but also moral contagion. The prostitute is supposed to be a risk to the (fragile) moral rectitude of men and the integrity of marriage and family. The modern version of the contagion argument is the radical feminists' claim that if one woman is a prostitute all women can in principle be treated as such (Sheila Jeffreys, cited in Chuang, 2010, p 1668). There lurks a fateful contradiction between the inexplicable nature of prostitution (something that no woman in her right mind would do) and the simple, unavoidable observation that so many women in every society engage in the act of prostitution, and often not for reasons of poverty, as our interviews clearly show (see also Dekker et al, 2006). It is little wonder then that 'prostitutes'- we deliberately use the more offensive label here - are regarded as a threat, to society, to the middle-class value system, and to institutions such as marriage, the family and motherhood. ${ }^{8}$ The upshot is that here is a direct connection between stigma as fear of contagion and the eradication, suppression and control of prostitution. We will see many examples of this in the pages to come.

The second implication is that the inherent danger of the 'prostitute' both occasions and legitimises the involvement of the state. This results in, for example, a remarkable catalogue of human rights and civil liberties that are breached or lost as a result of being deemed a prostitute, such as the right to work, to start or own a business, to migrate, to have custody of one's children, to refuse medical checks, to enjoy adequate labour relations and work conditions, to appeal to unjust tax claims, in general to access the justice system with grievances, to open a bank account, enter a mortgage or business loan, take out health insurance, start a sex business with other women, or support a husband or partner. (See Pheterson, 1996, pp 42-3 for a more extensive listing. See also ICRSE, 2015, and Jahnsen and Wagenaar, in press, for an overview of prohibitions on sex workers' behaviour in 21 European countries.) The International Committee on the Rights of Sex Workers in Europe (ICRSE) considers the prostitution stigma a form of structural violence. Structural violence is 'a form of violence resulting from and perpetuated by broader social arrangements, such

8 It is also no wonder that arguments that point to the fluid boundaries in sexual economics lack persuasion in the eyes of the public (Pheterson, 1996, p 9). Material compensation for female sexual services to men when integrated into marital or long-standing relationships are considered to be qualitatively different from such compensation outside such relationships. 
as historically rooted social structures and relationships, political organisation, and the logic of the economic system' (ICRSE, 2015, $\mathrm{p} 1)$. It is deemed structural because it is 'inscribed in the very social structures in which sex workers live and work' (ICRSE, 2015, p 1). The structural nature of the prostitution stigma explains the implication of the state in its enaction and perpetuation. In the following pages we will encounter many examples where well-meaning administrators design and implement measures that amount to a violation of the rights of sex workers and to their (implicit) designation as a lesser kind of citizen. Perhaps the most telling aspect of this breach of sex workers' rights is the indifferent, commonplace nature of it; measures or conditions that would be unacceptable when imposed on or suffered by members of another occupational group under the rule of law, are met with unconcern by politicians, officials, the media, or the public when foisted on sex workers (Wagenaar, 2015a). The enacting of stigma by the state must not be regarded as a form of retribution for transgressive behaviour, at least not in the advanced democracies of north-western Europe. Instead it is a 'business-as-usual', a collective attitude or ethos that results in the tacit and unnoticed shaping of the institutional reaction to prostitution. It is to the aspect of state control that we turn in the remainder of this section.

The stigma that is attached to prostitution makes prostitution a 'job unlike any other' (Jeffrey, 2015). ${ }^{9}$ Jeffrey argues that stigma has three effects on policy makers: it results in resistance to the location of sex businesses, in paternalistic approaches to prostitution that lead to the restriction of sex workers' freedom of movement, and in the perception of prostitution and sex workers as problems to be managed, rather than behaviours to be regulated when necessary and experts to be consulted (Jeffrey, 2015, p 2). In other words, stigma invites control. In many countries this results in the outright prohibition of prostitution, but one of the pernicious consequences of the persistence of stigma is that even the regulation or decriminalisation of prostitution does not guarantee a lessening of the urge to control (Jeffrey, 2015, p 2). As we will see on many occasions in this book, the tenacity of stigma is the mechanism by which regulatory approaches to prostitution generate negative, unintended consequences and progressive policies get reversed.

The alleged danger that is associated with prostitution results in a tendency of governments to control and restrict it wherever possible.

9 This is pointedly expressed by a sign on the wall of the Prostitution Information Centre in Amsterdam that states: 'Prostitution: a regular but not a normal occupation.' 
Usually the arguments are either the fear of an unbridled expansion of prostitution within a certain geographical area such as a municipality or nation, and/or the reduction of ostensible problems in the industry such as exploitation and trafficking. For example, after the Dutch parliament legalised sex facilities in 2000, every municipality immediately froze the number of allowable facilities to the ones that were already in operation. This, of course, gave greater oligopolistic power to the existing owners, most of whom were used to a business model in which the sex worker had few worker rights, and fiercely resisted the introduction of fair remuneration or adequate labour standards (see also Chapter Five). We can observe similar processes in Austria. In 1984, under the guise of protecting sex workers from exploitation, the Viennese government prohibited home-based sex work. A few Länder (Vorarlberg and Tyrol) subjected the licensing of sex facilities to the 'needs of the market', which resulted in a low number of facilities in Tyrol and the de facto prohibition of prostitution in Vorarlberg (Amesberger, 2014, p 239 onwards; see also Chapter Three.) To this very day the control argument is used in the Netherlands and in Austria to prohibit sex workers from starting their own small businesses from home. The result is that the legalisation of the sex industry in both countries has barely resulted in an improvement of the work conditions of sex workers. In Chapters Three and Four we will see further examples of the defeat of the ostensible goals of regulation and legalisation by the pervasiveness of stigma.

\section{Prostitution politics as morality politics ${ }^{10}$}

Let us begin with an observation about language. The uninitiated observer will quickly discover that there is no neutral ground when it comes to discussing prostitution and prostitution policy. Even the most basic terms such as 'prostitution' or 'sex work' suggest a moral position towards the provision of sexual services for money. The first, although a long-standing expression for the sex trade in many languages, is now the term of choice for activists who consider prostitution the equivalent of abuse and slavery. (In this book we still use it in its pre-abolitionist, more or less sociological meaning.) The term sex work is firmly related to a particular moral position that construes prostitution as work, with all that that entails in terms of labour rights, workplace conditions, adequate income and attitudes towards (women's) sexuality. Similarly when we define prostitution policy in pragmatic terms as the concerted

10 This section is based on, and is a further elaboration of, Wagenaar and Altink (2012). 
attempts of administrators and elected officials to protect the position and rights of sex workers and diminish the negative societal impact of different forms of prostitution - a definition that is a fair description of the position that is still held by many officials in Austria and the Netherlands - this in itself represents a moral perspective. Abolitionist policy makers would instead define prostitution policy as the concerted effort to eradicate prostitution from society, and indeed, as we will see in later chapters, many administrators in the Netherlands have gradually moved from the pragmatic to the abolitionist definition of prostitution policy. These examples show that it is impossible to discuss prostitution and prostitution policy without occupying a particular moral position. This makes prostitution policy an instance of morality politics.

Although policy theorists feel the need for the concept of morality politics, even a cursory glance of the literature shows it to be notoriously difficult to define in a clear, unequivocal way. Also, as we will see, it is exceedingly difficult to make general statements about morality politics, as there are always exceptions to the rule. In a general sense morality politics refers to policies in which first principles are at stake, over which exists deep conflict among the public, and which do not necessarily coincide with the left-right, liberal-conservative political divide (Mooney, 1999, p 675; Mooney, 2001; Engeli et al, 2012). ${ }^{11}$ This usually results in a denotative definition, the ubiquitous list of life, body and 'sin' issues that are considered to belong to the class of morality politics: abortion, contraception, gambling, same-sex marriage, drugs, pornography, capital punishment, physician-assisted suicide and prostitution.

In this book we choose to define morality politics through the effects that contestation over moral principles has on the policymaking process. We argue that while it may be difficult to define morality politics in a clear and consistent manner, certain policies that are characterised by seemingly irresolvable conflict over deep values show characteristics that not only set them apart from other policy fields, but also have the effect of making the design and implementation of a pragmatic, effective and humane policy exceedingly difficult. ${ }^{12}$ We speak of morality politics,

11 This shows in the unusual political composition of the abolitionist alliances in various countries. The neo-abolitionist coalition in the US consists of feminists, neoconservatives and evangelical Christians (Chuang, 2010, p 1664). In many European countries, in addition to feminists and Christian parties, Social Democrats and, often, the populist right take an abolitionist position.

12 See also Engeli et al (2012), who move away from a listing of characteristics of morality politics and argue for an impact-based approach that focuses on the political dynamics of conflict. 
instead of policy, to indicate that the issue has moved from the realm of policymaking (which despite unavoidable conflicts over ideas and instruments has the moral and instrumental aim to resolve or ameliorate a collective problem) to that of deep and intractable conflict (in which the struggle over the prevalence of symbolic positions takes precedence over resolving collective problems). Differently put, morality politics indicates a situation where the minimum common ground that is the condition for engaging in effective collective problem solving, has broken down into irreconcilable conflict over moral positions about what is right or virtuous with regard to the issue at hand. ${ }^{13}$ In many countries this is an apt description of prostitution policy, with one camp finding all prostitution inherently coercive and the prime manifestation of men's structural dominance over women, and the other camp arguing that women's right to (sexual) autonomy and privacy includes the right to sell sexual services for money when they choose to do so. This deep moral divide runs through virtually all contemporary debate about prostitution. It is probably fair to say that it is foundational in shaping prostitution policy, and that acknowledging and countervailing its many unfortunate implications is one of the toughest challenges of prostitution policy to which we return throughout this book.

We thus define morality policy by a configuration of substantive characteristics and effects as follows:

1. Morality policy is ruled by ideology. As Deborah Stone points out, all public policy is a struggle over the salience and interpretation of basic values (Stone, 1997). Concrete policy solutions embody different interpretations of such values. Two things distinguish morality politics from 'regular' policies with an ethical dimension. First, policies turn into morality politics when they are based on an unabashedly explicit ideology, or, differently put, when ideology

13 Political theorists capture this breakdown of political communication in the distinction between antagonism and agonism. Mouffe, for example, defines antagonism as the 'struggle between enemies' and agonism as the 'struggle between adversaries'. She argues that while conflict is unavoidable in pluralist societies, the purpose of democratic politics is to recognise this unavoidability of conflict and offer arrangements of governance and public debate to navigate and harness it in a productive way: "Envisaged from the point of view of "agonistic pluralism", the aim of democratic politics is to construct the "them" in such a way that it is no longer perceived as an enemy to be destroyed, but as an "adversary", that is, somebody whose ideas we do not put into question' (Mouffe, 2000, pp 101-2). This, to turn enemies into adversaries and arrive at some form of accommodation of conflict, is precisely what morality politics tries to prevent. In this sense morality politics is fundamentally regressive. 
begins to make up the larger part of the mix of evidence and doctrine that is the basis of all public policy (Hood and Jackson, 1997). Morality politics goes beyond the societal problem it professes to address and is usually a vehicle for a greater moral cause. For example, abolitionists use prostitution policy as a platform for various feminist causes, or to promote a conservative public order cause. ${ }^{14}$ Second, morality politics often has a pedagogical thrust. In its fully fledged form morality politics can turn into a moral crusade for one or another position (Gusfield, 1986). For example, one of the explicit aims of the 2014 Swedish Sex Purchase Act, for which the Swedish government allocates funds and mobilises its foreign service, was to export it to other countries. As Dodillet and Östergren observe:

Pamphlets, websites, articles, books and movies have been produced and lobby activities have been conducted towards the European Union (EU) and the rest of the world with the help of this material and via workshops, seminars and debates.... At the core of the marketing campaign has been the stated success of the Sex Purchase Act. (2013, p 110)

However, there is very little impartial research on the effects of the Swedish law to support its alleged effectiveness. The pedagogical thrust in morality politics is the dead-knell for the open debate that characterises agonistic democratic politics. All argument in policy debates is aimed at persuading the opponent, but the overt goal of ideological politics is to become hegemonic in that it effectively attempts to crowd out other ideas and positions to the point that these appear dubious, wrong, or even utterly unintelligible.

2. Moral policy is lay policy. Mooney considers this one of the key characteristics of moral policy (Mooney, 1999, p 676). Because the debate is about first principles and not the technical details of policy design and implementation, he argues, anyone can legitimately claim to be well informed. While in policy domains such as pensions, health or social security, experts occupy a central and generally accepted role of technical authority, in cases of moral politics everybody feels he has something worthwhile to say about the issue at hand. Morality politics is 'owned' by everyone, while sources of technical authority that might arbitrate conflicts of

14 Similarly Lakoff (2014) argues that conservative anti-abortionists are motivated more by a desire to punish sexually active women than by any self-proclaimed goal of 'protecting life'. 
belief or opinion are either absent or drowned out. Instead, every member of the public and of a nation's administration believes that he has an expert opinion about the issue at hand. ${ }^{15}$ The influence of the public makes it difficult for administrators to formulate and implement policy, as they always have to take into account assertive media reporting, pundits pronouncing strong opinions on policy measures, or elected officials who, often spurred by the media, impose abrupt changes in policy. In such cases it is often easier to just 'go with the flow' of public opinion and political expediency.

Generalised issue ownership in combination with the dominance of first principles gives the media an influential role in morality policy. In our research we found that the media exhibited a strong bias towards depicting prostitution as dominated by violent organised crime. Sex workers were overwhelmingly described as the passive, hapless victims of trafficking. In general the language in which prostitution was described was sensationalist, emotive and melodramatic, and consisted of detailed descriptions of sexual and physical abuse. Media reports are replete with vague, elastic, but unvaryingly alarming indications such as 'hundreds of thousands', 'millions', 'rapidly increasing', 'epidemic', or the currently popular 'tsunami'. The argument of choice was the generalisation to all sex workers of specific and carefully selected cases of, usually horrific, sexual and economic exploitation (Goraj, 2012; see also Fitzgerald and Abel, 2010; Vance, 2011).

3. The explicit ideology and the public ownership that drive a moral policy have several effects. Morality politics is emotionally charged. Measured discussions of prostitution policy are rare. The emotional charge of morality politics goes beyond the emotional investment that characterises all public policy. Discussions of moral policies such as prostitution policy are animated with strong emotions. It pays off to explore some of the implications of this.

15 We need to make an important caveat here. Ordinary people can and do play a constructive role in policymaking. This is the presumption - and observation that underpins the argument for democratic participation. In countless instances, historical and contemporary, civil society has enriched politics. In fact, in Chapter Six we will argue for the inclusion of sex workers in the policy process as a deliberate policy strategy. One of the functions of the inclusion of ordinary people is to counterbalance expert opinion with experiential knowledge. But here lies the crucial difference: the lay influence in the case of morality politics is largely devoid of experiential knowledge and tends to act therefore as a corrosive to constructive policymaking. 
The overriding emotions in debates about prostitution are anger and disgust. These emotions are close cousins (Giner-Sorolla, 2006, p 50), but while the presence of anger in the debate is there for everyone to see, disgust plays a more insidious role. One of the recurrent tropes in the contemporary debate on prostitution is the vehement expression of revulsion by the fact that women indiscriminately 'sell their bodies' to large numbers of men every day, or sit behind windows, scantily clad, subjected to the leering of disorderly and often drunken men. ${ }^{16}$ The clients are portrayed as deviants who lust after sex with young girls, or who derive sexual satisfaction from lording over helpless women who are kept in servitude by pimps and criminals. Emotions are affective reactions characterised by immediacy and directness. Emotions affect us on an embodied level. They need no explanation or legitimation. Emotions are; they are beyond right or wrong. Yet, this quality of directness should not make us lose sight of the ethical dimension of emotions and their effects on law and public policy (Nussbaum, 2004).

Abolitionism is the determination to drive prostitution from society because prostitution evokes feelings of disgust and repulsion - as well as anger that such repellent behaviour is allowed - in the actor. ${ }^{17}$

16 On 'indiscrimination' see Pheterson (1996). She argues that sex workers prefer to exert choice in the selection of clients, but are not always in a position to do so. Pheterson concludes: 'It is important to understand, however, that lack of choice is not inherent to prostitution but rather to abuse, poverty, racism, drug addiction, poor working conditions, inexperience and/or despair. Whores, like other workers, want to change those circumstances without necessarily changing their trade' (1996, p 39).

17 Some examples: the caption of an article by an abolitionist group about the arrest of a pimp who prostituted a 16-year-old in the south of the Netherlands: 'The Valkenburg case: disgust and anger' (www.stoploverboys.nu/nl/2015/02/07/ valkenburgse-affaire-walging-en-woede); and a letter to the editor of the Volkskrant, a national newspaper in the Netherlands with a large circulation: 'With disgust I have read the umpteenth article about forced prostitution and the ever increasing trafficking' (www.volkskrant.nl/archief/prostitutie a626617). Columnist Kathy Sheridan in the Irish Times writes under the heading 'Love/hate, fantasy/disgust: telling the grim truth about prostitution' the following: 'In many ways, Debbie's scene portrayed the sex industry as it likes to promote itself: benign facilitator of consensual, adult transactions in a safe, controlled, indoor environment. Debbie needed cash (for drugs in her case); punters paid. Win/win. The image went awry when the camera remained firmly focused on Debbie's face - a contortion of disgust, pain, shame, resignation' (www.irishtimes.com/opinion/love-hatefantasy-disgust-telling-the-grim-truth-about-prostitution-1.2006017). Roger Giner-Sorrolla explains the disgust reaction to prostitution as follows: 'Evolutionary 
Law, social etiquette, public policy and administrative regulation are inevitably suffused with emotions. Emotion can be the reason for a law or rule (as in anti-discrimination laws that directly aim to prevent emotions of hurt and humiliation in the protected group), or it can influence that law or rule in a more indirect way (as in the provision of services to refugees that are triggered by feelings of compassion). Nussbaum makes the important point that not all emotions are equal in providing valid grounds for the regulation of behaviour. While hurt, humiliation and compassion will generally be regarded as providing compelling normative and cognitive reasons for regulating behaviour - because we can think of many situations in which it is widely seen as reasonable to prevent (as in hurt and humiliation) or promote such emotions (as in compassion) - disgust, she argues, is a much more 'dubious emotion to evoke' in a policy context:

Disgust is very different from anger, in that its thoughtcontent is typically unreasonable, embodying magical ideas of contamination, and impossible aspirations to purity, immortality and nonanimality, that are just not in line with human life as we know it. (Nussbaum, 2004, p 14)

Nussbaum's quote is important for two reasons. First, she points to the utopian, if not eschatological, quality of aspirations of abolitionist thought. Not only do we not know of any society where prostitution is absent, but the underlying emotion that informs abolitionism

psychologists would argue that attitudes towards prostitution start from a negative baseline for the same reason that promiscuous sex is seen negatively, people with facial birthmarks or deformities are shunned, and indeed any form of social deviance involving the body raises eyebrows. In this view, people unconsciously try to protect themselves against any trait or behaviour that might signal a risk of infectious disease. Rational or not, deep-seated contagion concerns can explain the disgust reactions many people, including some sex workers themselves, feel in societies where sex is regarded negatively. Some degree of disgust can be expected towards any job title that comes into contact with negatively regarded bodily substances.... Sex work, no matter how protected and antiseptic, can be expected to arouse the same aversion. Disgust, and its close cousin contempt - an aversion based on social status rather than physical grossness - are also notably directed by some sex workers at their clients. After all they are participating in the same activities. Anger is another moral reaction to prostitution, one tied to perceptions of harm and the violation of moral rights.... In studies of emotion structure ... anger and disgust are very closely aligned. It takes very little for mere disgust to turn into anger, and to find a backup on the assumption of harm to others' (Giner-Sorolla, 2006, pp 49-50). 
evokes an idealised, utopian image of society that is outside the reach of ordinary human life. Second, and related to the first point, Nussbaum highlights the element of fantasy in regulation that is shaped by disgust as the overriding emotion. We will return to the role of fantasy in prostitution policy shortly.

To grasp the ethics of emotions we need to keep four things in mind. First, emotions are public entities. The fact that the experience of emotion is by and large individual should not obscure the fact that emotions are first of all public expressions. Emotions are means of communication. While we can have private emotions (a lump in our throat at a moving scene in a play or movie), emotions are bound to their expression, and their expression is, or is not, recognised by others. The expression of an emotion, or the very possession of an emotion in a particular circumstance, can be judged inappropriate or even offensive. Think of the disapprobation that people incur by laughing at a tragic scene or weeping uncontrollably at the death of a remote public figure. Emotions emerge and are shaped in public to express and communicate a position, a judgement, on events that are considered important to the community. When they figure in policy debates their role is above all to express a point of view.

This, second, implies that emotions are socially constructed, both in their content and their expression. They appear in public consciousness through exemplars, narratives, case stories and arguments in newspapers, policy reports and opinion pieces. These exemplars and narratives are repeated over and over again until both the explicit and implicit message have obtained an easy familiarity (Goraj, 2012). The affect of disgust that is currently central in the prostitution debate is evoked and constructed by carefully chosen detail: the 12-year-old girl who is sold into slavery and abused by adult men; the young adult woman, misled by ruthless criminals, who is 'raped' 40 times a day by men who prefer to look the other way; the young woman who is brutally beaten by pimps when she tries to gain her independence (Goraj, 2012). These images are repeated over and over again in newspaper articles, documentaries and movies. The point of these narratives is to evoke and anchor disgust and anger about the business of prostitution in the public's mind (Fairclough, 2003).

Third, when emotions in policy debates are socially constructed, it is imperative to look into their function in the public debate. The key here is the quality of emotions qua emotion. While arguments can potentially be countered, emotions, as we have seen, are their own justification. Because of their immediacy and embodied 
character, it is hard to argue with emotions. They function as an ultimum arbiter. By questioning, for example, the validity of disgust in the prostitution debate, or of the images and narratives that underlie disgust, the critic opens himself up to the charge that he is heartless and in support of the very practices that are 'obviously' revolting. In this sense, emotions in public policy almost always imply an ethics of evasion. They absolve the adherents of a particular political position from engaging in a discussion about the rightness or plausibility of that position. For example, the centrality of disgust in the abolitionist discourse on prostitution absolves its adherents from a serious discussion of the presence of prostitution in society, the reason why women enter the prostitution business, and the effects, intended and unintended, of various approaches to prostitution policy, or, most importantly, from listening to the voice of sex workers. In this way the ethics of emotional evasion might be one of the most pernicious effects of the stigma of prostitution. It literally banishes sex workers and their interests from what is imaginable and acceptable in public debate.

Fourth, and perhaps most importantly, emotions suggest solutions. They bridge the normative gap between analysis and action. In the case of the public role of disgust this can become very troubling indeed. It is helpful to return to Nussbaum once more:

Both of these emotions [Nussbaum also discusses shame as a problematic public emotion - authors] may easily become problems, however, both in the life of the individual and in the larger social life of which it is a part. In particular, both emotions are associated with forms of social behaviour in which a dominant group subordinates and stigmatizes other groups. In the case of disgust, properties pertinent to the subject's own fear of animality and mortality are projected onto a less powerful group and that group then becomes a vehicle for the dominant group's anxiety about itself. Because they and their bodies are found disgusting, members of the subordinated group typically experience various forms of discrimination.... An appearance of control is then frequently purchased by the creation of stigmatized subgroups who - whether because they become the focus for social anxieties about disorder and disruption, or because, quite simply, they are different and not 'normal,' and the comforting fiction of the 'normal' allows the dominant group to hide all the more effectively - come to 
exemplify threats of various types to the secure control of the dominant group. (Nussbaum, 2004, pp 336-7)

Nussbaum does not specifically address prostitution in her analysis of disgust in law, but this passage faithfully captures the emotional dynamics of much prostitution regulation.

The ubiquity of strong emotion in the prostitution debate is easy to observe. Expert reports, opinion pieces and government documents are written in the style of a moral crusade: a great wrong lives among us, here are some representative examples, it is imperative that we act forcefully and immediately (Asante and Schaapman, 2005; Roessingh and Ramesar, 2011; Tonkens, 2011). Proponents of abolitionism regularly use redbaiting tactics by accusing those in favour of legalisation as being paid by pimps or being in the service of the 'prostitution mafia' (Ditmore and Wijers, 2003, p 84)) or a 'prostitution lobby'. ${ }^{18}$ The purpose of a policy discussion in the case of morality politics is not so much the dispassionate exchange of ideas or the measured assessment of the expected effects of a policy alternative, but rather an opportunity to demonstrate the correctness of the speaker's position in the face of much allegedly wrongheaded opposition. The result is that debates about prostitution and prostitution policy have all the characteristics of a "dialogue of the deaf': the angry reiteration of original positions, the unwillingness to listen to the opponent's point of view, the demonisation of those who think differently.

4. Morality policy is resistant to facts. There are remarkably few precise, reliable facts available in prostitution policy. As we will see later in this chapter there are good reasons for that, but more important for the characterisation of morality policy is the apparent lack of interest from politicians, administrators and commentators to obtain the numbers or to get them right. Resistance to facts becomes disregard for evidence. In fact, data and evidence are one of the main battlegrounds in the morality wars between abolitionists and regulationists in prostitution policy. It needs little commentary that those who are on a crusade will have a strong incentive to inflate

18 Under the heading 'Hurentag: kein Tag zum Feiern' ('Whores' day: not a day to celebrate'), the Austrian association Feministischer Diskurs (Feminist Discourse) accuses the so-called prostitution lobby of neglecting to acknowledge that 60 per cent of prostitutes - it strongly objects to the term sex workers - experience mistreatment, coercion, rape and humiliation. The sources for this and other figures are 'international studies', but these are not listed in the article (www.stoppsexkauf. at/hurentag-kein-tag-zum-feiern). 
numbers. In the case of prostitution policy, abolitionists wilfully use inflated numbers on trafficked women, abusive clients or the proceeds of trafficking into prostitution to present their case and create a moral panic around trafficking (Weitzer, 2007; Doezema, 2010). Moreover, the media are remarkably deficient in reporting reliable numbers (Goraj, 2012). But even more serious, scholars and government organisations uncritically cite numbers they have found in other publications. ${ }^{19}$ In fact, one of the most dispiriting phenomena in current prostitution policy, and a sure sign that we are in the realm of morality politics, is the willingness of the prohibitionist camp to simply fabricate numbers. ${ }^{20}$ In a book on clients by one of the feminist spokeswomen who represents the prohibitionist camp in the Dutch prostitution debate, the author 'quotes' from scientific reports on clients, while in effect she was making up the numbers to fit her anti-prostitution position (van der Zee, 2015; http://achterhetraamopdewallen.blogspot.nl/2015/04/ de-nieuwe-oorlog-tegen-de-hoerenlopers.html?m=1). Similarly, 94 academics have compiled a long list of wrong, misleading and tendentious use of data in Mary Honeyball's (MEP) Report on prostitution and sexual exploitation and its impact on gender equality (Honeyball, 2014). ${ }^{21}$ Ideological disregard for the facts is part of official policy. The US State Department's 'fact sheet' on trafficking claims that countries that legalise or tolerate prostitution show an 'increase in the demand for sex slaves and the number of victimized foreign women - many likely victims of human trafficking', and uses this fabrication as a ground for sanctions (cited in Chuang, 2010, p 1681). Fabricating numbers is an effective strategy in morality politics. Usually the concocted figures get much publicity, while the retort is at best published on a website or blog that is read by

19 See Weitzer (2007) and Doezema (2010) for a number of high-profile examples.

20 Making up data is, sadly, not restricted to the prostitution debate. The Department for Work and Pensions (DWP) in the UK has admitted making up comments from supposed 'benefit claimants' that appeared in a leaflet about sanctions. The benefit sanctions policy is controversial because parliamentarians and other opponents consider the sanctions to be ineffective in helping people find a job and to inflict unnecessary hardship on them. The DWP had produced leaflets with photos and vignettes of people who claimed that the benefit regime had actually helped them. Both the photos and the stories were fictitious (www.independent.co.uk/news/ uk/politics/dwp-admits-making-up-quotes-by-benefit-claimants-saying-sanctionshelped-them-10460351.html; www.bbc.com/news/uk-politics-33974674). This example goes to show that morality politics can extend to almost any policy issue.

21 In the spirit of disclosure of possible conflict of interest, Hendrik Wagenaar has to reveal that he was one of the signatories of the reaction to Honeyball's report. 
only a small number of people. The result is that the image that is desired by the activist has been planted in the public's mind.

Another manifestation of this aspect of morality politics in prostitution is the lack of interest in evaluating the impact of policies and programmes. For example, the assertiveness with which the Swedish government promoted its client criminalisation policy stood in inverse relationship to the availability of solid research to evidence its outcomes. For years after its introduction there simply were no data available and standard baseline measurement had been omitted. When the government finally did conduct a study its lack of the most basic academic standards was widely criticised in the international community of prostitution scholars (Dodillet and Östergren, 2013). ${ }^{22}$ Other commentators have noticed a similar reluctance to submit favoured approaches to evaluation. ${ }^{23}$ Friedman, commenting on the exponential growth of rescue and rehabilitation programmes in the global South says for example: 'The sector has to accept impact assessments to see what is working... There has been a real resistance to this over the years, as if we don't have to be accountable' (cited in Kempadoo, 2012b, p 254).

5. A fifth characteristic of morality policy is a certain impatience with policy implementation. It has the appearance that for those who approach prostitution as a battle over morals, the formulation and announcement of policy is seen as more important than its implementation. Mooney thinks that the clash of first principles that characterises morality policy leads to a lack of interest in the outcomes of the policy. A stark example is again the 2014 Swedish Sex Purchase Act. Ten years after the Act was passed in the Swedish parliament, the results are downright disappointing (Florin, 2012). The decision to prosecute the clients of sex workers has led to only a modest decline in the number of sex workers and men's attitudes towards prostitution have not changed (Dodillet and

22 Of the other countries that implemented client criminalisation measures, Norway did conduct serious evaluation research. The outcome was not very positive for client criminalisation. Countries that have introduced legalisation are more likely to engage in serious policy evaluation. The Netherlands and New Zealand are examples.

23 Meanwhile a new evaluation - commissioned by the Swedish government was published. The evaluation was carried out by staff members of the County Administrative Board of Stockholm with the support of well-known academics like Charlotta Helmström from the University of Malmö. This report seems to adhere more to scientific standards (County Administrative Board of Stockholm et al, 2015). 
Östergren, 2013). More importantly, although health and social work organizations were supposed to play a central role in the implementation of the Act, no budget has been allocated for this (Florin, 2012). There is evidence that the situation of sex workers has deteriorated, with some cities having phased out all harm reduction programs. ${ }^{24}$ When confronted with these results, the Swedish minister brushed it aside as insignificant in light of the larger pedagogical goals of the law (Dodillet and Östergren, 2013; County Administrative Board of Stockholm et al, 2015). Without generalising too much from this example, we can conclude that in moral policy the symbolic dimension of the policy is at least as, if not more, important than its instrumental aspect (Edelman, 1985; Gusfield, 1986; Yanow, 1996). The purpose of the policy is to send out a signal to the world - both to supporters and opponents - that proponents of a certain policy proposal hold the right position on the issue.

6. Sixth, morality policies are vulnerable to abrupt and drastic change. Policy theorists are in agreement that in most domains policies are kept on course by a robust balance between stability and change. Constitutional and legal frameworks, fundamental social values, organisational structures and routines, and the secure membership of policy coalitions create stability. Change is mostly incremental; habit and the back talk of policy implementation initiate adjustment of the reigning order. Extraneous shocks might impel a more fundamental rethinking of goals, values and eventually policy programmes, but such transformations are black swans, rare and far between (Cairney, 2012, pp 207-9). These assumptions about stability in public policy have come under pressure in the years since 2008, when governments have felt compelled to drastically curtail their budgets. Yet, even while in the face of unsustainable budget deficits large changes in the organisation and delivery of education, healthcare and retirement policy have been proposed in many countries, institutional drag or resistance check their realisation. Institutional drag is the awareness that the functioning of a social domain depends on many taken-for-granted institutional practices, habits and traditions that support other valued or necessary elements of the domain. Institutional resistance emerges from actors who have a vested interest in the status quo, experts who have a deep

24 The new evaluation of the Swedish Sex Purchase Act 2014 does not deal with the issue of violence against sex workers and the provision of social and health services for them. (County Administrative Board of Stockholm et al, 2015). 
understanding of the underlying principles and real-world effects of the current system, and/or the public who have come to appreciate the benefits of the programme. Often such a situation does not exist in the case of morality politics. ${ }^{25}$ Morality politics turns the theorised balance between stability and change in public policy on its head. Radical change is not rare, and it happens, as we will see in Chapter Five, at the local level. By 'abrupt' and 'drastic' we mean changes towards policies that are based on wholly different values and underlying principles. We have already commented on the unwillingness to account for the proclaimed impacts of prohibitionist policies and rescue and rehabilitation programmes. The uncompromising nature of morality politics, in combination with a lack of reliable data and solid evaluation outcomes, has resulted in a situation in which policy debate is never settled (Tatalovich et al, 1994; Mooney, 1999, p 678) and policy makers, in the thrall of grand moral narratives of alleged policy failure, are willing to throw overboard, trusted values and clear evidence. That is what makes it politics instead of policy.

7. Previously, in discussing the popularity of the regime concept in discussions about prostitution policy and in our analysis of the role of strong emotions in abolitionism, we introduced the concept of fantasy or fantasmatic logics as the literature calls it (Glynos and Howarth, 2007). To conclude this section on morality politics we argue that morality politics is particularly prone to the influence of fantasmatic logics. In fact, it is the play of fantasy that forms the driving force behind morality politics and explains its different characteristics, such as the emotional valence of public debate, the fast and loose treatment of evidence, the lack of interest in serious policy evaluation and the tendency to ditch extant policies for radically different policies. So, what are fantasmatic logics?

In his 1971 classic on social change and organisational learning, the organisational theorist Donald Schön comments on what he calls 'the stable state':

I have believed for as long as I can remember in an afterlife within my own life - a calm, stable state to be reached after a time of troubles... The afterlife-within-my-own life is a

25 Outshoorn (personal communication) points out that abortion policies might be an exception. In western-European countries pro-life forces that attempt to roll back laws that allow abortion run into stiff resistance from both the general public and progressive political parties. 
form of belief in what I would like to call the Stable State. Belief in the stable state is belief in the unchangeability, the constancy of central aspects of our lives, or belief that we can attain such a constancy. Belief in the stable state is strong and deep in us. We institutionalize it in every domain. (1971, p 9)

Schön then continues with listing some of these domains: personal identity, 'the organizations and institutions in which we work', 'the stability of certain values' (1971, p 10). The function of the belief in the stable state is 'to protect us from apprehension of the threats inherent in change'. The stable state is a bulwark against the threat of uncertainty'. And as it is invested with much emotion, '[C]onsequently, our responses to attack on the stable state have been responses of desperation, largely destructive' (Schön, 1971, pp 10-11).

A generation later, the social theorists Jason Glynos and David Howarth introduce the concept of 'fantasmatic logics' (in addition to social and political logics) to explain the transformation and stabilisation of social and political regimes (Glynos and Howarth, 2007, p 133). In an echo of Schön's notion of the stable state, the operation of fantasmatic logic 'reinforces the social dimension of practices by covering over the fundamental lack in reality and keeping at bay what we have labelled "the real". In this respect, logics of fantasy have a key role to play in "filling up" or "completing" the void in the subject and the structure of social relations by bringing about closure' (Glynos and Howarth, 2007, p 146). Fantasy in politics functions through a 'narrative or logic that that promises a fullness-to-come once a named or implied obstacle is overcome - the beatific dimension of fantasy - or which foretells of disaster if the obstacle proves insurmountable, which might be termed the horrific dimension of fantasy' (Glynos and Howarth, 2007, p 147). And then in a sentence that is an uncanny prescient reference to the current prostitution debates, Glynos and Howarth add: 'For example, images of omnipotence or total control would represent the beatific dimension, while images of impotence or victimhood would represent the horrific dimension of such fantasmatic attempts to achieve or maintain closure' (2007, p 147). We recognise fantasy at work in public policy when there is an undeniable discrepancy between official statements and informal, unofficial reality. This is because fantasy attempts to bridge the gap between incompatible elements, for example between realistic statistics on prostitution 
and the inflated figures that the anti-trafficking lobby puts forward. Finally, fantasy in public policy is not a topic for quiet mirth. Real people are subjected to the dark side of fantasy. When the beatific utopia of the stable state, a world without conflict and politics, is threatened, the threat is rarely abstract. In fact, in most instances the threat comes from a clearly designated and identifiable group: ' $[T]$ his beatific dimension of fantasy is supported with an opposite, which explains why things are imperfect. There is an important by-product to this balancing-act: the exclusion/demonization of particular social group' (Yannis Stavrakakis, cited in Mert, 2015, p 43). It does not require much imagination to infer who the demonised groups are in contemporary prostitution policy (see also Wagenaar, 2015a).

In a world that celebrates rational and reasoned decision making it might seem counterintuitive or frivolous to emphasise the central role of fantasy. Yet, as Schön's remarkable reflections on the stable state and Glynos and Howarth's theory of fantasmatic logics indicate, fantasy is an important, and often hidden, driver of policy and public debate, providing energy and coherence to a particular contested topic. The effect is not only that it moves a topic to the top of the political agenda; fantasmatic narratives also suggests courses of action that will deliver us from our current ills. Fantasy operates in all domains of public policy; however, when a domain inhabits the extreme end of the morality dimension it is particularly prone to the utopian effects of fantasy, which leads - as we will show in the following chapters - to insatiable hunger for more instruments of control. To close this brief interlude on the role of fantasy in public policy, with clear implications for the formation of prostitution policy, we quote Deborah Stone on the function of stories:

What all these stories ... have in common is their assertion that there is choice. The choice may belong to society as whole, to certain elites, or to victims, but the drama in the story is always achieved by the conversion of a fact of nature into a deliberate human decision. Stories of control offer hope, just as stories of decline foster anxiety and despair. The two stories are often woven together, with the story of decline serving as the stage setting and the impetus of the story of control. The story of decline is meant to warn us of suffering and motivate us to seize control. (1997, p 144)

To sum up, the purpose of this section is not to provide a hard and fast definition of morality politics. We have characterised morality 
politics through its extreme position on a number of dimensions that characterise all public policy and the effects this has on the policymaking process. Our argument is that if policies are explicitly ideological, a proxy for a larger cause, almost exclusively owned by the general public, impervious to facts, discussed in emotionally highly charged language, concerned more with the symbolism of strong measures than the details of implementation, and prone to sudden policy reversals, we designate them as an instance of morality politics. In morality politics fantasy cuts a wide sway, motivating officials and citizens to act decisively to deliver society from a great wrong - no matter if the wrong flies in the face of evidence and the solution harms or excludes the very group that needs to be saved. We conclude that in most countries prostitution policy can be characterised as morality politics in this sense. That is not to say that there are no instances of dispassionate fact finding, measured searches for workable solutions or patient implementation of pragmatic policies in prostitution policy. We have in fact encountered quite a few such instances in our research. Our general argument is that the moral nature of prostitution policy makes it vulnerable to extremist positions, the breakdown of public dialogue, and the unchecked play of fantasy. In addition to the lack of data, the inaccessibility of the prostitution world, and the many exogenous forces that drive its development, the moral nature of prostitution policy is an additional obstacle to administrators and front-line bureaucrats to formulate, design and sustain a reasonable, pragmatic and humane public policy in this domain. Morality politics usually results in adversarial politics driven by the values and opinions of contesting factions. This places administrators and professionals who implement such policies in a difficult position. As Ansell puts it: 'Agencies must now manage their business in an environment of divisive politics, in which their actions are scrutinized and challenged by opposing sides' (2011, p 4).

\section{Paradoxes of immigration}

Elsewhere, walking around the muddy campsite [in Idomeni, at the border of Greece and Macedonia, next to the railroad that connects the harbour city of Piraeus with continental Europe, now blocked by the refugees - authors], which smelled of burning plastic and leaking toilets, there were people from Pakistan, Bangladesh, Somalia and Francophone West Africa - all now labelled 'economic migrants', regardless of their varied and complex reasons for 
travelling... Here in this valley between mountain ranges, three sets of interests had collided; the free movement of trade, the free movement of people in need, and the insecurities of Europe's settled populations. (Daniel Trilling in the London Review of Books, 17 December 2015, p 19)

As Trilling captures admirably, sites like Idomeni, or countless lesserknown crossings at the borders that divide southern and eastern Europe from the affluent, democratic north-west of the continent, capture the challenges and dilemmas of immigration policy in Europe today. While most migrants who travel to work in prostitution in northwest Europe are not from the countries that Trilling mentions in his reportage, they are still perceived by the authorities as 'economic migrants', heading for an unwanted, stigmatised profession, thus doubly frowned on. Traditionally, prostitution is closely associated with migration. In western Europe until the early 20th century this was mostly rural to urban internal migration (Walkowitz, 1982; Gibson, 1986; Corbin, 1990). This is still the case nowadays in many Asian countries (Kempadoo, 2012a). Today prostitution is caught up in shifts in the global organisation and distribution of capital, labour and citizenship and the large international migration streams that result from this. As Kempadoo argues:

From a perspective that combined analyses of sexual labor and gendered migration, the global sex trade was defined as one, but not the only, site in which human trafficking could be located. Sectors that required unskilled or semiskilled non-sexual labour, such as domestic service and manufacturing, as well as the racialization and feminization of the global work force and migration processes produced through the globalization of capitalism, became relevant to the analysis. (2012a, p xix)

As we will see in Chapter Five, migrants are attracted to prostitution because it offers various advantages over other occupations that are available to recent migrants. Over and over again, migrant sex workers declare that compared with other jobs in the low-end wage sector, prostitution offers a decent income, low entry thresholds, and a modicum of control over one's work situation. It is also a job that can be done part time, in addition to other work, although that seems more common among male than female migrant sex workers (Mai, 2009; but see Dekker et al, 2006). However, in almost all countries 
the combination of prostitution and migration proves to be toxic. Laws pertaining to prostitution are entangled with restrictive immigration law, and in the public debate fears about immigrants get mixed with fears about sex workers (Tampep International Foundation, 2015). In the end, non-national sex workers labour under a double stigma: that of being a sex worker and a migrant.

Let us take a closer look at some of the implications that the conjuncture of immigration and prostitution has for public policy. Migration, prostitution and public policy are related in two ways. First, and perhaps most pernicious, is the conflation in the public debate and, as a result, in the public mind, of prostitution with trafficking. This 'hyperfocus of many governments and advocacy groups on trafficking into forced prostitution' (Vance, 2011, p 933) has major consequences for public policy. It makes a serious debate on the situation of migrant sex workers and a form of regulation that balances their needs and those of society more or less impossible. A good example is the moral panic around pimps and criminal traffickers in many countries. Using migrant sex workers' statements, in Chapter Five we report that the networks around migrant sex workers are mostly made up of family members and that the concept of pimp, a key term in the abolitionist discourse, has considerable ambiguity. However, as we discussed in the section on morality politics, the debate on prostitution, and the ensuing policy proposals, take on a shrill, unyielding quality, in which the only 'reasonable' outcome seems to be the strictest possible control of prostitution, and preferably its prohibition, for the purpose of 'saving' the victim of trafficking and removing this moral blight from our midst. Only through close surveillance and control can 'traffickers' be discovered and their 'victims' rescued (Kempadoo, 2012a, p xv). The result is paradoxical. In most instances the alleged victim, the sex worker, is herself the victim of draconic measures that violate her human rights and civil liberties. Most measures inspired by the trafficking frame reduce the number of working places, make it more difficult for the sex worker to exert control over work conditions, or force her into unwanted dependency or mobility, thereby increasing the likelihood of the very same exploitation that the anti-trafficking advocates purport to eradicate.

Moreover, the exclusive focus on trafficking of young female sex workers misdirects our attention from very real issues of exploitation in other low-end labour markets, as well as in prostitution (Vance, 2011). More than half of the cases of trafficking that were reported by the Dutch National Rapporteur in 2010 for example, are outside the realm of prostitution, yet in the media coverage it is prostitution trafficking 
that gets all the attention (see also Ditmore, 2012, p 110). Sticking to the Netherlands, serious and repeated cases of labour exploitation have been reported in the construction, agricultural and meat-packing industry, yet no anti-trafficking activist has ever spoken out about these cases. Similarly, many underage asylum seekers have horrific histories of child labour or war trauma in their home countries, dwindle for years in forced idleness in asylum centres, and face the imminent threat of deportation. Yet, despite appealing to moral arguments of human decency and religious charity in the case of prostitution, the anti-trafficking lobby appears to have no interest in the moral scandal of the treatment of young asylum seekers. In fact, it took a moral panic about the alleged abduction of young female asylum seekers by criminal gangs to bring the issue of young asylum seekers to its attention - and then only briefly. The everyday exploitation of sex workers by the owners of clubs and window brothels (Altink and Bokelman, 2006; ICSRE, 2016) seems of little importance to activists and policy makers alike. In fact, as we will see in the next chapter, several measures that are currently enacted in Austria and the Netherlands are deliberately aimed at increasing the power of brothel owners in the regulation of prostitution and, as a result, increasing the dependency of sex workers.

The second implication of the conflation of migration and prostitution is that much prostitution is regulated via immigration law. While, legally, immigration law determines the fate of sex workers, it has two characteristics that have a negative impact on their position in society. First, the purpose of most immigration law is to restrict the entry of unwanted foreigners. Second, even in countries that are governed by the rule of law, immigration law, both on paper and in practice, tends to operate with less robust notions of citizenship than domestic law. The result is that for sex workers as well as migrants in general, immigration law is often applied without the required recourse to human rights or legal appeal. For example, a combination of immigration and prostitution law tipped many foreign sex workers into illegality more or less overnight when the Dutch parliament legalised brothels in $2000 .{ }^{26}$ Dutch immigration law at the time excluded prostitution as a lawful occupation, and the legalisation decision excluded non-EU nationals

26 No one knows exactly how many non-EU sex workers were affected by the measure. Non-EU nationals have not been allowed to work in Amsterdam since 1995, while in the cities of Groningen, Alkmaar and Rotterdam they were allowed to work with a special 'toleration visa'. At the time of the repeal of the ban on brothels in 2000, many non-EU sex workers had already been 'replaced' with sex workers from association countries. 
from working as sex workers in the Netherlands. Similarly, as the story of Dora with which we opened this book shows, sudden changes in immigration law - such as the Austrian government's abolition of the so-called prostitution visa with which 'dancers' were able to work and stay legally in Austria - may mean that migrant sex workers have to instantly leave the country where they have settled, to start all over again in another country. Underlying this disregard for human rights is the paradox that trafficking is framed as a human rights issue but dealt with by criminal law (Vance, 2011, p 936). Vance observes, for example, that international treaties to combat human trafficking, although couched in human rights language, mandate a range of law enforcement measures but leave optional the provision of 'rights-based services' (Vance, 2011, p 937). But perhaps equally detrimental to the social status of sex workers is that in many cases it is police officers, with their attendant symbolism of crime and law enforcement, rather than administrative officials who handle sex workers' encounters with the administrative face of society. The legal conflation of prostitution and immigration has the effect of criminalising the former. This, as we will see, has grave consequences for issues of trust and the willingness of sex workers to collaborate with government officials (Benoit et al, 2015).

We encounter other examples of criminal law-based legal regulation and the ensuing matter of disregard for sex workers' rights later in this book, but simply recording such infringements of sex workers' rights does little to further our understanding of prostitution policy. It is important that we understand the position of officials entrusted with designing and implementing prostitution policy. As we have seen, the size and composition of the sex trade is influenced by supranational forces in capital and labour markets, the global linkages created by the internet and social media, the existence, and persistence, of systems of bonded and indentured labour in developed and developing countries, and large movements from one global region to another of predominantly but not exclusively poor populations in search of improvement. Some men and women in these large migration streams seek independence and freedom from the global supply chains through sexual labour; some are moved through organised channels to work under conditions of coercion and exploitation in the sex trade. Throughout modern history this internationalisation of labour has been accompanied by persistent, often racialised, discourses of 'trafficking', 'organised crime' and more generalised condemnations of prostitution under the banner of the 'social evil' of prostitution, 'white slavery' and "trafficking' (Doezema, 2010). Differently put, while in the preceding section we discussed the moral nature of prostitution policy in general, 
conceptual terms, the entanglement of prostitution and migration results in a pervasive and dominant substantive ideology of prohibiting prostitution in the name of protecting victims of trafficking. At the same time we will see that much prostitution policy is local in nature. It is local policy makers who have to translate international regulation and national legislation into workable operational rules and procedures. It can be expected that most local officials have only a vague awareness of the larger, transnational, economic, demographic and discursive forces that shape the world they have to regulate. It is likely therefore that they will take the surface appearance of prostitution as it appears in the media - characterised by trafficking, migrants, crime, victims - at face value and act accordingly by tightening surveillance and control (Edelman, 1988, p 6). The challenge of the complex entanglements of prostitution and migration is, in other words, to design and implement policy in such a way that it does justice to the global backdrop of the sex trade and countervails the prohibitionist ideology that accompanies global migration. In Chapter Five we suggest modes of policymaking that do just that.

\section{Obstacles to obtaining reliable numbers about prostitution and sex workers}

Numbers play a key role in policymaking. Numbers indicate the size and nature of a societal problem, trends in its development, the size and composition of target groups, and the effectiveness of policy interventions. No nation can formulate effective macroeconomic policy, for example, without reliable statistics of economic growth, the money supply, employment, national debt, inflation, and import and export figures. Without precise and reliable numbers policy makers are to all intents and purposes blind. This suggests an urgent plea for the availability of a robust basis of evidence in public policy. However, the relationship between numbers and policy is far from linear. Policy, or rather the societal issues that trigger policy interventions, are organised according to large cognitive-appreciative frameworks (Rein, 1983a; Schön and Rein, 1994). Frames are tightly integrated configurations of beliefs, understandings, values, norms, facts and action preferences (Rein, 1983a, p 96). They usually have a narrative form (Stone, 1997), which is probably why Schön and Rein call them 'diagnostic-prescriptive stories' (Schön and Rein, 1994, p 26). People - politicians, administrators, stakeholders - use frames to structure vague, ambiguous and indeterminate situations and transform them into coherent, organised and recognizable 'problems' that allow for 
collective solutions (Schön and Rein, 1994, p 26). This process of framing is ubiquitous; no policy issue escapes it.

Not surprisingly, numbers are often contested in the adversarial environment in which policy is formulated (Stone, 1997, ch 7). There are good reasons for that. In most cases obtaining good statistics of a natural or social phenomenon is exceedingly difficult. Also, critics will contest the selection or interpretation of statistics. Under every act of counting, usually invisible to the outside observer, lies a decision as what to include and exclude from the category that is counted (Stone, 1997, ch 7). Often a barely acknowledged process of framing affords the selection of data and evidence as relevant or irrelevant to the problem at hand. In the field of prostitution all the above problems are compounded. Numbers are imprecise, unreliable, based on vaguely defined categories, and sometimes wildly off the mark. More seriously, in the contested morality politics of prostitution policy, some stakeholders resort to fabricating evidence, as we saw. Although not restricted to prostitution policy, numbers in prostitution are often used in strategic ways - not to inform but to promote. In fact, one central finding of this study is that, for good reasons, precise and reliable numbers on key aspects of prostitution are hard to come by. ${ }^{27}$ This should put policy makers on alert, as media reports and academic publications blithely, and with seeming authority, report prostitution statistics as if they were hard facts. We have come to conclude that no statistic on prostitution should be accepted without questioning its sources and the procedures by which it has been generated.

Nevertheless, it was an important goal of the project that informs this book to establish reliable and precise data on the number of sex workers in the participating cities, and possibly, countries. There are two arguments why precise and reliable numbers are important in prostitution policy. The first is that without a good understanding of the size, age and composition of the population of sex workers in a

27 See Weitzer (2015) for a number of instructive examples in which researchers have used creative methods to arrive at more precise estimates of the number of victims of trafficking. It almost goes without saying that their estimates are much lower than the numbers of 'victims' the neo-abolitionists and the anti-trafficking industry put forward. In Cambodia researchers counted 1,058 victims, or $3.7 \%$, in a population of 27,925 female sex workers. Weitzer (emphasis in original) comments: 'Note that the total number of sex workers in this study is a fraction of the number of trafficked sex workers alleged by Cambodian NGOs (80.000-100.000).' A study of over 5,000 households in five eastern European countries came to 108, or 2\%, of people who fitted the profile of a trafficking victim. Of these, 22 were victims of sex trafficking (Weitzer, 2015, p 231). 
particular locality it is difficult to make policy. Our second argument is an argument about moral hazard. Reliable, precise numbers form a factual counterweight in the moral debates about prostitution. Since the late 1980s prostitution has received unprecedented attention in the media and the entertainment industry, as well as in government reports, research studies, international conference speeches and statements from politicians. Bernstein speaks of a 'discursive explosion' and thinks that the almost obsessive attention given to prostitution mirrors that of social reformers of the early 20th century (2007, pp 12-13). The media, despite their interest in prostitution, are, however, remarkably deficient in reporting reliable numbers. ${ }^{28}$ But more serious scholars also uncritically cite numbers they have found in other publications. For example, Bernstein claims that there are 30,000 sex workers working in the Netherlands. She bases this number on a Swedish source and concludes that in the Netherlands the number of sex workers per capita is much higher than in Sweden (2007, p 163). ${ }^{29}$ Thirty thousand is a number that circulates on the internet and is often quoted in reports about the Netherlands, but there are good reasons to assume that it is a serious overestimate of the size of the prostitution market in the Netherlands. ${ }^{30}$ The dynamics of framing make beliefs quite

28 For example, a recent report on the prostitution market in Amsterdam (van Wijk et al, 2010) gives several careful, and well-founded, estimates of the number of sex workers working in the city in all types of prostitution. The researchers were careful to distinguish between daily numbers and cumulative numbers (that is, the number of different women that have at any one moment in the year worked as a prostitute in the city). They estimated the annual, cumulative number at 1,090 to 3,380, with the daily numbers for all types of prostitution about half the lower annual estimate. Nevertheless all newspapers and media reported that '5000 sex workers were working in Amsterdam', with some newspapers, wholly unwarranted, adding another 50 per cent to that number to arrive at a total of 7,500. The Dutch prohibitionist parliamentarian Gert Jan Segers outdoes even these high numbers by insisting in interviews that on a daily basis 8,000 sex workers are active in Amsterdam.

29 To be fair to Bernstein, she does mention in a footnote that providing precise statistical accounts of the sex industry is notoriously difficult. But she then uncritically asserts that her numbers provide a 'rough portrait' of the size of respective national prostitution markets (2007, p 234).

30 With regard to the Netherlands the number that is most often quoted nationally and internationally is 25,000 sex workers nationally. This number dates from 1999 and represents an extrapolation of estimates of municipal public health agencies (van der Helm and van Mens, 1999). Van Wijk et al (2010) report that a few years later the municipal public health agency in Amsterdam estimates that 8,000 sex workers are active in the city. That number has been quoted since. In both cases the estimates are highly dubious. For one thing, they probably represent aggregate annual numbers, although that is not clear from the original sources. 
impervious to numbers and evidence. Usually a solid and relatively uncontested core of data and evidence is required to put the brakes on the free flight of values and beliefs in a particular policy area. But if the constraining relation between evidence and belief is weak and circuitous, the opposite does not hold. Where accurate and reliable data are not available, policy doctrine will encounter little push-back from the real world. Policy will be based on unchecked frames, and in some instances, as we saw earlier, on emotion and fantasmatic logics. In Chapters Three and Four we will encounter many examples of policy proliferation that is unchecked by evidence.

Conceptual obstacles. There are conceptual and practical reasons why it is difficult to obtain reliable, precise numbers about prostitution. The first conceptual reason relates to the contested nature of prostitution policy, which aggravates political struggles over numbers. As Deborah Stone explains, numbers in policy have symbolic value. To count is to count as, and where you draw the line, so that some things are included and some excluded from your categories, is always a political decision (Stone, 1997, p 164). All numbers in public policy present moral images to their intended audience: 'Numbers make normative leaps' (Stone, 1997, p 167). They are a call to action. Struggles over conceptual boundaries and definitions are inherent to public policy.

The above applies in particular to prostitution policy. Even the central concept - prostitution - is the subject of intense debate. People define prostitution in different ways and include different types of sex work and sexual activity in the statistics. For example, are women who offer web $\mathrm{cam} /$ telephone sex or erotic massages subsumed under prostitution? What about actors in pornographic films? Or young, vulnerable girls from broken homes whose need for emotional support is sexually exploited by callous men in their environment? Does there have to be a certain degree of continuity and regularity for such activities to be called prostitution, or is it enough - as is the case in Austria - to take a financial/material reward once to be defined as a sex worker? The problem is that all of these images of prostitution are available 'out there' in the 'real world'. The problem is compounded when it comes to categories such as 'pimping', 'forced prostitution' or 'victims of trafficking'. In these cases the definition of the category is itself highly contested, as we will see in Chapter Six. Policy categories merge fact, moral belief and calls for action, and their adherents hold on to them with sincere conviction. Yet, the choice of what image of 'prostitution' or 'pimping, or 'forced prostitution' or 'victims of trafficking', prevails has significant consequences for the nature and extent of the issue that 
is the subject of public policy, as well as the type of policy instruments that are required for its solution.

The second conceptual issue is the distinction between daily and aggregate numbers. Surprisingly this important distinction is not often made in media or policy reports, or even scientific publications. The daily number (the number of women working in prostitution in a particular area on a given reference date) will give an indication of the actual size of the prostitution market in that area. In addition to the size of the sex trade in a particular location, this number is also an indicator of the 'pressure' that prostitution exerts on that location. Think of public nuisance, clients' cars driving through the neighbourhood, or the petty crime that is associated with some forms of prostitution. The aggregate number (the number of different women who worked in the area at least once in a given year) gives an indication of the total number of women who engage in prostitution in that area and of the intensity of mobility. The aggregate number cannot be used as an indication of the size of the local, or even national, prostitution market as it contains a large amount of double-counting (sex workers working in different cities in a particular year). It is useful, though, for service agencies to get an indication of the required capacity.

Practical obstacles. There are also practical obstacles in counting the number of sex workers. The first relates to the accurate and reliable compilation of statistics. Prostitution is not a homogeneous phenomenon. It comprises different work types such as street, window, club, home and escort prostitution, each of which presents its own challenges to counting. Moreover prostitution forms a world that is closed to outsiders and, particularly in countries where it is prohibited, operates in the shadows. When prostitution is mixed with criminal intent, such as in trafficking and brute exploitation, these problems of visibility are augmented. Moreover, as we will explain below, the level of mobility in prostitution can be extremely high. As a result most data sources are problematic. Police records generally only register sex workers who have been involved in, or are victims of, some kind of criminal activity, mostly violations of visa requirements or as alleged victims of trafficking or pimping. Tax records are rarely updated and contain many expired files, while an unknown number of sex workers work outside the tax system or are not accessible. It is not surprising then that most countries do not have centralised data banks that keep track of basic statistics on prostitution (Jahnsen and Wagenaar, in press). And even where such data registers exist they are often based on unreliable sources. Austria, with its otherwise well-organised and experienced public administration, provides a good example. 
Since 2007 the federal Ministry of the Interior in Austria has annually generated a Review of Situation (Lagebericht) with regard to prostitution. It contains data about the so-called red-light milieu in the country. The Lagebericht is compiled from data that are requested each year from the Departments of the Criminal Intelligence Services in the Bundesländer by the Department of Criminal Intelligence Service in Austria, a branch of the federal Ministry of the Interior. However, the police/criminal departments in the Bundesländer are not obliged to report to the Ministry of the Interior, because prostitution falls within the remit of these provinces. Therefore, the data are not collected and compiled in the same way in each province. At first blush the Lagebericht seems to give a comprehensive picture. Indeed the data derive from various sources like police investigations, checks of work sites, police district investigators in the milieu, reports of patrols and reports on imprisonment. However, the data are in reality highly unreliable. The definition of sex facility differs per province, ${ }^{31}$ registration of sex workers is differently organised per province, which results in different bases for estimates, and the number of unregistered sex workers is anybody's guess. ${ }^{32}$

Similarly, in the Netherlands there is no central registration of the number of sex workers. The Dutch authorities order periodical evaluations of the effects of the 2000 parliamentary decision that legalised the sex industry (Daalder, 2002, 2007, 2015), in which educated guesses as to the size of the national population can be found. The tax office can only provide data on the number of sex workers who are registered taxpayers. It admits that its files are unreliable because they are incomplete and many registered sex workers have exited sex work or left the country. The National Rapporteur on Human Trafficking

31 According to the information of the Criminal Intelligence Service in Austria there is no written definition about types of facility. It is said that the designations are related to the licenses given, but the licensing procedure does not distinguish between brothels and nightclubs, for example, while it leaves out Turkish-Albanian cafés or Tischdamenlokale, where prostitution takes place on a large scale, altogether.

32 The number of non-registered sex workers differs greatly according to the source one uses. The police estimate the number at 3,000 to 4,000 nationally. According to investigations by LEFÖ-Tampep, which rely mainly on the observations of provincial health directorates, health services and women's organisations, the ratio of registered to non-registered sex workers is 1:6. In the Austrian Tampep report of 2008/09 (Tampep International Foundation, 2009) it is assumed that 27,000 to 30,000 sex workers (registered and non-registered) work in Austria. It is not clear if these are daily or annual numbers. Aware of the negative consequences of inflated numbers all counselling organisations meanwhile refrain from estimating the dark number. 
and Comensha ${ }^{33}$ present annual data about the number of 'registered' victims of trafficking; in practice this number is based on the number of cases that are brought to court, that are investigated by the police and/or public prosecutor, or, in the case of Comensha, the number of suspected cases based on entries in its anonymous crime hotline (about 450 victims in prostitution in 2009) (Nationaal Rapporteur Mensenhandel, 2010, p 98). Some municipalities contract research agencies on a regular or incidental basis to make an inventory of the sex industry in their region or town (van Wijk et al, 2010; Oude Breuil, 2011). They rely on various data sources ranging from police and tax records to personal observation.

The second practical challenge in obtaining reliable statistics on the number of sex workers is high mobility. Challenged by the absence of reliable numbers, we set out - in hindsight rather naïvely - to obtain more precise and reliable data on the number of sex workers who worked in the various types of prostitution in a particular location. We started out with what we thought would be the easiest type to count: window prostitution. The number of windows is available from the city administration, and although it has considerably decreased since 2000, it does not fluctuate very much in the short term. We used different sources: police records, municipal statistical offices and health agencies. We also went out to do our own counting. Our field workers took position on a street corner and counted the number of sex workers working the windows within our field of observation on several successive days. They also counted the number of women working in a representative sample of clubs. What we discovered was another, and as far as we know unreported, obstacle to obtaining reliable numbers: an astonishing amount of mobility. For example, of a particular group of six windows in The Hague, three would be occupied from 13.00 to 18.00 hours, then all of them until midnight. However, the next day none was occupied until 18.00 hours and only two in the evening, and so on. Some women would only work for two hours, others the whole day. Through our interviews we discovered that mobility applied to

33 Comensha is an NGO that collects and provides data on trafficking, organises shelter for victims of trafficking, and advises the government on measures against trafficking. Although it is a private company, it is financed by the Dutch government. The Ministry of Justice often relies on Comensha for its data. Comensha presents itself as a strong advocate against trafficking. Its website presents stories of victims and keep track of the cumulative number of reports of trafficking by citizens via its anonymous telephone hotline. Comensha is regularly criticised for inflating numbers, for example by including suspected cases of trafficking or exploitation. 
location, geography, type of sex work and working hours. Subsequent discussion with police officers and other professionals confirmed our initial observation: high mobility is an intrinsic characteristic of the sex trade. In fact, many police officers told us that because of the high turnover of sex workers in a particular location, they had stopped bothering about the precise numbers (interview, police officers, the Netherlands).

We conclude from this discussion on obstacles to obtaining accurate and reliable statistics on prostitution and sex workers that numbers any numbers - in the literature on prostitution must be approached with caution. Ideally, the authors who publish numbers should provide their source, the methods of collection, and the strengths and limitations of the data. Similarly, readers must always ask themselves these same questions in assessing the quality of the reported numbers. Unfortunately these simple grounds for assessing the quality of the numbers are rarely presented. In fact, in the morally charged climate of prostitution policy, we have come to believe that the difficulty in obtaining accurate numbers about prostitution is treated as an invitation to provide ideologically expedient numbers. This would explain two persistent tropes in the literature on prostitution: the inflated estimate and the ubiquitous genre of the melodrama or 'sad story' (Vance, 2011). In the first case we encounter unsubstantiated estimates, always in large round numbers, always delivered with great authority, about the number of (street) sex workers, internet sex work, 'forced'sex workers, or victims of trafficking. The second feature capitalises instead on the absence of numbers. Here, the argument is grounded in, often lurid, tales of a single sex worker or victim who, by implication and through the use of vague quantifiers, ostensibly represents a large population. The purpose in both cases is the same: to make a moral point and to incite the audience to action. Numbers have symbolic value in all public policy. What distinguishes morality politics, as discussed in the preceding section, is that numbers are primarily used for their symbolic value, uncoupled from their factual, descriptive role, and with little reflection about the assumptions that determine the delineation of key categories.

\section{The ineluctable importance of the local in prostitution policy}

Like most contemporary policy, prostitution policy is enacted at multiple levels. In the regulation of prostitution, international agreements, national laws and regional or local rules interact in complex 
and unpredictable ways to shape the face of prostitution in society. For example, 117 nations have signed the UN Protocol to Prevent, Suppress and Punish Trafficking in Persons, Especially Women and Children. These countries have subscribed to a certain definition of trafficking, have put trafficking on the policy agenda, coordinate their investigative and enforcement activities regarding trafficking with other national police forces, have created programmes to assist victims of trafficking and have created a national agency (the National Rapporteur) to document the number of cases of trafficking. On the next level, national laws frame the broad policy approach to prostitution that a country chooses. These are the well-known 'policy regimes', such as prohibition of prostitution, the criminalisation of clients, and the legalisation of prostitution and sex facilities. But national policy also extends to fiscal policy and the regulation of immigration, issues that have an immediate impact on the sex trade and its actors. The next level down is the regional or local, where a myriad of rules and regulations translates national policy into a workable policy design that can be effectively implemented. In addition prostitution policy is shaped by NGOs and charities. While some have a largely advisory role at the national level, many operate at the local level in implementing policy. Our argument in this section - and in the book as a whole - is that local policymaking is essential in prostitution policy. It is essential for the impact of policy on the daily lives and experiences of the target groups of prostitution policy: sex workers, owners of sex facilities, clients and citizens. And it is essential for understanding prostitution policy, for grasping why so often the regulation of prostitution deviates from national laws, fails to reach its stated objectives or has unintended or even perverse consequences.

While international treaties and national law are obviously important in framing prostitution policy, we will argue that the local exerts sufficient autonomy to decisively shape the sex trade as it manifests itself 'on the ground'. While this is in itself not surprising, much public debate and academic analysis concerns national policymaking. The current acrimonious public debate about prostitution is almost exclusively focused on the moral differences of various policy regimes (for example, legalisation versus client criminalisation). Similarly, one of the most famous, or notorious, academic studies of prostitution policy is wholly concerned with establishing the statistical relationship between legalisation and the extent of trafficking (Cho et al, 2013; see Wagenaar, 2015b for a critique). The focus on national policy has two deplorable effects on understanding prostitution policy. First, it deflects attention from the everyday business of policy design and 
implementation that is crucial to the impact of prostitution policy on the target groups and on (urban) society. This can easily lead to the denial of the impact of policy on the sex trade in general. The earlier mentioned argument that large-scale economic or cultural transformations are the main drivers of the changes in prostitution, to the point that diametrically opposed policies are seen as ineffective in shaping its societal manifestation (Bernstein, 2007; Scoular, 2010), is one manifestation of this neglect of local policymaking. Second, the lack of attention to local policymaking prevents the analyst from understanding the complex relationship between the national and the local in shaping prostitution policy.

One indication of the importance of the local in prostitution policy is the observation that local policies may deviate considerably from national goals. This is a universal phenomenon. For example, while the German federal government made work in a sex facility legal in 2001, the Länder have so far resisted implementing the regulation (Pates, 2012). And while nationally prostitution has been decriminalised, some municipalities in New Zealand use advertising and zoning laws to restrict prostitution (Knight, 2010). Local policy implementation may deviate from national policy formulation for various reasons. Local circumstances usually prohibit implementation to the letter of the law; local actors may be reluctant to implement measures they consider meaningless or onerous, or conversely, local actors may step into a void left by the national government (Crowhurst, 2012); and local actors may experience the unforeseen implications of one law as it contradicts established laws in relevant other areas (Florin, 2012). Another important reason is that national politicians are further removed from the everyday reality of prostitution than local administrators. National politicians receive most of their information from policy reports and the media (Edelman, 1988). Because prostitution is a highly moralised and contested topic as we saw earlier in this chapter, this information is likely to be filtered through powerful cognitive-ideational frames (Schön and Rein, 1994; Stone, 1997). Local administrators are clearly not immune from these frames (no one is), but their proximity to the everyday world of prostitution exposes them to the immediate consequences of their and others' interventions on the actors in the field. The policy issues that they deal with are not abstract words or symbols but are embodied by actual people: sex workers, proprietors, and professionals (Maynard-Moody and Musheno, 2003). The policy scholar Robert Reich puts this nicely when he says: 
Public Administrators may be in a better position than legislators to foster a national debate over certain valueladen issues simply because the administrators deal with specific application of general principles. Legislators, on the other hand, often have an incentive to keep their discussion to a fairly high level of generality: delving into knotty details will likely be seen an invitation to controversy. (Cited in Ansell, 2011, p 156)

Differently put, when dealing with a controversial topic, elected officials tend to keep their distance from its real-world manifestations to avoid becoming embroiled in technical complications. Administrators do not have that luxury. At the local level 'the world talks back', as the policy scholars Donald Schön and Martin Rein (1994, p 34) famously said. ${ }^{34}$ We will see examples of this dynamic in Chapter Four.

The discretionary autonomy of local government works both ways, however. Local government may pursue policies that are either more emancipatory or more repressive than national policy. To make things even more complicated, activist local administrations will try to influence national governments, while national governments that feel they are hampered in their ability to make policy work through local governments try to get their way by other means. In this way the local and the national interact in complex recursive patterns. To give an example, in the early 1990s the German city of Dortmund experienced a serious street prostitution problem. Most of the business was concentrated in one neighbourhood: Nordmarkt. The nuisance created by clients cruising the narrow streets by night surveying the women disturbed the residents of Nordmarkt, a disadvantaged neighbourhood with a large percentage of ethnic minorities. The residents formed a coalition with the Mitternachtsmission, a local

34 The policy scholar Murray Edelman has trenchantly described this distinction between distal and proximate politics. Edelman speaks of politics as a 'spectator sport' in which symbolic elements, images and slogans that summarise a particular position on an issue play a key role. These symbolic elements depend on a certain distance from the real world of the social domain that is at stake: 'For most men [sic] most of the time politics is a series of pictures in the mind, placed there by television news, newspapers, magazines, and discussions. The pictures create a moving panorama taking place in a world the mass public never quite touches, yet one its members come to fear or cheer, often with passion and sometimes with action.... There is, on the other hand, the immediate world in which people make and do things that have directly observable consequences. In these activities men can check their acts and assumptions against the consequences and correct errors. There is feedback' $(1985, \mathrm{p}$ 5). 
charity, and persuaded the, initially reluctant, municipal government to create a tolerance zone for the outdoor sex workers. Because the city delayed the funds for establishing the zone, the residents helped out to set it up. This resulted in a working coalition between the residents, the charity and the police that successfully managed prostitution in Dortmund for over a decade, making Dortmund the only German city that attempted to implement the federal law that legalised the commercial exploitation of prostitution (Wagenaar, 2014). ${ }^{35}$

However, in today's hostile climate local governments are more likely to find ways to introduce policies that are more repressive than the national law. The Austrian province Vorarlberg illustrates this interplay of administrators, police and justice to repress legalised prostitution. The provision of sexual services (still called Unzucht, or sexual transgression, in the Vorarlberg Police Act, a legal term that suggests a sexual offence) is only allowed in licensed sex facilities. While the establishment of sex clubs is formally allowed under certain conditions, it is actively discouraged in Vorarlberg by making a needs assessment by the mayor or district authority a precondition. Several times now such needs assessments have been legally challenged. In one case, although the Constitutional Tribunal annulled the decision of the district authority to reject the opening of a brothel, a renewed appeal by the prospective brothel owner was rejected again by the appeals commission of the town of Hohenems and finally also by the Administrative Court of the Land Vorarlberg. The Administrative Court justified its decision - based on a statement by a police officer - that brothels are not needed as no illegal prostitution is witnessed in Vorarlberg and pertinent advertisements in regional newspapers are no proof that sexual services are provided in the district of Hohenems (Hämmerle, 2015). In the Netherlands, almost immediately after the Dutch parliament in October 2000 legalised brothels as regular business establishments, Dutch municipalities began to use the licensing system for brothels as a tool to discourage or phase out sex facilities. Currently Dutch cities are closing window brothels at a rapid pace, have clamped down on all forms of prostitution, frequently violate sex workers' rights and attempt to introduce sex worker registration and forms of client criminalisation. At the same time, the national government, following the lead of municipal administrations, congregates with the latter to find creative ways to discourage prostitution. We recount this story in more detail in Chapters Three and Four.

35 Currently the toleration zone in Dortmund has been closed and the collaboration between citizens, charity organisations and the police has collapsed. 
The lessons from these examples are twofold. First, local policy matters. The impact of prostitution policy on sex workers, proprietors, clients and communities is shaped by national legislation, but realised by local measures and regulations. The significance of this is that much of the local design and implementation of prostitution policy takes place on the edges of the democratic process. This is how our electoral liberal democracies function. Voters elect legislators in national and local parliaments, who then delegate the execution of their decisions to administrative agencies populated by experts (Manin, 1997). Administrators work under rules of democratic accountability and precepts of administrative ethos, but often their actions never reach city councils or national parliaments. In fact, as we will argue, there are good reasons to assume that certain marginal groups in society, such as sex workers, are less protected by the regime of democratic accountability than the rest of the polity (Wagenaar, 2015a). We will return to this in Chapters Five and Six.

The second insight is that the scalar distinctions in public policy are fluid and shifting. There are contradictory forces at work here. On the one hand, constitutional rules decree the relationship between national and local levels of government. For example, the German or Austrian constitutions prescribe both the level of autonomy of the regions as well as the distribution of tasks between the federal and provincial level. In a unitary state such as the Netherlands the relationship between the national and the municipal level is decreed in the so-called Gemeentewet (Municipal Law) (Andeweg and Irwin, 2002). In addition the national-local relationship is dictated by the power of the purse. Although local levels have some powers of taxation, they usually receive a large part of their funding from the federal or national government. The ratio between these two sources of income, as well as the extent to which national budgets are earmarked, determine the level of autonomy of the local. On the other hand, discourse can unite what is divided. In practice discourse acts as a soft coordination mechanism, bringing the activities of a large number of disparate actors under the same denominator (Schmidt and Radaelli, 2004). The Dutch example above illustrates the emergence of a discourse coalition around trafficking and 'forced' prostitution. This discourse coalition unites a wide range of actors from political and civil society; it is supported by its own authoritative institutions (parliament, national Rapporteur Mensenhandel), scientific research, media outlets and story lines. The result is an effective convergence of national and local policy. Germany, Sweden, France, Italy, the United Kingdom are all 
examples of the power of discourse in bridging the national and local in shaping prostitution policy.

Throughout this book, our focus will be on policy implementation, the phase of the policy process where plans and intentions are put into effect. This is the mundane but difficult work of establishing sufficient funding, assigning personnel, developing rules of procedure, selecting policy instruments, entering in negotiations with stakeholders, and organising public agencies, all with the purpose of making a difference in a particular societal domain (Stone, 1997; Howlett et al, 2009, p 160). Policy implementation relies on administrators, civil servants and professionals to design and manage the necessary actions, and for this reason usually takes place outside the glare of media attention. What distinguishes policy implementation from policy formulation is that it is always immersed in real-world situations. Policy formulation deals with ideas and ideals on the one hand and images and data that function as a proxy for the issue on the other. Policy formulation is at some remove from the world that is the subject of a policy initiative and therefore has a somewhat 'constructed' character (Edelman, 1988). Policy implementation, on the other hand, is always situated in a world where concrete individuals (administrators, sex workers, police officers, proprietors, citizens, media representatives) work and live. Administrators and professionals are likely to have face-to-face contacts with these individuals. Policy implementation is by definition local. Those engaged in policy implementation have to be highly attentive to the contextual particulars of the problem at hand. And they can be sure that their interventions will generate reactions, resistance and attempts at accommodation by the target audience and other stakeholders.

Policy implementation is crucial because it determines the outcome of a policy initiative. No matter how lofty, important or urgent a policy initiative is, if it cannot be translated into effective policy measures, the policy will fail, or worse, result in negative, unintended outcomes. But perhaps even more important in the case of prostitution policy is that policy implementation has a profound influence on the position and rights of a vulnerable group - sex workers. As we saw earlier, much of the literature moves on a higher level of aggregation, and even evaluation studies that try to measure the effects of national prostitution policies rarely relate these effects to the impacts of policy instruments and implementation measures. For two reasons we think this is an unfortunate bias in the literature. First, although macrodevelopments clearly influence social phenomena at lower levels of social aggregation, it is important that we demonstrate with some measure of precision how, in what ways, along which mechanisms 
these influences are realised. To explain social order we need to go beyond impressionistic indications of association. In modern social theory, structure and agency stand in a dialectical relationship to each other in which they bring each other into being (Giddens, 1984). In policy terms, social order is seen as the outcome of the more or less orchestrated practices of a large number of actors who move about in decentred policy networks (Rhodes, 1996; Bevir and Rhodes, 2010). We will return to these debates in the next chapter.

Second, because prostitution in contemporary society is so entangled with public policy, it is essential that we understand both the effects of state intervention on prostitution and how these come about. With effects we mean both intended and unintended effects. Prostitution, for reasons expounded in this chapter, is a particularly policy-resistant domain. In the absence of reliable data and exposed to fierce moral debates, politicians and administrators who deal with prostitution often design measures on the basis of ideological preferences (Chuang, 2010). In addition the target groups of prostitution policies - sex workers, proprietors, citizens - tend to resist or ignore government measures, or try to find accommodations for them that make sense to them in their daily life (Wagenaar, 1995). The result is that many measures aimed at regulating prostitution have either no effect or are counterproductive in that they make the problem they address worse and/or erode the civil rights of sex workers. The upshot is that to understand the nature and manifestations of prostitution in contemporary society it is important to understand the design and implementation of prostitution policies.

\section{Analysing prostitution policy}

In the remainder of this book we analyse prostitution policy in a way that is sensitive to insights into the policymaking process as formulated in the policy analysis literature. Thus, our analysis incorporates institutions, agenda setting, decision making, veto points, exogenous forces, actors, multi-level governance, ideas and discourse, and policy transfer. We do not pretend to integrate all these elements in one coherent framework that explains the shape of and changes in prostitution policy everywhere and at any time. This is not the state of policy theory in general, and given the complexity and contingency of the policy process, and unattainable aim overall. Second, our analysis also incorporates the five specific challenges of prostitution policy: stigma, the moral nature of prostitution policy, the lack of reliable and precise data, the role of migration in prostitution and prostitution policy, and the importance of the local in prostitution policy. In particular 
such an analysis must constructively address the challenges and risk that flow from the abolitionist versus regulationist controversy that affects the contemporary debate about prostitution. Third, we will develop our theory through a detailed analysis of two cases: prostitution policy in Austria and the Netherlands. Instead of formulating a theory in the abstract, we will show how insights from the policy literature and our own analysis in this chapter help us to explain and interpret these cases. In the final chapter we will attempt to draw more general insights from these analyses.

Our approach to policy analysis in this book is that in describing and analysing prostitution policy we consistently use the perspective of the elected official and public administrator. We try to put ourselves in the shoes of the officials and ask what the world looks like for them, and what challenges they face in designing and implementing prostitution policy. We opted for this pragmatic perspective for the following reason: the literature on public policy is an attempt to make sense of the policy process. This usually takes the form of identifying and describing the elements of public policy (actors, institutions, rules, power, ideas, traditions) to combine these in explanatory arguments about the development and outcome of the policy process (Cairney, 2012, p 2; John, 2012, p 2). With the exception of theories of administrative discretion, the official, and the way her/his world looks like, is conspicuously absent in these theories. That does not mean that these theories are useless; we will make ample use of the insights of policy literature in the chapters to come. But we do feel that we miss important aspects of the process of designing and implementing prostitution policy if we do not relate the policy literature to the challenges these officials face in their everyday working lives. 



\section{The local governance of prostitution: regulatory drift and implementation capture}

In this and the next chapter we discuss the formulation and implementation of prostitution policy in the two countries of study. To arrive at our stated goal of establishing a more comprehensively theorised understanding of prostitution policy, we link our empirical material to insights from policy theory in these chapters. Given our repeated assertion that local policymaking or policy implementation is paramount in shaping the outcomes of prostitution policy, we will first describe the implementation trajectory of the Dutch and Viennese reforms in the regulation of prostitution. To prepare for our analysis of implementation practices we will begin with introducing three key analytic concepts from the policy literature: policy implementation, policy design and policy instruments. We conclude this chapter by formulating the wider lessons of our analysis about implementing prostitution policy. In Chapter Four we turn to the formulation of prostitution policy.

\section{Policy implementation as policy formulation with different means}

National laws reflect the moral ambitions of the polity and/or ruling elite with regard to a particular social issue. The moral dimension of law is particularly pronounced when it comes to issues of morality politics such as prostitution. For example, at the introduction of the Norwegian Sex Purchase Act (2009) that criminalises clients, the Minister of Children, Equality and Social Inclusion, Audun Lysbakken, declared: "The law is one of the most powerful tools a society has to define its values and create attitudes" (cited in Jahnsen and Skilbrei, in press). But if law wants to go beyond a purely symbolic function, its ambitions require translation into action. This raises a host of normative, political, administrative and practical questions. Add to this the observation that prostitution policy can best be seen as a policy subsystem or policy network, with a large number of actors involved, from government, public administration and civil society (we return to this in Chapter 
Four), all of whom are engaged in a diversity of practices, and it is clear that the implementation of such a contested measure as the legalisation of the sex trade is an unpredictable, contingent, if not downright messy, affair.

This is not the place to reiterate 50 years of implementation research in the discipline of policy studies. ${ }^{36}$ Our perspective on policy implementation is that it requires distinct activities to translate policy intention into action, but that it is generally unhelpful to put too much weight on a strict distinction between policy formulation and implementation. Many of the same dynamics (such as national discourse), as well as actors (national government agencies, NGOs, pundits, stakeholders) that are involved in the policy formulation phase, are also involved in the translation of law into a workable practicaladministrative processes. Furthermore, in one of those recursive moments that characterise the field of prostitution policy, the translation of laws into action is often influenced and guided by judicial decision. For example, the decisions by the Supreme Court and the Higher Administrative Court in Austria, like the Sittenwidrigkeits clause, have shaped the direction of prostitution policies, sometimes binding, for decades. The point is not that (supreme) courts interpret the law - this is part of their constitutional mandate - but the example shows that the Supreme Court decision, by shaping the practical-administrative process, has contributed to a repressive turn in a policy that at the time tolerated prostitution. Besides the negative effects of the verdict on sex workers' rights ${ }^{37}$ the Sittenwidrigkeits clause reinforced the stigmatisation of sex workers. The conclusion is that policy implementation and formulation are overlaid and intersecting configurations of practice, made up of overlapping competences, meanings and materialities, and often involving the same actors. In that sense policy implementation is part of 'an ongoing process of policy making' (Hupe et al, 2014).

In early, so-called top-down, implementation theory, the law was seen as a set of instructions, or even less realistic, binding commands, issued by central government actors to lower-level administrators (Hogwood and Gunn, 1984). Subsequent research into the actual activities of administrators showed that a law could more fruitfully be seen as a general suggestion or admonition to point activities of

36 For such an overview, see Hill and Hupe (2014).

37 Just to give an example (more details in Chapter Four), an Austrian sex worker who initiated a law suit against her father because he had disinherited her lost her case as the court justified the rightness of disinheritance with the Sittenwidrigkeit of her profession. 
practical translation in a particular direction. One could say that the passing of a law triggers this process of translating law by the book into these practical-administrative processes. But what does this imply? First of all, different actors will interpret the practical implications, or even the goals of the law, in different ways. The interpretation of multiple and often conflicting values is an important part of the work of policy implementation. For example, in both the Netherlands and Vienna regulatory reform of prostitution has expressed a number of values, varying from containing and fighting trafficking to improving sex workers' labour rights. In both locations, justice officials as well as municipal actors have attached much more significance to the control of what they see as unlawful or immoral behaviour than improving the rights of sex workers. This is not coincidental. In the Netherlands, the repeal of the ban on brothels met a local policy space in which the regulation of prostitution was framed as, and organised to attain, the containment of its expansion and the control of its most egregious side effects. But what was it that the new law (or in this case, the repeal of a law) had changed exactly? First of all, the repeal introduced an important new meaning into the local practice configuration. The commercial exploitation of prostitution was no longer a crime but, in legal terms at least, it aspired to be a regular business. But stating that prostitution is a regular business and actually believing it are not the same. Policy actors did not change their opinion of brothels owners or sex workers. As a police manager in the city of The Hague characterised brothel owners at the time: "It's a different world. These are rogues. In a frank moment they will say: "We're only in it for the money." He added: "We already knew in '98 that we had to work towards a legalization of the sector. I know, these are the same boys and girls, but according to the law it is now a legal business sector" (cited in Wagenaar, 2006, pp 210-12). The aspiration expressed in the repeal, to transform the prostitution sector into a regular small business sector, was no longer in alignment, however, with the other elements of policy practice, such as the urge to contain and control prostitution, and the administrative routines that had developed over the years to bring that about. Local policy makers did indeed try to introduce new policy approaches that reflected the new situation. Brothel owners in The Hague were invited to participate in a deliberative forum to hammer out the details of a licensing system for brothels, although the pervasiveness of the stigma of prostitution did not change the habit of excluding sex workers from such forums. In hindsight, however, one has to conclude that this new approach was grafted onto an older practice of containing prostitution and overcoming the fragmentation of services within the city. In fact, 
the licensing system with its attendant requirement to monitor sex facilities, although it was the cornerstone of the legalisation of brothels, was in fact subjugated to the overriding goals of containment and control. In terms of practice theory, extant local policy at the time of the repeal consisted of an elaborate configuration of elements of a policy practice, in which the repeal introduced new symbolic and material elements that triggered an unpredictable process of alignment between those elements.

In contrast to the Dutch repeal of the ban on brothels, the new Viennese Prostitution Act (WPG) did not introduce a new meaning into the local practice orientation. Despite the attempt by the government to involve sex workers and other citizens - albeit only marginally - in the policy formulation process and the establishment of a steering group that oversaw the practical realisation of the law, the local practice configuration remained unchanged. Rather, the introduction of a licensing procedure for sex facilities as one of the main pillars of the WPG and its mastering was in alignment with longstanding traditions of control and containment of prostitution under the guise of improving working conditions, reducing exploitation and confining trafficking. The police successfully maintained its long-lasting dominance, including its defining power regarding the nature of the problem. In terms of practice this means that a reconfiguration of policy practice requires a fundamental reorientation of policy in terms of meanings and required competences, whereas the mere addition of a policy goal like the improvement of sex workers' situation does not evoke the necessity of other or new practical-administrative strategies and might get lost in the course of implementation and application. This leads us to our next issue.

Our second point is an extension of the first. Laws need to be translated into procedures and regulations that suggest how members of the target groups are expected to behave, and how relationships between government agencies and target groups, or between citizens and the state, are organised. In our later discussion of policy instruments, we unpack this statement, but here we want to make a different point. A new law and the procedures and regulations it spawns will have to be fitted into a dense landscape of existing procedures, practices and processes, both formal and informal. A considerable part of that work is technical and requires detailed, hands-on knowledge of hundreds if not thousands of rules, procedures and regulations. Another part is a deep, practical knowledge of the policy domain at hand, to ensure the workability and acceptability of the regulations. And, third, all this work has to fit local circumstances. While that fit with the regulatory 
environment, the policy domain and local circumstances is far from perfect, administrators usually try to design rules that do not conflict too much with existing regulation and practices and that promise a desired outcome in the real world. It is for these reasons that administrators at lower, provincial or municipal, levels of government do most of that work.

The work of policy translation does not start from scratch. Every legal-administrative system has routine, tried-and-tested procedures for handling new laws. While designing new regulation calls for a lot of creativity, much of the work is mundane and mechanistic. The work of policy implementation is always a fortuitous alliance between the habitual and the imaginative. For example, policy implementation requires that funding must be allocated to specific agencies and programmes, that personnel is hired or assigned, and that rules are formulated and procedures developed (Howlett and Ramesh, 2003, $\mathrm{p}$ 185). In most countries this work has been delegated to a professional administrative bureaucracy - or rather bureaucracies, as agencies at all levels and in different societal sectors have been authorised with designing policy implementation. In most countries this task extends to NGOs, charities and businesses (when public service delivery is contracted out). Civil and administrative law regulates the relationship between political decision makers and public administration. A variety of statutes designate which administrative level is assigned with the implementation of a policy, which agency is assigned which task, what type of regulation needs to be followed, how agencies and administrators deal with social organisations and citizens, and how appeal to administrative decisions is organised. The result is a densely interconnected, complex policy field.

For example, the Austrian constitution and additional treaties codify the competences of the federal state and the Länder. Based on these, the competence for prostitution policy is assigned to the Länder and its implementation to districts and communities. Some Länder (such as Oberösterreich) have developed specific prostitution laws, while others regulate prostitution within the Police Act. According to the new Sexual Service Act in Oberösterreich, for example, the municipalities are responsible for licensing sex facilities. Larger cities did not have a problem with this, but smaller ones shied away from this task, fearing conflicts in the community. Moreover, in small towns, mayors, caught up in morality politics, feared that they would be blamed for the authorisation of a sex facility and that adherence to the law would imperil their chances of re-election. Therefore, many small municipalities transferred this obligation back to the district. But, 
whereas in Oberösterreich the responsibility of licensing remained with the municipality or the district, Vienna has entrusted this task to the police. When the Dutch parliament legalised brothels, it delegated the implementation of the task to municipalities. This decision was guided by the mixture of municipal autonomy and co-governance that characterises the role of municipalities in the "decentralised unitary state' that is the Netherlands (Andeweg and Irwin, 2002). Prostitution policy is traditionally an area for co-governance in which central government enjoins broad guidelines, 'allowing local government considerable leeway in their implementation' (Andeweg and Irwin, 2002, p 166). The task of coordinating the dozens of municipalities with a prostitution scene was entrusted to the Association of Dutch Municipalities (Vereniging van Nederlandse Gemeenten, or VNG), an umbrella organisation that represents municipalities in its relation with central government. Anticipating the decision to legalise the sex trade, the VNG had designed a model for a licensing system for sex facilities, the key regulatory instrument prescribed by statute that would take the place of the regulated toleration system.

Yet the contingent nature of the practical work of fitting new regulation into existing regulation and making it work in the real world should not be underestimated. It requires a refitting and coordination of organisational routines, it exposes weaknesses in the organisation that require repair, it reveals contradictions in practical goals and in the immediate interests of different actors, it can pit one agency against another, it requires securing commitment from competing stakeholders, and it throws up unexpected negative unintended consequences (Wagenaar et al, 2010). To navigate these different challenges, to make this kind of administrative work possible in the first place, requires remarkable amounts of practical judgment and administrative discretion from the administrators involved (Wagenaar, 2004). Administrative discretion can take many forms, ranging from regrettable and unwarranted deviations from the law to the necessary situated judgement that makes effective local decision making possible in the first place (Kagan, 1978; Vinzant and Crothers, 1998). Examples of the first are the refusal of German states to implement the federal decision to legalise sex facilities (Pates, 2012), and the decision of the city of Stockholm not to provide harm reduction services to sex workers as it would facilitate prostitution (Ola Florin, personal communication). Another is the aforementioned refusal of the authorities in Vorarlberg to license sex facilities. An example of the second is the decision of the policy coordinator in The Hague in 2001 to create a platform of municipal regulators and local brothel owners to design a working 
licensing system (Wagenaar, 2006). Lower-level rule making, as we will see, can become a laboratory for new policy experiments, or for the introduction of wholly new policy aspirations. However, we should never lose sight of the fact that all these activities are embedded in the everyday mundane practices of allocating funding, formulating rules, hiring and assigning personnel, providing information and holding meetings. All these dispersed activities aggregate into to what Brodkin calls 'an indirect politics of administrative practice' (2007, $\mathrm{p} 2$ 2). Differently put, this 'secondary policy formation', in many cases with far-reaching consequences for the actors involved, takes place at a very workaday organisational level, by (mostly) non-elected officials, at some remove from political accountability processes.

Contemporary implementation theorists urge us to look beyond the so-called deficit model (Hupe et al, 2014). The original topdown approach assumed that lower-level administrators adhered to the instructions from central government. Richard Elmore describes this approach to analysing policy implementation as follows: 'It begins at the top of the process, with as clear as possible a statement of the policy maker's intent, and proceeds with a sequence of increasingly more specific steps to define what is expected of implementers at each level' (Elmore, 1980, p 602). When a policy fell short of its goals or failed altogether this was by implication ascribed to a failure or unwillingness of administrators - in other words to a deficit in the implementation process. Subsequent research showed that this image was empirically wrong (Hjern and Porter, 1981) and conceptually muddled (Elmore, 1980, p 603; Hogwood and Gunn, 1984, p 198). However its underlying logic and normative injunction of centralised control has always held a seductive sway over elected officials and policy analysts. We know that implementation is not hierarchy in action, but we feel that in a better world it should be. As our analysis so far shows policy implementation is only loosely coupled to political intent. Methodologically this leads to advice that the analyst's focus should be on 'micro-practices' and different and unexpected outputs, without too much normative frontloading of the analysis towards attaining policy goals.

However merely recording the activities of lower-level administrators might be empirically right, it also feels reductionist and morally empty. Loosely coupled is not the same as uncoupled. Implicit in the very idea of policy implementation is a notion of an 'end state or policy achievement' and an associated moral understanding, the moral ambition that is enunciated in the law. It is the responsibility of elected officials, administrators and professionals to realise that end 
state (Lane, 1987, p 528). Differently put, the understanding that policy implementation is in reality a complex set of discretionary actions by local actors does not mean that we, policy actors and analysts alike, should lose sight of a normative 'glue' that holds the policy process together. Lane makes a helpful distinction between the responsibility and the trust side of the implementation process. The first refers to an accountability norm that puts certain constraints on the implementation process. Differently put, no matter how interactive, improvisational and discretionary the implementation process is, we are always justified to enquire to what extent objectives have been accomplished, and what outcomes mean in light of the law's intentions (Lane, 1987, p 542). Even when the outcomes have little to do with the implementation process, we still ascribe them to the failure or success of a policy. For example, opponents of legalisation in the Netherlands insist that the law has failed because of the incidence of widespread trafficking and coercion in the licensed prostitution sector. Although the numbers on which this assessment is based are dubious, the impulse to evaluate a policy in terms of an accomplishment is both valid and inevitable.

The trust aspect of policy implementation refers to the public power entrusted to politicians, administrators and professionals in a democratic system to put policies into effect (Lane, 1987, p 542). The trust aspect balances autonomy, necessary for making the practical judgements to design regulation, and accountability with the constraints that follow from the intent of the law and from a more generalised administrative ethos. The decision of the city of The Hague to engage in deliberation with brothel owners in designing a licensing system is an example of the trust aspect. This kind of autonomy is granted to administrators on the implicit understanding that they do not sell out to powerful target groups such as brothel owners, treat citizens fairly and respectfully, and do not replace the original goals of the policy. Policy implementation, as Lane says, can be about improvisation, adaptation and learning, but it is also about the ability to deliver the normative promises that are embedded in a policy (Lane, 1987, p 543). This in turn upholds the idea that we can assess policies on their achievement, not on the simplistic centralistic sense of deviation from a clear instruction, but in a more subtle sense of comparing the normative intention of a policy with its actual effects on the ground. This does not only imply the assessment of policy outcome relative to the policy's normative intent, but also the rightness or feasibility of moral goals in light of the policy's (unintended) outcomes.

Perhaps the conclusion should be that the extent to which society's values shape policy implementation and, subsequently, a policy's 
impact on society, is above all an empirical question. It will differ between policy domains and within the same domain over time. But more importantly, analysts needs to ask themselves in what ways democratically ratified values enter administrative regulation, and conversely, how the effects of regulation reflect on these values. We will see in this chapter that discourse is a potent carrier of values, shaping how the actors perceive outcomes, and infusing the selection and application of policy instruments. This is the true meaning of the phrase 'indirect politics of administrative practice'. Although in many aspects a technical process, policy implementation also expresses the values that govern a policy domain, or, to put it differently, how society 'feels' about the policy issue at hand. This may result in value displacement, the extent to which another set of values replaces the values and aspirations that are expressed in the original policy. This is not necessarily a bad thing, as we argued earlier. Comparing outcomes and values is a two-way street. Inevitably, under the influence of experience and 'backtalk', understandings and sentiments regarding the issue at hand evolve. Nevertheless it is both necessary and legitimate to pose the normative question to what extent the implemented policy embodies the values of the original policy and/or if these values are still a fair representation of the collective standards and ambitions in a particular policy domain.

\section{Policy design and policy instruments}

Before we continue our analysis of the implementation of prostitution policy, we need to introduce two additional analytical concepts: policy design and policy instruments. Policy design is aimed at arriving at desired outcomes through the application of knowledge and experience about a particular social domain. It is less a purely technical activity of drawing up a blueprint and sticking to it, as an evolving activity of channelling the efforts of many actors in working towards an agreed goal. One can think of policy design as symbolic-material 'containers' or frameworks that channel 'practices-as-performance'. A good example of this is the so-called 'chain management' that the Dutch cities have adopted in fighting trafficking in which a large group of relevant actors regularly meet to inform each other and coordinate their activities. (We will discuss chain management shortly.) As Howlett puts it, policy design is: 
[T] he effort to more or less systematically develop efficient and effective means through the application of knowledge about policy means gained from experience, and reason, to the development and adoption of courses of action that are likely to succeed in attaining their desired goals or aims within specific policy contexts. (2011, p 22)

Howlett speaks of policy design as contextually 'constrained'. What he means is that the choice of policy instruments is shaped by the larger governance context; the same range of factor that influences policy implementation. Howlett fails to mention the influence that powerful ideas, practices and traditions (Bevir and Rhodes, 2010) - the frames of Schön and Rein (1994), as discussed in Chapter Two - exert on the design of policies. For example, as we will see, a long-standing Dutch tradition of taking the minority view into account in political decision making and of deliberating with the stakeholders of a policy has clearly influenced the choice of policy instruments at both the national and local level. On the other hand, although the policy environment constrains, it does not completely determine the design of a policy. As we will see, policy actors are free to insert elements from other governance styles into a design, thereby making every design in effect a patchwork of ideas and elements in which a national style is only vaguely recognisable.

National laws already contain many design elements - another instance of the continuity between policy formulation and implementation. A recent proposal for a new national prostitution law in the Netherlands called for a national registration system for sex workers. (We will discuss this law proposal in the next chapter.) In this case a registration system is part of a general design in which state agencies attempt to control prostitution among other activities by obtaining information about the size, composition and characteristics of the population of sex workers. Alternatively, the Swedish prostitution law famously introduced the criminalisation of clients as the core of a national policy aimed at reducing prostitution in Swedish society. A central element of policy design, as these examples show, is the choice of policy instruments. Policy instruments are 'the techniques or means through which states attempt to attain their goals' (Howlett, 2011, p 22). The basic idea is that the concept of a policy instrument brings order to the dizzying array of activities and techniques that governments have at their disposal. It is common to distinguish between substantive and procedural instruments. Substantive instruments are 'those policy techniques or mechanisms designed to directly or indirectly affect the behaviour of 
those involved in the production, consumption and distribution of different kinds of goods and services in society' (Howlett, 2011, p 25). An example would be a licensing and monitoring system to induce proprietors to offer a safe and hygienic work environment to sex workers. Procedural policy instruments affect production, consumption and distribution processes only indirectly. More specifically, they affect the behaviour of actors involved in policy implementation. An example of a procedural tool would be the creation of a centralised police unit to coordinate the fight against trafficking, or the dispensing of a subsidy to a sex workers' advocacy organisation.

Prostitution policy employs a variety of policy instruments, with each country displaying its own preferences and emphases in the choice of instruments. To comprehend the specific character of a country's implementation efforts it is helpful therefore to understand the different types of instrument that the literature distinguishes (Hood, 1986; Stone, 1997; Salamon and Lund, 2009). A common taxonomy is the one by Howlett (2011, p 129). Howlett distinguishes four types of instruments, as follows:

1. Organisational instruments, which 'rely upon the use of government institutions and personnel to affect policy output delivery and policy process change' (Howlett, 2011, p 63). Examples from the field of prostitution policy are municipal agencies, police departments and the municipal public health service. An ad hoc steering group of elected officials, administrators, police officers and NGOs, created to implement the new municipal prostitution law in Vienna, is another example of an organisational instrument.

2. Authoritative instruments, which 'involve, and rely primarily on, the ability of governments to direct or steer targets in the directions they would prefer them to go through the use of the real or perceived threat of state-enforced sanctions' (Howlett, 2011, p 83). Examples are laws such as the anti-trafficking laws that derive from the UN protocol that most countries have signed, as well as the myriad of quasi-judicial regulations that municipalities draw up to regulate prostitution.

3. Financial instruments, which are 'specific techniques involved in transferring treasure resources to or from other actors in order to encourage them to undertake some activity desired by governments through the provision of financial incentives, or to discourage them through the imposition of financial costs' (Howlett, 2011, p 101). Financial instruments involve taxes and user fees, as well as grants. For example, the city of Vienna fines outdoor sex workers who were 
working outside the designated areas. Authoritative and financial instruments merge into one another: when a sex facility has to close down for a month because of a breach of the rules, this has negative financial consequences for the proprietor.

4. Information-based instruments, which are defined as 'those policy techniques or mechanisms which rely on the use of information to directly or indirectly affect the behaviour of those involved in the production, consumption and distribution of different kinds of goods and services in society' (Howlett, 2011, p 116). Good examples are the information campaigns in various 'source' countries to discourage women from migrating to the Netherlands to enter the sex trade, or the Dutch Wet Bibob, which allows for the collection of information on the antecedents of proprietors. (We will discuss this instrument later in this chapter.)

To these four types of policy instrument, we would add a fifth: networking instruments. These consist of attempts by government agencies to bring together actors from government and civil society to inform, consult or deliberate on the design and implementation of policies. Examples are the aforementioned steering group established in the course of implementing the Viennese Prostitution Act 2011, and the network of municipal and law enforcement agencies and brothel owners that the city of The Hague created to design a workable licensing and monitoring system after the legalisation of brothels came into effect in October 2000 (Wagenaar, 2006). Networking instruments are a form of 'governance-driven democratization' (Warren, 2014). The purpose of networking instruments is to bring more, and more diverse, information and knowledge to bear on the issue at hand, to overcome the 'pluralized ungovernability' (Warren, 2014) that characterises contemporary urban government, and to encourage stakeholders and administrative agencies to commit to regulatory measures.

To analyse policy implementation in a meaningful way, we need to be able to relate the choice of instruments to some kind of stated rationale (Howlett and Ramesh, 2003, p 197). As we will see, in the real world of policy design and implementation, the choice of instruments is a messy process that is influenced as much by knowledge (both formal and experiential) as by tradition, ideology, unrecognized intellectual frames, convenience, accommodations and symbolism. Policy instruments vary according to a number of features, such as resource intensiveness (administrative cost, operational simplicity), targeting (precision, selectivity), political risk (chances and nature of opposition, visibility), and constraints on state activity (difficulties 
with coerciveness, ideological principles limiting state activity) (Linder and Peters, 1989). Some commentators argue that each type of instrument has a characteristic implementation 'profile' of advantages and disadvantages that policy makers take into account when they contemplate the realisation of a policy (Howlett, 2011, p 56). For example, regulations are reasonably cheap (although they require a monitoring and enforcement procedure to give them bite), and can be targeted with precision. However, they often generate resistance, they are rigid in that they do not take individual circumstances into account, and they might distort markets by burdening producers and consumers with additional costs.

In addition, Linder and Peters argue, a nation's policy style and political culture strongly influence the choice of policy instruments. Amesberger observes, for example, that in Vienna between 1965 and 1983 local government dealt with prostitution exclusively through authority-based measures (prohibitions, registration, fines), which were largely implemented by the police. The authorities defined prostitution as visible prostitution that had to be controlled and pushed back. After 1983 the government began to consult others, but these were mostly 'experts' recruited from the police and public health officials (Amesberger, 2014; see also Chapter Four). Only with the latest change of law were sex workers consulted. However, as we will see in Chapter Four, despite the Viennese government's attempt to promote the licensing of sex facilities, under the influence of a media campaign street prostitution became the focus of implementation and the police remained the most important authority in charge of it. While in Vienna a penchant for authority-based measures asserts itself against the intrusion of networking measures, we see the opposite in the Netherlands. A tendency for consultation and deliberation that is deeply anchored in the Dutch consociational political culture is now slowly suffused with authoritarian elements. The following extract from an interview with a city official illustrates this process:

Official: "We always invite the brothel owners to discuss proposed measures before we implement them." Interviewer: "Do they have influence over the design of these measures?"

Official: "We listen to them. But in the end they have to follow the rules." (Interview, city official, The Hague)

According to the policy analyst Deborah Stone, the term policy instrument gives the misleading impression of a more or less mechanical 
procedure that will function and deliver in the same way every time it is activated. Instead, as she suggests, policy instruments should be considered a kind of governance strategy, or as she puts it, 'ongoing strategies for structuring relationships and coordinating behaviour to achieve collective purposes' (Stone, 1997, p 259). She then adds the important caveat that policy instruments are much more relational and reactive than the mechanical instrument metaphor implies:

Effective maintenance of a community or pursuit of common goals cannot possibly be accomplished by governing every action or decision of individuals and organizations. Societies rely instead on broad structures and rules that will have a 'multiplier effect', shaping people's behaviour without continuous and specific directions. And because individuals, groups, and organizations within society have their own goals, they in turn use these structures and rules to help accomplish their own purposes. (Stone, 1997, p 259)

Stone's relational conception of policy instruments leads to two important insights. First, when officials employ policy instruments they must be prepared to encounter considerable 'slippage' between the policy's objective as embodied by the design and choice of instruments on the one hand and the target group's actual behaviour on the other. Policy is not the only, or even the most important, influence on people's behaviour (Elmore, 1980, p 604). In addition, people will assess the impact of the policy on their work and life situation, on the complex of meanings, competences, identity and materiality that make up their performative life forms, and try to accommodate the policy so as to minimise its effect on 'business as usual' (Wagenaar, 1995). For example, for more than 15 years now Dutch proprietors have resisted the introduction of labour rights in sex facilities, as it would imperil their tried and proven business model in which the costs of prostitution are carried by the sex worker and the profits by the proprietor (Roessingh and Ramesar, 2011) ${ }^{38}$ We must expect that

38 The book Slaves in the Polder. How Sex Workers, Cleaners, and Seasonal Laborers are being Exploited (in Dutch) by journalists Martijn Roessingh and Perdiep Ramesar, both working for the national newspaper Trouw, 'demonstrates' the alleged failure of the legalisation of brothels in the Netherlands by 'documenting' the rise of forced prostitution. On publication the book received a lot of publicity and became a cornerstone in the abolitionist campaign. However it turned out that Ramesar had used fictitious sources as the basis of much of the book (www.trouw.nl/tr/ nl/5133/Media-technologie/article/detail/3815470/2014/12/20/Twijfel-over- 
the capacity of governments to influence other people's behaviour is limited, particularly if they are enticed or summoned to do "what they otherwise might not do' (Stone, 1997, p 259). This applies a fortiori to situations where the social and cultural distance between policy maker and target audience is large, where the central behaviour is surrounded by a strong stigma, and where a large part of the target audience prefers to operate in the shadows. Second, because governments cannot - and preferably should not - monitor people's behaviour all of the time, and because the cost of sanctioning undesirable behaviours is often high (in terms of monitoring, enforcement and resistance), in most cases a more promising avenue of intervention is to collaborate with stakeholders to establish mutually agreeable norms, goals and delivery modes of the policy. ${ }^{39}$ This is a difficult and time-consuming approach that carries its own risks (co-optation of officials by stakeholders or vice versa), but ultimately it is probably the more effective and costefficient approach to implementing policy. For example, after many years the public health authorities in most large Dutch cities have gained sufficient trust among sex workers and proprietors to run an effective STD-prevention programme that is exclusively based on voluntary cooperation by sex workers. We return to collaborative policymaking in the final chapter.

Finally, the nature of the problem is an important factor in shaping policy implementation. Overall, the more complex and contested the problem, the greater the discretion that is required from administrators and the larger the range of actors involved. Clearly, apart from other factors, which we discuss later in the chapter, the morality politics of prostitution precludes any easy solution to policy implementation. In fact, the incessant, drawn-out contestation that accompanies the design and implementation of prostitution policy creates ample

brongebruik-Ramesar-leefde-al-langer.dhtml; see also: https://utrechtkrijgtspijt. wordpress.com/2014/12/29/ontslagen-trouw-journalist-ramesar-loog-ookover-prostitutie). After these revelations the publisher withdrew the book from the market and Roessingh publicly distanced himself from it. We nevertheless decided to use the book and refer to it in various instances. The sections we use and quote are based on publicly available sources. In addition, Hendrik Wagenaar has been extensively interviewed about his research by Roessingh and knows him as a journalist with high professional standards and integrity. The interview, which was critical of the repressive turn in Dutch prostitution policy, was almost integrally published in Trouw. Ramesar's breach of professional standards is another instance of the corrosive effects that morality politics has on the use of evidence.

39 Currently the terms of this equation are being rapidly rewritten with the advent of electronic surveillance techniques and the increasing capacity for the collection and analysis of big data. 
opportunity for different groups to try to insert their own agenda into the implementation process, not seldom resulting in policy stagnation. The continuing efforts of central and municipal officials to introduce some form of sex worker registration in the Netherlands, despite the fact that parliament has rejected registration twice on grounds of breach of privacy, is a good example of this. Third, the size, accessibility and legitimacy of the target group are important factors, as well as, fourth, the type of behavioural change the target group is required to make. A stigmatised and dispersed group such as (immigrant) sex workers is by definition in a disadvantageous position to officially resist policy measures. Finally, external conditions (economic, political and technological) may change, thus affecting the implementation of a policy. As we will see later, the decision to waive the visa requirement for citizens of so-called accession countries in 2004 played a large role in the repressive turn of Dutch prostitution policy.

To sum up, policy implementation is an open-ended, contingent process. The selection of policy instruments, one of the key moments in the implementation process, is determined by cultural traditions, the 'cost profile' of the instruments and the social status of the target group, as well as its cultural distance to administrators, and the preferences and experiences of administrators. In addition, members of the target audience do not accept instrument deployment passively. They assess the impact the instrument has on their life and act to defuse or moderate any effects they deem disruptive to their prospects and daily routines. As a result, the expected effect of a policy is highly unpredictable, encompassing the full spectrum from intended to unintended consequences to no effect. Effective intervention is often based on a laborious and time-consuming process of creating trust among hardto-reach and sceptical stakeholders. But even if administrative discretion is inevitable or is a requirement for efficacious policy implementation, it raises difficult issues of democratic accountability, particularly when administrators or police officers are dealing with a socially vulnerable, stigmatised population. Discretionary decisions affect the lives of real people. Because of the social and cultural distance between administrator and sex worker, an unfamiliarity that is easily accentuated and discursively amplified by the stigma adhering to prostitution, the consideration and fairness that citizens may expect in their dealings with servants of the state is easily overlooked (Edelman, 1988; Wagenaar, 2015a). Later in this chapter we will see many examples of insensitive, and even harsh, administrative action towards sex workers.

In the remainder of this chapter we discuss how local policy makers in Austria and the Netherlands have dealt with implementing national 
policy. In Chapter Six we discuss some alternatives of policy design that promise to take the special nature of prostitution as a policy target into account.

\section{Local policymaking in the Netherlands}

\section{The social and policy environment in the Netherlands before the legalisation of sex facilities}

When in October 2000 the Dutch parliament abolished the ban on brothels from the Criminal Code, and legalised from then on the ownership and management of sex facilities, it had four broad goals: to separate voluntary from involuntary prostitution; to 'protect the position' of sex workers (Outshoorn, 2004b, pp 198-9); to fight trafficking and other crimes associated with prostitution; and to prevent prostitution among under-age individuals. By making the business of prostitution the subject of administrative law, which regulates the operation of sex establishments, and labour law, which regulates the labour rights and workplace conditions of sex workers, parliament aimed to decriminalise commercial sex. Criminal law, the original province of the regulation of prostitution, was to be restricted to the criminal activities that accompanied (some) prostitution. Barring criminal activity, the argument went, the state has no business in the transactions that occur between women (and men) and their clients. The assumption was that by normalising the business of sex work and bringing it into the institutional core of the Dutch administrative and welfare regulatory framework, it would be easier to crack down on the illegal and criminal aspects of the prostitution sector. The central policy instrument in the implementation of the law was a licensing and monitoring system for sex facilities. The Dutch approach was thus designed as a mixture of regulating and decriminalising impulses. As prostitution policy falls within the remit of municipalities, implementation was devolved to local government.

What was the situation in Dutch cities regarding prostitution when the ban on brothels was abolished in October 2000? Preceding the repeal of the brothel law, two developments had unfolded in parallel to each other. On the one hand, the national discourse on prostitution reflected both ambiguity about prostitution among political authorities and confidence about the government's capacity for effective regulation among feminists and liberal opinion makers. On the other hand, in the 1970s and 1980s, under the influence of powerful external circumstances that caught the authorities unawares, the nature of 
the sex trade had changed appreciably, from a self-contained, selfregulated cottage industry to a variegated sex empire riddled with drug crimes and financed and controlled by organised crime. The Wallen, Amsterdam's famous red-light district underwent a metamorphosis in the 1970s and 1980s. The once quiet canals and alleyways became gaudy corridors of live sex theatres, porn shops, bars offering erotic entertainment, sex museums, erotic cinemas and saunas, thronging with rowdy, boisterous revellers on weekend nights. Moreover, the population of sex workers had become much more international and included an increasing number of immigrant sex workers, many without legal papers. At the end of the 1990s the police departments of large cities such as The Hague and Amsterdam felt that they had lost control of the red-light districts. In the big cities prostitution was a closed market in which ownership was distributed among a handful of powerful individuals. Owners were unwilling to give up the profits and prerogatives they had obtained over the years by operating outside the legal order. Although informal contacts between owners and city officials existed, these were characterised by antagonism and distrust. As prostitution constitutes a 24-hour economy, according to police officials the large number of clients created serious problems for the inhabitants of the prostitution neighbourhoods. Residents complained of constant noise and nuisance caused by cars cruising through the narrow streets, shouting in the streets, clients urinating in people's doorways, a generally threatening atmosphere, much criminal activity of drug addicts and pimps, and frequent muggings of clients. Turf fights between rival drug dealers led to shooting or stabbing incidents in the streets, some of them with deadly results. Police officers admit that enforcement was decidedly suboptimal (interviews, police officials, The Hague, 1993). The Hague even went so far at the end of the 1990s to assign its red-light district emergency status (interviews, police officials, The Hague, 1993). Public opinion at the time accepted prostitution as an acceptable job and supported the legalisation of brothels (Brants, 1998, p 630).

It was against this background that local officials felt the need for stricter forms of control. But they found themselves caught in a dilemma. While procuring and operating a brothel was officially a crime, enforcing the law and closing brothels was politically unacceptable in the tolerant cultural climate of the Netherlands in the 1980s and 1990s. The solution was the design of an informal model of regulation, based on ideas about legalisation that were being floated and discussed in political circles at the time. The policy theory was as follows: by bringing prostitution out into the open, 
'good' 'voluntary' prostitution could be separated from 'unwanted', exploitative prostitution. By imposing a set of regulations on brothels, it would be possible to contain voluntary prostitution within a clean, monitored sector and prosecute procurers who exploited illegal sex workers. The result was a system of informal regulation that became known as 'regulated tolerance' (Brants, 1998).

Regulated tolerance is the practice of not prosecuting certain offences while not officially legalising them (Brants, 1998, p 624). Regulated tolerance has been applied to social issues such as the use of soft drugs (the well-known 'coffee shops', so popular with foreign tourists in Amsterdam), the sale of pornography and euthanasia. Regulated tolerance, as Brants observes, is:

$[\mathrm{N}]$ ot merely a matter of the police turning a blind eye. It is a well-tried policy strategy that sometimes develops gradually at a local level, but may well be deliberately designed by the central government. It is often elaborately described in policy documents from the Ministry of Justice and, as such, subject to a certain degree of political control. (1998, p 624)

Regulated tolerance is motivated by a pragmatic understanding of the limits of criminal law in regulating certain activities, or the acknowledgement that, although an activity may formally be illegal, it is nevertheless socially common in statistical terms or morally widely accepted. Regulated tolerance is thus a form of semi-informal regulation. The philosophy behind it is a certain scepticism about criminal law as an adequate instrument for dealing with particular social issues (Brants, 1998, p 624). As Brants explains, regulated tolerance does not mean that the law is rescinded; the law remains in force. The legal basis for the non-prosecution of criminal offences is 'the widely used discretionary power of the public prosecutor to refrain from prosecution on public interest grounds' (Brants, 1998, p 624). There is a strong pragmatist element in this approach to law and its enforcement: in many cases officials felt the social damage done to the offender (and society's values) by prosecuting the offence (for example possessing a small quantity of cannabis) was larger than the 'crime' itself, and/or that the issue was better addressed by other means than the criminal law (as in the case of assisted suicide).

In practice, regulated tolerance involved a combination of written protocols and unwritten rules, and even, as in the case of Amsterdam, the creation of a new organisational policy instrument: the red-light district manager. Brothels, including window facilities, were asked to 
comply with a number of building and safety regulations. In addition brothel owners were obliged by law to check the identity papers of women who wanted to work in their facility. Brothels that were up to standard were given a so-called declaration of suitability (Brants, 1998, $\mathrm{p}$ 632). The problem, of course, was that the informal, deliberative nature of the system made enforcement difficult. Nevertheless, regulated tolerance was a form of a proto-licensing that was formalised with the long-awaited official legalisation covering brothels in 2000.

But perhaps more important for our analysis of the implementation of prostitution policy is the fact that in addition to guidelines and procedures, the collaboration of the prosecutor and the police with other city agencies (such as the municipal public health agencies, the fire brigade, the department that licenses bars and restaurants, as well as the tax authority) was necessary for informal regulation to work. In addition, city officials consulted organised interests such NGOs dealing with aspects of the sex trade, brothel owners, and the Rode Draad, the major Dutch sex worker advocacy organisation at the time. In fact, local and national policymaking was in unison here. The regulation of prostitution, both at the national and the local level, evolved into a political culture where consultation and participation were common, taken-for-granted elements. On the national level, in the run-up to the repeal of the ban on brothels, members of parliament regularly contacted NGOs that dealt with migrants and with trafficking. The Rode Draad was invited by the VNG to contribute to a handbook of prostitution policy that was to serve as model for Dutch municipalities. Brothel owners came together to formulate a 'covenant against trafficking'. Within this culture of collaboration, regulated tolerance at the local level was much more than just a policy instrument - it was a 'configuration that worked', an assembly of understandings, routines, actors and agencies, mutually understood roles, spatial distributions, relations, identities, values and feelings about prostitution (Shove et al, 2012, p 14). It was the concurrence of all these elements, the takenfor-granted interrelationships between people, and their activities, understandings and feelings, that anchored the regulatory system before the repeal firmly into Dutch public administration. And as in any complex practice configuration, the constituent elements do not necessarily neatly fit together, as they speak to different needs. This probably explains the peculiar, uneasy mixture of authoritative and networking instruments used to regulate prostitution in the four large Dutch cities in the late 1990s. While The Hague had regular consultations with the proprietors of the city's major sex facilities, it also created an emergency measure to provide the police with more 
powers to establish public order in the prostitution zones. Similarly, when Rotterdam closed its street prostitution zone in 2005, it consulted extensively with NGOs and other stakeholder organisations.

The significance of the emergence of this policy network or subsystem for the implementation of the legalisation of the sex trade in the Netherlands is twofold. First, it involved a large number of actors, both governmental and non-governmental, in discussing, designing and implementing prostitution policy, and provided them with the necessary knowledge and expertise about prostitution. For years to come, these would be the actors who would be consulted in the design and implementation of prostitution policy. If they were left out of the loop by the authorities, they would assert themselves by criticising and commenting on new proposals; the legitimacy they had acquired by being part of earlier networks made it that much harder to ignore them. The networks of municipal agencies in particular became skilled in coordinating their efforts in policy implementation, as we will see.

Second, the policy subsystem should not be seen as just a collection of actors, but as a large practice configuration, a configuration that stretched out in time and space and was connected though shared values, established relationships, mutually accepted roles and competences, routine activities, and joint understandings of the situation at hand (Shove et al, 2012, p 7). This is yet another argument not to place too much emphasis on the distinction between policy formulation and policy implementation. Many of the same actors who were aligned through this working configuration were involved in both stages of the policy process. This configuration also contained fractures and fissures, however. At the local level, public order was probably emphasised more strongly than at the national level. Brothel owners, while pretending to contribute to policy design, always pursued their own agenda of keeping the pre-repeal business model intact. Politicians from the religious parties were never happy with the repeal of the brothel ban to begin with. Later, as we will see, these fault lines would become the crystallisation points for far-reaching changes in the Dutch approach to the regulation of prostitution.

To sum up, in the Netherlands at the end of the 1990s, preceding the long-awaited legalisation of sex establishments, an approach to the regulation of prostitution emerged at the local level that would be the model for post-legalisation policy implementation. Its characteristics were a mixture of collaboration and control. While the keywords in the new regulatory regime were 'licensing' (vergunnen), 'enforcement' (handhaving) and 'monitoring' (toezicht), this did not preclude the inclusion of a large number of agencies and societal stakeholders. 
However, while city officials and brothels owners had developed a wary form of mutual recognition, sex workers were consistently excluded from the policy network. The members of these networks developed considerable skills and knowledge about prostitution and its regulation. This would become a particularly important factor with regard to city agencies. While the bureaucratic landscape in most cities was fragmented and sundered with interagency rivalries, the experience of cooperation during the days of regulated tolerance would form the basis for the efficient and proactive collaboration in law enforcement and policy implementation after legalisation. While officials went some way towards a genuine form of deliberation with stakeholders, the urge to control prostitution usually would get the better of them, resulting in an uneasy and forced style of interaction with stakeholders. It would be wrong though to dismiss the habit of consulting stakeholders in Dutch prostitution policy. In the consociational political culture of Dutch politics stakeholder consultation is second nature. We will see, however, how other more repressive and authoritarian approaches and instruments came to diminish the participatory impulse.

\section{Brothels legalised: developing administrative capacity}

Parliament's decision to abolish the procurement article from Dutch criminal law and in this way legalise brothels left Dutch municipalities firmly in charge of prostitution policy. Municipalities have considerable autonomy in the Dutch policy system; they can decide for themselves if and how they want to develop the local regulation of prostitution. Parliament had advised that only licensed facilities would be allowed to operate under the new legal regime. Thus a licensing and monitoring system, a combination of authoritative and information-based tools, became the key policy instrument in the design and implementation of the legalisation of the sex trade.

At the start of 2001 most municipalities faced an implementation task that was, by all accounts, difficult and challenging. A fragmented municipal apparatus faced a powerful and highly distrustful adversary that, after decades of operating outside the legal order, was unwilling to give up its lucrative practices. Administrators knew that wellendowed brothel owners would challenge them in court if necessary, and in many cases they did. ${ }^{40}$ Also, while the larger cities had a small

40 Part of the motivation to involve the court was to frustrate the implementation process. In The Hague the city had to go to court to establish clear-cut legal definitions of what constituted a brothel (as distinguished from a domestic dwelling), 
number of administrators and police officers with experience in dealing with the prostitution sector, the smaller towns had no such capacity. It proved that most administrators preferred not to be associated with the prostitution sector, with the result that young, recently hired, and wholly inexperienced employees, who were no match for the savvy and often duplicitous brothel owners, were assigned to this task (interviews with administrators, and observations, 2002). These employees made certain to hand the task over to someone else as soon as they could, leading to rapid turnover in the departments responsible for designing and implementing prostitution policy (interviews, municipal administrators, 2002-03). It would take a number of years for this personnel situation to settle down and for administrative experience to accumulate in this sector.

The large cities were reasonably well prepared and had attained some experience with informally regulating the prostitution sector within their borders. Moreover, the VNG had formulated and distributed a model licensing system. Although some municipalities in the orthodox Christian part of the country were reluctant and, in violation of the law, refused to allow sex facilities within their borders, most towns and cities organised themselves to implement a licensing and monitoring system. A 2006 evaluation of municipal prostitution policy in the Netherlands found that two thirds of municipalities had developed an explicit prostitution policy that was documented in a policy report (Flight et al, 2006). Licensing focused on clubs and window prostitution; escort and home prostitution was unregulated in more than half of the municipalities. In more than half of the municipalities city officials were in charge of policy; in a quarter it was the police. However in almost all municipalities the police were in charge of monitoring the licensed brothels. In $70 \%$ of cases, health and labour conditions were part of the agenda, although it not wholly clear in what ways. In about half of the municipalities trafficking is an explicit focus of local policy. We can conclude that until 2005 municipalities attempted to implement the new legal regime. Although there was a focus on control and containment through licensing and monitoring, the social and labour aspects of the repeal also received attention, particularly in the large cities where the municipal public health agencies continued

who was responsible for the goings-on in a brothel during business hours, and to settle the issue of operating hours. Interestingly, in the end in many such cases all parties were pleased with the court decision, as it created much-needed legal clarity (Wagenaar, 2006, pp 214-15). The court had inadvertently acted as a policy instrument. 
their practice of visiting brothels to provide services to sex workers (Flight et al, 2006).

When the law that legalised brothels came into effect in October 2000 it had three immediate consequences, all of which, although not directly related, issued from and reinforced the reinvigorated culture of control. First, all policies operate by creating categories of eligibility and non-eligibility. The definitions of and boundaries between these categories reflect the instrumental purpose of the law and the moral concerns of lawmakers. The repeal of the ban on brothels created a fourfold classification of sex workers that formed the basic architecture for its implementation (Outshoorn, 2012, 2014). The first category is the ethnically undefined Dutch sex worker who chooses to work in prostitution voluntarily. The second is the EU citizen who under EU rules has a right to work as a sex worker in the Netherlands and also works voluntarily. The third category comprises citizens from the accession countries (at the time of writing, Bulgaria and Romania) who are allowed to work as independent sex workers but not as employees. The fourth category consists of non-EU citizens who, because of their undocumented status, can only work illegally. As we will see in Chapter Five, because of their legal status the latter two groups are vulnerable to labour exploitation. In the public and political debate about prostitution the young woman from eastern Europe or the Balkans lured into prostitution by ruthless criminals became a dominant image (Outshoorn, 2014, p 181). In addition the law created a licensed and unlicensed prostitution sector. The first consisted of licensed brothels and was the subject of intense attention by agencies of the state. The second comprised escort agencies, home prostitution, massage parlours, bar prostitution and others, and was much less visible and therefore the subject of much concern and speculation among policy makers. However, there is little evidence of a displacement effect from the licensed to the unlicensed sector (Biesma et al, 2006).

Second, the municipalities inherited a business sector that, according to the Dutch journalists Roessingh and Ramesar, operated within a 'shady business culture'. Black money, tax avoidance, bribery, drugs and the exploitation of sex workers were common aspects of the prostitution business. As Roesingh and Ramesar note: 'Such a culture ... does not disappear because in The Hague the parliament declares that it wants to "normalize" the sector' (2011, p 173). This in itself difficult situation was made worse by another policy intervention that was informed by the stigma attached to prostitution. Although the expansionary days were over, municipal administrators charged with implementing a new licensing system feared an uncontrolled influx of 
sex workers who would be attracted by the legalised nature of the sex trade in the Netherlands. Pre-emptively more than half of municipalities - in fact the majority of urban municipalities with a prostitution market within their borders - limited the number of brothels within the city limits. Usually the maximum consisted of the stock of existing brothels, but quietly a few municipalities adopted so-called 'mortality' models: each brothel that closed down would not be replaced with another one. By thus freezing the market, unintentionally, the government created an oligopoly of proprietors who employed a business model of maximal profits with minimal investment. This would become a stumbling block in the attainment of the goals of legalisation.

Third, and perhaps most damaging to the position of sex workers, the government consistently refused to intervene in the labour relations between proprietors and sex workers, arguing that this was a matter of civil law and should be arranged between the two civil parties involved. ${ }^{41}$ The second goal of the 2000 repeal was 'protection of the position of sex workers'. Sex worker advocates had lobbied for the formulation 'improvement of the position', and in their discussions with the Minister of Justice and her civil servants made it clear that they had improvement of labour rights and work conditions in sex facilities in mind. The minister's position was that now that sex facilities had become regular businesses according to the law, labour rights would follow more or less automatically, similar to the situation in other business sectors. Proprietors would have to abide by labour laws, sex workers would be able to join trade unions, and proprietor organisations and unions would negotiate labour rights and work contracts, as was the usual practice in the Netherlands. The minister and her civil servants took a neutral position as to the nature of the relationship between proprietor and sex worker - labour contract or a contract sui generis - and, in hindsight naively, expected that this relationship would 'as a by-product of the abolition of the prohibition of brothels sort itself out' (Zuidema et al, 2006, p 3). For this reason the minister settled for the less binding formulation 'protection' instead of 'improvement'. What 'protection' entailed was left unspecified in the law, as we have seen. In practice many municipalities interpreted

41 As Zuidema et al say: 'Minister Sorgdrager [Minister of Justice at the time] her successor Korthals, and after that Minister Donner, argued that the position of the prostitute is dependent upon the civil law framework in which her work is embedded and the agreements made within that framework: "Involved parties carry the responsibility themselves that such agreements also lead to improvements of the position of the prostitute. The government has no involvement in this relationship and the agreements that are made therein"” $(2006, \mathrm{p} 2)$. 
it as providing public health services and sexually transmitted disease (STD) checks (interview, member of Rode Draad). In practice, these two developments, the emergence of an oligopoly of brothel owners and the self-removal of the state from the negotiations around the labour rights of sex workers not only gave proprietors more or less a free hand to successfully resist any improvement in the legal position of sex workers, but also, as we will see, gradually led the government to abandon the goal of improving the labour rights and work conditions of sex workers.

What did the practice complex of prostitution regulation look like five years after the repeal of the brothel ban? Most of the cities with a sizeable prostitution market within their borders had reconfigured the earlier routines of regulated tolerance. In terms of infrastructure and competences, they had expanded their public order and safety departments (Openbare Orde en Veiligheid) to include one or more officials who exclusively and routinely dealt with prostitution. The public health departments continued their outreach work. In stark contrast to Austria, the Dutch police were initially slow to take on prostitution as a policy regulatory practice. Their routine was to act when a crime was committed; prostitution regulation was largely an administrative activity. But in some cities police officers had the task of monitoring the licensed brothels assigned to them. Confronted with cases of trafficking and the difficulty of investigation and prosecution, the police began to organise and coordinate themselves nationally, creating a national network for investigating trafficking. In most cities a number of these officials and professionals developed considerable know-how about the prostitution scene within their municipality, often communicating directly with brothel owners. The new regulatory practice was supported by several laws and institutions. The repeal of the ban on brothels had made the licensing system the centrepiece of regulatory activity. Municipal prostitution officials developed administrative routines around the timely processing of licensing applications. This meant they had to communicate with a range of municipal agencies such as the housing and fire departments, the public health agency and the police, and file and synthesise information from all these different sources. Officials also had to develop a system of administrative penalties in case of infractions that was consistent and that would hold up when challenged in court. Although each city was free to organise its licensing as it saw fit, most followed the model licensing system that was developed by the VNG, making the licensing system a stable element in the creation of a nationally dispersed regulatory practice complex. 
Practices function as placeholders. Faced with a new legal situation regarding the regulation of prostitution, the municipalities gravitated towards the familiar: controlling the prostitution sector through a combination of authoritative instruments and deliberation with a variety of stakeholders. In an administrative climate that was largely defensive towards prostitution this led to a concerted effort by municipal administrations to contain the sector as much as possible. The licensing system proved to be an excellent instrument for this. Although well-established brothel owners could initially resist and frustrate the imposition of a licensing system, smaller brothels were not in this position. Some of the smaller brothels had, often arbitrary, conditions imposed on them that effectively put them out of business. For example, the female owner of a club in the town of Zwolle was suddenly faced with an administrative order to install a large and very expensive outside fire escape, although the fire squad had already approved the fire escapes inside her building. As she could not afford this expense, she went out of business (interview, brothel owner, 2003). The owner of a brothel in Rotterdam, an ex-sex worker who had opened a facility that operated in a sex worker-friendly way, was presented with so many petty building rules that she decided to close her business (interview, brothel owner, 2003). For these and other reasons (inability to deal with the licensing; temporary closure because of infractions) the number of brothels declined considerably after 2000. In 2000 the number of (private) clubs was estimated at 800. In November 2014 there were only 247 clubs left - a 70\% decline. Also the number of windows decreased in this period. In 1999 there were 2,096 windows, in 2014 1,224 - a $42 \%$ decline. ${ }^{42}$

It is difficult to gauge what know-how about the prostitution scene officials actually attained. The information obtained through the licensing applications and the recurrent monitoring of brothels

42 Since 2014 more windows have been closed in Amsterdam, Alkmaar, Utrecht, Groningen and The Hague through the use of the Wet Bibob (see Chapter Four) and through direct policy measures aimed at reducing the size of the prostitution sector. The number of escort agencies increased, however, between 2006 and 2015 from 90 to 125 (sources: window owners answering questions in 2009 on Hookers. $\mathrm{nl}$; data provided by the municipalities themselves; Daalder, 2015; van Wijk et al, 2015, p 107). The decline in clubs and windows cannot only be attributed to intensified regulation and enforcement on the part of the authorities. Innovation in the prostitution sector (the rise of internet prostitution and massage parlours), the sexualisation of the club scene, the economic crisis, and urban renewal leading to accelerating closure of windows all contributed to the overall decline in the number of sex facilities. 
largely concerned building safety, hygiene, the presence of drugs or arms, the presence of underage sex workers, the attendance of the owner or a manager on the premises during operating hours, and public nuisance around the facility. Owners were asked to check the legal papers of sex workers working in their facility, but were not held liable for not recognising falsified papers. The brothel inspections did not concern work conditions and labour relationships. As we will see, an industry-wide survey by the Rode Draad a few years later would reveal a considerable amount of labour exploitation of sex workers in clubs. And Hendrik Wagenaar, in his interviews with brothel owners in 2002 and 2003, in addition to a general attitude of accepting the licensing system, encountered quite a bit of evidence of corruption, illegal activity and hidden exploitation of sex workers, and a widely shared resistance against giving up the traditional 'shady' business model. In addition, officials had little or no information about prostitution outside the licensed sector, such as escort, bar and home prostitution. But overall, the shared perception at the time among officials and most stakeholders was that brothels, while far from being a 'clean' business sector, were more effectively integrated into a regulatory system than ever before. The excesses of the 1970s and 1980s in public nuisance, unbridled expansion, drug crimes and the illegal 'import' of sex workers from all over the world were a thing of the past.

In terms of meanings, the dominant sentiment in those years seemed to be one of pragmatism. In the realm of public administration actors were willing to accept the new situation and give it a chance. In line with public opinion, officials did not have strong moral sentiments about prostitution and accepted it as an inevitable part of the urban scene. They accepted the distinction in the repeal decision between 'good' voluntary and 'bad', coercive prostitution. As one police officer put it at the time:

" $[\mathrm{P}]$ rostitution is of all times. So I'm careful to express moral opinions about it. You deal with morality only in cases of brute exploitation, or in cases where juveniles are involved. Then, I think, citizens, and also clients, should have an opinion about that. But it's not to me to have an opinion about paid sex." (Cited in Wagenaar, 2006, p 219)

The licensing and monitoring system, in combination with the traditional Dutch practice of consulting stakeholders, led to a reconfiguration of the perceptions and feelings that actors had about 
each other. Officials guardedly noticed a willingness to cooperate on the part of brothel owners. As a police official commented:

"Am I pleased with my owners? Yes. It is printed in the newspaper. We have stated it straightforwardly: They're still rascals, if they can pull the rug from under you they won't hesitate. They're only in it for the money, absolutely. And they only cooperate because they have no choice. But I also have to say that they have a positive attitude. They try to cooperate. They try to contribute ideas, and we really meet on a continuous basis.... They have very sensible ideas." (Wagenaar, 2006, p 223)

Similarly, brothel owners also grudgingly accepted the new situation and the cities' newly developed regulatory expertise:

Owner 1: "We have to be honest to ourselves. We are only doing this for two years now, which means that you always have start-up problems. I don't think we should say that the city administration did everything wrong. I don't agree with that. If we're objective and honest, then the way that the city succeeded in reducing street crime...."

Owner 2: "... is just right ..."

Owner 1: “... has been just right. Period." (Wagenaar, 2006, p 222)

It is safe to conclude that five years after the repeal of the brothel ban a recognisable, dispersed and relatively stable administrative practice had developed aimed at regulating the business of prostitution. Yet, as we can infer from the statements of the actors involved, it was an exceedingly fragile configuration. It did the job, but some of its elements were weak and its linkages unstable. And, as we have already seen, sex workers were conspicuously absent from the network of relations around regulation. However, change, driven by various factors, was to come soon.

Despite the law's objectives of improving the position of sex workers, in the implementation of the law municipalities continued along the path of regulated tolerance by focusing primarily on control of the sector. In hindsight, this is hardly surprising. Policy implementation is not a wholly rational affair driven solely by expertise and by the informed choice of policy instruments relevant to the task at hand. Rather, as we saw, policy formulation and design is influenced by such 
factors as political and organisational culture, the actors' interpretation of the problem situation, the familiarity of organisational routines, the availability of certain administrative competences, the continuity of actors and constraints on state activity (Linder and Peters, 1989; Shove et al, 2012). Policy design is suspended in other words in a shared, largely unspoken, performative understanding of the target problem. In Chapter Two we argued that one of the major challenges to prostitution policy is the pervasive stigma that attaches to prostitution. Regulating or decriminalising prostitution does not remove this stigma and the resistances to prostitution that attend it. Following Jeffrey, we argued that stigma and resistance would most likely lead to an attitude among administrators in which prostitution is seen as a 'problem to be managed' (Jeffrey, 2015, p 2) and a tendency to control and restrict the sex trade. We also argued that this would quite likely lead to negative effects on the civil rights and labour market position of sex workers. In hindsight this was the script according to which prostitution policy unfolded in the Netherlands in the 15 years that followed the legalisation of the sex trade. By channelling administrative energy into designing and implementing ever more detailed schemes of regulating and controlling sex facilities and sex workers, Dutch municipalities effectively reintroduced a repressive, prohibitionist approach to prostitution. A decisive shift in the discourse on prostitution was the most important factor that broke the fragile alignment between the elements that made up the administrative practice configuration that had regulated the sex trade in the Netherlands in the previous three decades. A discourse that identified prostitution with trafficking set in motion a shift towards a much more repressive approach towards prostitution. The new buzzword would be 'enforcement' and new administrative practices rapidly developed to make effective enforcement possible. The result was among other things a further weakening of the social position of sex workers.

\section{The repressive turn}

Even in the best of circumstances prostitution policy is a form of morality politics. As we observed in Chapter Two, prostitution suffers from a pervasive social stigma. In our society even if we legalise it, and approach it with a pragmatic attitude, that does not mean that we, emotionally or morally, accept it as a 'normal' activity. With many people prostitution generates feelings of fear (of corrupting husbands and sons, and losing our daughters to it), disgust (with the thought of engaging in intimate activities with unappealing men, or clients 
having their way with helpless women), anger (in being confronted with prostitution and its side effects in our streets), anxiety (about its unbridled expansion in our cities), and compassion (with the victims of brute exploitation and violence at the hands of pimps and traffickers). Differently put, prostitution is an inherently unstable element in any regulatory practice, but particularly regulatory practices that aim at acceptance and normalisation. With many municipalities struggling to implement the legalisation of brothels, a number of powerful social and political developments occurred that would define the implementation path from 2005 onwards and shift it into a much more repressive direction.

From the moment of the passing of the repeal of the prohibition on brothels, Dutch local prostitution policy had to cope with strong exogenous influences, in particular the entry into the EU of eastern European countries, a, partly policy-induced, decline in the number of sex clubs, and the rise of the internet as a platform for recruiting clients. In addition, in the first decade of the 21st century the political climate became more conservative, and the conservative-centrist national government as well as local governments of different political stripes were less hesitant to impose authoritative measures on the sex trade.

Probably the most important development for local prostitution policy was the admittance to the EU of the countries of former eastern Europe. Until 2004 eastern European countries had accession status. For sex workers that implied that they could only work in the Netherlands as self-employed persons. As self-employment status had to be proven in the country of origin before departure and involved a laborious bureaucratic procedure. This put a brake on the number of women who legally migrated to the Netherlands to work in the sex industry. In 2004 most eastern European countries plus the Baltic states, except for Romania and Bulgaria, received full EU membership status; Romania and Bulgaria followed in 2007. In theory citizens from these countries could now work in salaried employment in the Netherlands. As economic conditions in these countries had not changed with their accession to the EU, and helped by affordable transportation possibilities such as budget airlines and bus services, labour migration began to increase - and not just in prostitution (Engbersen et al, 2009). The Polish construction worker and the Bulgarian agricultural day labourer became common figures in the Dutch labour market - and the media.

In the wake of this increase in migration, exploitation and trafficking seemed to be on the rise. We choose our words carefully as reality and rhetoric mix in ways that are difficult to disentangle. For example, around 2002, outreach workers in the then still operating toleration 
zones for street prostitution (tippelzones) in the large cities noticed a sharp increase in the number of young eastern European women in the zones. Most of them were dropped off by vans after the closing hours of clubs and picked up again when the toleration zone closed, strongly suggesting that third parties controlled them (interviews, outreach workers; personal observations, Hendrik Wagenaar). Because of their large numbers they drove down prices and displaced the addicted Dutch women for whom the zones were designed as a relatively safe alternative to the street. Outreach workers felt increasingly uneasy as they faced the dilemma that by providing support to the women they were abetting their exploitation (interviews, outreach workers). City officials also felt uneasy and in 2004 and 2005 Amsterdam, Rotterdam and The Hague decided to close down the toleration zones and abolish street prostitution within their borders. By 2005 street prostitution had more or less disappeared from the Dutch prostitution market. Only the cities of Arnhem and Utrecht still have a small toleration zone where access is regulated by a pass issued to the sex worker.

Coinciding with the increase in eastern European migration was the struggle with proprietors over the employment status of sex workers and the fiscal status of the facilities. Although the tax office concluded time and again that on the basis of legally defined 'facts and circumstances' sex workers had a de facto employment relationship with proprietors, the latter were successful in avoiding fully-fledged labour contracts with the ensuing mandatory payment of social security benefits. Proprietors argued that sex workers were independent contractors to whom they rented out rooms. They effectively played regional differences in tax policy, went to court numerous times to appeal the decision of the tax office and, disingenuously but effectively, referred to the Dutch constitution and international human rights treaties to argue that it is illegal to issue work instructions to a sex worker because of her right to self-determination and physical integrity. The government in the meantime, in answer to questions from parliamentarians, took the position that sex workers should have to go to court themselves to challenge proprietors. However, sex workers were understandably reluctant to give up their anonymity (Zuidema et al, 2006, p 12). In 2008 the tax office finally decided to break the impasse over the festering issue of the labour relationship by the introduction of the opting-in arrangement (outlined in Chapter Four).

The opting-in arrangement made it easy for citizens of EU countries to work in prostitution. Until 2012 women from Romania and Bulgaria were tolerated by the immigration service to work under the opting-in arrangement. At the same time there were signals of 
the prevalence of exploitation of migrants in the sex industry. The Rode Draad published an extensive survey in 2006 that showed that different forms and degrees of sexual and economic exploitation were widespread in the licensed sector (Altink and Bokelman, 2006; see also Chapter Five). At the same time officials in the cities observed a new migration pattern. In addition to single women who travelled on their own or with the help of relatives or friends to work in the sex industry, groups of young women from Hungary, Romania or Bulgaria, often of Roma background, moved into the window areas, only to move out again after a short period. The fact that many of them did not speak English, and that they moved in groups, suggested that third parties organised their employment in the sex industry.

But perhaps even more influential than these trends was an incident that had a profound effect on the national discourse on prostitution. In 2006 the national police started a large-scale investigation into a gang of Turkish traffickers (the Sneep case) who forced women to work in the sex industry. The sheer number of women (in the end 120 women were thought to be under the influence of the Sneep gang, of which, based on telephone taps, 78 were considered victims), the violence, and the fact that it all happened in the licensed window sector, sent shock waves through the world of politicians, police and administrators. In the media the brutality of the Sneep gang was widely reported and became the face of trafficking; almost overnight prostitution had become synonymous with violence and organised crime (Goraj, 2012). In the national policy discourse trafficking became the dominant theme, and many elected officials openly questioned the wisdom of legalising brothels. ${ }^{43}$ Local politicians in Amsterdam and Utrecht stated that "between 50 and 90 per cent of women behind the windows were forced". And the police report that was written about the Sneep investigation concluded that: 'It is an illusion that a clean,

43 Simultaneously with the Sneep affair, welfare and youth workers in the prostitution field were alarmed by the alleged rise in so called 'loverboys'. These were young men, often from ethnic minorities, who seduced (sometimes very) young girls to groom them to work as sex workers. A bestselling book by one of the alleged victims (Mosterd, 2008) turned the loverboy phenomenon into a national moral panic, and many schools and welfare agencies started campaigns to warn young girls for the dangers of loverboys. A research study by a leading Dutch criminologist (Bovenkerk et al, 2006) concluded that the loverboys were a contemporary version of ordinary pimps and that the phenomenon was probably not as widespread as suggested. When the Mosterd book turned out to be a hoax, the loverboy panic subsided somewhat. But yet again, in the media prostitution was identified with crime and exploitation. 
normal business has emerged. For years in the licensed window sector in Amsterdam, Alkmaar and Utrecht, traffickers, pimps and bodyguards could do as they pleased' (KLPD, 2008, p 8). Although, as we will see in Chapter Five, trafficking is a fuzzy concept, and prostitution is not synonymous with trafficking, the lesson of the case was a real one: the monitoring of licensed facilities had not prevented the exploitation of sex workers by the Sneep gang. The monitoring had been mostly administrative and had focused on the women's papers, but many of the women in the Sneep investigation had legal papers. Signals that the women were criminally exploited had been missed entirely. This lesson was not wasted on feminist and political opinion makers who had become increasingly unhappy with the legalisation efforts in the Netherlands, or on local policy makers, who saw an opportunity to increase their control over the sector.

The Sneep case had the effect of rallying the hitherto dispersed discontent with the legalisation of the sex trade in the Netherlands. Dutch prostitution policy had transformed into a moral crusade. Weitzer describes moral crusades as 'movements [that] define a particular condition as an unqualified evil, and see their mission as a righteous enterprise whose goals are both symbolic (attempting to redraw or bolster normative boundaries and moral standards) and instrumental (providing relief to victims, punishing evildoers)' (Weitzer, 2007, p 448). Moral crusaders advance inflated claims about the magnitude and urgency of the problem, ignoring and fabricating evidence. In the absence of solid data to support their claims, the melodramatic case presented as representative of the issue as a whole is the rhetorical trope of choice (Weitzer, 2007; Vance, 2011; Wagenaar and Altink, 2012). In the Netherlands the main proponents of the trafficking crusade were politicians of the Social-Democratic and fundamentalist Christian parties and radical feminists. They were supported by largely complacent media that overwhelmingly portrayed prostitution as identical to trafficking and organised crime and declared the legalisation of the sex trade a failed policy (Goraj, 2012).

On the surface nothing much changed. Licenses were still the cornerstone of Dutch prostitution policy. By 2014, 75\% of Dutch municipalities had developed a policy towards prostitution, the majority of those that had not declared that prostitution was not an issue in their municipality. The focus of the policy was the licensing of brothels (92.8\%), enforcement (69.2\%) and monitoring (60.8\%). Prevention $(38 \%)$ and social services $(24.5 \%)$ were much less common in municipal policy plans (van Wijk et al, 2015, p 50). As these numbers show, in addition to 'licensing' and 'monitoring', 'enforcement' had become a 
key term in municipal regulation. Municipalities began to design socalled 'enforcement arrangements' (handhavingsarrangmenten). The result was a rapid and decisive shift in the administrative practice complex aimed at the regulation of prostitution.

The collection of information became one of the key instruments in Dutch local prostitution policy. The need for more accurate and precise information arose from the shift towards a policy that almost exclusively focused on preventing and fighting the exploitation of sex workers. Officials are aware that exploitation is a phenomenon that takes place in a murky netherworld that is exceedingly hard to track down. "Those guys [traffickers] are getting smarter and smarter," as one seasoned police officer said to us. Officials see it as their task to stay as close as possible to, or disrupt, the activities of pimps and traffickers. As one police officer put it: "Because we collaborate closely, we are able to quickly anticipate issues for which no policy has been designed yet" (interview, police officer).

Information gathering takes different forms and is an integral part of enforcement or networking. In Utrecht, sex workers who wanted to work in the window area of the Zandpad were required to first register with the public health service. ${ }^{44}$ In this way the city hoped to get information on the number and identity of the women who work there, and obtain early signals of trafficking (interview, administrators). An example of enforcement-based information gathering comes from The Hague. As an element of the monitoring regime, officers from the vice squad regularly visit facilities to talk with sex workers. (The officers we interviewed said they visited facilities on a daily basis.) Following the lessons of the Sneep case the purpose of the visits is to detect indications of "trafficking" (interview, police officer). However, until recently, when police officers found indications of gross exploitation or maltreatment they had few legal instruments to do anything about it. Criminal law stipulated for example that a proprietor had to be convicted for trafficking twice in the past five years for the authorities to close down his facility. This was seen as an overly limiting condition. The city acted to create an administrative instrument that allowed more immediate intervention. The Department of Public Order and Safety, the police, the district attorney and the city council collaborated to create an 'enforcement arrangement'. The arrangement is organised

44 The Zandpad was the major licensed window sector in Utrecht. It is a small lane along the river Vecht with 35 houseboats that contained about 140 window prostitution spaces. The area is now closed as we will explain later. 
according to the principle that "we don't want to fight prostitution but the trafficking" (interview, administrator).

When the police find signals of 'trafficking' the 'victim' receives a socalled 'negative work notation'. This notation is restricted to the facility where she works. The indications need to be sufficiently strong to hold up in administrative court if the sex worker or proprietor decides to challenge the notation. In case the indicators are deemed insufficiently convincing by the police, the officer puts the woman on a 'watch list' (aandachtsvestiging) to be followed up in future inspections. Indicators are among other things physical (bruises), not being able to speak Dutch or English albeit in possession of legal papers, not knowing one's home address or how to get there, and being brought and dropped off by a third party. ${ }^{45}$ When there is a suspicion of being exploited the officer tries to persuade the sex worker to press charges against the trafficker and offers her access to social services. A negative work notation means that in practice the sex worker can no longer work in the facility where she was interviewed. The proprietor can still rent rooms to her but he runs a risk, under the terms of the enforcement arrangement, of incurring an administrative measure, such as a warning or a fine. In practice it means that the sex worker can no longer work in any of the licensed facilities in The Hague as proprietors now regularly ask the vice squad to interview any new sex worker who wants to work in the facility. Currently there are 80 women on the watch list and 40 with a negative work notation. According to the police officer we interviewed there is little evidence that sex workers with a negative work notation end up in the unlicensed prostitution sector. ${ }^{46}$ Most go to other cities.

A third type of instrument that plays an important role in local policymaking are networking tools. One of the characteristics of

45 The Chamber of Commerce also alerts the police when they suspect that a sex worker who registers as self-employed is exploited. Sometimes the border police (Koninklijke Marechaussee) alert local police forces when a border control reveals that women who are suspected sex workers and their handlers are on the way to the city.

46 The police officer thinks that these sex workers do not move to the unlicensed sector because "a trafficker wants to make a quick buck. Where can he do this? In window prostitution. Also clients don't like to go to a shady apartment and run the risk of being robbed. Moreover, the woman who opens the door is usually someone else than the one from the picture on the internet." Other cities have complained, he says, that they receive sex workers who are not allowed to work in The Hague. He thinks they should all follow the enforcement arrangement of The Hague, so that "all of the Netherlands becomes unattractive to traffickers" (interview, police officer). 
local prostitution policy in the Netherlands is the large number of actors that is involved. In most Dutch cities, the following actors are directly involved in delivering prostitution policy: city officials of the Department of Public Order and Safety, different branches of the police (vice squad), Immigration and Naturalization Services (Vreemdelingendienst), the district attorney, the Chamber of Commerce (where sex workers need to register as self-employed workers), labour inspection, public health (different branches), social work and outreach, youth services and the tax office. In addition city officials consult with proprietors and representatives of sex workers. Each of these actors deals with different aspects of the sex industry, from regulating and monitoring licensed facilities to providing health services to sex workers to investigating and prosecuting trafficking. In the contemporary policy landscape, policy implementation in almost any domain, but particularly when it comes to social regulation (Moran, 2002), is highly decentred in that it involves a large number of actors with greater or lesser amounts of autonomy and mutual dependency. The large number of actors involved in the local regulation of prostitution shows two things. First, regulating prostitution is, at the operational level, a difficult and laborious activity. It is a social phenomenon of great interconnectedness and dynamic complexity that cuts through the usual 'silos' of local public administration. Part of the complexity is self-induced. For example, the three cities have separate agencies that deal with licensed and unlicensed prostitution. This distinction is an inescapable artefact of the licensing system and makes administrative sense. However, reality does not always follow administrative rules; sex workers without the proper papers or who are suspected to be victims of trafficking are also to be found in the licensed sector. Second, Dutch city officials are acutely aware that efficacy in such a densely connected organisational field requires close collaboration between a wide range of actors, each of which possesses specialised information or skills (interviews, municipal authorities). Thus they express an acute need for innovative, flexible collaboration and coordination arrangements.

The rationale for coordinating services is obvious: collaboration enables agencies to provide integrated, comprehensive services. To achieve that, the division of labour that follows the historical professionalisation of service delivery needs to be undone when services meet real-world problems that do not respect institutionalised demarcation lines. However, multi-agency collaboration is exceedingly hard to achieve in public administration, and despite a proliferation of models and solutions, few administrative systems have succeeded in effectively integrating different administrative and professional 
bodies. (Rein, 1983b; Peters, 2006). Most cities have more or less formalised their collaboration and coordination in something they call 'chain management' (Rosendal et al, 2009). In chain management complementary services are linked in a sequential chain, often led by a 'chain manager', in an attempt to coordinate resources for realising service delivery. But again, in practice chain management has hardly brought the hoped-for improvements in service coordination. To be successful chain management requires continuity of personnel and an attitude, shared among all participants in the chain, of 'further professionalization of one's own discipline and the importance of working together in multidisciplinary teams for the benefit of the client' (Huijsman et al, 2009, p 384).

In the realm of interagency collaboration, the repeal of the ban on brothels, and the subsequent problems in implementing it, have resulted in genuine public innovation. Immediately after the passing of the parliamentary decision to repeal, the architect of the licensing system in The Hague complained about the problems he had in getting the different municipal agencies to work together: "The chain is as strong as its weakest link," he repeatedly admonished the assembled agencies (interview with police officer, 2003). In the ensuing years most cities have mastered the art of multi-agency collaboration. The city of Rotterdam is a good example. It has developed a successful model of chain management that in slightly different form has been adopted by the other two Dutch cities in our project. The Rotterdam system consists of seven actors who regularly meet to manage prostitution at the operational level. The agencies are social work, police, the district attorney, labour inspection, municipal health services, youth services, and the tax office. Each partner in the chain has a mandate to make decisions for his or her agency to provide the organisational capacity to address the problems that come up and implement decisions. ${ }^{47}$ 'Chain

47 There is an important principle of administrative reform - recursiveness - at work here that needs to be brought out. Through recursiveness organisations can overcome the limitations of hierarchy and bring the experiential knowledge of frontline workers into the rule formulation and decision making of their management. Where hierarchy is important for safeguarding democratic accountability, it usually results in rigidity in operational procedure and the inward-looking perspective that thwarts multi-agency collaboration. Its limitations are acutely felt in situations that are characterised by dynamic complexity and require constant adaptation to circumstances that change in unpredictable ways. Recursiveness happens when an organisation is able to mix hierarchy with heterarchy. "When a level of organization shifts back and forth between superordinate ... and subordinate ... you have the possibility of a powerful form of recursiveness that possibly overcomes the tension between top-down and bottom-up organization' (Ansell, 2011, p 107). 
managers' manage the collaborative arrangement. Their task is to follow up on any decisions that the partners have made and address any tensions that might arise in the collaboration. In the meeting concrete cases are discussed. (The meeting is called 'case meeting'.) The purpose of the case meeting is "to get the victims out and prosecute the traffickers" (interview, administrator). Victims of gross exploitation receive care and traffickers are either prosecuted, or, barring prosecution, further information is collected to make future prosecution possible. The meeting allows the partners to exchange information and use their collective intelligence and administrative capacity to explore the best way to address an issue. For example, when one of the partners has encountered a case of gross exploitation the partners discuss the most effective response, for example to start a criminal investigation of the middlemen or to have the tax office go after their proceeds. Once every six weeks the group has a so-called 'chain management' meeting in which more overarching issues are addressed, such as trends in prostitution or changing migration patterns. The members of the group have not changed in the past years. This has allowed mutual trust to develop among the participants as well as an attitude that each partner, to be effective, has to take the interest and contributions of the other partners into account. Finally, the group is backed up by a so-called 'steering group', made up of the heads of the participating agencies. The steering group decides on the direction that prostitution policy should take and safeguards the quality of the coordination in the chain.

A fourth category of measures used in local prostitution policy in the Netherlands is authoritative instruments. An analysis of the design of local prostitution policy showed a considerable increase in the use of authoritative instruments (van Rooijen, 2012). The two most important of these are the 'administrative measure' (bestuurlijke maatregel) (in combination with the Wet Bibob), and, recently the introduction of the local registration of sex workers. Administrative measures belong to the province of administrative law. They are measures, with the power of law, issued by an administrative or elected body to put an end to an

In organisational terms this means that organisational spaces are created in which subordinate staff members have temporary decision-making power over higher levels of the organisation. 'In most organizations this is likely to happen on the behavioural rather than the structural level,' Ansell adds (2011, p 107). This leads to familiarity of top-level managers with the operational world of day-to-day policy implementation, and shared ownership of problems. The power of recursiveness in organisations is that it allows for 'a continuous and interlocking cycle of perspectives' (Ansell, 2011, p 104). Recursiveness is considered a prerequisite for collective learning in (networks of) organisations. 
infraction of the law or municipal ruling. In the case of administrative measures the district attorney and municipal officials may impose punishments without involving courts or judges. These punishments can be fines, restraining orders, or the revocation of licenses and closure of sex facilities. ${ }^{48}$ The administrative measure has gained in popularity in recent years. For example, in 2008 Rotterdam used seven administrative measures in regulating prostitution; in 2010 the number had increased threefold to 21 (van Rooijen, 2012, p 55). A common procedure in Rotterdam is the following: based on information from the information analysts and the police, the police set up an entrapment by inviting sex workers who advertise on the internet for an assignment in a particular hotel. When the sex worker does not have legal papers or cannot prove that she has a license in Rotterdam, she receives an administrative warning from the Department of Public Order and Safety. If she is caught again, she receives a fine of $€ 5,000$. One may question how useful this measure is. Many sex workers in the escort business work at a remove from the town where they live. Even if they have a license in one municipality, this is not valid in another. Warning them merely keeps them away from Rotterdam. This is yet another case of regulation-induced mobility.

As this example shows authoritative instruments are used most effectively in combination with information instruments. Administrative measures, for example, are used in combination with the aforementioned Wet Bibob to contain and reduce the size of the prostitution sector. The core of the Wet Bibob is the coupling of a number of large national databases from the tax office, the Immigration and Naturalisation Service and the criminal justice system. Before issuing or renewing a license (not just for prostitution facilities but also bars, restaurants, coffee shops and call shops), municipalities ask the national Bibob office to do a search for any improprieties or criminal antecedents of the owner. This can be an unpaid tax bill, prior convictions, or irregularities in the ownership of the facility. If such irregularities are found, the municipality can issue an administrative measure, usually to deny the license. Proprietors have the right to appeal the decision. The Wet Bibob has been successfully used in the three cities to contain and reduce the size of the prostitution sector. Amsterdam has closed dozens of windows through the use of the Act. In 2009 municipalities submitted 260 requests for advice with the

48 www.hetccv.nl/dossiers/boas-in-de openbareruimte/stappen/menu_ nalevingsstrategie/menu_sanctie/bestuursrecht.html 
national Bibob agency, 23 of which concerned prostitution; in 2010 the numbers were 212 and 19 respectively.

Registration systems similarly merge elements of authoritative and information tools, as in the example of Utrecht. Cities with a sizeable prostitution market, such as Amsterdam, The Hague and Groningen, have launched so-called intake interviews. Multi-agency enforcement teams hold the interviews. On pain of a fine or closure of their facility, brothel owners are obliged to register every new sex worker for an intake interview with the city. The purpose of these interviews is 'to collect information and give advice' and to collect signals of abuse (interview with administrator, 2003). In The Hague when the intake team believes that the sex worker is a victim of trafficking, it denies her a work permit. As far as we know there is no possibility of appealing this decision. It is unclear what information about the sex worker is collected, for how long that information is stored, and who has access to it. Given the popularity of registration among politicians and administrators as an instrument of control, it is useful to discuss its merits on the basis of empirical evidence.

Part rule, part incentive, part information, registration is a hybrid instrument. It functions as a rule by adjuring sex workers and proprietors to engage in desired behaviour. It acts as an incentive in prescribing behaviour that results in the avoidance of fines or in access to state-provided services (Stone, 1997, p 282). Registration is meant to act as a disincentive to traffickers. And it provides authorities with information about the number, identity and characteristics of sex workers who are active in a particular geographic or administrative space. However, in the case of both rules and incentives there is never a direct correspondence between the measure as designed by authorities and as it is received by the target audience (Wagenaar, 1995; Stone, 1997, p 272). In general, sex workers have little trust in authorities (Benoit et al, 2015) and consider registration a threat to their privacy. Moreover, the operational logistics of sex worker registration effectively preclude its use as an information instrument. The experiences with registration in Vienna might help us to obtain a better understanding of the way that this policy instrument works in practice. Registration has been mandatory in Vienna since 1968. Sex workers can only obtain their health-check booklet when they register with the police. Since 2011 sex workers have received a leaflet when they register that informs them about social services, and contains a referral to LEFÖ, an NGO for sex work. LEFÖ also declares that the mobility of sex workers interferes with the registration procedure. It takes about a week to register when there are no complications. However, when 
the sex worker has worked abroad for while or when her last STD check was more than three months ago, she has to undergo a new health check. Until then she cannot be registered and, thus, cannot work legally. When rules are perceived to have a negative impact on the quotidian, the everyday practices that structure the target group's life, the sex worker will attempt to adapt the rule so that it is either rendered ineffective or more convenient to the receiver (Wagenaar, 1995). Many sex workers, according to LEFÖ, do not bother to negotiate this threshold to work and move to another part of Austria or work without registration. The police estimate that there were 3,000 to 4,000 unregistered sex workers working in Austria in 2010. ${ }^{49}$

Not only does registration interfere with the world of the sex worker, the stated goals of registration are also often in conflict with each other. On the one hand, cities want to establish a connection with what they see as 'isolated' sex workers; on the other hand, they impose onerous measures on these sex workers. Moreover, cities' definition of the problem - the risk of trafficking - does not correspond with the sex worker's perception of the problems she faces, namely labour exploitation by a monopolistic brothel owner. In fact, by involving proprietors in intake and registration, sex workers become even more dependent on them and the city is in fact abetting this type of everyday exploitation. The intended incentive to the sex worker to seek help is interpreted instead by the latter as one more obstacle to making a living.

We have focused on the feasibility and workability of registration in this section, not on the well-known objections regarding privacy and the disputed logic of singling sex work out as the only occupation that requires mandatory registration. Our conclusion is that registration has too many conflicting objectives, ignores the agency of the sex worker, violates administrative propriety, and results in evasion or 'playing the system'. The experiences of Vienna and recently Utrecht throw doubt on the ability of registration to attain its stated goals of knowing who works in sex work, inducing sex workers to seek help and thus preventing trafficking.

As the preceding analysis shows, since about 2005 local prostitution policy in the Netherlands has focused almost exclusively on the fight against trafficking. In practice this means that most policy instruments serve a repressive purpose. In the large majority of Dutch municipalities prostitution policy consists of a licensing system, a policy for the establishment of brothels (in many instances a so-called extinction policy in which no new establishment licenses are allowed

49 As so often in prostitution, this number cannot be verified. 
when a brothel closes down) and the execution of monitoring and enforcement. Prevention, harm reduction, social services and exit programmes are usually not part of formal policy plans (van Wijk et al, 2015, p 109). In the large cities the municipal public health agencies and a variety of NGOs provide health and social services. Monitoring and enforcement has resulted in considerable public innovation, particularly in overcoming the coordination problem. Most municipalities now have a formal, so-called enforcement arrangement, and are also part of regional chain management configurations. Enforcement focuses on the licensed and unlicensed sector. In most cases the police organise the inspections. Monitoring of the licensed sector takes place through periodic inspections of brothels; enforcement teams hold intake interviews and register the passport details of sex workers. Inspections of the unlicensed sector take place through entrapment; the police pose as a client and invite escort workers who advertise on the internet to a hotel where they inspect their papers (van Wijk et al, 2015, p 111). Since 2010, municipalities have issued over 300 sanctions and written over 200 administrative reports, the majority against and about unlicensed home prostitution. ${ }^{50}$ A concerted action in May 2013, in which 500 internet ads were selected and 73 inspected, resulted in the apprehension of two sex workers who were considered victims of trafficking (van Wijk et al, 2015, p 112).

In our analysis of the local implementation of the legalisation of the commercial exploitation of prostitution in the Netherlands, two things stand out. First, Dutch local policy is a classic case of regulatory drift and goal displacement. Regulatory drift denotes a gradual change in the focus of a policy as the result of a succession of small decisions at the implementation level, without any formal decision at higher levels of authority (Mitchell and Herring, 2006, p 5). Regulatory drift is the subtle shift in instrument choice over time, where each choice in

50 Administrative reports are part of a number of information and authoritative instruments that local administrations can use in maintaining law and public order. The administrative report is compiled on the initiative of the district attorney with the help of different police and investigatory agencies. These reports describe 'signals, bottlenecks and unwanted situations in society'. These situations may concern public nuisance as well as organised crime. The objective of the reports is to provide advice to local administrations to prevent or terminate the unwanted situation. As mentioned earlier, there is no imperative to verify the assertions made in these reports. And, as the events in Utrecht described in the following section demonstrate, neither is there an obligation to publish their contents (www.hetccv. $\mathrm{nl} /$ instrumenten/bestuurlijke-aanpak/menu-bestuurlijk-instrumentarium/index (accessed 9 September 2015). 
itself is legitimated by, what at the time, seemed good reasons. Since 2000 , we have observed a more frequent deployment of authority instruments such as punishments, fines and administrative measures. Information instruments are put to use in the fight against trafficking and the containment of prostitution. We speak of drift, as every implementation decision seemed in itself logical or warranted at the time, yet, taken together, they have resulted in goal displacement. Goal displacement implies the increased emphasis or de facto abandonment of policy goals. In the Netherlands we see this in the abandonment of the improvement of labour relations in the prostitution sector, the backgrounding of social services and harm reduction in municipal policy, and the almost exclusive emphasis on fighting and preventing trafficking. Fifteen years after the passing of the repeal of the ban on brothels, one of its central goals, improving the 'legal position' and work conditions of sex workers, has been more or less abandoned in favour of a focus on fighting and preventing trafficking and the curtailment of prostitution in society.

Second, in a climate of antagonism towards prostitution, repression is an essentially open-ended objective. To the official there is always the possibility of more and better information that may lead to more and better containment of the prostitution business. In this way, repression easily results in a loss of perspective in which not only are the original goals of the policy abandoned but, more disturbingly, the violation of the rights of sex workers - supposedly the 'victim' that needs to be protected - also becomes accepted collateral of the policy at hand. The following example illustrates this point. ${ }^{51}$

In 2010 the city of Utrecht was the first city in the Netherlands to announce the introduction of a registration system for sex workers who chose to work in the Zandpad window area in the city. The measure is part of the so-called 'barrier model' in the prevention of and fight against trafficking. Another such barrier is that sex workers can only rent rooms for a minimum period of four weeks. According to city officials, this is to prevent the rapid turnover that characterises trafficking. In addition the number of hours a sex worker can work has been limited to 12, the number of inspections has increased (from four to 40 per year), there are more CCTV cameras, and support services have longer opening hours. The rationale behind the measures is that erecting administrative barriers to working in the prostitution

51 In addition to reports and other publications, the following description of the Utrecht case has benefited from information provided to Hendrik Wagenaar by Marjan Wijers. Any errors or misinterpretations are the author's only. 
sector, and the greater administrative scrutiny and visibility of the sex workers this entails, will act as a disincentive to traffickers. All sex workers who wanted to work at the Zandpad area had a mandatory intake interview before they were registered. The purpose of the interview was to detect 'signals' of trafficking, to provide the sex workers with information about support, and to disrupt the sex worker's isolation, if only temporarily. Proprietors could only rent out rooms to registered sex workers. With the registration measure the city looked ahead to the new national prostitution law that intended to make national registration the cornerstone of Dutch prostitution policy (Bestuursinformatie Gemeente Utrecht, 2012, p 6).

The measures were evaluated by a commercial research agency. According to the official evaluation, the turnover of sex workers at the Zandpad decreased. In one in eight intake interviews, officials concluded that there were signals of trafficking and informed the police. ${ }^{52}$ In these cases, the sex worker was registered and obtained a work license, although the police doubted that trafficking would be prevented as a result of the interviews. Many women who hardly spoke Dutch, English or German nevertheless arranged for registration within a week (Bestuursinformatie Gemeente Utrecht, 2012, p 7). The police believed that the 'quality of the signals' had improved (Bestuursinformatie Gemeente Utrecht, 2012, p 8). The city concluded that collaboration between partners had also improved. Sex workers were unhappy with the four-week minimum rental period as it forced them to continue working when they are ill or had their period (Bestuursinformatie Gemeente Utrecht, 2012, p 7). The evaluation does not speak of the 'contamination' of the registration files; as far as we know, sex workers who moved to another city were not systematically deregistered and removed from the registration files.

Given the alleged success of the registration system, the next move in Utrecht's prostitution policy came as a surprise. In June 2013, city officials suddenly announced that all the windows at the Zandpad would be closed within a month. More than 100 sex workers lost their workplace. According to a so-called 'administrative report' drawn

52 Interestingly, and not noticed by anyone involved in or commenting on the Utrecht case, $12.5 \%$ is much less than the alarmist numbers that are put out by the abolitionists in the Dutch prostitution debate. In fact, despite the circumstance that the 'signals' were vague and expansive and officials had an incentive to find cases of trafficking to prove the efficacy of the intake and registration system, the number is much closer to the number in our sample of $10 \%$ of sex workers who reported having been in an exploitative situation in their career as sex workers (see Chapter Five). 
up by the city, unspecified abuses had been found in the window brothels on the Zandpad. The report has never been made public, and assertions that are put forward in administrative reports do not require independent verification. Subsequent inquiries with the police revealed that the 'abuses' included excessively high rental rates, a waiting list that could be 'jumped' for a fee, and unwanted behaviour towards sex workers by employees of the brothel owner; labour exploitation within brothels in other words. The police concluded that there were no instances of trafficking at the Zandpad as far as they could assert. Subsequent research has shown that many of the sex workers from the Zandpad ended up in non-licensed prostitution venues. Independent research concluded that the city's measures to fight trafficking had negatively affected the position of sex workers (Siegel, 2015). ${ }^{53}$

The example shows that repression is indeed a hungry beast that continuously needs to be fed, a situation we explore further in Chapter Four. Around 2015 most municipalities were part of an integrated enforcement arrangement. These arrangements have been shaped by an ever more strident national discourse on trafficking, and have in turn influenced the proposal for a national Wet Regulering Prostitution (Wrp; Law for the Regulation of Prostitution). The $W r p$ has been defeated twice in the Dutch Upper Chamber (because of conflicts with national and $\mathrm{EU}$ privacy regulation and the lack of clarity about the enforcement of the proposed criminalisation of the clients of non-registered sex workers), but a revised version was passed in the Dutch Lower Chamber on 21 June 2016. It is currently scheduled for discussion in the Upper Chamber. In anticipation of the new law the VNG has formulated a model APV, or General Local Ordinance regarding prostitution. This model APV implies a quantum jump in repression, in many cases resulting in the de facto abolition of prostitution at the municipal level. Many towns and cities are closing window brothels;

53 In the tellingly titled Closing Brothels or Closing Eyes, Siegel concludes that since the closure many women 'are in worse condition: financially, mentally and physically'. Siegel found that sex workers did not understand why the windows had been closed. The lack of trust in municipal authorities has increased, as well as the mutual distrust among sex workers. The municipality lacks any knowledge about mobility, new work sites and the situation of sex workers since the closure. She concludes that: 'Hundreds of sex workers, who were not affected by trafficking problems, have been the victim of the city of Utrecht's ill thought-out and rash decision to close the Zandpad' (www.ciroc.nl/uploads/ciroc/2015_ciroc_pdf/Zandpad\%20 presentatie\%203\%20juni\%202015.pdf; see also Siegel, 2015, p 148). 
in Amsterdam this has become entwined with a general urban renewal and gentrification policy aimed at stimulating the tourist industry. The cities of Amsterdam, The Hague and Groningen have introduced de facto registration systems disguised as mandatory intake interviews, tests that assess the sex worker's independence (Amsterdam) or a 'positive work recommendation' (The Hague). Groningen has announced to persecute the clients of illegal sex workers. And with the exception of Amsterdam and Rotterdam all cities have declared working from home illegal. The model APV and the ensuing step-up in repressive measures by Dutch municipalities are examples of the complex dialectic of local and national policy. Before we discuss this new twist in Dutch prostitution policy, we first need to discuss Austrian local policy and policymaking at the national level in both countries.

\section{Local policymaking in Vienna}

\section{The social and policy environment in Vienna before the reform law of 2010}

In the Austrian political system the Bundesländer (provinces) have contrary to the Netherlands - a strong position. Austria is a federal state and not a unitary one like the Netherlands. In the Federal Constitutional Law, competences and tasks are distributed between the federal state and the Bundesländer. Although the general competence for legislation and law implementation lies with the Länder, in fact only a few matters of legislation are within in their remit; regional security and prostitution are among them. Differently put, the provinces' most important task is the implementation of national laws. Each Bundesland has an elected body, the parliament, with a six-year period of office. Vienna is one of the nine Austrian Bundesländer and has been governed for decades by the Social Democratic Party (SPÖ). Since 2010 a coalition of Social Democrats and the Greens has ruled Vienna, which has brought some changes in the political culture. In the realm of prostitution the Länder have considerable autonomy, albeit national legislation like the criminal law, public health related and fiscal laws shape regional prostitution policy too (see Chapter Four).

Both Austria and the Netherlands have a national tradition of respect for the rule of law and cherish an independent expert bureaucracy. The two hang together. Recruitment for a position in one of the state's bureaucracies is based on the Weberian principles of expertise and merit. Changes of government after elections do not lead to wholesale changes in the composition of the bureaucracy. The result 
is a bureaucratic ethos in which values of justice, fairness, transparency and equal treatment before the law are deeply ingrained. The difference between the Dutch and Austrian public administration is in the former's propensity for innovation. While the Dutch bureaucracy is the originator of much public innovation, the Austrian one is more inclined to stay within its given task of applying legal rules and politically formulated aims. Both approaches have advantages and disadvantages when it comes to prostitution policy. In the preceding section of this chapter we have seen how Dutch local officials' constant ambition to innovate has resulted in a regulatory drift towards an increasingly repressive policy. However, as we will see, the more conservative Austrian administrative tradition is no guarantee of fair treatment and respect for the rights of peripheral groups.

As in many European countries prostitution is more or less accepted as part of the social landscape in Austria. This does not mean that sex workers have the same rights or enjoy the same extent of citizenship as other citizens. The pervasive stigma that rests on prostitution makes itself felt in the way that prostitution laws are formulated (as we will see in Chapter Four), but above all in the design and implementation of administrative measures that aim to regulate the sex trade. Similar to the Netherlands, we will see that much of this regulation is not very effective. We will speculate about the reasons for this at the end of this chapter. But more worrisome is the observation that much regulation has been designed and is implemented without the necessary regard for the human and civil rights of sex workers. The goal of containing and controlling prostitution pervades every aspect of the political-legal-administrative system in Austria. This makes Austria a fascinating example of a larger pattern: even countries where prostitution is legalised and that uphold the rule of law and values of fairness, equality and justice in the relation between citizens and the state, show little compunction in suspending these values when it comes to the treatment of sex workers. This infringement of rights seems to be accepted by the responsible politicians in charge as an inevitable by-product of regulation that is designed to control prostitution; this despite politicians' official rhetoric of protecting the position and circumstances of a vulnerable group. For reasons of comparability we focus on local policymaking in Vienna in this section.

\section{The regulation of prostitution in Vienna before 2011}

Initially prostitution in Vienna was regulated within the Viennese Police Act; in 1984 a Prostitution Act followed and was amended 
twice until the new Viennese Prostitution Act 2011 (WPG 2011) was enacted. In addition, several regulatory injunctions accompanied the implementation. With regard to the goals and design of prostitution policy the city administration has been consistent over this period. In the past four decades three tendencies have prevailed in the regulation of prostitution in Vienna: a continuous restriction of street prostitution through the extension of prohibition areas, the authorisation/approval of brothels, and the extension of police power. The policy instruments that the city has marshalled for the regulation of the sex trade are predominantly authoritative instruments (Amesberger, 2014, p 215 onwards).

Before the first Viennese Police Regulation for Prostitution (1974), several district authorities had already restricted street prostitution to specified areas or prohibited it altogether in their districts. Soliciting in prohibited areas was met by large fines. These authoritative measures were triggered by an alleged increase of outdoor sex workers due to the partial decriminalisation of prostitution with the amendment of the federal Criminal Code. ${ }^{54}$ The measures were aimed at repressing visible prostitution. The arguments provided for the necessity of restrictions are familiar: to promote cleanliness, to prohibit the harassment of residents, and to minimise (international) reputation damage for the city and the loss of earnings for businesses in street prostitution areas. As street prostitution bans were, and still are, driven by real estate interests and attempts at gentrification, it is not surprising that outdoor prostitution was gradually moved from the affluent first district to the poorer neighbourhoods along the Gürtel and the area around the Westbahnhof and, finally, to the industrial zones of Vienna. ${ }^{55}$ With the first Viennese Prostitution Act (1984) prohibition zone regulations were introduced; a 1991 amendment to the law restricted the outdoor

${ }^{54}$ Because of a lack of data it has never been clear whether such an increase was actually established or only feared. Moreover, the counting of outdoor sex workers in the designated areas from June to October 2010 by SOPHIE-mobil, a counselling and outreach organisation, resulted in a total number of between 100 and 120 (SOPHIE-mobil, 2011, p 16 onwards). This is not a large number in a city of 1.8 million inhabitants. We acknowledge, of course, that for the residents of the designated prostitution areas the presence of a couple of dozen outdoor sex workers and their prospective clients in their neighbourhood may present considerable nuisance.

55 The Gürtel underwent a multimillion-euro renewal at the end of the 1990s - cofunded by the EU - which led to the displacement of outdoor sex workers. With regard to the area around the Westbahnhof the expulsion of street prostitution is not clearly connected with gentrification. Continuing protest by residents, supported by the media, is likely to have had a stronger influence. 
areas for soliciting clients even further. ${ }^{56}$ The gradual extension of areas prohibiting street prostitution resulted in confusing standards, which even for the police were opaque and difficult to enforce. For outdoor sex workers these regulations resulted in a large number of fines and high levels of indebtedness (source: interviews with sex workers and NGOs). As we describe in Chapter Four, instruments like zoning regulations and fining have not resulted in less nuisance or fewer conflicts with residents.

Similar to the Netherlands, from the late 1970s onwards Vienna experimented with the semi-formal legalisation of brothels. With the new police regulation for prostitution in 1974 the authorisation of brothels became a possibility. ${ }^{57}$ The conditions for approval were rather minimal compared with today's. A facility was approved when the general regulations concerning gastronomy, zoning regulations and a few safety standards were observed. Some of these standards were established for the protection of neighbours. The legislator was concerned about 'unacceptable optical and acoustical harassments' (WPG 1991) and also determined for the first time that sex facilities be equipped with sanitary arrangements. Rules for the protection of neighbours and juveniles were specified in building regulations and police decrees. Fines and the possibility of shutting down sex facilities were powerful authoritative implementation instruments. The law did not contain any requirements as to the suitability or reliability of sex facility owners and managers. That is, any adult citizen could run a sex facility.

Similar to the Netherlands, home-based sex work is forbidden in Austria. With the prohibition of apartment prostitution in 1984, the Viennese government simultaneously reduced the autonomy of sex workers and strengthened the position of facility owners. In both countries the prohibition of home prostitution follows from a desire by the authorities to control prostitution and sex workers.

The police have always had a decisive role in Vienna in controlling prostitution, prostitution establishments and sex workers. In 1868 the gynaecologist Wilhelm Schlesinger, with considerable prescience, wrote in his booklet Prostitution in Wien und Paris (Prostitution in

56 For example it was prohibited to solicit clients within a distance of $150 \mathrm{~m}$ of churches, hospitals, elderly homes, schools and kindergardens. In other words, the opening of a school or kindergarden automatically rendered a former legal soliciting zone illegal. In theory, this restriction also applied to brothels, but it was never enforced.

57 The first brothel was approved in the first Viennese district in 1974. 
Vienna and Paris): "For the hundredth time in the last one hundred years, one wants to "regulate prostitution" in Vienna anew! The doctors want to do so, the municipal council shall do it, the police will do it!' (Schlesinger, 1868, p 1; translation by the authors). ${ }^{58}$ This quote illustrates the position of the police as a central, and in many instances, determining actor in the implementation of prostitution policy in Vienna. One would assume that with the legalisation of prostitution the controlling power of the police would be diminished, but as the subsequent legislation shows, the partial decriminalisation seem to come at the price of extending the controlling and fining power of the police. In fact, this near monopoly of the police on policy implementation is so strong that we have called it agency capture; no matter what measures are proposed and enacted into law, in the end it is predominantly the police that appropriate, or are charged with, their implementation. As the police, like every government organisation can only operate according to standard operating routines and a set organisational culture, this means that prostitution policy, at its operational level, is framed by the organisational practices of the police. Already in 1968, an obligatory registration for sex workers with the police had been introduced. This was not abandoned later on, but the obligations on sex workers were extended: with the second amendment of the local prostitution law (1991) it became compulsory to announce interruptions in sex work (because of holidays, sickness and so on) or the termination of sex work. Although most registered sex workers did not observe this rule (source: interviews), the legislator stubbornly stuck to it until 2011. We will see more examples of agency capture later in this chapter.

Police and politicians have high expectations about the effectiveness of the instrument of registration. ${ }^{59}$ Similar to the Netherlands, authorities

58 'Zum hundertsten Male seit hundert Jahren will man nun wieder einmal in Wien “die Prostitution regeln!” Das Doktoren-Kollegium will sie regeln, der Gemeinderath soll sie regeln, die Polizei wird sie regeln!'

59 Registration regimes vary. Vienna is the only province where sex workers have to register with police; in some Länder they have to register with the municipality or district authority and in others, such as Oberösterreich, an indirect form of registration takes place - here brothel managers have to deliver all personal data of sex workers working in their establishment to the district authority and the tax office. Not announcing sex workers with the authority may result in fines of up to $€ 5,000$ (in cases of recurrence up to $€ 10,000$ ) for the facility owner. The fine for sex workers for non-registration in Vienna is up to $€ 800$ (in cases of recurrence up to $€ 1,600)$. The fact that registration is mandatory and that non-registration carries heavy fines does not mean, however, that all sex workers register. The police estimate that only half of all sex workers in Austria have registered. It is assumed 
perceive the merits of this instrument to lie in establishing contact with sex workers, in protecting them from crimes, in prohibiting human trafficking and in effecting a more efficient resolution of criminal offences. There is no empirical evidence that the instrument of registration has ever met these expectations. For example, in a meeting of the working group on prostitution (see Chapter Four) members of the police stated that among the identified victims of human trafficking in sexual exploitations the majority had registered with the police and only a few were detected when registering (for example, because of false papers). This means that in the majority of cases the exploitation happens after the sex worker has registered herself. As in the Netherlands, registration raises the matter of the protection of sensitive personal data and privacy. As it is only possible to become registered with medical proof of being free of STDs, an exchange of data between the public health office and the police is necessary. Furthermore, by request of the police, the outpatient clinic regularly exchanges information for the purpose of matching records with police data. Due to a lack of legal foundation this practice was dismissed for a brief period of time, but it gained legal footing with the WPG 2011. Such cooperation between police and municipal health offices is an example of the use of collaborative instruments for authoritative purposes. General regulations relating to data protection dictate that records about prostitution be deleted after six months (before 1991, it was five years).

Without effective enforcements, or at least the threat of enforcement, compliance with the law can be expected to be low. Inspections and fines are such enforcement instruments. Statistics about imposed penalties provide insight into the extent to which policy instruments are used (for example, controlling prohibition areas) and whether they result in the desired outcomes. The statistics show that these authoritative instruments are widely employed. The Viennese police routinely monitor sex facilities and outdoor areas, but also conduct raids and joint operations with financial and social insurance authorities and the magistrate. By way of illustration, in 2010, 19 joint operations took place, resulting in 273 inspections of sex establishments, 900 police reports concerning managers and sex workers and 15 immediate closures of facilities (Presse- und Informationsdienst der Stadt Wien,

that the number of Austrian citizens among non-registered sex workers is much higher than among registered ones as many of them work in their own homes (which, as we have seen, is illegal). 
2011). ${ }^{60}$ The figures about fines issued to individual sex workers after an 'administrative' complaint - primarily due to the police observing an infraction of the rules during an inspection of a sex facility or a soliciting zone - are a further indicator of the predominance of authoritative instruments in implementing laws. The number of fines imposed on sex workers in Vienna is remarkably large.${ }^{61}$ In 2011, each registered sex worker was fined on average three times. Taking into account the estimated numbers of non-registered sex workers, the figures still add up to two administrative complaints per sex worker. No other Austrian province/Land has such high numbers of administrative complaints, neither in total nor per sex worker. Forty percent of all complaints concerned violations of regulations regarding street-based prostitution. That prohibition of outdoor sex work and fines do not deter sex workers indicates that there is a need for workplaces outside of brothels. However, the remaining $60 \%$ of charges concern illicit prostitution (for example, no registration or no valid health check).

Law development in the area of prostitution - all state and federal laws are written by civil servants and/or the executive on behalf of politicians - has always been within the remit of a small, closed policy community of politicians and legal-technical experts. External experts from the field of health and social work became involved for the first time only when the WPG 1984 was amended in 1991. Women's organisations had no influence over this process. This way of using the knowledge of domain-specific experts for advising on legal amendments continued in the years following the amendment with the inclusion of other professions and policy fields. For instance, once a sociologist was consulted, NGOs advocating for full decriminalisation and the improvement of working conditions, as well as the Department of Women's Affairs and the Viennese equality body, were admitted by the authorities to the law development process. Although their actual influence on the content of the laws remains unclear, the inclusion of non-governmental actors/stakeholders in processes of opinion formation and decision making indicate a rethinking of politicians and administrators of the governance of prostitution in Vienna. However, despite this tentative opening to external experts, sex workers and sex

60 The complaints did not only concern violations of prostitution related laws but also breaches of the commercial code and other laws.

61 In 2008, 7,609 administrative fines were imposed; in 2009, 10,819; in 2010, 7,609; in 2011, 10,592; in 2012, 8,694; and in 2013, 7,388 (source: Viennese police department). 
facility managers remained excluded from processes of law formulation and implementation design.

Information policies targeting the wider public in Vienna have largely focused on awareness raising about human trafficking and sexual exploitation in the city's sex trade. Information leaflets and a radio broadcast were aimed at sensitising clients to the existence of trafficking and a peer education programme (conducted by LEFÖ) sought to inform sex workers. Only in the course of the implementation of the WPG 2011 were sex workers and facility managers more extensively informed about the upcoming legal changes. Since the end of the 1990s the city of Vienna has financed NGOs offering counselling and outreach work for sex workers. By outsourcing these tasks to NGOs the city acknowledges the necessity of support for sex workers and that politics, administration and the police have limited expertise in the field. The importance of such organisational policy instruments has been stressed once again in the new Prostitution Act, although in a somewhat conditional way, as it is stated that 'given the availability of sufficient financial means' counselling will be offered (WPG 2011, $\left.\int 5(2)\right)$.

Although new approaches have been tentatively applied in the course of law formulation and policy implementation of the WPG 2011, the deployment of predominantly authoritative instruments, such as the restriction of outdoor prostitution, the licensing of sex clubs, and the extension of police power, has continued. In the following section we will describe the challenges of a new approach to governing prostitution in Vienna, the policy instruments that have been employed and the outcomes of the various policy initiatives.

\section{New approaches, a new law and disappointing outcomes}

In the first decade of this century, prostitution has been the subject of intense attention in Vienna. It was the heated political climate around street prostitution, and pressure from residents and their political representatives and the media, that led, first, to a so-called seven-point plan, and subsequently to a new municipal Act. ${ }^{62}$ Executive City

62 In 2011 the three major Austrian newspapers carried more than 80 reports about street prostitution in Vienna. Residents of prostitution areas were in close contact with the media. The dailies and weeklies, as well as Viennese televison programmes, frequently reported on street prostitution, with an exclusive focus on the nuisance for residents. The media were very critical about politicians at the provincial and district level and their proposals for solution (especially the sevenpoint programme and, later, the new law). The citizens' initiatives gained a lot of 
Councillor for Women's Issues Sandra Frauenberger proposed the socalled 'seven-point plan' in May 2010. It proposed support for residents of street prostitution areas and sex workers (through the establishment of a hotline for reporting nuisance and other problems), the relocation of street prostitution to two less populated streets, more police control of street prostitution, the intention to adjust the Viennese Prostitution Act, more outreach work by NGOs, and a financial contribution to the Dutch-Austrian research project on which this book is based.

The genesis of the seven-point plan, and its evolution into a new Viennese prostitution law, forms an apt illustration of the dynamics of policy design and implementation in this area. First, we notice the continuous pressure from media, political spokesmen and the public. The intense media attention more or less forced elected officials into a particular framing of the problem of prostitution in the city. Despite the fact that Vienna had about 500 sex facilities at this time, the focus of the debate, and of subsequent policy initiatives, is disproportionally on the 100 to 120 outdoor sex workers who work the streets of Vienna. There is little discursive space to consider alternative problem definitions or to listen to other voices, such as those of the NGOs that try to bring the rights of sex workers to the attention of policy makers.

Second, some of the city's authorities feel that they have few effective means to control prostitution. In a moment of candour, Ms Frauenberger, the Executive City Councillor responsible for prostitution, stated that she did not know what was realistically possible in terms of steering prostitution. She added that she wanted to attempt to mobilise "community-political instead of legalistic means" to achieve structural change (source: interview). Ms Frauenberger feels that prostitution in Vienna is largely driven by exogenous forces that are difficult, if not impossible, to control. With the city's proximity to eastern Europe, the most potent extraneous force is immigration. The councillor's statement also shows an awareness of different governance arrangements, as well as, given the policy-resistant nature of the prostitution field, a willingness to experiment with these.

coverage by the media. The media reports were fuelled by district politicians of various political parties who exerted pressure on the Executive City Councillor for Women's Issues. They introduced motions and resolutions at the city parliament and submitted parliamentary questions, such as that by the Greens regarding the seven-point programme. The right-wing Freedom Party issued a resolution from all of its district councillors in September 2010 proposing the introduction of client punishment. The SPÖ (Social Democrats) of the 15th district issued a Bill concerning the relocation of street prostitution in February 2011. Politicians at the district level also exerted pressure through a large number of press releases. 
Governance modes are more or less consistent 'packages' of policy foci, understandings of state-society relationship, broad governance aims and preferred policy instruments (Considine, 2005; Howlett, 2011, p 9). For example, 'legal governance' focuses on legality or the promotion of law and order and frames the relationship of the state to society in terms of legislation and administration, and its preferred instrument are laws, regulations and taxes. Ms Frauenberger expresses awareness of the limitations of regulation in a field such as prostitution that is characterised by dynamic complexity, and feels a need to open up the traditional monopoly of politicians and legaltechnical experts in designing policy measures. The alternative that she suggests has elements of another governance arrangement, 'network governance'. Network governance focuses on relationships with the aim of promoting inter-actor problem solving, which sees the state as collaborating with society, and the institution of task forces, clientele agencies (such as NGOs) and stakeholder conferences. In terms of instrument theory the councillor introduced organisational instruments of a collaborative nature into the policy process. For example, in the implementation of the seven-point plan the city collaborates with a number of municipal departments (Promotion and Co-ordination of Women's Issues and the Department for Elections and Specific Legal Affairs, officials from the STD-outpatient clinic and representatives of the city boroughs in which street prostitution takes place. In a subsequent phase of the project a formal steering group was formed to implement the new prostitution law.

One of the driving forces behind the tentative introduction of networking instruments was the realisation among politicians and administrators that the organisations involved in regulating prostitution in Vienna were working without coordination, resulting in the duplication of efforts and organisations, often unknowingly, confounding each other's activities (interviews, administrators). For this reason, Ms Frauenberger ordered the municipal Law Department to involve the relevant stakeholders in the formulation of the new Prostitution act. As the head of the Law Department emphasised, prostitution is a topic that straddles many administrative sectors and therefore requires the know-how of a wide range of actors. A period of intense consultation began. In two so-called structured dialogue forums, political representatives, administrators of various agencies, NGOs, residents, proprietors and sex workers were consulted. Additionally, the councillor invited over 20 sex workers to obtain 
first-hand information about working conditions and their concerns. ${ }^{63}$ Participants had mixed feelings about the consultation forums. Although they appreciated them as potentially valuable innovations in the traditionally antagonistic Austrian political climate, they also felt the participants did not come closer to each other or change their positions. The 'dialogue' amounted to a repetition of familiar positions. Some participants attributed this to the high escalation level of the issue of street prostitution, but it is likely that the dialogue was not adequately designed. ${ }^{64}$ For example, residents who did not object to prostitution in their neighbourhood were not represented at the forums. ${ }^{65}$ Moreover, soon after the consultation rounds the final formulation of the Act entered the political arena and was finally agreed with great difficulty in intensive and unyielding (beinharte) negotiations between the two coalition partners (interview, politicians and administrators).

A third lesson, as will become clear, is that policy design is not a one-off process, but instead extends in time as an Act or rule slowly winds its way through the policy cycle, the administrative bureaucracies and the professional organisations. At each step the same pressures that shape problem definition also influence later design and implementation stages. One of the goals of the new legislation was to move street prostitution out of residential areas, but to continue to enable it in non-residential areas and in designated toleration zones (which can be in residential areas). In addition the goal was to make the regulations more transparent, in particular the rule that states that no prostitution is to take place within 150 meters of schools and churches, which had in the past led to a large number of fines for sex workers. However,

${ }_{63}$ Ms Frauenberger, who participated in the consultations with sex workers, declared later that she was struck by the fact that they were strong, self-sufficient women, who did not give the impression of being dependent or victims, and who strongly defended their right to work on the street. Not surprisingly, the outdoor sex workers especially argued for a repeal of the prohibition areas in Vienna.

64 The literature on public policy mediation and collaboration provides guidelines for the design of productive dialogue in contentious, adversarial policy situations. In general successful dialogue requires careful and patient acknowledgement of each party's history, identity and position, something that, in a climate of deep and prolonged conflict, can usually only be accomplished with the help of an experienced mediator (Forester, 2009; Innes and Booher, 2010). We discuss the possibilities for successful collaborative governance in prostitution policy in Chapter Six.

65 Although the meetings were announced as 'dialogue forum', officials of the city administration state that they were not designed as such, but more as meetings in which angry residents could vent their feelings. They acknowledge that they fell short in calming the situation and encouraging people to listen to each other. 
good intentions do not automatically translate into good outcomes. Prostitution policy, as we saw in Chapter Two, is always vulnerable to moral pressure. The road to the implementation of the new Viennese prostitution legislation vindicates this point. Despite the involvement of many stakeholders in the design of the new Viennese Prostitution Act, including a limited consultation of sex workers, and a genuine desire among officials to try a more networked mode of governance, the situation of street workers deteriorated considerably.

The publication of the seven-point plan did not decrease the pressure on the policy makers. Political parties, residents, media and NGOs all clamoured for a new prostitution law, albeit for different reasons. The Executive City Councillor then decided to set the formulation for the Prostitution Act (WPG), as already announced in the seven-point plan, in motion. The Act was to contain the prohibition of street prostitution in residential areas, the designation of a toleration zone for street prostitution, a licensing procedure for brothels, and fines for clients who solicit sex workers outside of the designated areas. From the very start the WPG was developed in a climate characterised by contentiousness and political manoeuvring. As evidenced by the high number of press releases and the many statements in the Viennese parliament, the political opposition in Vienna used the issue for political competition (interviews with politicians; media coverage; parliamentary debates). Also the WPG took shape within a clear law and order framework that maintained the dominant position of the police with regard to problem definition and agenda setting. ${ }^{66}$ Although the police did not write the first draft of the law, they had a strong influence on the new prostitution law. The police continually informed politicians about the shortcomings of the old law, particularly emphasising the insufficient means and instruments at their disposal to effectively deal with illicit prostitution. The police were involved in the development of the WPG in as far as they were invited to give their opinion on several measures and to comment on the final version.

The goals of the new Act were to improve the work and life situation of sex workers in Vienna, to regulate street prostitution and to fight trafficking. The major instruments were a licensing system for sex facilities, the prohibition of street prostitution in residential areas, the

66 The delegation by the city of law implementation and enforcement to the police dates back to the 19 th century. This tradition was upheld in the 20th century with the regulation of prostitution within the Police Act. This long-lasting tradition meant that it was more or less self-evident that the police once again would have a strong role in the development and implementation of the new prostitution law. 
prosecution of clients who solicit outside designated areas, a lowering and if possible an amnesty of the fines that sex workers had accrued, ${ }^{67}$ and an extension of police powers.

To expedite the implementation of the new Act a steering group was created in which political representatives, administrative agencies, police officials, NGOs and officials of the affected city boroughs participated. The idea was to keep all parties informed, coordinate policymaking, and create broad support for the new Act among the stakeholders. However, the participants were frustrated in their hopes. Very soon the group focused almost exclusively on the selection of the designated zones for street prostitution in the boroughs, as agreed in the difficult negotiations between the two coalition partners. This effort has failed so far. The steering group has no decision-making power and the boroughs have vetoed every proposal for a designated street-walking zone. ${ }^{68}$

The city of Vienna has introduced further implementation measures: the Viennese government strengthened the role of NGOs LEFÖ and SOPHIE. Both received three-year contracts. LEFÖ was awarded funding for counselling newcomers in sex work and accompanying them (with their agreement) to the police for registration. According to LEFÖ, these services are welcomed and accepted by many sex workers (interview with LEFÖ official, 2012). SOPHIE received financial resources for outreach work and the operation of a hotline (for residents and sex workers). The city of Vienna also published online city maps designating the areas where sex workers are permitted to solicit clients outdoors.

At the time of writing this book, the implementation of the new Viennese Prostitution Act has fallen well short of its stated goals (the relocation of outdoor prostitution from residential areas, a transfer to indoor prostitution, the licensing of brothels and a reduction in human trafficking). While outdoor prostitution has been moved out

${ }_{67}$ Police officers had fined street workers who solicited outside the permitted areas. Many workers had outstanding fines amounting to thousands of euros. As they did not possess the means to pay the fines, they were in effect forced to work to clear them. The idea was to break through this vicious cycle. It turned out, however, that a general amnesty was legally impossible.

68 The process was considerably more complex than described here. The designation of tolerance zones is statutorily only done by the regional police, the Landespolizei. After some political pressure the police formally put in a request with the borough administration for the designation of a tolerance zone within a residential area, which was subsequently rejected. The borough chairman explained that he feared that toleration zones would only attract more sex workers to the area. 
of residential areas, and brothels in Vienna are required to apply for a license, only limited transfer from outdoor to indoor prostitution has taken place as far as we can see. NGOs and the police estimate that about half of street-based sex workers have moved to indoor prostitution. Both observe an increase in illicit apartment prostitution. The police assume that the remaining sex workers have left the city and that most of these have been replaced by newcomers. ${ }^{69}$ The policies also resulted in a number of negative unintended consequences such as the lack of infrastructure for outdoor sex workers, overcrowding and brawls among sex workers, pollution of parking lots, and the provision of sexual activities in public spaces. Meanwhile only a few sex workers solicit clients outdoors in two remote streets on the outskirts of the city, but as the continual high number of fines for transgressing zone regulations show, illicit outdoor prostitution has not vanished since.

The Viennese experience underscores our claim that studying and understanding the dynamic of policy implementation is crucial in understanding the effects of prostitution policy. While the public debate almost exclusively focused on broad design templates that embody clear moral principles, the real story unfolds in the myriad interactions between administrators and professionals on the one hand and sex workers, proprietors, clients and NGOs on the other. The development of prostitution policy in Vienna demonstrates the complexity and interconnectedness of the prostitution domain, the enduring role of the police in shaping policy implementation, the gap between policy design and the lives of sex workers, and the continuing influence of problem framing and media pressure on each phase of the implementation process. For example, the licensing of 500 sex facilities in Vienna, as an instrument to improve the working conditions of sex workers, made hardly any progress in the year after the Prostitution Act was passed and has resulted meanwhile in a stark reduction of legal facilities. The Act stipulated that new facilities required a 'license', ${ }^{70}$ while existing facilities had one year's grace to apply for one. Despite an information campaign by the police, proprietors have been reluctant

69 Source: interviews; contribution by Wolfgang Langer (Viennese Police Department) at the expert conference Exchange of Experiences on Regulatory Measures in the Area of Sex Work, Vienna, 10-11 June 2013.

70 We put 'license' in quotation marks as it is not a license in the strict sense of Austrian law. Proprietors must register the brothel and are permitted to operate if they fulfil the necessary requirements. In the strict sense of the word a license would make it necessary for neighbours and nearby residents to be heard by the administration. This is not part of the procedure in Vienna. 
to apply for 'licenses'. ${ }^{71}$ Their argument for not doing so is that the costs of abiding by the new regulations for safety and hygiene as well as for structural alterations to their establishment are too high, especially for small establishments, but insiders believe that this was a tactical manoeuvre by the proprietors. Possibly the need for proof of the proprietors' reliability (and for proof of on-site management) was another obstacle in applying for a 'license'. The city was patient with reluctant proprietors, and did not immediately close down brothels that had not been 'licensed'.

We also observe that licensing authorities have created their own obstacles to obtaining approvals. Although guidelines have been formulated for equipping sex facilities in a safe and hygienic manner, they leave much scope for interpretation (regarding, for example, which kind of alarm system is necessary). Proprietors and civil engineers complained about functionaries' arbitrariness and contradictory demands caused by a lack of specificity. The proceedings would often take so long that the licensing procedure would become unaffordable for small businesses. ${ }^{72}$ Three years after the enforcement of the WPG 2011, about 300 sex facilities had received authorisation. This is a reduction of about 200 facilities. So far it is not possible to give a clear picture of the effects of the reduction in the number of facilities, but in general the pattern in Vienna after the introduction of the licensing system follows that in the Netherlands. The majority of the 'licensed' sex facilities is still small; about $80 \%$ have a maximum of five rooms. Thus, the number of legal workplaces has diminished dramatically whereas the number of registered sex workers has increased (from about 2,700 in 2011 to 3,600 in 2014). This imbalance of developments is to the advantage of sex facility managers. Fewer legal workplaces and more sex workers on the market mean that the managers have more negotiating power. It became easier for them to dictate working conditions (for example with regard to type of sexual services provided, and working hours and provisions). Insiders also witness a rise in illegal apartment prostitution related to the loss of legal workplaces (indoors and outdoors) (source: interviews). Also there is little evidence that the

71 In September 2012, that is two months before the end of the transitional period, 70 proprietors had applied for a 'license', eight facilities had been granted one, and one application had been turned down.

72 Contribution by Evelyne Tomes (head of the professional association of civil engineers for Vienna, Niederösterreich and Burgenland) at the expert conference Exchange of Experiences on Regulatory Measures in the Area of Sex Work, Vienna, 10-11 June 2013). 
city created an effective monitoring apparatus, of the kind discussed in the section on Dutch local policy.

On the face of it, the prohibition of prostitution in residential areas can be called a success. Following an information campaign by NGOs and increased police presence in the affected areas, sex workers disappeared from the areas in a matter of days. At first this did not result in a decrease of the number of street workers. A few months after the Act became effective NGOs counted the same number of women who were by then concentrated in the two designated areas, the Prater and the Auhof, although half of the women were new. However, under pressure from residents and businesses near the Prater, and swayed by the argument that children and tourists should not be exposed to the sight of women soliciting, the city introduced two new regulations that constrained both the area and the times that street prostitution was allowed. Up until then about 20 women had been working in the area, but by 2012 more than 100 sex workers were fighting for a place. The result was that prices decreased drastically (to as low as $€ 5$ for oral sex, according to outreach workers) and physical fights among sex workers, often along ethnic lines, were quite common. Some businesses in the Prater organised an informal 'security service' that expelled women from parking lots and prevented outreach workers from doing their job. The police refused to act against this form of vigilance. Despite the repeated assertions of politicians to create an infrastructure for outdoor sex workers, there were no sanitary facilities in the Prater and the Auhof and no sites where sexual services could be carried out. Sex in cars is forbidden and there were only a few hotels in the vicinity of the Prater. Additionally, according to outreach personnel, sex workers who returned from a hotel within a residential area to the designated zone risked being fined for violating the rules, although the police deny this. As a result, the public parking garage in the Prater had, according to an outreach worker, been turned in a big open-air brothel. The stated goal of improving the work situation of sex workers has not been reached in the case of street prostitution since.

Three years after the enforcement of the law the situation for streetbased prostitution had again changed dramatically. After imposing a number of incremental limits on street prostitution, the Prater, a traditional soliciting area (it has fulfilled this function for about 200 years), has been declared a prohibition zone. ${ }^{73}$ For reasons of safety, the suitability of the Auhof as a site for outdoor prostitution has always

73 The closure was expedited by concerns about the international reputation of the University of Economics and Business, which moved to the area in 2013. 
been disputed. It is a remote non-residential area without infrastructure (the nearby hotel denies access to sex workers) that is poorly lit and without public transport (source: interviews; media; observation). It was finally closed because the proprietors of the businesses in the area denied access to sex workers. Neither the sex workers nor the outreach workers of various NGOs were informed about this. Politicians at district level and in the city council also claimed to have been caught off guard by the shutdown. Following media reports, this was proven to be implausible as at least half of this area belongs to the city (Thalhammer, 2014). Thus, outdoor sex workers were expelled once more without due process. This incident illustrates how a lack of coordination and sloppy implementation violates the human rights of a vulnerable, stigmatised group. At the time of writing this chapter (February 2016), the area for street-based prostitution has been reduced to two small streets in outskirt industrial areas. Altogether about 20 to 40 sex workers (depending on the season) solicit clients there. Despite this small number of sex workers and despite the fact that these streets are not located in or near residential areas, residents and some politicians continue to confront district authorities with protests and petitions. Authorities of the 23rd district have conceded to residents' protests and have restricted the time for soliciting clients outdoors to night hours. ${ }^{74}$ Especially harsh is the resistance in the 21st district, where about 15 sex workers solicit clients. A member of the right-wing Freedom Party collected signatures to prohibit outdoor prostitution in the district on the grounds that it is responsible for drugs activity and car accidents, although the police do not see any evidence to back up these allegations (Amara, 2014 and other media/TV reports). ${ }^{75}$ Sex workers suffer from harassment by vigilante residents (taking pictures, verbal and physical attacks). Furthermore, the police report fights among the 'protectors' of sex workers and instances of sex workers paying protection money.

The example of Viennese street-based prostitution demonstrates the negative effects that giving in to morality politics has on the policy process. Lacking any evidence, residents and politicians create

74 See: Verordnung der Landespolizeidirektion Wien, GZ:P3/63593/10/2013, released 20 June 2013.

75 Voices that advocate for legalising outdoor prostitution and against further restrictions are rare, but among them are a few individual residents and residents' groups like the Stuwer Committee in the second district, which launched a campaign called Lieber Rotlicht statt Blaulicht (Better Red Lights Than Blue Lights; see www.stuwer.info). The NGO LEFÖ protested in an open letter to the district and city politicians against the introduction of time restrictions for street-based prostitution. 
the impression that the residents are endangered by outdoor sex work. Sex workers and prostitution are defined as a problem, not the policies towards prostitution. The police, who have traditionally been tasked with implementing prostitution law in Vienna, reinforce this perception. Police operating routines designate certain manifestations of prostitution as both 'problematic' and 'feasible for intervention'. The result is that street prostitution, although a small part in Vienna's prostitution market, has become the focal point of policy implementation, while the regulation of the much larger club scene proceeds slowly.

Another lesson learned is that expelling street prostitution from residential areas will not pacify residents. It is the visibility of outdoor prostitution, itself largely an effect of excessive media attention, that disturbs and becomes a source of conflict. In an overheated, moralistic public climate, repression is an open-ended process. But the developments with regard to street prostitution are also a lesson about the resistance of sex workers who try to circumvent regulations perceived as disadvantageous to their work practices. Although sex workers vacated the main soliciting areas within residential districts within a few days after the WPG 2011 came into effect, it would be a mistake to conclude that the 'problem' was solved. On the basis of statistics on issued fines, just a few weeks after the prohibition of outdoor sex work in residential areas, some sex workers had returned. According to the Viennese Police Department, 3,536 complaints were filed in 2012 and 3,627 in 2013 (email correspondence with Wolfgang Langer, 22 August 2013 and 24 January 2014). From the point of view of Ms Frauenberger, the new Prostitution Act is (still) a success as the number of sex workers in the legalised soliciting areas has decreased and a number of outdoor sex workers moved indoors (source: interview; media reports). However, the goal of improving working conditions for outdoor sex workers has been set back considerably; the new regulations have been detrimental to the autonomy, safety, income and human rights of outdoor sex workers. Viennese police officers are satisfied with the new law, not least because they now have an additional instrument to investigate 'secret prostitution' and to shut down sex facilities with the help of undercover agents (interviews, police). Furthermore, they are allowed to enter apartments without the consent of the tenant or proprietor when illegal prostitution is suspected. Considering that illegal prostitution is not a criminal but an administrative offence, one might question the appropriateness of such an instrument. In the name of prohibiting illegal prostitution the 
human right to privacy is sacrificed while the effectiveness of such measures remains low at best. ${ }^{76}$

\section{Conclusion: policy implementation, morality politics and the corrosive effects of discourse}

What are the wider lessons for the possibilities and limits of regulating prostitution from our analysis of its implementation in the major cities of Austria and the Netherlands? In the introduction to this chapter we questioned the abiding notion of a stable and hierarchical relationship between politics and administration. On the other hand, we did not want to abandon core democratic principles of responsibility and accountability, both of which require that we do not narrow our analysis of policy implementation to a chaotic struggle between actors and instead uphold some basic notion of policy goals and policy accomplishments (Lane, 1987). We also want to go beyond the rather facile conclusion that policy implementation is political, or more precisely, that it is the continuation of politics at a lower scalar level. Although that observation obviously rings true, our aim in our analysis of the implementation of prostitution policy in this chapter is to take into account three major empirical findings: first, that the legalisation of brothels in the Netherlands and the new Prostitution Act in Vienna had clearly formulated goals that embodied progressive values concerning the regulation of prostitution and the position of sex workers in society; second, that the implementation of prostitution policy in both countries was entrusted to a cadre of experienced officials who operated within the rule of law and a long-standing administrative ethos of fair and responsible public administration; and third, that nevertheless in both countries, mostly through the instruments and techniques of policy implementation, progressive policy goals quickly transformed into a repressive form of regulation. The remarkable thing about this turn towards repression is that it occurred under the political radar as it were, largely beyond the influence of elected bodies such as city councils or national parliaments. We have observed two mechanisms: regulatory drift in the Netherlands, the accretion of dozens of dispersed administrative measures that add up to a reversion of the original more progressive goals of the repeal of the ban on

76 According to a newspaper report, the Viennese police closed 14 illegal brothels up to February 2014 (Amara, 2014). In this article the head of the responsible police department stresses that the employment of an undercover agent was only the final step in long-lasting and expensive investigations. 
brothels; and agency capture in Vienna, the narrowing and overturning of a balanced comprehensive policy by the operating routines and organisational culture of one organisation, the police, that was thrust into this position as the result of a century-long tradition. However, while these mechanisms describe the pathways towards the repressive turn, they do not explain it. That is, they do not explain how such a proclivity towards repression was accepted and why it has gone unchecked in two different countries with such different politicaladministrative cultures. The answer is: discourse.

Our first observation is that discourse matters as much in the implementation as the formation phase of public policy. In the next chapter we will see that national discourse plays a major role in the formulation of (national) prostitution policy. Not surprisingly the sway that discourse has over policymaking is not suddenly switched off when policies move into the implementation phase. As we have seen, discourse hypostatises conflict. Deep conflicts in society acuminate in discourse. But reversely, public discourse, through its contentious nature, has the effect of imposing on the policy process a recurrent dynamic of domination and resistance, of hegemony and subjugation, in this way, as it were, orienting the policy process away from its technical-instrumental aims and towards the realm of morality politics. How does discourse infuse every element of the policy process with irresolvable conflict?

Every law has both an explicit and implicit meaning, but discourse provides the master narrative that gives moral significance to the social project that a law embodies (Stone, 1997, pp 138-47). Discourse provides the cognitive, moral and emotional link between policy values and intentions as expressed in the legal texts that enter a nation's law books, the myriad activities of administrators and professionals that translate these intentions into workable regulations, and the effect these regulations have on society. Discourse also provides the backdrop to the sense of policy accomplishment by which we hold our politicians, administrators and professionals to account. And more concretely, discourse directs attention and shapes the assessment of outcomes and their presumed relation to policymaking. Both in Vienna and the Netherlands, administrators work in a relentless media climate in which prostitution is consistently associated with organised crime and trafficking. Administrators fear the media as much as they use them. When we discussed the final draft of the report of our study, for example, the three Dutch cities asked for postponement of its publication to prepare the mayor for possible questions from the media. In Vienna, hostile media almost compelled city administrators to submit 
to an emboldened police and initially narrow the implementation of the 'seven-point plan' down to only one point: to remove street prostitution from the city centre. At the same time city officials in the Netherlands gave interviews to national media about the alleged prevalence of forced prostitution in their municipality, and made sure that raids on brothel areas in search of victims of trafficking were widely broadcast on local television.

What these examples suggest is that, although the media exert enormous influence over the policy process, the relationship between policy implementation and discourse is more complex than that. Politicians are not just 'dupes' of media discourse, being swept up in discursive forces beyond their control. They also use the media to 'plant' their message in the public's consciousness. By giving interviews and citing convenient figures, they carefully create a particular image of prostitution. The circumstance that it is a national politician doing this gives the message currency and authority. Activists repeat and embellish this message over and over again, until it has become a particular, taken-for-granted way of talking about and understanding the world whose political antecedents are effaced (Jørgensen and Phillips, 2002, pp 1,37). In fact, elected officials, activists and journalist often work in tandem to actively promote a particular image of a social issue. Such moral entrepreneurship crowds out other ways of talking and thinking. By robbing these alternatives of credibility and authority, they come to be considered as marginal and suspect. In Chapter Two, in the section on morality politics, we described some of the tactics that resulted in this absolutist quality of certain problem framings: massaging the facts, imbuing statements with strong emotions and denouncing opponents are a few of them.

Administrators work under a double injunction: the one that issues from the law and its objectives (no matter how ambiguous and conflicted these may be) and a national discourse that results in some understandings and interpretations of prostitution being taken for granted and becoming self-evident. The significance of this is that in the policymaking process administrators form the link between knowing and acting. A preference for certain policy instruments, or the way these are administered, are shaped by administrators' understandings and interpretations of prostitution. A shared master narrative about prostitution mediates these interpretations. Discourse's soft power explains how even administrators' deployment of their discretionary capacity, the kind of off-the-cuff improvisation that is necessary to make policies work on the ground, is shaped by the master narrative - in our case a dominant narrative of prostitution as 
organised crime and trafficking. Before long, elected officials, pundits, the media and administrators formed what Foucault calls a 'discursive formation': an interconnected set of statements, knowledge, facts, procedures, routines, organisations, metaphors and ways of speaking that taken together define prostitution, or better, that prescribe what is sayable and doable in this policy domain, and what falls outside the spectrum of acceptable statements and actions (Rose and Miller, 1992). At this point facts and data have lost a reasonable hold on policy makers. Instead policy makers mobilise their own facts to support a preconceived discursive position. For example, we set out to count the number of sex workers. And, while we acknowledged the difficulties that accrue to this task and described our methods in great detail (see Chapter Two), administrators from the three Dutch cities never really accepted our careful estimates that suggested that the sex trade was much smaller than was generally assumed. This applies even more to repeated 'disappointing' outcomes of inquiries into trafficking or raids on prostitution districts that fail to identify the predicted large number of victims. ${ }^{77}$ Low numbers do not fit the discourse of trafficking as a major social problem; thus realistic numbers are either ignored or 'neutralised' with rhetorical statements that we are only witnessing 'the tip of the iceberg' or that the 'dark number' surely is much larger. In cases such as this discourse has firmly established a particular reality regarding prostitution, a reality that is sustained and held in place by the very actions that constitute it.

The significance of this observation for an analysis of the policy process is that it upsets the balance of trust that, as a complement to the related notions of responsibility and accountability, governs the implementation process (Lane, 1987). Citizens, and the target audience in particular, are quite willing to accept that policy implementation requires interaction, negotiation and administrative discretion, but they also expect that politicians, administrators and professionals who are involved in implementation can be trusted to respect the moral thrust of the original intention, however ambiguous it may be, act within reason, respect the facts on the ground, and be impartial, respectful and sincere in their interactions with stakeholders. To actively promote a particular set of values in creating a discourse turns the official into an

77 The low 'yield' of raids on prostitution districts for the purpose of catching traffickers and saving exploited sex workers is a recurrent but unacknowledged phenomenon. See, for example, www.theguardian.com/uk/2009/oct/20/ government-trafficking-enquiry-fails. 
advocate, who is willing to narrow the law's original intent to certain factional interests.

Our second and related observation is the pernicious influence of morality politics on policy implementation. This statement contains a considerable inner complexity that we do not want to walk away from. As we noticed in Chapter Two, morality politics is not a characteristic of particular policies, although some policies, such as those relating to the 'body' and 'sin', seem forever mired in irresolvable moral conflict. Each and every policy can, under particular circumstances, become a pawn in a moral controversy. The bitter discussions about budgetary austerity or genetically modified food are examples where such knowledge- and technology-heavy domains as economic or food policy have moved into the realm of morality politics. What these examples demonstrate is that policy implementation is not a phase of a general 'policy process'. One cannot discuss policy implementation in a particular domain without taking into account the substantive values that are at stake in the moral debate. This is the key message of Deborah Stone's theory of public policy: public policy is not so much a process but a protracted struggle over the interpretation and realisation of important societal values (Stone, 1997). In addition, it is important to trace who dominates this struggle, in other words, who holds the balance of institutional and discursive power. In the case of prostitution policy this is, as we have seen, an alliance of politicians, administrators, the media, fundamentalist Christian groups, Social Democrats, activist feminists and academics. This is the discourse coalition (Hajer, 1993) that has promoted the abolitionist values that are linked to rhetorical arguments of the ubiquity of trafficking, organised crime and coercion in prostitution.

The Dutch case shows the damaging influence that such a value position has on policy implementation. We have seen how policy implementation in Dutch cities have gradually become more repressive and how even seemingly neutral instruments such as networking that were initially used to enhance communication with target groups, have been used to inhibit and repress prostitution. We call this phenomenon regulatory drift. Regulatory drift denotes a gradual change in the focus and goals of a policy as the result of a succession of small decisions at the implementation level, without any formal decision at higher levels of authority (Mitchell and Herring, 2006, p 5). The selection and deployment of policy instruments is a key element of regulatory drift. Since 2000, we have observed in Dutch cities a more frequent deployment of authority instruments such as punishments, fines and administrative measures. Today, 15 years after the passing of the repeal 
of the ban on brothels of 2000, one of its central goals - improving the 'legal position' and work conditions of sex workers - has been abandoned in favour of an almost exclusive focus on 'enforcement', fighting and preventing trafficking, and discouraging prostitution altogether. The significance of regulatory drift is that it may, and in our case did, result in a de facto new policy, that is antithetical to the original policy goals, without any parliamentary process.

In Vienna on the other hand, then and now, the trafficking discourse has had the effect of allowing the police to move into a key position in the implementation of prostitution policy. We called this agency capture of the implementation process, not in the sense that the police actively lobby to obtain the authorisation to implement prostitution policy (although they did that too), but in the more covert sense of a complex of political, cultural and ideational forces that foreground the police as the logical actor for such a task (which explains why their lobbying was successful). The effect of the police as the organisation of choice is profound. The problem perception, practices and organisational culture of the police strongly shape the implementation process. As a result, policy implementation has focused on 'easy' targets (street workers, mostly ethnic minorities) and has been more circumspect with 'difficult' targets (licensing for sex facilities). What makes the latter target more difficult is that proprietors have more rights than street-based sex workers. The shutdown of a facility by authorities has to be justified according to legal provisions and the principle of legal certainty safeguards entrepreneurs (not just sex facility proprietors) from overnight changes. Although we do not have proof of direct political intervention by facility owners, it is likely that the high-end enterprises did exert such pressure. ${ }^{78}$ Furthermore, sex facilities are a more difficult target as appropriate guidelines relating to equipment and safety provisions had to be developed for a variety of sex facilities (notwithstanding different requirements for small and large facilities). The application of these guidelines has revealed their deficiencies; while they leave considerable discretion to the authorities, they increase the dependency of proprietors on the goodwill of civil servants. The reduction in the number of legal workplaces means that it is easier for managers to set working conditions unilaterally. The result of

78 According to some interviewees, the police are less restrictive when it comes to the authorisation of such facilities. While these are rumours, they bear some probability. When it came to an amendment to taxation requirements on brothel operators and sex workers, the managers of sex facility chains intervened at the Ministry of Finance (interview, proprietor). 
this process of implementation capture by the police is that over and over again the progressive policy goals of Viennese prostitution policy initiatives take a back seat to more repressive and regressive implementation practices.

These observations about the implementation of prostitution policy in light of implicit notions of accountability and trust that govern this phase of the policy process have three further implications. The first is that repression is a hungry beast, as we concluded earlier. Our analysis shows that there is no end to the quest for ever more perfect means of detecting and repressing 'trafficking'. The 'fantasmatic logic' of repression ushers in an irrepressible, escalating fantasy of ever more intrusive measures to incapacitate a powerful and devious opponent and effectively control the policy domain at hand. For example, despite its rhetoric of improving the situation of sex workers, the WPG 2011 in Vienna gives the police the authority to close a sex facility immediately without a court hearing (although such a decision has to be provided within one month after shutting down the brothel), to enter private apartments when prostitution is suspected and to use undercover agents to fight illicit prostitution and trafficking. In the Netherlands the moral panic that 'forced prostitution' was taking place in licensed brothels logically led to enforcement arrangements and the mobilisation of public innovation, a range of authoritative measures, and a tendency to seek out the limits of what is legally permissible. As forced prostitution by its nature was portrayed as hidden, clever detection aimed at outwitting the trafficker had the task of exposing this hidden crime, hence the introduction of intake interviews and 'signals of trafficking', for example. But what is a valid signal? If a sex worker does not speak Dutch, is dropped off at her work site by someone in an expensive car and does not know her home address, the chances are high that she is being exploited. But do we capture all cases this way? Do we really get at the dark number? Hence, the reliance on more exotic signs such as 'takes a lapdog to work' (to alleviate the isolation of the forced sex worker), 'advertises on the internet' (to increase business for the pimp), 'sex worker seems sad' (to indicate her despondency about her situation), and 'recruits clients through recommendations from other clients' (an indication of an underground circuit of predatory clients). We do not want to sound facetious here, because the implications are far from amusing. Once the sex worker has the status of 'victim of trafficking' ascribed to her by means of one or more of the indicators, she is denied a work permit and has to leave the city. As we saw, there is no possibility of appeal to this 'verdict'. The municipality offers the opportunity to enter a victim programme, but only if the sex worker is 
willing to testify against her traffickers. Few sex workers have sufficient trust in the authorities, or the effectiveness of such programmes, to take them up on this offer. We could retell this story with regard to entrapment schemes, the closure of windows, or the sudden revocation of immigration, work or fiscal rules. In all these cases, sex workers, who are engaged in a legal vocation, may have their rights revoked through an administrative measure without any possibility of appeal.

And this is the second implication. The examples in this chapter show how the violation of the human and civil rights of sex workers are the casual outcomes of ordinary but ideology-driven administrative behaviour in a political-administrative system that abides in all other respects by the rule of law. However, a form of groupthink makes the violation of the human and civil rights of a group of citizens not only thinkable but also acceptable as the inescapable cost of fighting trafficking and discouraging prostitution. 'Trafficking' becomes a symbolic rallying point, an abstract but powerful signifier, in relation to which the fate of concrete individuals becomes insignificant.

The third implication is that we need to ask ourselves what the repressive turn means for our assessment of the implementation of prostitution regulation in the context of its legalisation. In his overview of models of policy implementation, Lane makes the following important observation:

In whatever way implementation takes place, it is always valid to inquire into the extent to which objectives have been accomplished and the degree to which outcomes have occurred that work against the objectives. This is the basis for judging the accountability of implementors and the responsibility of politicians and officials. (1987, p 542)

In light of the accountability-trust nexus that implicitly governs the process of policy implementation, it is safe to conclude that Dutch and Viennese officials have drifted far away from the initially progressive objectives of their respective prostitution laws. Even when in the Netherlands a new national prostitution law was defeated twice in parliament, and a series of arguments had emerged that questioned the current approach and its assumptions, a coalition of local officials and national politicians worked behind the scenes to safeguard the main elements of the repressive approach. The logic of repression exerted an inexorable force on officials and politicians in both countries. Increasingly they closed themselves off from actors who had different ideas. Research reports that offered data and analyses that questioned 
the reigning narrative of trafficking and victimhood were consistently ignored (Wagenaar et al, 2013; Siegel, 2015). Repression has become a self-propelling tunnel vision. However, one can argue that with the WPG 2011 in Vienna and the new 2016 national prostitution law in the Netherlands, the accountability dimension of the implementation process has formally at least been restored. It is to the story of national policymaking that we turn in the next chapter. 



\section{The national governance of prostitution: political rationality and the politics of discourse}

\section{Introduction: policy subsystems and policy streams}

In the policy literature, policy formulation, the emergence of policy agendas and the introduction of legislation are associated less with a particular identifiable phase of the policy process than with policy institutions and policy networks. Groups of organisations and individuals organise around a specific social issue to discuss solutions, ideas and political strategy. The formal arrangements of government - cabinets (working with ministries), legislatures - then make, or block, decisions. Policy networks are made up of members from government and civil society. They can, for example, include members of parliament, high-ranking civil servants and experts from municipal agencies on the one hand, and lobbyists, academic experts, NGOs and members of the target group on the other. What unites these groups is an interest in the issue at hand, expertise, resources and trust. Some actors in the groups harbour resources, such as money, information, influence, decision-making power or legitimacy, that the other actors need. When such groups are in operation long enough, its members develop mutual trust, sometimes even friendships, despite the fact that they might disagree with each other's position on the issue. Policy networks may be open, loose and shifting (whence they are called issue networks) or stable and with restricted membership (whence they are called policy communities) (Rhodes, 1996). The policy network around prostitution in the Netherlands always had the more open character of an issue network with different actors being admitted when other members feel that these have a contribution to make. Some authors argue that each policy sector is characterised by a particular policymaking style that is itself explained by the nature of the policy network that is active in that sector. Such networks are then called 'policy subsystems' (Howlett and Ramesh, 2003). It is difficult though to disentangle cause and effect here. Are policy styles the result of the composition and operating style of a network or has the network 
adapted to the nature of the social issue and imparted a certain style to the issue at hand? Designing industrial or health policy is very different from dealing with a moral issue such as prostitution policy.

In the sequential stage model of policymaking, policy formulation is usually framed in terms of the decisions that the legislature and the executive make. This image of policy formulation nicely fits with our image of how electoral democracy works. As John summarises it: 'Policy emerges from the will of the people; constitutional checks and balances modify political decisions; and groups and experts seek to have an influence at the formulation and implementation stages' (2012, $\mathrm{p}$ 18). Nowadays the consensus in the literature is that legislative or executive decisions are a provisional moment of desistance in a more unruly process of issue formulation and agenda setting, and, as we saw in the preceding chapter, policy implementation. Policy problems, no matter how apparently urgent, are not indubitable but constructed. In any policy sector an assembly of groups and individuals who strive to get their favoured solution and preferred problem formulation accepted actively constructs policy issues. Issues can move in and out of public consciousness. For example, while social inequality was high on the political agenda during the days of the expansion of the welfare state, it more or less disappeared as a political issue during the 1990s and 2000s, only to reappear again after the financial crash of 2008.

Current theories of agenda setting portray the process as an 'organised anarchy' of ideas, solutions and opportunities, in which 'collections of choices [are] looking for problems, issues and feelings [are] looking for decision situations in which they might be aired, solutions [are] looking for issues to which they might be an answer, and decision makers [are] looking for work' (Cohen et al, 1972, p 4). From this dispersed, decentred perspective, Kingdon famously conceptualises agenda setting and policy formulation as consisting of three 'streams' of problems, solutions and politics that move along independently of each other (Kingdon, 2011). This is not the place to extensively summarise Kingdon's seminal book on public policies. We restrict ourselves to a few key suppositions. First, the streams are uncoupled because of the different roles and mandates of the actors in the policy process. The executive dominates the agenda, but cannot determine the policy alternatives that are considered. Interest groups can bring an issue to attention, but cannot determine which solutions specialist communities of experts favour. Media and opinion polls can push an issue up the agenda, but not long enough for solutions to be developed. And experts can design solutions, but have little influence over the agenda. Second, one of the key functions of policy networks or 
subsystems is the development of solutions. It takes a lot of time and effort to design feasible policy solutions - feasible, that is, in terms of technical efficacy, anticipated costs, receptivity among policy makers and public acceptability. To bridge the gap between the problem and solution stream, proposals are developed in anticipation of future problems. The policy stream, third, is about the receptivity of the political community and the public to certain problem formulations and solutions. Fourth, advocates, or 'policy entrepreneurs', lie in wait in and around government with their pet solutions in hand for problems to float by to which to attach their solutions. This, finally, may result at times in a sudden convergence of the three streams. As Kingdon states:

Separate streams come together at critical times. A problem is recognized, a solution is developed and available in the policy community, a political change makes it the right time for policy change, and potential constraints are not severe ... these policy windows, the opportunities for action, present themselves and stay open for only short periods. (Kingdon, 2002, p 174)

In this chapter we show that the 'organised anarchy' of agenda setting and political decision making expresses itself in an ongoing tension between institutionalised political rationality and public discourse. By political rationality we mean those time-tested processes of parliamentary coalition building and decision making that make it possible for a polity to engage in collective problem solving. These are the dispersed but patterned processes that the great policy scholar Charles Lindblom calls 'mutual adjustment', and that taken together form the 'intelligence of democracy' (Lindblom, 1965). We show that these institutionalised processes are affected by unruly public discourse, in the process curtailing the inclusiveness and effectiveness of the collective decision-making process. In Chapters Five and Six we argue for political interaction and decision-making strategies that are better adjusted to the intrinsic complexity of prostitution policy.

\section{National policy in the Netherlands}

\section{The politics of policy formulation: slouching towards decriminalisation, 1970-2000}

Although prostitution itself - the trade of sexual services for money - has been legal since the beginning of the 19th century in the 
Netherlands, until 2000 the commercial exploitation of prostitution was forbidden. The Morality Acts of 1911 outlawed brothels and made pimping a criminal offense (Outshoorn, 2004b, p 185). In the 1970s two developments occurred that undermined this prohibitionist approach to the sex trade: the rapid expansion of the prostitution market and a parallel feminist discourse on women's rights, sexuality and prostitution.

Counting sex workers is fraught with difficulties, as we argued in Chapter Two, and yet everyone agrees that the sex industry in the Netherlands underwent a period of rapid expansion in the 1970s. There is no single explanation for this expansion. A more tolerant attitude towards sex and pornography and the availability of large amounts of black money from the construction industry (Altink, 1995, p 100) resulted in the growth of the number of porn shops, sex theatres and sex clubs. Some neighbourhoods, such as Katendrecht in Rotterdam and the Wallen in Amsterdam, traditionally had a stable amount of window prostitution. For decades residents and prostitutes had lived in peaceful coexistence in these neighbourhoods. These residents were now suddenly confronted with owners who aggressively bought up buildings to turn them into brothels and sex theatres. As more and more money flowed into the sex trade, the business professionalised; in most cities a cartel of a few powerful owners dominated the market. Before long, residents were not only suffering from the nuisance and disturbance that a larger number of clients created in the neighbourhood, but were also intimidated by the pimps and small criminals that followed in the wake of the sex trade. ${ }^{79}$ Finally, to supply the expanded sex trade, owners flush with money began to import sex workers: women from south-east Asia and Latin America became familiar fixtures of the club and window scene. In an attempt to regain control, the city of Rotterdam floated the idea of setting up a government-managed Eros Centre. However, the courts turned down the proposal on grounds that it violated the ban on brothels. The Association of Dutch Municipalities (Vereniging van Nederlandse Gemeenten, or VNG) began to lobby for a repeal of the ban on brothels on the grounds that it would make the regulation of prostitution easier (Outshoorn, 2004b, p 186).

Parallel to the industry's expansion, an active discourse on women's rights and prostitution emerged in feminist circles. Until the middle of the 1980s prostitution was the remit of the Ministry of Health and Welfare and the Ministry of Justice. This distribution of labour

79 The expansion was not confined to the cities. In many rural areas so-called 'sex farms' in converted farmhouses emerged where prostitution took place. 
represented the state's twin concerns over prostitution for most of the 20th century: sexually transmitted diseases and public order. At the beginning of the 1980s this changed drastically. In the early 1980s women's emancipation became a formal policy goal of the Dutch government. In 1977 women's emancipation was institutionalised through the creation of a dedicated secretary of state (staatssecretaris, a specialised second-tier minister who has a seat in the Dutch cabinet), and the Directorate for Coordination of Emancipation Policy (Directie Coördinatie Emancipatiebeleid, or DCE) to support the political office holder. The DCE was a department of the Ministry of Social Affairs and Labour Relations. ${ }^{80}$ With a well-established position in the institutional heart of Dutch government, and strong links to a well-organised bureaucracy, the DCE and its officials had considerable agenda-setting power. Sexual violence against women was one of the issues the directorate selected as its focus. The DCE organised the key conference on violence against women in 1982 (the so-called Kijkduin conference), and it wrote two important policy papers, one on sexual violence against women and one on the status of women, that attracted considerable attention in the media. In both policy papers prostitution and trafficking were also addressed. In addition, the DCE initiated and financed research on prostitution and trafficking, subsidised the First World Whore Congress in Amsterdam in 1985, and it funded two organisations that were to become key players in the prostitution policy network: the Rode Draad (Red Thread) and the Stichting Tegen Vrouwenhandel (Foundation against Trafficking in Women, or STV) (Outshoorn, 2004b; Haveman, 1998, p 174).

80 In addition, the government installed a permanent advisory committee for women's emancipation, the Emancipation Council, and parliament created a standing committee for emancipation policy. Women's emancipation was, thus, strongly represented in the institutional core of politics and government in the Netherlands. This rapid institutionalisation was the result of pressure by the women's movement. The social movement Man-Vrouw-Maatschappij (Man-WomanSociety, or MVM) pressured the cabinet in 1973 to create a national committee for women's emancipation. In reply to the societal pressure the cabinet created the Emancipation Committee in 1974. This was an archetypical case of a policy entrepreneur, the social movement MVM, using a policy window to advance its case. The window was created as a result of the cabinet being dominated by Social Democrats (the members of MVM had extensive contacts with the top echelons of the Social Democratic party) and the UN declaring 1975 the Year of the Woman. The Emancipation Committee formulated an emancipation agenda and created a blueprint for its institutionalisation. In 1981, it was replaced by the Emancipation Council. 
Thus, in the 1980s a new policy network around women's emancipation had emerged that was led by the DCE, and in which politicians, officials, academic experts, and advocates for and representatives of sex workers participated. The network benefited from the institutional authority and legitimacy of politicians and officials of the DCE. The DCE contributed considerable legal and procedural competence to the group, as well as access to key politicians in the Dutch cabinet and high-ranking officials in the Ministry of Justice and the Ministry of Health and Welfare (Outshoorn, 2004b, p 192). Through its position at the heart of the Dutch government it gave women's emancipation and women's rights an indisputable authority. But apart from its considerable institutional capital, to its members it presented the excitement and energy of developing new ideas and engaging in positive social action. The feminist network offered splendid opportunities for policy innovation and collective learning on the issue of how to effectuate women's rights, fight violence against women and give prostitution an accepted place in society. It was driven by the members' trust in each other, and some of the friendships that developed in those days are still at work in the current new sex workers' organisation PROUD. ${ }^{81}$

It was this network that would dominate and institutionalise the national discourse on prostitution in the 1980s and 1990s, and it was one of the driving forces behind the repeal of the ban on brothels. In the feminist debates at the administrative and political centre of Dutch national politics the issue of prostitution was subsumed under the larger debate on women's rights and the fight against sexual violence against women. ${ }^{82}$ The dominant image underlying this frame was that of the free, autonomous woman who voluntarily opted for prostitution as a job. Prostitution came to be seen in terms of work - sex work. From this framing of prostitution, an important implication followed that would be central in the design of Dutch prostitution policy until 2005: the distinction between voluntary and involuntary prostitution.

This distinction followed from the concern with trafficking that was one of the outcomes of the 1982 Kijkduin conference on sexual violence. Participants to the prostitution debate were confronted with conflicting information. On the one hand, they heard heartrending stories of victims of trafficking (predominantly from developing

81 We discuss the emergence of PROUD later in this section.

82 The DCE was, for example, active in the struggle to raise consciousness among, largely male, police officers and the judiciary that rape is a serious crime and that the way a woman dresses can never be a mitigating factor in rape. 
countries); on the other hand, they listened to emancipated, assertive Dutch women who explained why they had chosen to enter the prostitution business. As Outshoorn comments wryly, few feminists were willing to ascribe false consciousness to these women (2004b, $\mathrm{p}$ 190). In fact, the testimony of these strong, autonomous women coincided seamlessly with the discourse on female sexual agency and self-determination that was the lingua franca of the discourse on women's rights. In terms of this discourse, prostitution was seen as the private affair of free citizens - that is, as long as the exchange of sex for money is voluntary on the part of the woman, as is obviously not the case with victims of trafficking. As Haveman, a legal scholar and advocate for the decriminalisation of prostitution, wrote at the time: 'The assumption of the right to physical and psychological integrity gives women the freedom to choose for prostitution. Not prostitution as such, but coercion and violence must be combated, because these violate the integrity of prostitutes' (1998, p 175). And as long as prostitution is voluntary it must be considered work. These ideas strongly influenced the first bill on the legalisation of brothels, the so called Bill 18202 (Outshoorn, 2004b, p 190).

Thus, one of the key elements in the feminist-administrative discourse on prostitution was the distinction between 'good' or voluntary prostitution and 'bad' or forced prostitution. Irrespective of whether this distinction would hold up in practice, it came to fulfil several important functions in the development of Dutch prostitution policy in the 1980s and 1990s. One of the most important was that it bridged the cognitive dissonance between the undeniable evidence of trafficking in the wake of the expanding sex industry and the deeply entrenched emancipatory women's rights discourse in the Netherlands. But equally important was that it suggested a practical course of action that would accommodate the two contending frames of social control and women's rights. The feminist lobby put three demands on the political agenda: repealing the ban on brothels to allow for more effective regulation, providing residence permits to victims of trafficking to enable them to testify against their traffickers, and setting higher penalties for traffickers (Outshoorn, 2012, p 234). It was for this reason that the feminist debate converged with the simultaneous political debate on the legalisation of brothels.

While the feminist discourse unfolded at the national level, a parallel local discourse was developing in Dutch cities. As we saw earlier, the rapid expansion of the prostitution sector in the 1970s meant that towns and cities with a prostitution sector were confronted with the challenge of how to regulate a rapidly growing prostitution scene plus 
the associated drug crime and public nuisance that were overtaking whole neighbourhoods. Looking back on this period, several of the police officers interviewed said that they felt they had lost control of those neighbourhoods; they had to fight their way back in, as one of them put it (interviews, police officers). The members of the municipal network were the mayor, police officials and members of the office of the district attorney, usually at the municipal level. Through their contacts at the Ministry of Justice and the VNG they were firmly linked to the national power centres. The dominant frame in thinking about prostitution in the cities was one of social control rather than women's rights and self-determination. This meant that in the policy domain of prostitution two networks were active: a dominant feminist one that framed prostitution in terms of women's rights and work, and a municipal one that framed it in terms of crime and public order. The two networks employed different root images of the sex worker: respectively as an autonomous self-determining woman who chooses sex work voluntarily, and someone, possibly a victim of gross exploitation, who is part of an unlawful world of sex and crime that poses a direct threat to public order in the city. The network structure of Dutch prostitution policy before 2000 was thus decidedly disjointed, although both legs of the network were linked to the political machinery of parliament, parties and the executive.

Yet, in the Dutch consociational political culture the two networks were not wholly separated. Local officials of the large cities were regularly invited to events organised by NGOs such as the Rode Draad (interview, police officer; Wagenaar, 2006). ${ }^{83}$ The combination of a relatively favourable attitude towards prostitution among opinion makers and key national policy makers and a tradition of consultation among officials led to local policies in which it was common to deliberate with proprietors and involve NGOs and other stakeholders in policy design and implementation. The period of regulated tolerance is important for understanding the Dutch policy culture at that time.

83 For purposes of disclosure, Hendrik Wagenaar participated in several of the conferences organised by the Rode Draad in the early 2000s. In one he was a keynote speaker. At these conferences, politicians and officials, both national and local, mingled with professionals, police officers, sex workers and brothel owners. Police officials and sex workers were seen to jointly participate in panels. The atmosphere was congenial, upbeat and positive. It felt as if participants sensed they were part of a, perhaps unique, social experiment. Yet, at one of those conferences, the author spoke to a female brothel owner who already complained about what she called administrative harassment by the administration of the town where her brothel was located. A year after that, she decided to close her business. 
National law and local rules were rarely imposed unilaterally in Dutch political culture at the time. Even when a measure was clearly repressive, the affected group would be informed and consulted. Preceding the decision to abolish the ban on brothels, organisations representing sex workers, proprietors and social services were consulted by civil servants and members of parliament. By organising conferences and courses the national government created support among municipalities for the new law. At the local level the regime of regulated tolerance had created consultation channels and a modicum of trust between authorities and brothel owners. An indication of this was that proprietors formulated a covenant to keep trafficking out of their establishments, and, on the issue of a minimum client age, declared a ban for those under the age of 18. We will see later, however, that the proprietors played a duplicitous role in the implementation of the new law.

One of the problems of the policy network approach is its lack of explanatory power (John, 2012, p 74). It describes the topography of policy discourse and suggests how policy agendas and solutions are floated, but it hardly explains how policy decisions are made and outcomes realised. So it is with the networks that were involved in the repeal of the brothel ban in the Netherlands. The feminist and municipal networks were beholden to one of the most powerful practices in Dutch governance: coalition politics. Coalition politics are ruled by the principle of political rationality. The Netherlands is a republic of minorities (Andeweg and Irwin, 2002); in the proportional election system no party can ever hope to attain a parliamentary majority. Dutch politics is by definition coalition politics, and in order not to endanger the coalition, party discipline is strict during debates over political issues. However, in terms of values and competences, in this institutional landscape politicians and officials live by the principle of avoiding alienating a political opponent (as you might need him in the future to form a coalition) or riding roughshod over minorities (as you might need their vote in tight situations). The dominant competences are deliberation, negotiation and bargaining. Many generations of consociationalism - the deliberation between elites at the top end of denominational pillars - have installed an ethos in politicians that, in addition to their party, they represent the larger interest of preserving a political system that supersedes sectional interests. To make this practice of delicate balancing and compromise work, much of it takes place outside the glare of the media. ${ }^{84}$

84 The Dutch word for this kind of coalition dealing is 'backroom politics' (achterkamertjespolitiek). 
In 1983 the Liberal Minister of Justice submitted a Bill to parliament to modernise the Penal Code. This was the beginning of a long, convoluted political journey that ended in 1999 with the repeal of the ban on brothels. During the parliamentary debates in 1983, the Christian Democrats suggested doing away with the prohibition on brothels to allow municipalities a more effective regulation of prostitution (Outshoorn, 2004b, p 188). A majority supported the amendment. The Christian Democrats, who would later oppose the Bill, took a pragmatic stance: prohibiting brothels had not prevented the expansion of the sex trade; regulation promised better results. But contrary to the parties of the left, who saw prostitution as work, and the Liberals, who framed it as a gender-neutral market transaction, they persisted in framing prostitution as a moral vice and the sex worker as victim. So, three parties with wholly different understandings of prostitution, each for their own reasons, supported the repeal of the ban on brothels. The by now widely accepted distinction between voluntary and coerced prostitution had to paper over this schism. To incorporate the amendment the Bill was revised and resubmitted to parliament in 1985 as Bill 18202, the repeal of the brothel ban. The Lower House passed the Bill in 1987. Pending acceptance by the Higher Chamber the ban on brothels had in effect been repealed.

The Senate or Upper House discussed the Bill in 1989. In the Dutch parliamentary system the task of the Upper House is to review Bills on their concurrence with the constitution and with international agreements, and on their legal quality, including whether they conflict with other Bills in the body of the law. It does not have the right to amend Bills and can only pass or fail them in their entirety. The Christian Democrats in the Upper House objected to the sex work frame and wanted municipalities to have the option to refuse brothels on their territory. Other parties noticed that the way that coercion was phrased in the Bill did not correspond with the wording of trafficking in the Penal Code. In the absence of a majority, it was agreed that debate would be postponed until the new Bill on trafficking that was due in the Lower House was debated by the Upper House (Outshoorn, 2004b, p 190).

The DEC had increased awareness of trafficking and, working with sympathetic police officials and attorney generals, issued new guidelines in the fight against trafficking. In light of what is to come with regard to the debate on prostitution after 2000, it is important to make two observations at this point. First, before the commercial exploitation of prostitution was legalised, it was the feminist policy subsystem that insisted on a broadened definition of trafficking (in which trafficking 
was defined as violence, the threat of violence, and deceit in the recruitment of women for prostitution) and to raise the penalties for this offence. This was meant to provide a legal foundation to the allimportant distinction between voluntary and coerced prostitution, which was at the heart of the legalisation of brothels. Second, the same policy term can have widely different meanings in different networks/ discourses. In the feminist-municipal policy networks of the 1980s trafficking was framed as a threat to a business that was defined by voluntary prostitution by autonomous women who exerted their right to sexual and occupational self-determination. In the 2000s trafficking became the symbol for a failed policy and a morally corrupt activity in which debased men impose their perverse desires on powerless female victims. It requires no explanation that these different imageries suggest different policy measures. ${ }^{85}$ In the 1980 s politicians, officials and feminists were in agreement about the need for a reformulated trafficking Bill as an instrument in the regulation of prostitution. As a majority supported the proposal the Bill was revised to incorporate the legalisation of sex facilities. The revision, which was submitted in 1985, contained all the well-known elements and arguments that support the Dutch legalisation approach.

Central to the Bill was the distinction between forced and voluntary prostitution. The latter should be regarded as work. Two important expectations were attached to the sex work frame. Defining prostitution as work would enable administrators to integrate the sex trade into the legal/fiscal/administrative framework that regulates the small business sector in the Netherlands. Barring certain peculiarities (such as the constitutional stipulation that women cannot be held by an employer to provide sexual services), prostitution would in principle not differ from other small business sectors such as hospitality or hairdressing businesses. In fact, by lifting the prohibition on running a sex facility, local authorities could employ the full range of legal and policy instruments - issuing licenses, prescribing opening hours, regulating fire hazards, setting health standards and improving labour conditions - to 'normalise' the prostitution business. The second expectation was that by making the business 'transparent' it would be easier to crack down on forced prostitution and maintain public order in the cities.

85 Outshoorn observes that earlier representations of the sex worker included the victim of poverty, the 'fallen' woman and the psychiatrically disturbed woman. The essential difference between these and the image of victims of trafficking is that in the former cases sex workers were not criminalised and never lost their civil rights (2012, p 234). 
With hindsight this was an ambitious programme; indeed, it widely exceeded the more modest goal of legalising sex facilities. And because it fitted so well with the wider Dutch tradition of approaching moral issues in a pragmatic, 'realistic' way, few people in 1985 questioned the policy theory that underpinned the legalisation effort. The Bill communicated that prostitution was seen as an undeniable, enduring element of urban life that is best accepted and regulated so that the safety of sex workers and the quality of life of inner-city neighbourhoods are protected. Outshoorn provides a quote from the Liberal Minister of Justice from a speech before parliament at the time that captures all the assumptions and expectations that surrounded the legalisation Bill:

\begin{abstract}
"Prostitution has existed for a long time and will continue to do so. This requires a realistic approach on the part of the government ... prohibition is not the way to proceed ... but one should allow for voluntary prostitution. The authorities can then regulate prostitution and the prostitution sector. It can then become healthy, safe, transparent, and cleansed from criminal side-effects." (Cited in Outshoorn, 2004b, p 185)
\end{abstract}

The Liberal Minister of Justice introduced the Bill (Bill 21027) in 1988. It contained a more workable definition of trafficking that focused on coercion, higher penalties and increased services for victims. When Bill 21027 was finally discussed in 1992 the political landscape had changed. This would have dire consequences for the legalisation of brothels. One of the central elements of parliamentary practices is that certain actors possess veto power. Actors with veto power can block policy. This gives them strong bargaining power and the capacity to shape policy compared with actors who do not have such power (Tsebelis, 2002; John, 2012, p 36). In general, parliamentary actors have veto power where, for example, the members of the feminist network do not. But within parliament some actors have more veto power than others. In the Dutch postwar political landscape, the Christian Democrats held a pivotal position. As the largest party they could either govern with the left or the right. The new Christian Democratic Minister of Justice was, both ideologically and personally, a staunch opponent of prostitution. When he introduced Bill 21027 to the Lower House in 1992 he had radically changed its character. The purpose of the Bill was to clarify the definition of trafficking. But in a highly unusual move the minister put the decriminalisation of the commercial exploitation of the sex 
trade, ${ }^{86}$ which had been agreed by the Lower House in 1988, back in the draft of the trafficking Bill. This was unusual because first, the Bill was not labelled a Bill against trafficking but a Bill to repeal the ban on brothels. He reintroduced among other things the constitutionally dubious freedom of municipalities not to allow brothels within their boundaries. Second, the minister merged immigration policy with prostitution policy. Whereas in the original Bill trafficking was defined as coercion, in the new Bill this principle, and the adjacent distinction between voluntary and coerced prostitution, had been abandoned for women from outside the EU. Recruiting women from outside the EU to work in prostitution, as well as working as a non-EU resident in the sex trade, are considered criminal offences. The Penal Code was in fact used as an instrument for immigration policy. The opposition to the Bill was fierce. However, it became clear from the Christian Democratic spokesmen that opponents feared uncontrolled flows of prostitutes to the Netherlands. The explanatory memorandum that accompanied the Bill declared that one of its aims was to stop 'the stream of foreign prostitutes' (Outshoorn, 2012, p 236). The old stigma raised its head again. And although the Social Democratic party was unhappy with the Bill, in the end it voted with its Christian Democratic coalition partner and the Bill passed through the Lower House.

This was not the end of the story. By then the issue of the legalisation of the commercial exploitation of prostitution, seen by most actors involved in prostitution policy as a means for more effective regulation, was firmly in the hand of the legislature. Bill 21027 moved to the Upper House in 1993 where the critique was extensive and severe. The Christian Democrats always wanted Christian-dominated municipalities to have the freedom to prohibit prostitution within their borders. The Bill had a clause that gave municipalities considerable discretion in regulating prostitution. They had three options: to license brothels (for voluntary prostitution), to prohibit all prostitution, or to prohibit unlicensed prostitution. This would create three types of municipality when it came to prostitution policy. The Senate concluded that this created various insurmountable legal issues. Constitutionally, by handing over discretionary power to municipalities to declare unlicensed commercial exploitation of prostitution a crime, violated both the Gemeentewet, the law that regulates the relationship between the national and municipal governments, and the Penal Code. Criminal law is national and never territorial (Haveman and Wijers, 1993, p 31).

86 This was possible because the legalisation Bill, although passed by the Lower House, had not yet been approved by the Upper House, as explained earlier. 
As the same behaviour could be declared criminal in one municipality and legal in a neighbouring one, criminal law experts feared that the law would be unenforceable. More generally, the Upper House was very critical that the Criminal Code was being used for immigration policy, and feared that the unintended consequence of the trafficking clause, whose purpose it was to protect vulnerable women from developing countries, would push these women into illegal prostitution (Haveman and Wijers, 1993). And, finally, senators found it unacceptable that the minister had reintroduced a ban on brothels when the Lower House had already repealed the brothel ban (Outshoorn, 2004b, p 194).

In Chapter Two we listed morality politics as an obstacle to adequate policymaking in the case of prostitution policy. The story of Bill 21027 demonstrates two examples of the effect of moralism on policymaking. First, prohibitionist, ideological zeal blinds authorities. Prohibitionism leads its proponents to deliberate attempts to move policy towards the limits of what is legally acceptable - and beyond - and results in technically deficient law- and policymaking. We saw examples of this in the case of Utrecht in Chapter Three, and we will see more such examples in the new national prostitution law discussed later in this section. Second, and somewhat related to the first effect, authorities may engage in abrupt policy changes. In the case of Bill 21027 the minister had no adequate answers to the Senate's objections. When the Upper House threatened to fail both the original Bill 18202 (the repeal of the brothel ban) and the new trafficking Bill (Bill 21027), he withdrew the first and took the offending articles out of the second. The result was that, after the parliament had voted for the legalisation of brothels, legalisation was vetoed nevertheless through an unprecedented parliamentary backdoor manoeuvre.

But the parliamentary veto did not mean that the legalisation of brothels was off the agenda. The feminist and municipal lobbies, each for its own reasons, remained active in pushing for a repeal of the brothel ban. The large cities began to anticipate the repeal by setting standards for brothels under the regulated tolerance regime. In 1994 coalition politics opened a new policy window. A new cabinet without Christian Democrats, consisting of a majority coalition of Social Democrats and two Liberal parties, drafted a new Bill that contained most of the elements of the original repeal Bill 18202. ${ }^{87}$ The Bill was introduced in the Lower House in 1997, and it was passed in 1999. Lawmakers expected that turning voluntary prostitution into work would lead

87 This was the first time since 1918 that religious parties were not part of the coalition (Outshoorn, 2012, p 235). 
to the normalisation and better control of the sex trade. However, the euphoria among sex worker advocates and progressive politicians over this political victory concealed considerable opposition to the legalisation of the sex trade. The vote was neatly split between religious and secular parties. The Christian parties stuck to their abolitionist position and could count on solid support from religious media and church-based organisations (Outshoorn, 2012, p 235). It would not require much additional opposition to the legalised sex trade for the repeal of the ban on brothels to be threatened. That opposition was not long in coming. Almost immediately after the Bill came into effect in 2000, developments would disprove the ideals and expectations of the supporters of the repeal.

\section{The return to (semi-)prohibition}

When the Dutch parliament enacted the repeal of the brothel ban, most actors, as well as national and international observers, saw it as a landmark in the struggle for a more effective and humane regulation of prostitution - or, alternatively, a deplorable symbol of misguided permissiveness. Yet, by 2000 the policy networks that were involved in the design of prostitution policy had undergone a significant shift. The institutionalisation of women's emancipation in the Dutch executive had turned out to be remarkably fragile. One reason for this was that the various agencies and advisory bodies saw it as their task to coordinate emancipation policy across the other ministries. In the siloed structure of Dutch national government this put the issue of emancipation at an immediate disadvantage - something of an afterthought compared with core issues such as education, social affairs, or defence policy. In 1986 the office of secretary of state for emancipation was abolished; its remit now belonged to the Minister of Social Affairs. By way of compensation a Ministerial Committee for Emancipation Policy, chaired by the Prime Minister, was created as a subcommittee of the Ministerial Council, the highest policymaking body in the country, consisting of ministers and secretaries of state. In 1991 the committee was abolished again. In 1994 the standing committee followed, and in 1997 the Emancipation Council was disbanded (Outshoorn and Swiebel, 1998). Early 2000 women's emancipation had become a peripheral issue in Dutch national governance. The feminist network, so important in putting and keeping the issue of sex worker rights on the political agenda and for designing the legal-technical instruments to effect these rights, had disintegrated and lost its institutional hold inside the Dutch executive. What was left were the municipal network 
and the perennial practice of coalition politics. This shift in the political equilibrium would have profound effects on the formation of Dutch prostitution politics after 2000 .

The repeal had always been controversial. It had only passed parliament because the Christian Democrats had been left out of the governing coalition. It is little wonder therefore, as Outshoorn observes, that the debate about the expected effects of the repeal started immediately (2012, p 237). The Research Agency of the Ministry of Justice, the Centre for Scientific Research and Documentation (WODC), conducted an evaluation of the repeal in 2001-02. Although it was too premature to make any conclusive statements, the general conclusion was that the effects of the law on the licensed prostitution sector were moderately positive (Daalder, 2002). Interviews with police officials in those days confirmed this guarded conclusion. A police official in a region in the eastern part of the Netherlands declared that despite much talk about "displacement effects" (prostitution moving from the licensed to the unlicensed sector) he had encountered very few instances of this so far (interview, police official, 2003). This echoed the mood among municipal officials who implemented the law, most large cities and towns began to implement the repeal with hopes to create a clean, well-controlled prostitution sector. The escort sector seemed to be thriving, but because it was not location-bound, little was known about it at the time. The National Rapporteur reported an increase in trafficking from 284 cases in 2001 to 909 in 2009, but that was largely because of the broadening of the definition in 2005 and the inclusion of trafficking in other industries besides prostitution. What changed was initially not so much the reality on the ground, but the discourse about prostitution.

The first shot in what would become a publicity war around prostitution came from an unexpected angle. In 2005, Karina Schaapman, a Social Democratic member of the Amsterdam city council and former sex worker, published a policy report for her party (with her colleague Amma Asante, also a councillor for the Social Democrats) in which she denounced prostitution in general and the legalisation of brothels in particular (Asante and Schaapman, 2005). It is easy to dismiss the report for its tendentious reasoning and its use of fabricated numbers, but its real impact was in resetting the tenor of the national debate on prostitution and its influence of the national leadership of the Social Democratic party. The rhetoric was one of rape, abuse, slavery and sex addiction. No self-respecting woman would voluntarily enter the sex trade; sex workers were pressured into it because of drug addiction, debts or childhood sexual abuse. To visit 
a sex worker was 'not normal', and clients were despicable men who were acting out their 'sex addiction' (Asante and Schaapman, 2005). In effect, Schaapman introduced the angry, emotional, ad hominem, no-holds-barred rhetoric of radical feminism that had poisoned the negotiations around the UN Protocol to Prevent, Suppress and Punish Trafficking in Persons, Especially Women and Children (see Chapter Two). This represented a significant change in the Dutch prostitution debate. So far the debate between proponents and opponents of the legalisation of brothels had taken place within the confines of Dutch coalition politics. According to the political rationality of coalition politics, this automatically imposed some constraints on the rhetorical amplitude of the exchange of opinion. Schaapman's book and reports took the debate out of the coalition arena, set new standards of what is permissible and acceptable in the public discussion, and introduced the unbridgeable ideological divide between prostitution as work and prostitution as, by definition, coerced and illicit. The immediate effect of Schaapman's report was that it convinced the powerful Amsterdam alderman Lodewijk Asscher (Social Democrat) and a number of Social Democratic members of the national parliament to take up the fight against prostitution (see also Weitzer, 2012, p 160).

A second strand in the national discourse was the moral panic around 'loverboys'. A moral panic may be defined as 'an episode, often triggered by alarming media stories and reinforced by reactive laws and public policy, of exaggerated or misdirected public concern, anxiety, fear, or anger over a perceived threat to social order' (Krinsky, 2013, p 1; see also Cohen, 2011). Moral panics are constructed by the media and have a clearly recognisable pattern in which they build up from early anxiety to a crescendo and then fade away again. The 'loverboy' panic started in 1995 when, in a trafficking case that involved adolescent girls and young Dutch-Moroccan men, the alleged victims, to the bafflement of the authorities, protected the defendants and declared to have engaged in prostitution out of love for them. ${ }^{88}$ Sporadic media reports followed in which young girls were portrayed as being preyed

88 Details of the loverboy hype are from http://sekswerkerfgoed.nl/loverboys-eenernstig-probleem-een-hype-of-allebei.. The term 'loverboy' is pseudo-English that is used only in some continental countries The overheated discursive climate around prostitution has given rise to several short, sharp moral panics, such as the one about 'Breezer sletjes' (Breezer sluts), young girls at sex parties in ethnic minority areas who, according to social workers' reports, 'sold' sexual favours for a Breezer, a low-alcohol drink. Another such case involved men who had paid sex with mentally handicapped girls, a spurious claim that even made it into parliamentary debates (Outshoorn, 2012, p 240). 
on by handsome young men from ethnic minority groups. By 2000 the loverboy phenomenon had taken on the proportions of media hype. The organisation Child Right estimated that there were 9,000 female and 6,000 male victims of loverboys. Experts pontificated on television about the causes of the phenomenon, television broadcasted shocking documentaries, and youth service agencies were spurred into designing information and prevention programmes. The apex of the moral panic was a book by one of the alleged victims that sold over 200,000 copies nationally (Mosterd, 2008). The author appeared on countless television shows, until her book was exposed as a fraud, after which the hype quickly subsided. A more measured report by the criminologist Bovenkerk and colleagues concluded that loverboys were a modern incarnation of the traditional pimp and that the phenomenon had been overstated. However, the report also concluded that the legalisation of brothels had not eradicated pimping from the licensed sector (Bovenkerk et al, 2006).

By 2005 a veritable media industry had emerged around the issue of prostitution. Prostitution was invariably depicted as associated with organised crime, sex workers were seen as victims, and prostitution as an unstoppable 'tsunami' that had washed over the Netherlands. Newspapers featured lurid stories of sex and violence, and the favoured trope was the melodramatic story that was seen as representative of the whole industry (Vance, 2011; Goraj, 2012). The message that was repeated over and over again was that the legalisation policy had failed and that it had in fact generated massive amounts of trafficking. ${ }^{89}$ The media gave ample coverage to a new network that consisted of prohibitionist activists made up of parliamentarians of the Social Democratic and the small Christian fundamentalist parties (and their ever-present spokesman Gert-Jan Segers), the aforementioned alderman and later Minister of Social Affairs, Asscher, radical feminists, and journalists from the orthodox Christian broadcasting network Evangelische Omroep (Evangelical Broadcasting). Members of the network had easy access to the media, and used the strident rhetorical

89 By way of illustration of the mood of the times, in 2004 journalists of what was then one of the more serious television new shows approached Hendrik Wagenaar. They wanted to do an item on the effects of the repeal of the brothel ban. In the preliminary conversation about the item the programme makers declared that they wanted to demonstrate that the legalisation policy had failed. Wagenaar said that under those conditions he did not see a valid reason to participate. The programme makers assured him that the programme would give a fair hearing to all points of view. Needless to say, when the programme was aired it turned out be a diatribe against legalisation and the author's more nuanced statements were not included. 
tools that had been introduced by the Schaapman report: fabricated numbers, presented as 'scientific', that suggested a prostitution sector out of control; highly charged, emotional language; and personal attacks on the proponents of legalisation, including suggestions that they were paid by traffickers or pimps. Network members also organised prohibitionist conferences and a 'scientific fact-finding mission' to Sweden to study the successful model of client criminalisation. ${ }^{90}$ It was in this discursive environment that the Sneep case hit the headlines.

We described this case of trafficking in the licensed prostitution sector in Chapter Three; here we focus on its discursive effects. Analysts from the National Police Force reconstructed the case to examine how it had unfolded. Their conclusion was no surprise to students of public administration: there had been little coordination of the activities of the agencies and actors involved with prostitution. Each had picked up signs of coercion but each failed to act on the signals for fear of jeopardising its own interests (KLPD, 2008, pp 104-10). The media focused mainly on one statistic that had been quoted by police officials, plus the conclusion of the report. The statistic that was repeated over and over again by the major actors of the prohibitionist network was that 'between 50 and 90 per cent' of sex workers who worked behind the windows in Amsterdam were 'forced' to do so. The conclusion was that: 'It is an illusion that a clean, normal sector has emerged' (KLPD, 2008, p 8). By 2008 the discursive consensus in the Netherlands was clear: the legalisation of brothels had failed. It was time to formulate a new national prostitution law. In the public consciousness prostitution was framed in terms of vulnerable eastern European women who were the victims of ruthless Turkish or Balkan traffickers. A Christian Democratic parliamentarian summarised the mood of the time: "The romantic expectations about the repeal of the ban on brothels in 2000 had led to nothing" (cited in Outshoorn, 2012, p 240).

While the media wars picked up steam, other, less visible, developments quietly undermined the official goals of the 2000 legalisation of brothels. The purpose of the 2000 decision to repeal the brothel ban was to decriminalise prostitution by removing the sale of sexual services and its management from the Penal Code and transform what was traditionally a market that operated in the shadows into a regular business sector regulated by labour law, administrative law,

90 This trip, which was made by a Christian fundamentalist and Social Democratic member of parliament and received intense coverage in the media, was paid for by the orthodox Christian broadcasting station Evangelische Omroep. This fact was conveniently left out of the media reports of the trip. 
immigration law, the tax code and local health and safety regulations. This did not materialise, because three different legal and administrative measures proved to be the undoing of the goals of the repeal of the ban on brothels.

Apart from a concern over vulnerable sex workers from Asian and Latin American countries, the issue of immigration was low on the agenda of the feminist network that ushered in the repeal of the ban on brothels. But immigration was intertwined with prostitution from the start. In debates in parliament the Christian Democratic Party had repeatedly expressed concerns that the tolerant Dutch prostitution regime would attract foreign women to work as sex workers in the Netherlands. This resulted in members of parliament formulating amendments to the repeal of the ban on brothels that made it illegal for sex workers from outside the EU or EEA, that is, European Economic Area countries to work in the Netherlands. As we have already seen this affected hundreds of women, but more important perhaps is that labour law was used to bar foreign sex workers from the Dutch market. From the start of the new tolerant regime, banning migrants became the unofficial policy of Dutch prostitution law. Many of the national laws that had a remit for prostitution were laws that regulated work undertaken by non-EU nationals (Wet Arbeid Vreemdelingen, Law Regulating Work for Aliens) or were intended to combat trafficking (Mensenhandelartikel 250a Wetboek van Strafrecht, Criminal Code Trafficking Clause). At the same time licensing laws in combination with mandatory identification requirements that had been extended in 2005 to everyone residing in the Netherlands, including sex workers, ${ }^{91}$ made it almost impossible for persons without legal papers to work within the licensed sector of the prostitution market. Similar to Austria, laws and regulations aimed at migrants had a profound effect on the design and implementation of prostitution policy. This was partly the result of a sharp increase in labour migration after the 2004 expansion of the EU, when women (and men) from eastern European countries came to work in the sex industry in the affluent countries of northwestern Europe, and partly the effect of a renewed emphasis on law and order, both nationally and internationally, in the political debate on issues of crime and safety in the Netherlands. Another factor was stigma, with the attendant fear of contamination and uncontrolled expansion of the sex trade. Moreover, and again similar to the situation in Austria, rules and regulations pertaining to immigrants are changed

91 Since 2005, everyone residing in the Netherlands is obliged to carry an identification card or passport. 
more easily and are less bound by administrative ethos than regulation in other domains. Both Dutch and Austrian governmental agencies issued rulings that changed the status of migrant sex workers overnight. We will return to the confluence of prostitution, immigration and the fight against trafficking in the next chapter.

It is important to mention two additional national laws that were applied to prostitution and had the effect of undoing the goals and spirit of the 2000 legalisation. The first is the so called 'opting-in' arrangement. Although the improvement of the position of sex workers was an official goal of the repeal of the ban on brothels, the Dutch government considered labour relations to be an issue that belonged to civil law and something to be arranged between proprietors and sex workers without interference from the government. The government argued that, similar to other business sectors, labour rights in the area of prostitution should be negotiated between employers and organised labour. Although legally correct, this was a naive position. There was no sex workers' union in the Netherlands at the time. In the early 2000s Dutch sex worker activists attempted to establish a union, the Dutch Federation of National Unions was willing to take on the cause of sex workers. However, very few sex workers signed up as members of the fledgling union and the effort was abandoned. The absence of organised representation for sex workers allowed proprietors in the Netherlands to frustrate the introduction of adequate labour contracts and work conditions in their facilities.

While the Ministry of Social Affairs and Labour Relations declined to get involved in regulating the sex trade, the tax office took the issue of labour relations on board through its attempts to design a proper fiscal regime for brothels and sex workers. After several attempts to settle the issue that foundered on the organised resistance of brothel owners, it came up with the so-called opting-in arrangement. The opting-in arrangement allows the wage-tax regime to be applied to those whose working conditions are not governed by conventional labour relations between employer and employee. The sex worker and the proprietor must apply for the opting-in arrangement at the tax office. The money that goes towards taxes is deducted before the owner pays the sex worker. The sex worker does not pay social security and neither can she claim the social protection rights that are connected with employment. In order to safeguard sex workers' rights, a 'package' of conditions was included. This concerned the right of sex workers to set their own working hours, to wear clothing of their own choosing, to refuse clients and certain sexual acts, to refuse to drink with clients, and to get a receipt for income earned. There was 
also an agreement relieving the sex worker of any obligation to hand over a percentage of earnings for unspecified 'services' to the owner. This 'package' was meant to remedy a flaw in the system. The optingin system was originally designed for workers without conventional labour rights, such as preachers or pastors hired by religious institutions, writers paid by publishers, and members of local councils. It was never intended to be used by brothel owners to exercise authority over sex workers. However, from the diary entries (see the Appendix) and the interviews that informed our research, as well as reports from the Rode Draad (2012), we conclude that most brothel owners tend to violate the conditions of the package with the exception perhaps of sex workers' rights to refuse alcoholic drinks and to choose their own clothing. While well intentioned, the opting-in arrangement also had the unintended effect of removing the issue of labour rights from the political agenda. With the imprimatur of the tax office, sex workers were now officially regarded as self-employed.

The third national law that undermined the goals of the repeal of the ban on brothels was the so-called Wet Bibob, or Integrity Assessment Act, that we encountered in Chapter Three. The purpose of the law is to assess the integrity of the proprietors of certain 'sensitive' business sectors such as brothels, gaming parlours, bars, and public contracts over $€ 200,000$. By combining a number of large databases, a national agency assesses the source of financing, the transparency of management and the integrity of the owner's business partners. The owner has the right to view and appeal his file only after his application for a license has been refused. The Wet Bibob is the result of a 1996 parliamentary inquiry into new ways to fight organised crime. In fact it grants all municipalities in the Netherlands the right to initiate criminal investigations into any business registered within their district limits. If there is any suspicion of involvement in criminal activities (and just being befriended by someone who has been convicted for crimes can be sufficient grounds for suspicion), the permit of the business is withdrawn, forcing its closure. Soon after its implementation in 2003, the municipality of Amsterdam deployed a Bibob procedure to shut down the glamorous high-class brothel Yab Yum. For years, the municipality had tried to close this brothel because of its ties with the Hells Angels motorbike club, which was at the time prosecuted for suspected involvement in organised crime. Although the then Social Democratic mayor Job Cohen portrayed the successful Bibob procedure as a legal victory, some prominent legal experts were critical. They argued that the law fundamentally reverses the burden of proof (as suspicion forms the basis of legal action). The Wet Bibob has been 
used by some municipalities, such as Amsterdam and Alkmaar, to refuse owners of window facilities or clubs permission to renew their license. In this way, and by buying up buildings with a prostitution license, the city of Amsterdam closed down 100 of its windows between 2006 and 2012 (Volkskrant, 29 May 2012). It is unclear, however, how successful this authoritative instrument is. Soon after his inauguration, the current mayor of Amsterdam, Eberhard van der Laan, initiated a series of Bibob investigations of brothels in the red-light district. None of these investigations found suspicions of criminal activities. However, the Bibob procedure in combination with administrative measures (bestuurlijke maatregel - see Chapter Three) have been used effectively to downsize the prostitution business in some cities.

When in 2007 a new coalition of Christian Democrats, Social Democrats and a small Christian Fundamentalist party was formed, the issue of a new national prostitution law to reverse the legalisation of brothels was back on the agenda. A Bill was introduced to parliament in November 2009, called the Law for the Regulation of Prostitution and Suppression of Abuse in the Sex Industry, or Wrp (Bill 32211). The Bill in fact reversed the decriminalisation impetus of 2000 by designing a law that was specifically targeted at prostitution. As the title of the Bill indicates, its major aim is to intensify regulation to fight trafficking, crime and abuse in the sex trade. To this end the Bill proposed the scaling-up of several policy instruments that were already popular in the 'enforcement arrangements' that most municipalities had introduced over the years: licensing or prohibition of various forms of prostitution (most municipalities opted for disallowing home prostitution), raising the age for sex work to 21 years, the creation of exit programmes, a national registration system for sex workers (with penalties for sex workers who failed to register) and penalties for clients who solicited unregistered sex workers. In many ways the new national law represented the codification of developments at the local level. The cornerstone of the Bill was the proposed national registration system. The Bill was based on an image of comprehensive control. As the Minister of Justice (Liberal) declared: "By the introduction of a compulsory licensing system in combination with compulsory registration and the national register of escort services, an almost closed administrative system is erected that can improve the fight against abuses in the sex industry and the judicial suppression of forced prostitution" (cited in Outshoorn, 2012, p 241). The law led to much critique by NGOs of the privacy risks of the proposed registration and the unenforceability of the limited client criminalisation aspects, and had a negative reception from the Raad van State, the country's legal advisory 
institution that assesses the quality of new legislation. Nevertheless the Lower House adopted the law. The law encountered opposition in the Senate, however. The government introduced some changes, but on 30 October 2012 the Senate rejected the law, mostly because of concern about the privacy aspects of the proposed registration system.

When on 28 May 2013 the Dutch Upper Chamber rejected a new version of the Wrp once again (on similar grounds of violation of privacy rules and for reasons of unenforceability) national prostitution policy had reached an impasse. The cities were furious that their efforts at registering sex workers has been frustrated by the rejection of national law (source: email from Platform 31 to Hendrik Wagenaar). At that point there was a remarkable development: local policy makers began to work in concert with national policy makers to implement a policy that was far more regressive than anything that had been seen so far. The format was the 'enforcement arrangements' that were already in place in most cities, but the spirit was blatantly abolitionist: the removal, or at least, reduction of prostitution from Dutch cities. The mechanism to realise this programme was a model General Local Ordinance developed by the VNG.

On 1 March 2014, the Minister of Justice submitted a revised draft of the national law to the Lower Chamber. ${ }^{92}$ It contained a range of measures that, taken together, would alter the landscape of prostitution by creating a series of far-reaching powers for municipalities to constrain sex work. One of the most important elements of the proposal was to make home prostitution impossible. Through the rise of the internet, home prostitution, or working in a small collective of sex workers, has become an attractive alternative to working for a third party. By legally defining the home as a 'sex facility' (similar to large sex clubs, escort agencies or window brothels), independent sex workers who chose to work from home are subject to the same, expensive and extended, procedures to obtain a license, and must comply with the same health and safety regulations, and monitoring and inspection procedures, as large facilities. Moreover, obtaining a license requires that the name and address of the sex worker is publicly available, that the license is entered into a national register and that it is visible on the façade of the building where she works. This combination of rules makes it de facto impossible for home workers to start a business. ${ }^{93}$ Moreover, as

92 The following section has benefited from letters and unpublished documents from Marjan Wijers, Laurens Buijs and Esther Verrips.

93 The official criterion for being designated as a business is 'operating like a business' (bedriffsmatig werken). The criteria are very broad, however. Advertising (on the internet for example) is already an indicator for 'operating like a business'. 
the proposed law makes unlicensed prostitution punishable (with a maximum of six months in prison or a fine), the sex worker is forced to work for an established proprietor. For the first time in more than a century the proposal criminalises sex workers in the Netherlands. The clients of 'unlicensed sex workers' are also criminalised and face a large fine. The law has also extended the powers of local authorities to enter premises, including private homes, without the permission of the residents if they have a 'reasonable suspicion' that unlicensed prostitution is taking place. This opens the door for arbitrary behaviour, as a number of recent incidents confirm. ${ }^{94}$ Finally, the proposal aims to reduce the number of work sites for prostitution. The law has increased the powers of municipalities to refuse a license to a new sex facility. Traditionally the only ground for refusal, apart from the criminal antecedents of the proprietor and not meeting health and safety standards, was in cases where the sex facility is in an area subject to zoning. Changing zoning is a long and tedious procedure that involves approval by the municipal council. In the proposal licenses can also be refused on grounds of 'public order' or 'housing and living environment', designations that can be established by officials without democratic approval. The law also makes it possible for municipalities to ban prostitution altogether. Taken together the expectation is that the number of work sites will shrink.

That this is not just speculation has been proven by subsequent developments. Emboldened by the proposal for the new national law and the radical closure of Utrechts's prostitution zone, several cities (Amsterdam, Alkmaar, Groningen) have announced the closure of large numbers of window brothels. In Amsterdam the red-light district is part of a large urban renewal project that aims to attract more tourists through hotel construction and the gentrification of the inner-city area. If the closures go ahead, prostitution will have to be removed

94 In the town of Alkmaar at 6 am, officials from the Department of Construction and Housing, accompanied by police officials, entered the houses of a number of foreign sex workers who legally worked in the local window area. The sex workers had to provide personal information (for example, about boyfriends who lived there or visited them) and their personal address in their country of origin. The sex workers were very upset as in most cases their families back home did not know that they worked in the prostitution sector. In another town a sex worker (a taxpayer) tried to register as such; shortly thereafter her home was invaded by six police officers (source: letter from M. van den Burg to members of the Standing Committee for Security and Justice of the Lower House, protesting against the WPG). 
from these areas. In the meantime the $\mathrm{VNG}$, in anticipation of the new law, has formulated a model General Local Ordinance (APV) for prostitution. In addition to the elements already discussed, it has added some of its own. In particular it obliges proprietors to conduct an intake with every sex worker who wants to work in his or her establishment. The purpose of the intake is to establish that the sex worker has not been forced or exploited. To this end the proprietor needs to establish if the sex worker is zelfredzaam, a term that is difficult to translate but that evokes 'independency'. The sex worker needs to be able to communicate with proprietors, inspectors and clients. To this end the proprietor may subject the sex worker to an official language test. The APV formulates a wide range of other stipulations regarding business administration of the sex worker and the proprietor and the management of the brothel. The upshot of these measures is that the sex worker is now wholly dependent on the proprietor if she wants to work.

\section{National policy in Austria}

As in many European countries prostitution is more or less accepted as part of the social landscape in Austria. This does not mean that sex workers have the same rights or enjoy citizenship to the same extent as other citizens. The pervasive stigma that rests on prostitution makes itself felt in the way that prostitution laws are formulated and in the design and implementation of administrative measures that aim to regulate the sex trade. Similar to the Netherlands, much of this regulation is not very effective, and has been designed and implemented without the necessary regard for the human and civil rights of sex workers. The goal of containing and controlling prostitution pervades every aspect of the political-legal-administrative system in Austria. This makes Austria, like the Netherlands, a fascinating example of a larger pattern: even countries where prostitution is legalised and that uphold the rule of law and values of fairness, equality and justice in relations between citizens and the state, show little compunction in suspending these values when it comes to the treatment of sex workers. This infringement of rights seems to be accepted as an inevitable byproduct of regulation that is designed to control prostitution, despite politicians' official rhetoric of protecting the position and circumstances of a vulnerable group. We illustrate this by looking in more detail at four areas of law and the regulation of prostitution in Austria: the legal status of prostitution as 'against morals', compulsory checks for sexually transmitted disease (STD), the tax regime for sex workers and their 
access to Austrian social security programmes, and immigration law as it pertains to migrant sex workers. But before we do this, we describe the policy network that is involved in prostitution policy.

Austria is a federal state, in which the nine Länder have considerable autonomous decision-making power. In domains such as education, welfare, and also prostitution, policies with national import are largely shaped by regional governments. The most important legal change regarding prostitution policy came along with a major amendment of the Criminal Law of 1975. Within this framework each province has introduced its own legislation regarding the regulation of prostitution. This major change we take as the starting point to describe the social and policy environment in Austria in general and Vienna in particular.

Similar to the Netherlands, Austria has an active, progressive and well-institutionalised women's policy that has gradually developed since the 1970s. In the period of the Social Democratic government under the legendary chancellor Bruno Kreisky (1970-83), not only was Criminal Law amended but also the Family Law and the Civil Code. For the first time in Austria's history (1975) women achieved legal equality with men and were no longer subordinated to their husbands. Although it was only recently that a Ministry of Women's Affairs was established, a State Secretary for Women's Affairs was introduced in 1979 and finally a Minister for Women's Affairs (within the Federal Chancellery), in 1990. On the regional level, a Women's Department of the city of Vienna followed in 1992. The institutionalisation of women's policy was a result of the growing pressure of the second feminist movement that demanded gender equality, the representation of women in politics and also the consideration of the gender-specific effects of policies. Further milestones in achieving gender equality were set in the field of employment and the domestic sphere. For example, in close cooperation with feminist groups, Austria has developed and implemented one of the first and still one of the best violence protection laws (1997) in Europe (Dearing and Haller, 2005).

With regard to prostitution several conferences about sexual violence were held at the national level in which prostitution and trafficking were important topics. These conferences were organised to coincide with the world women's conference in Beijing in 1995. The Minister for Women's Affairs and the Viennese Women's Department have been active in a number of areas such as financing research on prostitution and NGOs working in the field of sex work. Furthermore, in 2001 the Viennese Women's Department, together with NGOs LEFÖ/Tampep and MILENA, and with the cooperation of La Strada (based in Prague), organised a seminar on prostitution as a transnational phenomenon in 
Prague. Similar to the Netherlands, a densely interconnected policy subsystem around the issue of prostitution emerged in Austria in the 1980s. Feminists, both in an advocacy role and in institutional positions that extended deep into the political sphere and the government bureaucracy, played an important role in this subsystem. Members of the subsystem promoted progressive prostitution policies and the acceptance of prostitution as work, while acknowledging the risks of trafficking.

The institutionalisation of prostitution as a policy domain led to a flurry of legislative activity in Austria. In the 1990s the federal government established a task force on human trafficking led by the Ministry for European and International Affairs and composed of various ministries and institutions at the regional level as well as NGOs. The task force recommended a review of prostitution legislation. It also promoted the development of legislation for workplace safety and social security in prostitution. This eventually resulted in the first National Action Plan against human trafficking in 2007 and 2008. This recommendation was informed by the insight that the sex trade would not vanish with prohibition and that working conditions can only be influenced with legalisation. Subsequently, under the guidance of the women's section at the Federal Chancellery, experts developed a comprehensive catalogue of measures (ExpertInnenkreis Prostitution, 2008), among them the establishment of a working group that deals with regulations at the level of the Länder. This working group, Länderkompetenzen Prostitution, ${ }^{95}$ was finally installed in 2009 within the framework of a task force on human trafficking (AG Länderkompetenzen Prostitution, 2012, p 4 onwards). The federal working group, chaired by the Ministry of Education and Women's Affairs (now the Ministry of Health and Women's Affairs), consists of representatives of the Länder administration, police forces, health offices, NGOs and an academic expert in prostitution. ${ }^{96}$ Sex workers and sex worker organisations have not yet been appointed to the working group. The group's main task is the review of the diverse regulations concerning prostitution and their effects on working conditions. The discussions in the working group - it meets twice a year - are summarised in periodical reports that aim to support regional and

95 In 2015 the working group was renamed Arbeitsgruppe Prostitution (Prostitution Working Group).

96 So far the position of academic expert has been held by Helga Amesberger. 
local politicians in their decisions. ${ }^{97}$ Although the positions towards prostitution are not uniform within the working group, a general agreement about a regulative and decriminalising approach exists. The working group also took a firm position against the legal ban on the purchase of sexual services and against the punishment of clients (AG Prostitution, 2014).

NGOs working in the field of prostitution always had and still have an important role in the national and regional public discourse. In the 1990s the NGOs, especially LEFÖ and several others that no longer exist, ${ }^{98}$ always acted from a perspective that defines prostitution as a service profession..$^{99}$ Not all Länder have NGOs specialised in sex work. Most of these NGOs live a precarious existence as they are financially dependent on the public sector. In Vienna the situation for both NGOs, LEFÖ and SOPHIE, temporarily improved with the implementation of the new Prostitution Act, but they have been affected by budget cuts again since then. With the expansion of outreach work and counselling programmes these NGOs have obtained financial contracts with the city of Vienna.

Alliances of feminist groups and sex worker initiatives emerged from time to time in Vienna in the 1980s, but they did not last long. The sex worker initiatives themselves were short-lived. One example is a protest involving sex workers who operated the self-organised brothel Weinstock in Vienna. As police repression got more severe in the early 1980s they wrote a pamphlet protesting against the marriage prohibition for sex workers, paternalism in the sex trade and other harassments. ${ }^{100}$

97 Two reports have been published so far; see AG Länderkompetenzen Prostitution (2012) and AG Prostitution (2015).

98 For instance Lilith, which wanted to enhance the communication among sex workers and between sex workers and non-sex workers. It was the successor project of Schlußstrich, an EU-funded project that did not gain enough funding to continue (Amesberger et al, 1999, p 70 onwards).

99 At the end of 1990s the NGOs maiz and LENA were founded in Oberösterreich; in the 2000s there followed SOPHIE in Vienna, SXA-Info (information and counselling for sex workers and multipliers) in Styria, Caritas in Carinthia, Frau \& Arbeit in Salzburg and iBus in Tyrol. This list is not complete. There are some departments within organisations that offer counselling for sex workers and do outreach work; some are connected with churches. The Sexworker-Forum für professionelle Sexarbeit has special status - it is primarily an internet platform, which nevertheless provides, besides information, support for sex workers. It is financially independent (source: interview, Christian Knappik). This forum is hardly acknowledged by the authorities as a stakeholder/representative of sex workers.

100 The building in which the brothel was located was bought by the city of Vienna and afterwards demolished in March 1981. This meant the end of this sex worker initiative. 
At the same time another initiative launched by a group of 13 Viennese sex workers demanded the abolition of prohibition zones and the legalisation of street prostitution and hour hotels (Gassenstrich and Stundenhotels) as well as self-governed brothels (Waldenberg, 2012, p 116 onwards). In 1986, to give another example, Ms Eva founded the Association of Austrian Prostitutes (Verband der Prostituierten Österreichs, or VdPÖ) as reaction to the three-year retrospective taxation of sex workers. ${ }^{101}$ The VdPÖ launched an extensive catalogue of demands requesting improvements in tax law and health provisions as well as measures against the discrimination of sex workers, such as the repeal of the occupational ban in certain fields for former sex workers, the abolition of registration and the decriminalisation of sex work (Neuweg, 1990, p 80 onwards; Waldenberg, 2012, p 120 onwards). Waldenberg concluded that the VdPÖ acted more like a union - it did not offer counselling in areas such as AIDS/HIV or exit programmes - and this might have been the reason for it not being awarded state funds (for counselling or meeting rooms, for example) (Waldenberg, 2012, p 124).

Since the 1990s self-organisation has decreased, although in Vienna the Initiative for Whores (Initiative für Huren) campaigned against the expansion of prohibition zones. This group also submitted a petition to political representatives of the city of Vienna, which politicians declined to accept. Nevertheless, a loose coalition of sex worker initiatives, feminists and NGOs that denounced the moral double standard with regard to prostitution generated enough political pressure for sex workers to gain access to national insurance (AG Länderkompetenzen Prostitution, 2012, p 4). In 2005, an online forum - the Sex Worker Forum - was established to represent the interests of sex workers in Austria: ' $[\mathrm{t}]$ he Forum works to protect and to promote the human rights of adult women, men and transgender persons in voluntary sex work' (Sex Worker Forum Austria, 2013, p 3). It is a platform for those seeking to improve their life and working conditions and a forum for exchange and networking. Its main political aims are complete equality of prostitution with other occupations, the decriminalisation of the entire sector and the abolishment of compulsory registration and health checks for sex workers (Amesberger et al, in press).

101 The association had a branch in Innsbruck (Tyrol) and in Vienna. The association's newspaper Horizontal was published four times a year. In 1989 it had 28 members. Non-sex workers could be members of the VdPÖ but were not entitled to vote (Neuweg, 1990, p 80 onwards) It is not known how long this association existed. 
This brief historical retrospective serves to illustrate that a rich substratum of sex worker advocacy organisations and NGOs exists in Austria, and in its capital Vienna in particular, keeping sex worker rights on the political agenda. However, similar to the Netherlands, this discourse of labour rights and decriminalisation of the sex trade has increasingly lost out against the abolitionist discourse of trafficking. As a result most sex workers' demands still have not been met by Austrian/Viennese prostitution policies; in fact since the early 1990s the situation of sex workers situation has worsened in several respects.

In the 2000s the Viennese parliament frequently debated prostitution. The political discourse, like the public one, was marked by heated debates. The fragile consensus of the 1980s and 1990s that had framed prostitution as an issue of sex worker rights had disintegrated by then. In Vienna, too, prostitution had acquired all the characteristics of morality politics. Politicians of all parties (except for the Greens and the LIF ${ }^{102}$ ), the media and various civil society stakeholders exerted considerable political pressure in favour of accepting the abolitionist trafficking agenda. One indication of this, among others, is that between April 2004 and June 2011 (when the WPG 2011 was accepted by the Viennese government) prostitution and human trafficking in relation to prostitution were addressed 29 times in the Viennese parliament. The framing of the political discourse in Vienna (and the rest of Austria) had evident regressive tendencies, demonstrating themes and patterns that were common in the 19th century. ${ }^{103}$ Prostitution was once again regarded as a threat to public order, morals, public health and minors. With the influx of migrant sex workers from eastern Europe, the discourse became ethnicised and the already previously existing polarisation between 'good', registered, and 'bad', illegal, sex workers deepened (El-Nagashi, 2010). At the same time the discourse somehow lost its gender dimension; prostitution was described as something that is unrelated to gendered labour market positions and inequality. Consequently, policies were primarily focused on the reduction of prostitution, especially of visible prostitution, as we saw in the preceding chapter.

In the 1990s, prostitution was partially framed as a social problem, a matter of poverty. Therefore, counselling, harm reduction and assistance to quit sex work, as well as the improvement of working conditions, and social rights, were considered effective means of problem resolution.

${ }^{102}$ LIF - Liberales Forum (Liberal Forum). The party does not exist anymore.

103 The description of the discursive frames in Austria follows largely the analysis by Amesberger et al, in press. 
Nevertheless, '[w]hile this frame gained some importance in the period leading up to the partial inclusion of sex workers in the social security system in 1997, it was never particularly strong and has been rather de-articulated since then' (Amesberger et al, in press). The same befell the prostitution-is-work frame, which has been promoted by counselling services for sex workers since the 1990s. Although this discourse never gained much power, the lobbying for the recognition of sex work as a deliberatively chosen occupation by these NGOs was important insofar as it kept alive the decriminalisation track in prostitution policy (Amesberger, 2014, p 224). The sex work frame was overpowered, however, by the discourse of human trafficking and forced prostitution. The focus on problem resolution shifted towards persecuting traffickers and reducing illegal immigration and away from harm reduction and support for victims of human trafficking. The discourse about prostitution has become re-gendered in the past few years by defining prostitution as male violence. Since 2010, a small feminist group supported by several Christian NGOs like Solwodi and Herzwerk have campaigned for a prohibition of sex purchase and the introduction of the Nordic model of client criminalisation. ${ }^{104}$

As Hrzeniak and colleagues (2007) have shown for Austria and Hamen (2011) for Oberösterreich, different frames are tied to different political parties but elements of various frames are found within all political parties. In Vienna, too, prostitution is discussed in connection with criminality (coercion, illegality, human trafficking and drugs) and as a threat to juveniles and to the moral order. This kind of discourse is mainly led by the right-wing populist Freedom Party and People's Party and to a lesser extent by the Social Democrats. As everywhere else, this 'criminalisation frame' propagates both the criminalisation and victimisation of the sex workers. The Social Democrats promote the view that prostitution is a manifestation of our patriarchal system; here again the sex worker is seen as a victim. The Green Party pursues an approach that emphasises the socioeconomic situation and human rights of sex workers. ${ }^{105}$ As in the Netherlands, the media play an important role in fuelling the political und public discourse in general and the criminalisation frame in particular. By way of illustration, in 2011 alone at least 80 articles in the national daily newspapers dealt with the issue of prostitution. Trafficking of women in sexual

${ }^{104}$ See www.stoppsexkauf.at.

105 This summary description of the political parliamentary discourse in Vienna is based on the analysis of of the minutes of the Viennese State Legislative Assembly (Landtag) and the city council (Gemeinderat) (2001-11). 
exploitation, forced prostitution and street-based sex work were their main concerns. Opponents of street prostitution areas (residents and business managers) often succeeded in promoting their views via these newspapers and local TV programmes.

\section{'Against good morals'}

In 1975 prostitution was removed from criminal law, which regulated prostitution, pimping and client punishment. The background to this measure was that the Constitutional Court regarded police discretion in enforcing the vagrancy law as unconstitutional and its consequences as inequitable (Sauer, 2003, p 12). Similar to the Netherlands, prostitution is now within the remit of civil and administrative law and regional and local administrative ordinances and bylaws. The highly regulatory character of Austrian prostitution policies is reflected in the multitude of specific regulations for sex workers within the Civil Code, alien police law, income tax law, immigration police law, AIDS law, STD law and the National Insurance Act, to name the most important ones. In addition, criminal law still specifies several offences related to prostitution. ${ }^{106}$

The majority of the criminal offences that are delineated in Austrian criminal law aim to protect sexual integrity and sexual selfdetermination; a few are related to the restriction of liberty. It is not the single offences and regulations that are of interest here, but the intentions of the legislator, which disclose political values and attitudes towards prostitution and the framing of prostitution and sex workers. Criminal law expert, Lyane Sautner, identifies three major objectives in Austrian prostitution law: the protection of juveniles, the protection of sex workers against (structural) disadvantages, and the prevention of adults from entering prostitution (Sautner, 2012, p 6 onwards). The legislation considers juveniles and sex workers especially worthy of protection as prostitution touches on sensitive areas of sexual integrity, freedom of will and property. At the same time, by declaring 'leading

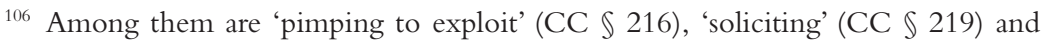
'illicit sexual acts in public' (CC $\$ 218$ ), which are liable to prosecution under the Penal Code. Trade in prostitution across the borders is also subject to penalty (CC $\$ 217)$. On other words, it is illegal for a sex worker to cross the border with the client. Trafficking in women - into prostitution and into other forms of coerced labour - is punished according to the Austrian Penal Code (CC \$ 104a). The 1975 legalisation of prostitution concerned only heterosexual prostitution; same-sex prostitution remained a criminal offense (CC \$ 210) until 1989 (Sautner, 2012, p 2). 
into prostitution' ('Zuführen zur Prostitution', CC \215) a felony, the law discourages prostituting oneself. The conclusion is that the state considers prostitution socially undesirable. Moreover, the law is paternalistic towards women and it stigmatises and limits the liberty of sex workers (Sautner, 2012, p 7). In the remainder of this section we discuss the ways in which it does this.

Although prostitution is no longer a criminal offence, in 1989 the Supreme Court of Justice defined it as 'sittenwidrig' - 'against good morals' (OGH 28.06.1989, 3 Ob 516/89). ${ }^{107}$ This had far-reaching consequences for sex workers, because, although legal in a formal sense, prostitution could for this reason never be a legally recognised occupation that for example granted the right to enter a contract (such as a labour contract with a proprietor) or other workers' rights. This made the position of sex workers in Austria very ambivalent. The Supreme Court of Justice provided several justifications for its decision. Prostitution is inherently against morals because it occurs in a situation where male clients are inherently weak-willed, often drunk and overcome by lust. Moreover, families need to be protected against the effects of prostitution, as it promotes adultery. In general, the Sittenwidrigkeits clause was meant to impede the commercialisation of sex (Marktler, 2012, p 15 onwards). These arguments illustrate how gender and the red-light 'milieu' are socially constructed. Prostitution is considered a danger for irrational, instinct-driven men and their families, and the sex trade is criminalised as it allegedly takes advantage of the client's weaknesses. Contrary to the aforementioned intentions of criminal provisions relating to prostitution, for the Supreme Court of Justice it is the client and the family as an institution that have to be protected, not the sex worker.

In April 2012 the Supreme Court of Justice unexpectedly removed the Sittenwidrigkeits clause (Oberste Gerechtshof, $3 \mathrm{Ob} 45 / 12 \mathrm{~g}$ ). With this reversal of its earlier position the court acknowledged the inconsistency of the former decision. It emphasised that prostitution is allowed in Austria and sufficiently regulated in specific prostitution laws at the provincial level. The court also disagreed with the previously stated need for the protection of clients and the family and declared sex workers a vulnerable group that requires protection by the law. In its decision the court also clearly stated that the Sittenwidrigkeits clause had weakened the position of the sex worker. So far the consequences for the prostitution field cannot be overseen. The removal of the

107 Austria is not an exception in this; prostitution was also sittenwidrig in Germany and Switzerland. 
Sittenwidrigkeits clause has so far not been integrated into labour or trade law, and it seems unlikely that this will happen anytime soon. Although the repeal was the outcome of a claim in which the Supreme Court had to prove whether the demand for payment of delivered sexual services opposed the Sittenwidrigkeits clause (Marktler, 2012, p 17), there are no indications, and it seems in fact quite unlikely (as we will see later in the discussion about the inclusion of prostitution in the national insurance system) that prostitution will be recognised as work.

\section{Compulsory STD checks}

Austria's national policy has a strong regulatory dimension with an emphasis on public order, public health and fiscal compliance. Compulsory STD checks are one of the longest-standing policy instruments in Austria for controlling sex workers. The discourse about compulsory health checks is fierce, and as we show in the following discussion, it is a prime example of the pervasive effects of stigma and the gendered nature of policymaking in this domain. Compulsory STD checks were introduced in Vienna in the middle of the 19th century - at the time, twice weekly. This temporary measure for preventing the spread of syphilis became, as Sabitzer (2000) puts it, a permanent condition. This regional regulation was adopted nationwide in a decree from 1918 and has remained in force with few changes since (Amesberger, 2016, p 178). Female sex workers can only work when they carry a booklet that states that they passed the STD check. As of January 2016 a decree has been issued that reduces the frequency of the STD checks to once every six weeks. ${ }^{108}$ The requirement for sex workers to provide medical proof of being free from STDs before commencing sex work remained unchanged, along with the ban on providing sexual services if a sex worker has symptoms of STD.

Control through public health measures, in conjunction with registration, is a central element of Austrian prostitution policy. Austria is one of the few countries in the world that sticks to compulsory STD checks (Jahnsen and Wagenaar, in press). Yet historically there has also been strong opposition to compulsory medical investigations (see, for example, Schlesinger, 1868; Grün, 1907). At the beginning of the 20 th century, in an early intuition of the working of morality politics, the Viennese medical doctor Heinrich Grün expressed his anger that every layperson, every doctor or non-doctor, teacher, priest, politician,

${ }^{108}$ Medical tests for syphilis and HIV have to be repeated every third month. Some provinces additionally demand checks for tuberculosis. 
police officer or suffragette, intervenes in the discussion out of moral indignation but without any knowledge of the subject (1907, p 2). It outraged him because the discourse had an impact on the choice of regulation. Today the issue of compulsory health checks is as alive as it was in fin-de-siècle Vienna. During the research interviews for this book, one of the authors (Amesberger) was often astonished by officials' visceral defence of compulsory STD checks. Whether police officers, administrators or politicians, they all considered the abolition to be to the detriment of migrant, poorly educated, sex workers. The discussions within the federal working group on prostitution also displayed the controversial nature of this topic. Whereas service providers advocate voluntary STD checks of good quality and free of charge, members of police and administration insist on maintaining their compulsory nature (AG Prostitution, 2015, p 36), often with a frequency that makes no medical sense.

The stalemate over compulsory STD checks suggests that issues other than the health of sex workers or the public are at stake. At least three characteristics of morality politics are at work here. First, although the underlying ideology is not overt in this discourse, the debate is a manifestation of the struggle over the (female) body. It is not by accident that compulsory STD checks became a popular form of regulation in the middle of the 19th century. Foucault describes in a ground-breaking work that the body became the focus of scientific and political interest in the 18th century (1983, p 95 onwards). He names four powerful strategic complexes - four specific 'dispositifs' of knowledge and power - that emerged in the realm of sex at this time and were used as a form of social control through societal institutions. ${ }^{109}$ With this transformation (supported by medicine, biology, pedagogy and other fields), sex became an affair of the state, a concern for the entire social body. According to this genealogy compulsory, STD checks can therefore be considered a form of social control over the female body and female sexuality. Second, moral policy is lay policy. As discussed earlier, anyone may claim to be well informed and to have an opinion on the subject and the solution. Third, morality politics ignores evidence. Although the preface of the draft regulation states that scientific medical standards should be met, the legislator ignores empirical research that shows low STD infection rates among

109 These four mechanisms comprised a rendering of the female body as hysterical; a pedagogic interest in children's sexuality; the socialisation of reproductive behavior; and a psychologising of perverse lust. 
sex workers and suggests adverse effects stemming from compulsory STD checks.

Furthermore, the social construction of sex workers has changed little since the 19th century. Grün already denounces the construction of prostitutes as 'fallen girls' who are either too lazy to work or naïve and uneducated and therefore prone to seduction. He ascribes these collective images as a lack of knowledge about the socioeconomic conditions that support prostitution. He also states that clients are released from liability. In today's discussion remarkably similar images abound. While at the time of Heinrich Grün it was the poor, innocent, naïve, uneducated migrant girl from the countryside, now it is the poor, uneducated migrant girl from abroad (primarily from Romania and Bulgaria and from Roma communities). Proponents think that compulsory STD checks are necessary because migrant sex workers are assumed to have scant knowledge about health protection and because too many would be willing to provide unprotected sexual services on the request of clients or brothel managers. Opponents consider compulsory STD checks to be a violation of human rights and a measure that contributes to the stigmatisation of sex workers, as it fosters the assumption that they are endangering public health. ${ }^{110}$ Furthermore, compulsory STD checks are deemed counterproductive: on the one hand, clients feel that it is safe to ask for unprotected sex, and on the other hand, such an obligation undermines the personal responsibility of both clients and sex workers.

The formulation and implementation of the law concerning compulsory STD checks tell us a lot about political culture in Austria with regard to prostitution policy. Like the repeal of the Sittenwidrigkeits clause, the new decree on compulsory STD checks took many by surprise. Although for about five years there had been infrequent meetings to discuss the issue at the Ministry of Health, an amendment of the regulation seemed far off. In 2014, the Viennese outpatient clinic prepared a proposal for new regulations that it sought to discuss with the federal working group on prostitution before submitting it to the Ministry of Health. It is not known whether such a proposal was ever submitted. However, in May 2015 the Ministry of Health published a draft regulation for review by the wider public. The working group had not been consulted about the new law, but at the invitation of the group's chairperson, the draft was presented by a

110 The Sexworker Forum submitted a complaint to the UN High Commissioner for Human Rights with regard to discrimination against sex workers in terms of rights to work and to health (28 June 2013). 
member of the ministry. But neither the subsequent discussion, nor the written statement by the working group and the statements of others involved in the review process (that all raised, among others, concerns about the feasibility of the regulation) led to substantial changes to the draft. This short description of the process depicts again the absence of a willingness to cooperate with others outside of a small and tight circle of officials. A political culture of cross-sectional collaboration and knowledge exchange still seems to be at best in its infancy in the Austrian regulatory process with regard to prostitution. With regard to implementation of the new rules the ministry sought cooperation with members of the working group on prostitution, who were invited to speak at a seminar for public health officers. It became evident that the public health officers felt quite unprepared for their new information tasks - during the first medical investigation, they would have to inform attendees not only about protection measures concerning STDs and pregnancy but also about counselling and support services for sex workers. Outreach workers and counselling services indeed report that sex workers are not at all informed about the new regulation and the effect it will have. ${ }^{111}$

\section{Fiscal law}

The history of taxation of sex workers and their inclusion in the social security regime in Austria is another example of the absence of implementation design with all the attendant consequences regarding equal treatment, and of a lack of collaboration at all stages from law formulation to implementation. It is also demonstrates that such failures almost always have a negative effect on the position and rights of sex workers. Since 1983 sex workers have had to pay taxes, for which purposes they are administratively categorised as independent contractors. Since 1998 they have also been eligible for some social security programmes. Depending on their income, sex workers have to pay income tax and value added tax. Above a certain income threshold it is mandatory to be insured through the social security system for private enterprises (health, accident and pension insurance). ${ }^{112}$ Irrespective of level of income, self-employed people must still register with the SVA

111 Source: personal conversation with members of the prostitution working group.

112 All self-employed people come under the remit of the Social Insurance Authority for Business (SVA). Insurance is only compulsory in cases where income is more than $€ 5,000$ per year. Sex workers who earn less than this may opt in to the SVA insurance scheme, but will only be insured against illness and accident. 
within one month. ${ }^{113}$ Insurance cover for health and accidents starts at the moment of registration, or the beginning of self-employment, whichever comes first. ${ }^{114}$ The opt-in system does not cover pensions insurance. This was the law until July 2014; implementation of the law varied greatly among the Länder and even the districts.

Until then the fiscal authorities considered sex workers (including those working in clubs/brothels) predominantly as "newly selfemployed' (Neue Selbständige), who either registered themselves at the local fiscal office or paid a flat tax of between $€ 250$ and $€ 350$ per month via the sex facility manager. The flat tax model was introduced because of problems with assessing sex workers' incomes and because of sex workers' resistance to these assessments. ${ }^{115}$ It was an easy and efficient way to collect taxes that did not require many resources from the tax offices: the brothel owner was held responsible; the tax office had to administer only one rather than multiple tax accounts (depending on the number of sex workers working in an establishment); and there were no complicated and lengthy procedures. One of the great advantages of devolving tax collection to proprietors was that it guaranteed that more mobile migrant sex workers paid taxes. For those sex workers who had a net income above $€ 1,800$ per month, as well as for those who did not want to bother with bookkeeping and income declarations, this type of tax collection was advantageous too. This is one side of the coin.

The other side is that the flat tax lacked legal foundation, which led to its abolishment in July 2014. Moreover, the flat tax was an example of a 'postcode regulation' - in other words, sex workers were taxed according to where they worked. Moreover, the lump sum itself varied from province to province (between $€ 250$ and $€ 350$ per month) and only a few tax offices agreed to a reduction in cases of part-time work. NGOs reported that the flat tax model caused some tax offices to refuse to register sex workers individually, a right that was guaranteed only with the support of an NGO. This flat tax system made sex workers wholly dependent on the proprietor in their fiscal dealings with the

113 According to verbal information from the SVA (27 January 2011), although freelancers are exempted from paying for insurance if they earn less than $€ 5,000$, they must nevertheless register with the SVA.

${ }^{114}$ It is not known how many sex workers obtain social insurance. Inquiries at the SVA revealed only low numbers. It is assumed that the majority of sex workers mention other professions (such as masseuse or dancer) when they apply for insurance.

115 As described earlier, the sex worker organization VdPÖ protested against the arbitrary income assessment that was driven by the myth of exorbitant earnings in the sex industry. 
state. Proprietors collected the money but sex workers had no proof that they had transferred it. Moreover, sex workers paying the flat tax did not have personal tax accounts and so were unable to prove their yearly income, something that is a precondition for renting a flat, obtaining credit or - and this is relevant for migrant sex workers receiving permanent residency in Austria. All these aspects resulted in considerable unequal treatment of sex workers by authorities.

Convenience trumped legality, but because of the unlawful implementation of the tax law and because of the fact that some work relations in brothels resembled dependent employment, the Ministry of Finance eventually released a decree that listed a number of criteria for assessing work relationships as dependent or self-employed. ${ }^{116}$ To summarise a complex set of laws and regulations, when the tax office considers work relations to be 'dependent', the employer pays social security contributions in respect of the employee's wages. In fact, in practice the sex worker pays the contributions, without gaining much advantage, as the contributions only generate limited entitlement to benefits. The only advantage is that the sex worker is insured against illness and disability and builds up a pension. But 'regular' employees also have the right to paid sick leave and paid holidays. Almost all proprietors circumvent these rights (source: interview with NGO). The dependent employment decree was unilaterally developed without consultation with experts in the field of prostitution. It is not surprising that it was widely criticised for its adverse effects on sex workers. Brothel managers pass on all social security contributions to the sex workers, so their income is considerably reduced. It is common practice for proprietors to withhold client payments from the sex worker until all taxes and contributions are covered. As taxes have to be paid in advance at the beginning of the month, sex workers who want to change their workplace have to stay at their current establishment for the whole month in order to avoid paying tax twice.

With the annulment of the Sittenwidrigkeits clause, secure employment contracts for sex workers became theoretically possible. The dependent employment decree seemed to acknowledge this development. However, in autumn 2015 the Ministry of Labour, Social Affairs and Consumer Protection published a draft amendment to the national Social Law (SRÄG) that stipulated that sex workers were to be explicitly excluded from General Social Security (ASVG) even when the tax office classified the work relationship as dependent. According to the legislator, inclusion in the ASVG would contradict Article 8

${ }^{116}$ Decree BMF-010203/0243-VI/B/2014. 
of the European Convention on Human Rights (the 'right to respect for private and family life'). The right to sexual self-determination contained within Article 8 was considered incompatible with dependent employment. ${ }^{117}$ The draft amendment drew considerable criticism from a wide range of actors. ${ }^{118}$ The consensus was that the exclusion of sex workers from the ASVG would contradict the principle of equal treatment, would therefore be discriminatory and would have serious detrimental effects for sex workers. Furthermore, sexual self-determination is protected by the Austrian criminal law, while the employer's right to give instruction is also restricted in other occupations, such as judges. This unanimous reaction led the executive to withdraw the proposal.

This short overview of fiscal and employment law regarding sex workers once again demonstrates that administrative agencies regularly violate the rights of sex workers when applying administrative regulations. Perhaps the most distressing aspects of this are the habitual ease with which sex workers' needs and rights are overlooked and the fact that the uncertainty and impairment that are caused by these rules and their implementation would be widely considered unacceptable with any other occupational group.

\section{Immigration law}

As in most European countries, prostitution regulation in Austria is strongly shaped by immigration laws. In 2013 about 95\% of registered sex workers in Vienna were migrants (source: Viennese Police Directorate). With respect to the right of residency and work Austrian immigration law distinguishes three groups of non-EU nationals: citizens of the European Economic Area (EEA), non-EEA citizens, and asylum seekers. EEA citizens have the right to take up residence

117 169/ME XXV. GP; see "Explanations to the Ministerial Draft "SozialrechtsÄnderungsgesetz 2015”, , p 7 onwards (https://www.parlament.gv.at/PAKT/VHG/ XXV/ME/ME_00169/fname_480262.pdf). Dutch brothel owners also used this article, rather self-servingly, to argue against labour contracts with the attendant social security contributions.

118 Among them are counselling services for sex workers (LEFÖ, LENA), legal experts from university departments, the Austrian Association of Female Lawyers, the City of Vienna and Carinthian Government, the Klagsverband zur Durchsetzung der Rechte von Diskriminierungsopfern (Association of NGOs Against Discrimination) and the Federal Chamber of Labour. It is interesting that the Austrian Trade Union Federation did not comment on the exclusion of sex workers from the ASVG. All reviews on the SRÄG are accessible at https://www. parlament.gv.at/PAKT/VHG/XXV/ME/ME_00169/index.shtml. 
and, similar to EU citizens, have full access to the labour market. They can work in paid employment and work as a self-employed person or freelancer - also as a sex worker. For the citizens of those member states that accessed the European Union in May 2004 and January 2007 access to the labour market in Austria was restricted to a sevenyear period, and they could only work as self-employed persons. ${ }^{119}$ Non-EEA citizens who want to work as prostitutes in Austria need a specific visa according to the Alien Police Law. ${ }^{120}$ Such a visa can be issued for self-employment or employment, but only for three to six months within a 12-month period. These visas are very hard to obtain and are the only opportunity for non-EEA-citizens to enter Austria. Since 2003, asylum seekers have been able to work as self-employed sex workers after a period of three months from applying for asylum.

Although immigration law is for the largest part not specifically directed at sex workers, it nevertheless affects the sex trade in Austria. As immigration law determines who has access to the Austrian labour market, changes in the law are immediately reflected in the national composition of migrant sex workers. A few figures by way of illustration: in 2006, half of Viennese sex workers came from one of the EU-25 countries (those that accessed the EU in 2004); in 2012 this number dropped to 38\%. Sex workers from EU-27 countries (including those in the $2007 \mathrm{EU}$ accession) constituted only $2 \%$ of all Viennese sex workers in 2006 and 45\% in 2012, suggesting a large influx of Romanian and Bulgarian citizens in the Viennese sex trade. ${ }^{121}$ These numbers indicate that sex work is an entrance door for low-wage female migrants who do not have full access to the Austrian labour market. The effects of immigration law are also reflected in the number of 'third-country' members: only seven of 100 sex workers belong to this group, whereas 83 of 100 are members of states that accessed the EU in 2004 or 2007. For the first group the Austrian labour market is de facto closed (Amesberger, 2014, p 157). The possibility for asylum seekers also to work in the field of prostitution frequently raises concerns, as it is believed (not evidenced) that many are victims of

119 Those countries gaining accession to the EU on 1 May 2004 were Hungary, Czech Republic, Slovakia, Estonia, Latvia, Lithuania, Slovenia, Poland, Cyprus and Malta (Malta and Cyprus were not subject to a transitional period for free movement). Bulgaria and Romania accessed the EU on 1 January 2007. Citizens of the former group gained full access to the labour market in May 2011, and those of the latter states obtained full access in January 2014.

120 This law came into force on 1 January 2006.

121 A detailed statistical analysis of the Austrian sex market is provided in Amesberger, 2014, ch IV.4. 
trafficking (ExpertInnenkreis Prostitution im Rahmen der Task Force Menschenhandel, 2008, p 46; interviews; media reports). According to the Viennese police $1.9 \%$ of Viennese sex workers are asylum seekers, mostly Nigerian citizens.

Immigration law and its implementation also affect the mobility of sex workers and often induce mobility. Dora, whose story opens this book, expresses this aspect of the immigrant sex worker's life when she says: "You go to bed with one law and wake up with another." She referred to the abolishment of the aforementioned "prostitution visa', which rendered all sex workers with such a visa illegal overnight. Another example is an EU regulation covering 'third-country' nationals with a Schengen visa in Vienna, which stipulates that such persons are allowed to stay for three months in another EU country but must not work there. Nevertheless, the Viennese police did not apply this regulation until spring 2012. ${ }^{122}$ The new rulings restrict the work possibilities of non-EU nationals in the sex trade. Although EU citizens who are sex workers have a less vulnerable position with regard to working and residency rights, their legal status is nevertheless weak. To give an example, in cooperation with the police the city of Salzburg developed a 'concept' stating that sex workers who have received three police reports because of illegal prostitution will be deported to their home countries when caught a fourth time. This measure was deemed necessary for the protection of public health, according to the vice-mayor of the city (Ruep, 2015). In fact, it is an experiment to contain illegal street prostitution on one neighbourhood of the city by way of forced mobility. Dora's observation about overnight changes in the law is still valid.

\section{Conclusion}

In Chapter Three we argued that, from a practice perspective, the common distinction between central and local policymaking does not hold up. Local government is only subordinate to central lawmaking institutions in the eyes of national politicians and of journalists who are traditionally focused on national politics. Instead, as we argued, the actors who are involved in prostitution policy, their ideas, understandings and actions, overlap to the point that it is hard to disentangle national policy decisions from local policy initiatives and

122 This is another instance of postcode law: according to NGOs working in other Austrian provinces this regulation is not applied outside Vienna. 
implementation. According to Peter John, this insight holds across other policy areas as well:

(T)here is a tradition going back to the mid-nineteenth century tradition of Parliament simply reproducing in common form what local authorities are already doing ... (T)here is an informal network of decision makers operating across central and local government where many actors influence decision making. Ideas and influence circulate among the different bodies that have an input into policy by virtue of their role in the implementation of decisions. (John, 2012, pp 43-44)

While John's observation relates to the UK, the previous chapters show that it is equally applicable to the continental democracies of Austria and the Netherlands.

Both countries have pursued an approach to prostitution policy that, on the surface at least, can be characterised as pragmatic (Sullivan, 2010, p 104; Outshoorn, 2001, p 476). Pragmatism is an attitude towards the governance of morally contested issues in which the societal outcomes of policy interventions are weighed against moral principle and principle is overruled when outcomes are deemed negative. This results in the position that criminalising prostitution would it make more difficult to control, would drain resources away from other more pressing enforcement areas, and would be detrimental to the position of sex workers. Pragmatism leads to harm reduction policies, for example. Pragmatism was also the underlying principle of the Dutch policy of regulated tolerance, in which authorities considered the price of enforcing the prohibition on brothels as greater than entering into an informal agreement with brothel owners to regulate the sex trade. The problem with pragmatism, as these chapters show, is that it is not immune to the corrosive effects of the pervading stigmatisation of prostitution. In both the Netherlands and Austria, stigma eventually undermined whatever pragmatist or idealist ambitions existed in prostitution policy and both countries reverted once more to a repressive stance towards prostitution that aims at control and abatement. We saw in Chapter Three that, on the level of policy implementation, agency capture and an aggregation of small, instrumental measures and local bylaws gradually shifted the implementation of national prostitution law away from its original goals towards an outright repressive stance. But what are the mechanisms that push national policy from its initial legalising goals towards a much more repressive outcome? 
The formulation and adoption of national law is the result of coalition politics - coalitions of stakeholders within, between and outside parties. Groups of stakeholders, loosely organised in networks of more or less likeminded actors, develop and try out ideas and solutions. Key players, often those who occupy veto points, introduce these ideas in parliament. Based on the composition of parliament, a winning majority for a particular proposal is more or less likely. In this sense national policymaking is remarkably fragile. The Dutch example both shows how a law can pass the legislature and afterwards still be defeated by deft political manoeuvring, or conversely, how a sudden parliamentary majority opens the way for the repeal of the ban on brothels. However, the adoption of a law says little about its acceptance in society, or the larger political and administrative community. The New Zealand Prostitution Reform Act of 2003 was passed with a razor-thin majority of one vote. Nevertheless the decriminalisation of prostitution has since then been accepted by the public, the media and the political and administrative community in New Zealand. In Vienna and the Netherlands more comfortable parliamentary majorities for the legalisation of the commercial exploitation of prostitution were reversed at both the administrative and legal level.

The first factor in the lack of acceptance of a more normalised position of prostitution in society is discourse. While in New Zealand prostitution is discussed in the media and in political forums in pragmatic and reasonable terms, in Austria and the Netherlands the national discourse has become virulently abolitionist. In fact, national and local policymaking were linked by a dominant discourse of prostitution as trafficking and inherently coerced and by an urge to control and contain a stigmatised activity. Although both countries have made prostitution and its commercial exploitation legal, after decades of legalisation prostitution is still discursively, morally and emotionally connected with criminality, human trafficking and ethnically charged images of migrant victims (and perpetrators). Despite an official rhetoric of transforming prostitution into a regular business sector and protecting and improving the civil and labour rights of sex workers, prostitution is still subjected to special, sector-specific laws and regulations whose explicit aim is to control an activity that is thought to be out of control or forever threatening to veer out of control. Thus, Sullivan's observations about Australian prostitution policy have a much wider resonance. She argues that legalisation is accompanied by a: 
... deep and ongoing 'social ambivalence' towards both prostitution and all parties who participate in selling and buying prostitution services ... so legal brothels are operated by 'mainstream' business people but are not treated as 'mainstream' businesses. Sex workers are also not treated like 'normal' workers (this is particularly evident in the requirements for health examinations). (Sullivan, 2010, p 103)

This unequal treatment and social ambivalence is reflected in the full panoply of constituents of public policy, from legal regulations, their justifications and underlying problem definitions, to the implementation of the law and choice of policy instruments, the selection of implementing agencies, and the ideas and intrinsic values that suffuse all of these. This ambivalence about prostitution, expressed in a dominant discourse of prostitution as crime and trafficking, explains how two countries with two different national legal and administrative traditions, both of which have legalised prostitution and its commercial exploitation, have ended up with by and large identical repressive policies.

Discourse paves the way for an important mechanism that complements the regulatory drift and agency capture that operate at the level of policy implementation. At the national level the sex trade is shaped as much, or perhaps even more, by laws that are tangential to prostitution as by laws that are specifically directed at it. In both Austria and the Netherlands immigration law, labour law and fiscal law have determined the legality of (certain forms of) prostitution for certain national groups, the type of labour arrangement, the locations that are available for work, the level of earnings, and the possibilities for social mobility. Public health laws in Austria have singled out sex workers as an increased risk and subjected them to unnecessarily frequent STD testing. Moreover, these laws, in place since the mid-19th century, have proved remarkably resistant to change, even in the face of medical evidence contesting their effectiveness, suggesting that they are to be regarded more a measure of control than as a public health measure. Austrian fiscal law provides similar inconsistencies. While prostitution is legally considered to be 'against good morals', preventing sex workers from entering into contracts, this has not deterred the tax office from bringing sex workers into the fiscal framework of the Austrian welfare state. In the Netherlands a law that governs the collection of data on taxes, social security and criminal justice was used to limit the number of sex facilities and thus the number of workplaces available to sex 
workers. In the next chapter we will see how immigration and labour laws are used - and in some cases strategically resisted - to limit the possibilities for work for migrant sex workers. The rationale behind the application of accessory law to regulate the sex trade derives from stigma, moral revulsion and a generalised aversion of immigrants. National discourse expresses and sustains the stigma and the feelings that the sex trade and immigration engender. Formal decisions to legalise prostitution, on the other hand, are the contingent outcome of coalition politics and do little to alleviate the social stigma and make prostitution acceptable among the general population and political decision makers (Jeffrey, 2015). The fear of uncontrollable expansion and contagion as well as the urge to eradicate prostitution from the urban landscape, or at the very least to contain it as much as possible, leads to the use of a broad spectrum of legal instruments in the fight against prostitution. The book of law is rarely uniform. Accessory law - as is the case in both Austria and the Netherlands - can counteract national prostitution law, undoing or preventing the application of legal sector-specific law.

This opportunistic use of accessory law and policy instruments to contain prostitution even extends to the public sector. For example, since the 1980s government bureaucracies at the national and city level have widely experimented with collaborative forms of governance, attempting to involve civil society actors in policy formulation and implementation. Such experiments also extend to the administrative process itself, particularly in overcoming the perennial problem of information deficiencies and horizontal coordination in public administration (Rein, 1983b; Peters, 2006). In Chapter Three, we saw how local administrators in Rotterdam and The Hague have created so-called chain management arrangements to coordinate the fight against trafficking. In chain management, complementary services are linked laterally and sequentially, often led by a 'chain manager', in an attempt to coordinate resources for delivering client- or patientcentred services. Chain management originated in the desire to improve healthcare and social services in a fragmented service landscape (Vos and Wagenaar, 2014). The point we make is that public innovation is a costly endeavour that requires resources, perseverance and strong political support. It is testimony to the power of the abolitionist ideology that this wealth of resources has been dedicated to creating enforcement arrangements in the fight against prostitution. Moreover, as we have seen, the law is often applied in such a way that it violates the human rights of sex workers. In Austria the laws regulating STD checks, and fiscal law and immigration law, are applied in inconsistent, 
and in some instances even legally dubious, ways. With the Wet Bibob the Netherlands has adopted a law that ignores the universal human right of presumption of innocence.

Thus, while both countries, despite an initially pragmatic and accepting stance towards prostitution, have reverted to control, containment, and in the case of the Netherlands, the forced closure of a large number of brothels, the two countries, because of their different political structure and regulatory traditions, have taken a somewhat different road towards repression. Law and political tradition in the Netherlands stipulate that while local government has considerable autonomy, both in terms of regulations, and personnel and mutual dependencies, there are strong links between the national and the local. It can be argued, and this chapter provides ample evidence for this observation, that in the case of prostitution policy the national and the local form a single policy subsystem. Austria is a federal state in which the Länder enjoy considerable autonomy in setting prostitution policy. National law forms a loose regulatory framework that allows the provinces discretion in formulating their own policies. As we have seen, a federally organised platform has hardly any impact on policy coordination. What binds Austrian public administration is a strong regulatory tradition, a shared belief that societal sectors can be fairly and effectively governed by issuing detailed rules that are grounded in laws that have been democratically debated. Stigma has affected regulation in different ways in these two legal-administrative systems.

In the densely networked policy system of the Netherlands the intrinsic suspicion, distaste and anxiety that prostitution evokes among the general public influenced the agenda-setting process first of all. Early, and initially isolated, abolitionist reactions to the repeal of the brothel ban, such as Christian Democratic parliamentarians' warnings of uncontrollable migration and the factually dubious and rhetorically charged report of two Social Democratic councillors in Amsterdam, reverberated throughout the policy subsystem. It only took one actual case of gross exploitation for national politicians, powerful aldermen, radical feminists, pundits, and Christian news outlets and broadcasting stations to jump on the trafficking bandwagon. By 2005 the political agenda on prostitution was firmly reframed in terms of trafficking, organised crime and reversing the legalisation of sex facilities (see also Outshoorn, 2012). The trafficking agenda, and the acrimonious national debate that supported it, permeated the offices of countless administrative bodies, acting as a virtual coordination mechanism that inexorably led to ever more authoritarian and repressive measures. 
In the more fragmented Austrian administrative system, the national debate was more subdued than in the Netherlands. Austrian prostitution policy of the past five decades has been characterised by continuity: continuity in restraining visible prostitution, continuity in the deployment and extension of police power, continuity in a minimal respect for the rights and wellbeing of sex workers, and continuity in the non-involvement of sex workers in the process of law formulation and implementation. Discontinuities, in the sense of abrupt changes, are mostly found in the field of immigration policy. Yet, the relatively sober approach to prostitution does not make the country immune to the effects of stigma. One of the unintended negative consequences of the fragmented federal system is that differences in regional policy design and implementation have led to far-reaching unequal treatment of sex workers in Austria, which some consider a violation of fundamental civil rights (Prantner, 2006, p 34). But more important is the insidious effect of stigma in the design of rules and their implementation by the police. Despite a strong tradition of allegiance to the rule of law (Rechtsstaat) and a bureaucratic ethos of impartial and fair administration, Austrian regulation of prostitution has been consistently aimed at containing and opposing sex workers. The effect has been the legally sanctioned and administratively facilitated erosion of the position and rights of sex workers in Austria. 



\section{Understanding the policy field: migration, prostitution, trafficking and exploitation}

\section{Introduction: prostitution as a complex policy field}

In this chapter we discuss the complex and intricate relationship between migration, prostitution, trafficking and exploitation. What makes this relationship a difficult topic for policy makers and analysts alike has empirical, conceptual and practical grounds. Empirically, there is a lack of solid, reliable evidence on the extent of trafficking and slavery. In addition the field of migration and unfree labour conditions resists any form of simplification or even categorisation. Weitzer speaks in this regard of 'tremendous complexity and heterogeneity' (2015, $\mathrm{p} 224)$. Conceptually the migration issue poses two problems. The first is the entanglement of global with national and local phenomena. For example, because of the stigmatised nature of prostitution, it proves to be difficult for policy makers to see the continuities between the exploitation of vulnerable immigrants and the everyday exploitation of sex workers, or, to put it differently, to regard the exploitation that is emblematic even of large swathes of the regulated sex trade as a form of labour exploitation (see the section on prostitution and exploitation later in this chapter). The second problem is the difficulty of distinguishing between reality and rhetoric: between the reality of (female) migration into prostitution and its interpretation in the media, in policy and in law, in particular the framing of migrant prostitution as trafficking. Practically, it is exceedingly difficult to disentangle the reality of prostitution 'on the ground' from the effects of national immigration and labour law. As we show in this chapter, the latter have as much, if not more, impact on the everyday life of sex workers as designated prostitution law. In fact, most of the rules and bylaws that regulate prostitution are a hard to disentangle from the amalgam of prostitution, immigration, labour, fiscal and social security law.

There are important policy lessons to be drawn from this argument. Because of the disturbing nature of exchanging sex for money, prostitution is in the public's imagination - and that of most officials 
as well - at heart seen as a dyadic transaction between two people: the sex worker and the client. This transaction can be 'distorted' by third parties such as brothel owners, managers or pimps, but that does not detract from the basic template that shapes our perception of prostitution. ${ }^{123}$ Our argument suggests a wholly different template, however. Prostitution is not a dyadic relationship but is simultaneously part and outcome of a larger, geographically dispersed, system that involves a score of actors. And even this image is not quite correct. The system is not just a network of actors; it also consists of the relationships between these actors, their understandings and explanations of the situation at hand, and the specific political-economic-cultural spaces within and between which these actors move. We call such a system a policy field. By this we mean a domain of concerted action that is characterised by multiplicity, complexity, interdependency, emergence, uncertainty and unpredictability (Wagenaar, 2007; Ison, 2010, p 10).

The idea of a policy field is not specific to prostitution. All domains of concerted human action - health, education, monetary policy, climate change, energy, public transport - are policy fields. The abiding characteristic of a policy field is complexity. Complexity means that it is the connections between the actors and between the actors and their environments that drive the system. That means that systems are always dynamic, in movement, developing. More importantly, it means that the properties of the system are emergent; that is, the properties of the system (for example an influx of sex workers from Hungary in Vienna, the rise of internet recruitment in prostitution, or the sudden criminalisation of the client) 'arise or come into being at a particular level of organisation and ... are not possessed by constituent subsystems. These properties emerge from the operational or relational dynamics between the elements or subsystems that comprise a system'

123 The quotation marks around the term 'distorted' are meant to capture a simplified and erroneous image of prostitution. Third parties form a much larger category that forms the biotope of (migrant) prostitution. We will see examples of this in the remainder of this chapter. Tampep, a European network for HIV/STD prevention and health promotion among migrant sex workers, defines third parties as follows: 'This term is used to describe anyone involved in the transaction of sex work who is neither the client nor the sex worker. The term third parties is broad as it can refer to people sex workers work for (owners, managers, agents), work with (agents, bookers), and hire (drivers, web designers) as well as individuals (receptionists, security). A third party is understood as an individual who controls, coordinates or supervises the sex workers' labour practices (how they work) or labour process (when and where they work) for direct or indirect financial compensation. Also sex workers can be considered as third parties when they work with together with other sex workers.' (Stella, 2015, p 1). 
(Ison, 2010, p 21). Emergence means that the properties of the system are the outcome of the interactions between the parts, not of the properties of the parts themselves. For example, the liquidity of water is the emergent outcome of the interaction between molecules that do not have that property. In human systems actors continually adapt to each other's actions thereby reshaping their collective destination (Axelrod and Cohen, 2000, p xi).

The property of emergence has two important implications for policy makers and analysts alike. First, emergence makes dynamic systems, and by implications, policy situations highly unpredictable. In fact, the denser the interconnections, the messier and more unpredictable the situation. Second, we are never outside systems. A policy maker's interventions are an inherent part of the policy field. Policy makers or analysts might think that they are observing the situation objectively, from an external point of view, but their interpretations and the actions that flow from them influence the perceptions and actions of the other actors in the system, who will adjust their own actions, resulting in new and unforeseen emergent outcomes. These are, of course, the unintended consequences that bedevil all policymaking (Merton, 1936; Sieber, 1981; Wagenaar, 1995; Ison, 2010, p 30).

The following example illustrates these complex relational dynamics. Felicia, a Romanian sex worker who works from a window in Amsterdam, describes her decision to work in prostitution thus:

I had a regular job in Romania. I worked in a small supermarket where I made $€ 200$ to $€ 250$ per month. I also went to school. I studied graphic design, but I didn't finish that program.... I had it with life in Romania. It was without any perspective. A friend of mine who worked here already asked me if I would consider sex work. I wanted more in life. Make money. Money is the only reason why I now do this work. ${ }^{124}$

What Felicia tells us is that working in the sex trade is, for her at least, based on an assessment of the earnings potential and work conditions of the different job options that were realistically available to her. In other words the choice was to continue living in poverty and dependency, or make a better life for herself. As we also saw in Dora's story, a young woman in Romania or Bulgaria, with some education, comes to see her perspective on the job or marriage market as hopeless. She

${ }^{124}$ www.polshoogtemagazine.nl/felicia-anna 
harbours certain images of life in the affluent countries of western Europe, images that are obtained through the internet, the media or stories of friends who already live there. She is not alone in her situation. A postwar legacy of economic extraction during Soviet rule has left these countries with an underperforming economy, corrupt officials and a compromised rule of law (Judt, 2005). In some parts of Eastern Europe gender relations are downright patriarchal. As a result thousands of young women and men, often those with some education and initiative, choose to leave the country to find a better life in western Europe. Many end up working in the low-end service industry, some in prostitution. Migration is difficult and requires support, so the woman asks relatives to help her (or relatives in equally dire straits offer practical support in the hope of profiting from the move), or the migrant finds people in the arrival country to help her find housing, a place to work, and negotiate rules and regulations. She also discovers that the rules for legal employment of new immigrants restrict her possibilities, possibilities that are not so rosy to begin with for female immigrants without money and with little education and/ or education that is not highly valued in the arrival country. Often migrants pay these third parties money for their services, in some, but not all, cases because these third parties pressure the migrants to hand over their earnings. Officials in the arrival country witness an increase in the number of young women from eastern European countries who work in prostitution, who barely speak the language, and who seem to be handing over money to third parties. They interpret this situation as trafficking and begin to design and implement policies (such as the enforcement schemes described in Chapter Three) to deal with this. This puts the women in a difficult situation as their possibilities for legal work become even smaller. ${ }^{125}$ They react by moving to a different city or country.

We could continue, but the point, we hope, is clear: prostitution is a complex system. In fact, our example is misleading in that it is too linear. The relationships, interactions and understandings described are recursive; they operate simultaneously on different levels of aggregation, creating complex loops of positive and negative feedback that strengthen or weaken effects (Ison, 2010). Prostitution is a policy field 'of coexisting and mutually interdependent factors' and relations that produce unexpected and often unforeseen outcomes (Wagenaar,

125 See the discussion in Chapter Four of the different categories of sex workers, and the consequences for their work status, that have been created by the repeal of the ban on brothels in the Netherlands. 
2007; Ison, 2010, p 32). The results of some processes within the system are the input to other processes, so that the process is modified. The result is a policy situation with uncertain boundaries that is characterised by complexity, uncertainty, interdependency and agency. Within the organisation of this book, we see that after the local politics of policy implementation described in Chapter Three, and the national politics of policy formulation in Chapter Four, we now have moved up one more level to the transnational and comprehensive politics of (labour) migration and the ways nations and municipalities react to this. The analysis of a policy field such as prostitution requires that we understand and bring together all these levels and all the different actors, relations, interactions, understandings, stories and discourses, and trace the emergent outcomes of the field.

In Chapter Two we argued that the challenges of prostitution policy put local policy makers in a difficult position. We now return to this observation and conclude that it applies even more when we think of prostitution in terms of a dynamic policy field that is characterised by complexity. Policy makers are entrusted with the task of designing rules and measures to regulate prostitution in the neighbourhoods and streets of their locality while these same phenomena are the outcome, the substrate, of transnational forces that are wholly outside of their control. Moreover, the laws, bylaws, policy instruments and organisational procedures that officials have at their disposal instantly become part of the larger policy field and create a thicket of unintended consequences that fall outside the horizon of most officials and elected officials. It is not just that policymaking in such circumstances can only be reactive and, as a result of the intrinsic lack of reliable data, myopic; there is also a real risk that, as a result, it will be confused, latching onto the wrong aspects of the problem, in the process worsening instead of alleviating the problem. In fact, as we will see, in many cases the laws that are designed to combat or prevent harsh exploitation in prostitution not only fail to address the root causes of the problem, but also have adverse effects that increase the vulnerabilities of the target groups and even bring the very categories, such as 'slavery', that 'create' the problem, into being (Kotiswaran and Okyere, 2015). In Chapter Six we suggest how to harness such complexity. One important strategy is to allow more diversity into the (analysis of) the complex policy situation instead of fitting the elements into simplified schemata (Axelrod and Cohen, 2000). For example, instead of projecting on the migrant sex worker the collective images that are driven by radical feminist and anti-immigrant ideology, it would be more productive to take seriously the migrant sex worker's self-understanding of prostitution as work, as 
a discerning occupational choice in a situation in which thousands of female migrants find themselves worldwide, both today and in the past. This reframing of prostitution as a legitimate occupation will then draw attention to the continuity of the situation of sex workers with that of other migrant groups, to the exploitative labour arrangements these new migrants encounter in the arrival country, and to the unintended effects of the very laws and regulations that are intended to support migrant (sex) workers.

Our purpose in this chapter is to take the transnational character of prostitution seriously, and to situate it in an analysis of labour migration and labour exploitation. We then trace the effects of policy makers' framing of migration and exploitation on prostitution policy. We also suggest a workable alternative for the concept of trafficking, which, as many experts agree, currently exerts such a negative influence on prostitution policy worldwide. Instead of trafficking we suggest 'labour exploitation'. We argue that an exploitation framework not only does more justice to the experiences of migrant sex workers than the trafficking framework, but also avoids the negative consequences on sex workers' rights of the trafficking framework, and augurs a more humane and effective prostitution policy.

\section{Migration, prostitution and coercion}

JulieBindel@bindelj.@mvdbeer@RachelRMoran@ amnesty LOL! I called you a PIMP, not a TRAFFICKER. Both the same, but Dutch cops believe diff. YOU ARE A PIMP! (Tweet from Julie Bindel, Guardian journalist, addressed to Mark van de Beer, IT specialist, prostitution activist and partner of a sex worker in the Netherlands)

In our interviews with sex workers we tried to construct in detail the pathways into prostitution. How did the respondent arrive at the decision? What did they know about prostitution? Were they aware that they were going to work in prostitution in the destination country? Who helped them with the immigration process and with the entry into the prostitution business? We were also interested in the issue of coercion. In the public debate coercion at the point of departure is a central issue. According to abolitionist activists and their followers, young women enter the sex trade because they are deceived, coerced or threatened with violence against themselves or their family. So we asked if coercion and exploitation was involved. In the Appendix we discuss the nature of the sample and the procedure for collecting the 
data. We are confident that the sample is representative of the majority of migrant sex workers who worked in Austria and the Netherlands at the time of the research and that the use of (ex-)sex workers and outreach workers as interviewers guarantees reliable data.

It did not prove to be easy to obtain these personal histories. A large number of our respondents were initially reluctant to reconstruct in some detail the road that led them from a village in Romania or Costa Rica to a brothel at the Austrian-Italian border or a window in the redlight district in The Hague. Typical answers were, "It just happened", or "I don't know", which we read as expressions of an initial resistance to address the issue. But usually, when the interviewer managed to establish sufficient trust with the respondent, the latter began to relate in more detail her personal pathway into prostitution. Friends, family and acquaintances turned out to be crucial.

Most of our interviewees learned about the possibility to work in prostitution from friends, family or acquaintances who already worked as sex workers (see also Dekker et al, 2006). The latter informed our interviewees about what the work entailed, provided information about work types and sites, helped to find a workplace, and supported them in organising the journey to the destination country and finding a place to live. This is in accord with the literature on the migration of low-income groups. One of the defining factors in this process is the availability of role models of people who have already migrated and have returned with money. They were the first in a chain of migration of friends, family members and villagers. This seems indeed the most appropriate description of the prostitution trajectory of the women we spoke with in the course of our research. This also explains the choice of the country of destination. The newcomers use the networks and the information of migrants who have arrived before them. Having a personal relationship with someone who has already worked in prostitution not only results in much practical support but also helps to lower thresholds of misgiving, doubt and shame:

"I knew this already when I still lived in Bratislava, from my friends. When I visited them. So, I was familiar with it. And when I came to Vienna my friend told me the truth, that she works in a nightclub and that she makes good money. I said, okay, I don't know this. I don't know this in Austria. And she took me with her and said, without any coercion, 'Try it, for two or three days, when it is okay and you like it, then you can work with us. When not ...' So no one had forced me. It was my own decision. I decided for it myself 
and I said, okay, I will do it. I didn't have the possibility at that time to work somewhere else." (Interview 80)

Most sex workers received their introduction to prostitution from friends and colleagues, who conveyed practical knowledge about various sexual practices, safe sex, sexual routines with clients, fees, how to refuse clients or unwanted sexual practices, basic German or English vocabulary to be able to communicate with clients, and so on. These social networks were also decisive in deciding to which country or city to emigrate to, as well as what type of prostitution to undertake. A Bulgarian sex worker was very outspoken about this; she came from a small town in which many women had experience with prostitution, so that "there were different ways to this activity" (interview 2). Many of our interviewees also searched the internet for information about prostitution or work opportunities and regulation in Austria or the Netherlands. The pathway into prostitution is not different therefore from other forms of labour migration. Social networks are crucial to obtaining information about the possibilities of and conditions for work, finding a place to live, and integrating into a new environment. All but one of our interviewees who were introduced by friends/colleagues declared that they chose prostitution voluntarily. Nevertheless, similar to the experience of most who migrate for work reasons, the first two or three months in the new job and the new country were not always easy. (See also Felicia's story later in this section.)

Many immigrants make use of a support structure of family, friends, acquaintances and helpers to gain a foothold in the new country. The following interview selections show not only how such support ranges from straightforward assistance to downright exploitation, but also the different perspectives of our interviewees on "pimps" and their agency. ${ }^{126}$ For example, a number of women who had prepared for

126 The quotation marks around the term 'pimp' demonstrates the difficulties the term presents to the analyst. First, the term is vague. As the Bindel tweet at the beginning of this section demonstrates, very different third parties who have very different relationships with sex workers are labeled 'pimps'. In the end it is hardly possible to identify the defining characteristics of a pimp, and subsequently to treat it as an analytical category. Second, the category of pimp has almost only negative connotations that are frequently taken for granted, even though, as we see later in this section, sex workers themselves characterised services provided by third parties typically labeled 'pimps' as indispensable. Although we do not deny the existence of exploitation by third parties, the term 'pimp' seems to be used mostly as a shibboleth in the struggle for abolitionism. 
immigration through the internet or who had replied to an advert, usually made use of helpers to effectuate the move to another country. These helpers would pick the woman up from the station or the airport, help her find a place to live and mediate in finding a suitable workplace. These people would then be paid for their assistance. In some cases this ended the service relationship and others not. Beate is a case in point:

"No, when I arrived in this country, there was, how shall I say this, euphemistically speaking, a helper. He was not a brothel owner. He and some woman had looked for workplaces for me.... I didn't have to pay for the trip, but later, when I began to work, some money was deducted from my earnings, about $€ 5$ per client, irrespective of what I had earned that night." (interview 93)

Eventually this interviewee found herself a new workplace to escape these charges. A sex worker from the Czech Republic who had replied to an advert told us about attempts at extortion. The man who had picked her up from the station and had taken her to her new workplace tried to extract money from her afterwards. Our interviewee refused to pay him and informed the brothel owner. She told us in the interview that two of her colleagues not only paid the extortionist but were also unable to put an end to the payments by changing their workplace (interview 1). Veronyka, a Moldavian woman who was forced into prostitution by violent criminals, managed to escape from her captors with the help of the Dutch police. When she was free she voluntarily started in prostitution again on a part-time basis. As she explains:

"I wanted to find out how it was like to work independently, without being forced. I had read something about prostitution and had met people who did it voluntarily.... The first few weeks it felt odd. I had promised myself that I would stop if it would not feel ok. Now I was able to choose my own clients. Those were nice men. I enjoyed myself. I became more and more self-confident. I continued doing so for two years, but I stopped when I got a serious relation. Another positive effect: until I re-entered I had problems relating to men. But because of the job I became more self-confident." (interview 23). 
When sex workers are thought of as having a pimp, it is generally assumed that their entry into the sex trade was involuntary. Five of our interviewees indicated that they arrived in Austria with their pimp - this is what they called him - who was around when they started in prostitution, but also said that they were not coerced into it. In a number of cases exploitation, and violence, started later. Natasha, for example, related that a woman brought her from Moldavia to Vienna by car. This woman was a pimp according to Natasha. She said that Natasha only needed to pay the rent and some money for food. She lived in a room with three other women. The pimp lied about the rent; she said that she would keep Natasha's earnings for her, to keep them safe. Natasha said that she was naive enough to give the woman her earnings. When she asked for her share of the money the woman said she only had $€ 1,000$; the rest has been spent on food and costs for various documents. Natasha lost about $€ 8,000$. Dora, as explained in the interview relayed in Chapter One, also lost her earnings, but she and some of her colleagues filed a complaint with the police; she for pimping, the others for rape and physical violence as well as pimping. The man was convicted to two years in prison.

An illustration of the difficulty in assessing the precise nature of the relationship between the sex worker and third parties is illustrated by Anna's story. She came from Hungary to work in Austria. She had already worked as a sex worker in Hungary. She also had a pimp her word - there who had been "like a father" to her and whom she had given half her income. In Vienna she managed and worked in her own studio. Her pimp acted as her agent and put her in touch with other sex workers who could work in her studio. Anna would receive a small commission from the women, which she would split on a $50-50$ basis with her procurer. "Live and let live. That is what I learned from, how shall I say it, my helper, my father." She adds that she was never exploited and that she would never exploit anyone else. This interviewee portrays her procurer as a mainstay of her professional life, who is remunerated for his services. She cannot and will not perceive this as exploitation.

What makes these situations difficult to judge is that the sex worker has an emotional relationship with the alleged procurer. When there is no physical or emotional violence involved, it is exceedingly difficult to disentangle logistical and emotional support from dependency and economic exploitation. Some women said that they came to Austria with their partners to look for work. When they were unable to obtain a work permit, prostitution offered a way out. Does this make the partner a pimp? Three examples. Tina came to Vienna with her 
boyfriend. Neither one of them managed to obtain a work permit. Her boyfriend knew the owner of a nightclub and Tina decided to work there as a sex worker (interview 40). Anjuta's story is different. She came to Austria to study. She fell in love with an Austrian man whose business was not doing well. She supported him financially with money that she borrowed from her parents and friends. Nevertheless the firm went bankrupt. Anjuta's partner could not find work and Anjuta decided to offer sexual services to pay off her and her partner's debts (interview 48). In another case, a Czech sex worker said that her husband was responsible for looking after their children and for doing the household chores. Until recently the family lived off her income; now her husband has a part-time job (interview 1). Despite repeated questioning, all three women maintained that their entry into prostitution was voluntary, and that they were in personal relationships in which income sharing is commonplace.

As Julie Bindel's tweet illustrated, a lot of confusion exists around the issue of pimping. Some of that confusion is inadvertent, as when The Guardian (11 December 2013) reported that pimping is legal in the Netherlands. 'Pimping', the abuse of dependency relations, often enforced by violence, threats of violence and sexual exploitation, is in fact a criminal activity according to the law and remains subject to punishment as an element of trafficking. What has been legalised in the Netherlands is the operation of a licensed brothel. Some of that 'confusion' is wilful. The concept of a pimp has been caught up in the trafficking controversy that afflicts the prostitution debate, as Bindel's angry accusation of Mark van de Beer illustrates. Our interviews with migrant sex workers paint a complex picture of the contentious issue of procuring and forced prostitution. First, the distinction between 'helper' and 'procurer' is vague; many helpers act as procurer and many sex workers perceive their procurers as a source of vital support. Clearcut coercion backed up by violence, as in the case of Veronyka, was rare in our sample. Migrants need third parties to secure a job, a house, and to negotiate their interactions with the authorities, but this might provoke dependency and make them vulnerable to exploitation. As Sanghere concludes: ' $(T)$ he perpetrators of trafficking in the form of recruiters and agents are primarily small-time operators functioning mostly in an individual capacity, and are based upon personal and sometimes familial sets of relationships' (Sanghere, 2012, p 16). The stigmatisation of prostitution and the criminalisation of the work settings of sex workers increases this vulnerability. Moreover, as we will see below, the lack of access to labour rights makes it impossible for 
sex workers to challenge third parties and access justice. Dora's story at the opening of this book is illustrative here.

Second, the interviews also showed that although many women had a procurer at some stage of their career, only one of them indicated that she was forced into prostitution. However about $10 \%$ of the sex workers in our sample declared that they had been economically and/or sexually exploited while working as a sex worker in the arrival country. ${ }^{127} \mathrm{We}$ will return to this later in the chapter. Third, most of the interviewees were able to free themselves from an exploitative relationship with a procurer. Singlehandedly, or with the help of friends, club owners, clients or the authorities, they resisted, left the house that they shared with the procurer, found a new workplace, and moved on to a more independent working situation. Fourth, personal relationships make it difficult to establish the nature of procurement. Is the procurer a scrounger who lives off the proceeds of the woman's prostitution or is he someone who provides essential services and/or emotional support to the sex worker? Are the partners, parents, siblings or (grown-up) children who are supported by the earnings of sex workers procurers? Where does one draw the line? Fifth, the pervasive stigma attached to prostitution and the laws in many countries that make it illegal to provide services such as housing or transport to sex workers force many sex workers to rely on 'personal' contacts or shady persons who are willing to run the risk 'for a price'. Both Dutch and Austrian law define procuring broadly, so that anyone who benefits from the earnings of sex work would be considered as engaged in the criminal activity of procuring.

We think our research allows us to draw two important lessons for policy makers on the issue of procuring. The first is that we need to take the voice of sex workers seriously. Like anyone else, sex workers have relationships that provide practical and emotional support in work and personal life. What from the outside looks like procuring may be experienced as a more supportive relationship by the sex worker, or, in a more ambivalent vein, a relationship that has both exploitative and supportive elements. When it comes to prostitution, however, it seems that ambivalence is not tolerated. Yet, the interviews showed that sex

127 This number is similar to the percentage of migrant sex workers who reported being exploited by middlemen in Mai's study of migrant workers in the UK sex industry (Mai, 2009). Given the convergence between these two different samples in three different countries at two moments in time (2009 and 2013), one wonders if the statistic of $10 \%$ represents the incidence of exploitation by middlemen in the population of migrant sex workers. 
workers were capable of distinguishing when affective or supportive relationships became exploitative, and act on it. This is not an argument to leave sex workers to their own means when it comes to dealing with procuring, but instead to accept their agency and listen to them. Our interviews show that the current public discourse that distinguishes between voluntary and forced prostitution is misguided. Apart from the fact that the distinction is not always clear, that it denies the agency of sex workers, ignores their voice, and ascribes to them the blanket status of victim, it is quite likely counter-productive in that it covers up real exploitative situations. We will discuss this in the section on prostitution and exploitation. Second, as we discuss more extensively in the next section, the laws and regulations that regulate migration in Europe and its nation states, such as Austria and the Netherlands, do not deter but in fact facilitate dependency and exploitation. Most immigration laws seriously curtail the autonomy of sex workers. In this sense prostitution does not differ appreciably from other forms of labour migration such as the construction industry, cleaning and domestic services, and agriculture. Migrants, particularly those who do not speak the language of the destination country, have to rely on supportive networks and have to operate within legal frameworks that make them vulnerable to exploitation. This applies even more to female migrants (O’Connell Davidson, 2006; Le Breton, 2011; Vance, 2011). Perhaps it is instructive to end this section by returning to Felicia.

Felicia writes a blog on prostitution and prostitution policy (http:// achterhetraamopdewallen.blogspot.nl/?m=1) and was a member of the Dutch sex workers' organisation PROUD. In one of her blogs (translated by the authors) she describes how she came to the Netherlands:

I am Felicia, a 27-year-old sex worker from Romania ... I have worked here for about 4 years now, non-coerced, not exploited and wholly out of my own free will. ... About 4 years ago I came to this country to work here in the Netherlands as a sex worker. I was aware of what I came to do here, nobody lied to me that I would be a dancer, or work in a restaurant or become a model or something. I was told the truth that I would go and work as a sex worker in a country where prostitution is legal and an honest occupation. Nobody forced me to do this, nobody lied to me about what I would be doing here, and nobody exploited me. But to come to the Netherlands, to get all the paperwork straightened out, and to find a place 
to work and a place to live, is something that you simply can't manage on your own without help. The people that helped me were a couple. She worked as a sex worker in the Netherlands for 7 years already and he was her boyfriend. They helped me to come to the Netherlands, they paid my flight tickets, they moved to a new apartment so that I could stay with them, they helped me with the different registrations in this country, they helped me to find a place to work, to arrange the paper work that I needed to be able to work, they paid the rent for my work place, etc. I knew from the start that they would pay all this for me and that I would pay them back later. As they invested a lot of time and money in me, paying them back was the least I could do. It never was a matter of exploitation or signing a contract or something like that. After about 9 months I left the apartment of the couple that helped me and lived by myself. In the mean time I knew the ropes in Amsterdam. I now knew how to get to work, and how to get things done. I didn't need their help anymore.

Felicia's story is familiar to anyone who has emigrated to another country to start a new life there. The migrant finds herself in an alien environment. She has not mastered the rules, procedures, organisations and customs that are required to establish herself as a citizen, employee and resident. She feels lost at times and is dependent on the advice, support and kindness of others. However, according to the definition of trafficking in the UN Protocol to Prevent, Suppress and Punish Trafficking in Persons, Especially Women and Children and the even broader definition in the trafficking article in the Dutch Penal Code, Felicia would be considered a victim and the couple that helped her pimps or traffickers.

\section{How immigration and labour law shape the 'modern slavery' problem}

In the affluent countries of north-western Europe, prostitution is to a large extent a migration issue. As reported earlier in the book, $90 \%$ per cent of sex workers in Austria and about 70\% in the Netherlands are migrants. This is a common situation in most of the countries of north-western Europe. Most of these immigrants are from central and eastern European countries such as Hungary, Romania or Bulgaria. The remainder are from African countries (mostly Nigeria), Asian 
countries (Thailand and increasingly, China) and Latin America. The migratory nature of sex work is part of a larger trend in which structurally wide income inequalities, limited economic and social opportunities and deeply embedded corruption lead many of its citizens to migrate to the affluent, mature democracies of western Europe to improve their employment prospects and to sustain their families at home. Internet access, low-cost transportation and travel opportunities bring the possibility of migration within the purview of many. The absence of visa requirements for citizens of EU and European Economic Area (EEA) countries removes yet another barrier for cross-border movement. Poverty and lack of prospects among women, combined with injurious gender relations in the home country, have resulted in the feminisation of migration; many young women, particularly those with some secondary or higher education, look for better prospects elsewhere (Phillips, 2015). The result is that in our connected, networked world, migration is an ineluctable reality. ${ }^{128}$

But even if migration is legal, even in the best of times it is a highly ambivalent issue for the high-income administrative states of north-western Europe. Inescapably immigrants are graded according to desirability with respect to the cultural, economic and religious make-up of the arrival country. Highly educated and/or high-income immigrants are favoured, both in public opinion and formal law, over groups with little requisite education, the 'wrong' skills and no independent wealth. Certain ethnic or religious groups are held in higher esteem than others. The moral politics of desirability is expressed in the language with which we designate immigrants. The most frequently applied labels in policy parlance are 'undocumented' and 'temporary foreign worker'. ${ }^{29}$ This framing of people, who in the case of EU and EEA countries are making use of the (somewhat constricted) legal right to free movement of people within the EU, has, as always, strong repercussions for the target group. Discursively, migrants, and sex worker migrants in particular, are considered 'cheap' and 'disposable', a marginal, substandard class of citizen. Legally, the categories 'illegal' and 'temporary', and the laws that give expression

128 The United Nations estimates that in 2013 there were 232 million international migrants worldwide, 57 million more than there were in 2000. Today much (but not all) of human migration is shaped by enormous spatial disparities in prosperity, peace and power (Sharma, 2015, p 36). The author does not discuss how these numbers were arrived at.

129 This is official, bureaucratic language. We are not talking about crude popular designations such as 'fortune seekers', 'people whose values are fundamentally at odds with our Christian culture', or the currently popular (in the UK) 'vermin'. 
to these designations, limit the labour market options of such migrants to low-skilled, dead-end, poorly protected jobs or nominal selfemployment, and limits their rights and mobility (Cruz, 2015, p 70; Sharma, 2015, p 36). In the ironic dialectic of public discourse this entrapment is then held against these migrants, and reinforces their public image as deficient, non-citizens.

In every country immigration law is highly complex and exceedingly difficult to navigate. ${ }^{130}$ Several factors contribute to this complexity. A large part of immigration law consists of bylaws, which are formulated and applied by officials in various agencies outside the purview of elected legislators. ${ }^{131}$ In addition immigration law, like all law, is shaped by value positions that favour the interest of one group over that of another. There are also EU laws, like the Employers' Sanction Directive, the Return Directive and the UN Protocol to Prevent, Suppress and Punish Trafficking in Persons, Especially Women and Children, that have significant impact on migrants' situation by criminalising migrant sex workers. Finally, law on paper is different from law in practice; the implementation of immigration law is dependent on the allocation of resources to national and local immigration offices, local policy choices, agency capture, and so on - the familiar dynamics of

130 The personal experience of one of us (Hendrik Wagenaar) serves to illustrate this point. As a PhD student in the United States in the 1980s, I found myself at some point in between two visas. My old exchange visitor's visa had expired and I needed a student visa that allowed part-time work. The new visa however was not forthcoming. Legally I was no longer allowed to work, but my employer at the time (Harvard Medical School) was kind enough to continue the contract in an informal way by safeguarding my salary until I had a new visa. I took the services of an immigration lawyer. He was a practical, savvy man who quickly found out where my application was languishing: an office of the US Immigration Service in Washington DC that, as he said, "had no address and no telephone number". While we chatted about immigration law he commented on its complexity. By way of illustration he pointed to a thick tome on his desk. I asked if this contained US immigration law. He smiled wryly and said: "No, only the changes of the last six months." As he saw no way to contact the officials who were responsible for my visa application, he suggested that I contact the constituency office of my congressman. As a foreigner who could not vote, I was not represented by a congressman, but a journalist friend of mine knew the head of the constituency office of senator Barney Frank. The office took on my case and within two weeks I received a message that I could pick up my new visa at the Boston branch of the US Immigration Office. Personal connections, and a spouse who had an income while mine was frozen, solved the problem, but only because I was a privileged immigrant with financial resources and personal connections.

131 Under the rule of law these by-laws can of course be, and sometimes are, challenged in court. 
policy implementation as described in Chapter Three. Finally, as we explain in this section, immigration law, and related prostitution law, is closely allied to criminal law, while its presentation is often couched in the language of human rights. The effect is twofold. Immigration law presents a bewildering and contradictory maze of claims, images, agencies and practices to its target group of immigrants. Yet, immigration law powerfully shapes the position, possibilities, rights and capacities of the people to whom it applies. To grasp these complex relationships, we look at the example of domestic workers in the UK.

A change in the immigration rules for overseas domestic workers in the UK that was introduced in April 2012 removed the right of such workers to change employers. In fact, the name of the employer is entered on the migrant's visa. As Roberts argues: 'This effectively removes any bargaining power from within an already unbalanced employment relationship, with migrant domestic workers left unable to resign, question, or challenge any aspect of their treatment' and expose them to exploitation and abuse (2015, p 15). That this is not a mere theoretical issue is borne out by numbers provided by Kalayaan, a charity that supports overseas domestic workers. Kalayaan reports high numbers of domestic workers who are not allowed to leave the house unsupervised, who do not have their own room, who work more than 16 hours per day and who earn less than $£, 50$ per week (Roberts, 2015). In 2015 the House of Lords voted for an amendment to the Modern Slavery Act 2015 that would abolish the controversial 'tied visa' requirement that was introduced by the coalition government in 2012 and reinstate the right to change employers. However, the House of Commons overturned the amendment and passed an amendment of its own that allows only those workers who have entered the National Referral Mechanism (NRM) and have been identified as trafficked to be given the possibility of obtaining a six-month visa as a domestic worker. The purported reason for this amendment is that it helps to report and prosecute abusive employers. As Roberts makes clear the NRM is largely ineffective as it has not led to any convictions for trafficking for domestic servitude. Domestic workers consider it risky to register with the NRM as there is no guarantee of protection until they receive a positive decision through the NRM. The alternative is to run away, which automatically makes the worker illegal. The government's stated reason for restricting the right to change employers in 2012 was to reduce migration into the UK.

The case of domestic workers and the Modern Slavery Act illustrates several aspects of the nature of immigration legislation and its effects on the migrant worker. First, it is an example of the kind of 'light- 
touch regulation' that governs immigration and immigrant labour in a neoliberal economy. By providing information that will enable customers, campaigners, and shareholders to hold big businesses to account instead of imposing licensing requirements or enforcing labour legislation, the regulation overwhelmingly relies on information instruments instead of licensing or enforcing labour requirements. The rationale for this is in the distinction between criminal and labour law in regulating migrant labour. The British government is reluctant to impose labour regulation on high-income households (see the statement by Karen Bradley, the minister responsible for slavery and organised crime in the then coalition government, in Fudge, 2015, $\mathrm{p}$ 22). Yet, via the Modern Slavery Act the government signals it is willing to subject those same households to criminal law. However, as virtually no prosecutions have been started in practice this amounts to little more than symbolic policy. The reason is the biased division of labour in fighting labour exploitation that is hardwired into the body of law and regulation and puts the onus of discovery, challenge and redress on the shoulders of the weakest party. It is the marginal worker who has to carry the burden of exploitation, its exposure and the precarious position she puts herself in when she challenges her employer. The second, related, point is that this illustrates the powerful symbolic effects of immigration law. The 2015 Act is part of a concerted drive by the UK government to fight 'modern slavery'. However, the label and its associated legal technology powerfully shape the moral and practical division of labour in dealing with migrant labour. As Fudge puts it: 'The problem with the modern slavery paradigm is that it is difficult, if not impossible, to dislodge it from the technologies of legal governance, criminal law and border controls, that are mobilised in its cause. These technologies tend to target marginal players rather than tackle the social processes that normalise exploitation' (2015, p 23).

We will see that the case of domestic workers is paradigmatic for the way that sex workers are treated under immigration law, with the added consideration that the stigma attached to prostitution makes the position of sex workers vis-à-vis immigration law even more precarious.

\section{Prostitution and exploitation}

In 2005, the Dutch NGO Rode Draad engaged in a unique programme. It had received a small grant from the Ministry of Social Affairs and Labour Relations to visit all sex facilities in the Netherlands (clubs, window brothels, massage salons, including even some unlicensed facilities) to distribute information about labour rights. The Rode 
Draad saw this as an opportunity not only to distribute but also to collect information on labour relations and work conditions in the Dutch prostitution sector. It collected the addresses of 633 of the estimated 800 sex facilities in operation and visited over half of them (Altink and Bokelman, 2006). At the same time, as part of the official evaluation of the repeal of the ban on brothels, a team of researchers interviewed 354 sex workers and 49 facility owners about labour relations and working conditions in the Dutch sex industry (Dekker et al, 2006). The picture that emerges from these two studies is ambivalent.

In their study Altink and Bokelman are more negative about labour relations in the sex trade than Dekker and colleagues. ${ }^{132}$ What they discovered, five years after the repeal of the brothel ban in the Netherlands, was a widespread pattern of labour exploitation (Altink and Bokelman, 2006). Almost none of the facilities offered adequate employment contracts; the women who worked there were allegedly self-employed, which was often a euphemism for informal and insecure work arrangements. In almost all facilities the sex worker was selfemployed only in name; in reality the contractual relationship had all the obligations of employment and few of the rights. (In quite a few facilities the Rode Draad field workers were not allowed to speak to the 'self-employed' women.) In quite a few cases the proprietor had created elaborate contractual constructions that allowed them to skim off large fees from the sex worker's earnings and that put all the risk of business with the sex worker. In more remote rural areas sex workers often lived on the premises, making them completely dependent on the proprietor. On average, these sex workers received only $50 \%$ of their earnings, often less if the proprietor made deductions for VAT or even non-existing social security payments. Owners often did not provide invoices for earnings or rent paid. Many sex workers experienced difficulties with obtaining their earnings from the proprietor, and had to ask repeatedly for their money. The Rode Draad points out that this almost universal commission system acts as an incentive for the proprietor to put pressure on sex workers to engage in additional sexual activities or unsafe sex to increase earnings. Work hours were long. Many facilities issued 'fines' to sex workers for issues such as showing up late to violating (illegal) competition clauses.

132 One reason for the difference might be that Dekker and colleagues interviewed sex workers in facilities where the owner or manager had given his or her permission for the interview (2006, p 12). The field workers in the Altink and Bokelman study showed up at the facility unannounced. 
In the report by Dekker and colleagues, however, $80 \%$ of sex workers stated that they could refuse clients and determine the activities they preferred to engage in (2006, p 45). Agreements - about work times, dress code, earnings, house rules - between the sex worker and facility owners and managers were mostly verbal. Sixty per cent of sex workers set their own working hours (this differed between windows and escort on the one hand and clubs and massage salons on the other). Escorts and window workers mostly set their own rates; those who worked in clubs followed the 'house' prices. Over $60 \%$ of sex workers were free to take a day off, go on holiday or decide what clothes to wear. Security was an important reason to work in a club. Managers would remove unpleasant clients from the premises; $86 \%$ said that they did not feel threatened by the comments or behaviour of managers (Dekker et al, 2006, p 46). Dekker and colleagues also found a high level of mobility in sex facilities. Two thirds of interviewed sex workers had changed facility. The prospect of higher earnings elsewhere (a new sex worker initially attracts more clients) was mentioned in 30\% of cases; but $48 \%$ had moved because of problems with management, bad atmosphere in the facility or bad treatment by management (Dekkers et al, 2006, p 24).

These two studies of labour relations in the Dutch sex trade present a mixed picture. Although the licensed sector in the Netherlands presents a relatively decent, ordered image, labour relations are a far cry from what they are in most other sectors. According to Dekker and colleagues, most sex workers prefer to work as independent contractors for the freedom it offers them and accept the relationship of authority in licensed brothels for the security and peace of mind it gives them (Dekker et al, 2006, p 82). However, the prevalence of independent contracting also makes sex workers vulnerable to labour exploitation. Because most agreements are oral, sex workers are dependent on owners and managers for honouring them and do not have recourse to formal dispute procedures in cases of disagreement. The result is that many sex workers seem to accept everyday forms of exploitation. Dekker and colleagues also seem to acknowledge this when they state: '[Sex workers] understand that in practice this [the authority relationship in sex facilities] has always been the case and that in the prostitution sector labour relations and rules differ from other sectors' (Dekker et al, 2006, p 53).

This is the face of labour relations in prostitution: not the alleged coercion in the country of departure or the relatively rare violent exploitation by criminal gangs but instead the widespread, everyday, taken-for-granted ('This has always been the case') labour 
exploitation in the clubs and brothels of the arrival country. In 2016 the International Committee on the Rights of Sex Workers in Europe (ICRSE) published a report on exploitation in the sex trade (ICRSE, 2016). ICRSE defines exploitation as "labour arrangements that enable one person to take unfair advantage of the work of another person' (ICRSE, 2016, p 4). ICRSE then makes two observations. First, exploitation in prostitution has received little attention. Second, exploitation belongs to the realm of work and can only be understood by situating it in the wider field of exploitative work practices: 'Only by focusing on sex workers' working conditions, as well as employment practices and arrangements under which sexual services are sold and exchanged can we come to a better understanding of and challenge exploitation in [the] sex industry' (ICRSE, 2016, p 4).

The scarcity of analysis of labour exploitation in prostitution is not accidental, of course. The current dominant framing of prostitution as trafficking and slavery directs the attention of policy makers and the public away from work conditions and labour relations and towards immigration and criminal law. In country after country governments are not only reluctant to intervene in labour relations in the sex industry, they also formulate laws that codify the slavery framework and cut back on measures and agencies whose task it is to uphold and enforce labour regulations (Robinson, 2015, p 26; ICRSE, 2016, pp 6-7). Instead, as we have seen, considerable amounts of time and energy are invested in 'enforcement schemes', 'chain arrangements' to coordinate the fight against trafficking, and registration schemes to detect 'signals of trafficking', while the police force is the agency of choice for implementing prostitution policy. Yet, the reality is that in every country thousands of sex workers exchange sexual services for money in a large variety of sex facilities. By framing these services as a form of slavery obscures the reality of these women's lives and the ubiquity of exploitative work practices to which they are subjected.

What did ICRSE find in its survey of exploitative work practice in the sex industry in Europe? It observes that in the vast majority of countries the sex industry is part of the informal economy. This is that part of the labour market that is not recognised by the state, that is outside regulation and control (although often not outside the reach of taxation), and where therefore protection and benefits granted to people working in formal economies are lacking (ICRSE, 2016, p 8). Informality in the labour market is a double-edged sword. On the one hand, it provides low-threshold jobs to unskilled workers or workers who would otherwise be excluded from the formal economy such as migrant labourers; on the other hand, it creates the conditions for 
labour exploitation where third parties unduly profit from the labour of sex workers. ICRSE points out that according to self-reports by sex workers and contrary to the abolitionist perception, these exploitative third parties are rarely clients, and that instances in which clients refuse to pay or otherwise violate the service agreement are considered a form of abuse or sexual violence (ICRSE, 2016, p 8).

Labour exploitation expresses itself foremost in the contingent and casual character of the labour arrangement. This applies as much to prostitution as any other form of precarious work. With regard to prostitution ICRSE observes that, similar to the two Dutch industrywide surveys: 'The vast majority of sex workers in the region [Europe and Central Asia] are engaged in insecure, irregular and flexible labour arrangements, which do not grant them certainty of employment or income stability' (ICRSE, 2016, p 8). These deliberately unclear contractual arrangements have far-reaching implications for the labour relations and work conditions of sex workers. Seemingly self-employed, most sex workers suffer high levels of control over and regulation of their work (ICRSE, 2016, p 9). The insecurity of the contractual arrangement results in economic dependency on the proprietor or manager. In most countries sex workers do not have access to social security benefits such as sick or parental leave, paid holiday leave, or sickness, disability and pension benefits. On the other hand exploitative work practices, such as abrupt and arbitrary termination of employment, income manipulation and extremely long working hours, are widespread. Exploitative labour arrangements in prostitution are determined by two factors. The first is the prevailing business model in the sex industry. In its essence it is an informal relationship that on the one hand serves the interests in freedom and cash payments of the sex worker, but on the other hand deprives her of her rights and earnings. Or as ICRSE puts it:

What is rarely being discussed, however, is that the prosperity of the sex industry is largely guaranteed and furthered at the expense of sex workers' income and their economic security. This is due to the unfair internal organisation of workplace economies within the sex industry, which allows third parties - venue owners, bosses, managers, administrators, procurers, or landlords - to take advantage of and capitalise on sex workers' earnings, labour, skills, and time. (ICRSE, 2016, p 11) 
This exploitative business model results in common practices such as taking commissions that can reach $50 \%$ or more (in some cases because flat fees are decoupled from the actual number of clients the sex worker receives), entry fees to the facility or fees for 'services' such as safe-sex supplies, cleaning, laundry and security, arbitrary fines, and mandatory charges for room rental, drinks or food (ICRSE, 2016, $\mathrm{p} 12)$. Although this was hardly the case in the licensed sector in the Netherlands (and according to our own interviews the same applies to Austria), ICRSE reports that many sex workers in Europe suffer hazardous and substandard work conditions, that responsibility for financing personal safety equipment and health services is shifted on to sex workers, and that in too many cases proprietors or managers pressure sex workers into unsafe sex exchanges.

The second factor relates to the structural determinants of labour relations in the sex industry such as the fact that sex workers operate in a context of illegality and repressive regulation and are not covered by the employment laws that apply in other industries. It goes without saying that the position of (undocumented) migrant sex workers in the sexual services industry is even more precarious than that of indigenous workers. The common practice of tying the right to work of migrant workers to their employer, the continuous threat of being deported and workers' dependency on immigration bureaucracies for the proper licenses and papers to be able to work, put the migrant sex worker in an even more vulnerable position vis-à vis-owners, managers and unscrupulous middlemen.

Three additional circumstances contribute to the insecurities inherent in the sex worker's labour relations. The first is the criminalisation of the sex worker (and in many countries clients and third parties) through a range of repressive laws and administrative measures that seek to regulate prostitution. As we have seen in the previous chapters, the often deliberate over-association of prostitution with crime reinforces the stigma of prostitution, puts sex workers in an even more vulnerable position and disempowers them in the workplace. We will return to this point in the next section. This disempowerment is augmented by the unwillingness of governments to actively protect the labour rights of sex workers. As we saw in Chapter Three after the repeal of the brothel ban that elevated sex facilities to the status of regular businesses subject to civil and administrative law, the Dutch government took the position that the relationship between the sex workers and the business owner was a matter of civil law and precluded the interference of the state. While formally correct, this position was both naïve and disingenuous. It was naive because the unionisation that the minister 
counted on had never taken place and is a difficult challenge in general in the sex industry (Gall, 2014; we return to this point in Chapter Six). It was disingenuous because Labour Inspection, the agency that is responsible for monitoring and enforcing labour law and does so in most other industries, kept itself at a distance from the sex industry. We saw a similar attitude being displayed by the UK government in the monitoring and enforcement of its laws in the case of domestic workers. Third, many countries and municipalities have closed the only route available to sex workers to escape the precarious labour relations governing the sex industry, namely true self-employment. As we saw in Chapter Three, out of fear of losing control over the sex trade, most governments have made it illegal for sex workers to start their own business and/or work from their own house, or treat such arrangements as similar to large commercial sex clubs or even as a form of pimping or trafficking.

We return to the regulation of prostitution and the issue of exploitation in the next and final section of this chapter. But first we discuss the all-important issue of trafficking and prostitution.

\section{Prostitution, trafficking and exploitation: an alternative framework}

In a rational world this would be a brief section. As the voices of the migrant sex workers we interviewed testified, exploitation in the country of origin happens but is part and parcel of the process of migrating, often involves family members or other people with whom the sex worker has an emotional bond, and is usually effectively handled by the sex worker herself, if necessary with the help of the police, friends or clients. We have also seen that economic exploitation in the sex trade is widespread, but that it happens at the workplace in the arrival country and flows from the prevailing business model in which informal work arrangements put sex workers in a position of dependency on owners. All this is made possible and perpetuated by legal frameworks that fail to recognise sex work as a legitimate form of work or employment. Yet, few things in prostitution policy are rational, and the concepts of trafficking (and, in the Anglo-Saxon world, the increasingly popular 'slavery') play a central role in the law, policy and the public discourse surrounding prostitution and immigration. Trafficking, and the associated concepts of 'victim' and 'forced prostitution', have become the central symbols in the morality battles over the place of prostitution in contemporary society. Conforming to the characteristics of morality politics of Chapter Two, trafficking 
must above all be regarded as an emotional shibboleth that expresses disgust and revulsion at the idea of women exchanging sexual services and intimacy with male clients for money. The experiences of one of our interviewees - a Dutch police officer who monitors brothels in search of 'signals of trafficking' - illustrate this point.

The official is an experienced police officer with a long career in the serious crime unit of the police force. During the interview he exclaimed in an emotional voice that he considered trafficking "one of the most heinous crimes". To put this in perspective, this is the view of someone who has witnessed aggravated assault and murder. When asked to elaborate on this statement, he embarked on a long exposition that showed a strong identification with "innocent young women" whose "lives were destroyed" by ruthless traffickers. He related a lengthy story about a sex worker whom he had persuaded to leave the sex trade to continue with her education. To his dismay, however, she subsequently returned to prostitution. He attributed this to a combination of bureaucratic inertia (the delay of financial support to allow the woman to study) and the irreversible effects on her personality of having worked in prostitution. In discussing his work of inspecting brothels and detecting 'signals of trafficking', he said that some of the women whom he designated 'victims' objected to his characterisation. This was not just because they received a negative work notation, he said. He gave an example: "One of the women was from Romania. She had a university education. But she only made $€ 350$ a month there. Here she makes $€ 700$ a day. It doesn't bother her that she has to pay someone $€ 300$ a day" (interview, police officer). ${ }^{133}$

The police officer continued by stating that the legal article that defines trafficking is very broad. This, in his view, is an advantage. It is not only about coercion and violence, he said: "You find the nuance in the transport, the housing, the recruitment, and in taking advantage of the women. It is of those things that the cleverness of the trafficker consists." He went on to complain that district attorneys and judges often "don't get it" - they do not understand how trafficking works - and quoted a district attorney, who said of a sex worker who came from Hungary to work on a ' $50-50$ basis', that that was 'reasonable, wasn't it'. The police officer expressed astonishment at so much naïveté. "No", he said emphatically, "it isn't reasonable. This is trafficking"

133 The fact that we repeatedly heard similar stories among police officers suggests that the figures on earnings are not accurate, but serve a rhetorical purpose. Our data show that earnings are generally lower and more erratic. 
(interview, police officer). ${ }^{134}$ It is not our intention to criticise this police officer - he was a reasonable and dedicated public official - but to illustrate a frame of mind that has engulfed the political debate on prostitution in Austria, the Netherlands and the rest of the world in the 2000s in which trafficking functions as the rallying point for groups who seek to abolish prostitution from society.

Trafficking means different things to different people. In the extensive literature on trafficking, the concept has been framed as sexual violence against women, as a form of organised crime, as a human rights problem, as a migration issue and a problem of labour rights. But this misses the point. The inherent fuzziness of the concept is an advantage as long as it fulfils its role of tying prostitution unfavourably to migration and crime. We saw in Chapter Two that the vehement discussions of the formulation of the trafficking article in the UN Protocol to Prevent, Suppress and Punish Trafficking in Persons, Especially Women and Children reflected the stand-off on this point between abolitionists and those who were in favour of decriminalising prostitution. The result was a partial victory for the abolitionist camp in two respects. The trafficking article was deliberately framed in a broad way to allow member states to interpret it according to national circumstances. And it tied the concept of exploitation to the migration process (and measures that involve policing borders and enforcing migration law against sex workers) while ignoring exploitation at the workplace. The concept of trafficking with its emphasis on organised crime and what transpires in the country of origin obscures the exploitative relationships in the host country and the risks to which recent immigrants are exposed. As O'Connell Davidson observes, the UN protocol has had the negative consequence that it puts the alleged threat of organised crime instead of the human and labour rights of immigrants at the centre of attention: $[T]$ he Trafficking Protocol is problematic from a human and migrants' rights perspective because it attaches special significance to situations in which abuses at the point of destination are linked to the use of force or deception within the migration process. State parties are not being required to meet newer or higher standards with respect to protecting the rights of any migrant person who is subject to deception, force and exploitation within their borders, but only with respect to those who have also been cheated and exploited within the migratory process. (2006, p 9)

134 We agree with the police officer here; it is not reasonable. But we disagree that commissions are an instance of trafficking. As we have seen, they constitute labour exploitation. 
The UN protocol put the concept of trafficking centre stage in the public debate, bestowed it with legal authority, and framed it as sexual violence against women and a form of organised crime, instead of as a human rights problem and a problem of labour rights. The protocol is far from a neutral or benign tool that helps nations to develop policy instruments or uniform data collection procedures, but has very real negative effects 'on the ground' on sex workers' rights. The development of prostitution policy in the Netherlands is a case in point.

The trafficking article is the longest and most unclear article in the Dutch Penal Code. ${ }^{135}$ Its main elements concern recruitment, transport and exploitation. The UN protocol is interpreted expansively in the Netherlands and declares all recruitment of women for sex work in another country as illegal. ${ }^{136}$ The issue of the motivation, advance knowledge or consent of the woman to enter into the sex business that used to play a role in court proceedings has thereby become moot. Since the signing of the UN Protocol, exploitation is a key element of the definition of trafficking in Austria and the Netherlands. Clause 2 of the trafficking article in Dutch criminal law specifies the legal definition of exploitation: 'The exploitation of another person in prostitution, other forms of sexual exploitation, forced or indentured labour, other forms of sexual exploitation, forced or indentured labour or services, slavery or indenture that is comparable to slavery.' ${ }^{137}$ The legal definition of exploitation could in principle be considered a positive development that makes it possible to design policy strategies and policy tools to fight

135 According to District Attorney O.V.J. ten Kate at the launch of the book De Fuik by Henk Werson in Amsterdam on 19 January 2012 (Werson, 2012).

136 Strictly speaking that would mean that someone who, for example, gave a sex worker who works in Dortmund a ride across the border to Amsterdam would be guilty of trafficking. In practice these broad-spectrum definitions of trafficking, while ideologically gratifying, do not work. Dutch law, for example, makes a distinction between acts of trafficking that are 'strafwaardig' and 'niet-strafwaardig'. This translates roughly as 'punishable and 'non-punishable'. 'Punishable' requires the well-known elements of gain, deception and/or violence. Giving a cross-border ride to a befriended sex worker would be considered 'non-punishable' and would not lead to prosecution. Austrian law makes distinguishes between trafficking and trans-border trade in prostitution (Grenzüberschreitender Prostitutionshandel) which is also punishable according the Penal Code but not as severely as human trafficking. Indeed often accusations of human trafficking are later downgraded to Grenzüberschreitender Prostitutionshandel as the existence of exploitation cannot be proven. The conclusion must be that the expansive definition of trafficking is symbolic politics.

137 Austrian law also puts exploitation at centre stage, be it exploitation in prostitution, begging, labour in general, or the sale of organs. 
the kind of exploitation that is endemic in a stigmatised profession such as prostitution, were it not for the fact that the dominant trafficking discourse has led to much confusion, myopia, incoherencies and contradictions that have precluded such a development so far. First, as Sanghere perceptively notes, 'The dominant trafficking paradigm rests upon an absence of the critical distinction between trafficking and migration on the one hand and trafficking and prostitution on the other' (2012, p 10). One of the implications of this confusion between trafficking, migration, prostitution and coercion has been a persistent misdirection of the focus of policy. Equating trafficking with migration has resulted in a move to stop and curb the latter. Yet, as analysts and international organisations have concluded over and over again, the solution exacerbates the problem: 'Lack of legal rights to mobility and legally accepted forms of livelihood compel marginal and vulnerable groups to lead underground lives, enhancing manifold their vulnerability to harms such as trafficking, bondage, slavery-like working and living conditions, and HIV/AIDS' (Sanghere, 2012, p 8; see also Vance, 2011, p 935). The effect of this persistent anti-migration stance is to approach the migration of low-wage workers with an 'ethos of criminality' (Vance, 2011, p 936), particularly when the migrants are women and sex workers. Every step in the sex worker's migration trajectory, from the journey to the country of destination, the people whom she enlists to assist her in travelling and settling, the housing she finds in the country of residence, the conditions of work, the wages she earns, her partners and colleagues, are all tainted by an assumption of illegality. The assumption of illegality only perpetuates the vulnerable position of low wage migrant as it keeps them from accessing the services and enjoying the rights that are extended to recognised citizens (Sanghere, 2012, p 9; see also Baptista and LEFÖ, 2014, p 10 onwards). At the same time the confusion between prostitution and coercion has resulted in an attempt to eradicate prostitution altogether, and to expose prostitution policy to various forms of religious and radical feminist-inspired abolitionism. The result is that policy initiatives are misdirected. In the popular discourse and the minds of officials exploitation of migrants is restricted to 'forced prostitution' instead of the much more commonplace and persistent forms of exploitation in occupations such as the cleaning industry, meat packing, domestic services, construction and agriculture that are available to low-wage migrants (Caixeta, 2005; Vance, 2011, p 939). Moreover, the very real problem of workplace exploitation in prostitution dissolves in vague allusions to 'trafficking', 'forced or illegal prostitution' and the alleged iniquity of clients. 
The basic meaning of exploitation, as we saw in the previous section, centres on the notions of taking unfair advantage of someone's else's work, unacceptable work conditions and/or the deprivation of worker rights. ${ }^{138}$ We argue that the concept has considerable advantages in guiding both an effective and humane policy towards sex workers and other migrants. First, it reorients attention from the complexities and ambivalences of what transpires between the women and the middlemen in the country of origin and the irresolvable issue of women's alleged consent or naïveté, to the work situation and labour rights in the destination country (Andrijasevic, 2004; O'Connell Davidson, 2006; Amesberger, 2014; ICSRE, 2016). Second, it brings into the purview of the policy maker the endemic exploitation that occurs in sex facilities, including licensed ones (Altink and Bokelman, 2006; O'Connell Davidson, 2006, pp 11-14; ICRSE, 2016). Third, it moves us away from prostitution essentialism, or the belief that exploitation is a defining factor of prostitution only. ${ }^{139}$ Instead, exploitation is a feature of many types of work, particularly, but in our neoliberal economy not exclusively, at the lower end of the labour

138 The Austrian jurisdiction distinguishes Ausnutzung (taking unfair advantage) and Ausbeutung (exploitation). According to the High Court, taking unfair advantage is given when there is no or no commensurate reward and at least $50 \%$ of the income is taken away; exploitation is defined as a cut-off of $75 \%$ or more (source: OGH [Oberste Gerichtshof - Supreme Court] 13Os65/06t from 23 June 2006, 15Os122/07s from 21 January 2008, 12Os24/07g from 31 May 2007). It seems that Austrian facility owners are aware of this distinction and play the system accordingly.

139 Essentialism is a common fallacy in social and political analysis. 'If a group of objects referred to by a common term (be they people, institutions, or practices) do not have any universally shared attributes, then clearly they do not have a common essence. If they do have some shared attributes, this alone does not mean these are essential rather than accidental, even if they occur in 100\% of cases. "Associational thinking", which assumes that what happens to go together must go together, is therefore analytically feeble. If we are to understand the structure of any object of study, we need to distinguish those features that merely happen to coexist - and perhaps interact - but could exist apart from those that could not exist without a certain other feature' (Sayer, 2000, pp 84-5). Essentialism is important because it does two kinds of moral work, particularly, but not exclusively, in a morally contested area as prostitution policy. First, it cuts the object's ties with its social context and defines it as somehow unique, incomparable to any other object or activity. Essentialism thereby obscures the wider context that sustains a social object. To be aware of the constructionist nature of a social or policy definition helps us to look for similarities with and analogies to other social objects, which in turn enables us to broaden our understanding of the object. Second, as we have allegedly reached the rock bottom of determining factors, essentialist reasoning is meant to shut down any further discussion. 
market, such as agriculture, the construction industry, the cleaning business domestic services and the rapidly expanding 'gig economy' (Kapur, 2012; Kempadoo, 2012b; Sanghere, 2012) ${ }^{140}$ Moreover people with a vulnerable position in the labour market, such as children, women or recent or illegal immigrants, run a greater risk of being exploited (Caixeta, 2005; Baptista and LEFÖ, 2014).

In the conclusion of this chapter we put forward a policy alternative to the concepts of trafficking, forced prostitution and exploitation as an intrinsic element of the migration process. Our alternative is meant to help policy makers recognise situations of labour exploitation and abuse in prostitution in an unequivocal way and design appropriate measures that target the perpetrators instead of the victims of exploitation. Our starting point is that exploitation is a potential characteristic of many (employment) relationships. Because of the stigmatised and migratory nature of prostitution as well as its precarious legal status, exploitation, like in the low-end service industry in general, is prevalent in the sexual services industry. Such labour exploitation can be broken down into different categories: working for substandard wages or income; overly long working hours; dependency on third parties; and forms of sexual violence such the inability of the sex worker to choose or refuse clients, to refuse unwanted sexual activities (from clients, managers or third parties) or to determine the conditions for sexual service provision.

Reframing trafficking in terms of labour exploitation has six beneficial effects on policymaking. First, we become aware that labour exploitation is not restricted to prostitution, but instead is a risk factor in all forms of employment, particularly of vulnerable populations such as children, migrant women, recent and undocumented immigrants and those with little education. ${ }^{141}$ Second, it directs the attention of policy makers to the site where the exploitation occurs, the workplace, and away from the ambiguous and usually misunderstood migration process. The concept of labour exploitation also makes us aware, third, that exploitation in prostitution is not a monolithic phenomenon

${ }^{140}$ On the gig economy, see www.theguardian.com/commentisfree/2015/jul/26/ will-we-get-by-gig-economy.

141 The current practice of so-called zero hour contracts or unpaid 'internships' are examples of economic exploitation in the regular labour market. Also, sexual violence is not only a problem in the field of sex work but also in other fields of work. One of us (Helga Amesberger) has just finished some research on the sexual harassment of young people in work and training situations. She found that it was very difficult for the young women and men in question to talk about the harassment with persons of trust within their company or with functionaries of trade unions, and to seek help. 
but that it exists in different forms and gradations. Fourth, framing prostitution and its various forms and gradations of exploitation as a form of labour migration restores agency to the migrant sex worker. The concept of trafficking prevents us from grasping the diversity of reasons why immigrant women choose to enter prostitution, the exploitation that occurs in the host country after immigration, and the fact that exploitation is experienced by immigrants and local (low-income) women alike. Instead of a helpless victim the (migrant) sex worker becomes an individual who makes conscious choices in a situation of, often considerable, constraints. Indeed in our fieldwork we encountered many women who had voluntarily decided to move from, for example, Romania or Bulgaria to Austria or the Netherlands to work in prostitution, who endured excessively long working hours and had to hand over a considerable part of their earnings to brothel owners, but who nevertheless managed to send money home on a regular basis, and who claimed that, despite everything, life was better than in the country of origin where they had no prospects at all. This does not detract from the exploitative nature of the labour situation in which these women find themselves. The measure of exploitation is relative to the labour and workplace laws of the host country. Therefore the concept of labour exploitation lays the responsibility, and the leverage points for policy intervention, at the doorstep of those who are responsible for this situation: the middlemen, the venue and business owners and the officials who develop and implement migration, sex work and labour policies that create and sustain precarious labour. And finally, the concept of coercion prevents awareness that there are longstanding laws, administrative measures and enforcement agencies in the destination country that play - or should play - a role in preventing labour exploitation in the workplace, for nationals and immigrants alike.

The concepts of trafficking (and its widely used corollary, forced prostitution) enjoy their popularity because of their symbolic meaning (Doezema, 2010). They signal the moral position that prostitution is 'essentially' a form of male domination over women. Reframing these concepts as different forms of exploitation creates a productive set of analogies with similar phenomena in other occupations. It also redefines the problematic and muddled concept of trafficking as one, extreme, manifestation of the sexual and economic exploitation of recent immigrants from low-wage, underdeveloped countries to highwage, developed nations. The net effect is to take the different forms of sexual and economic exploitation out of the morality politics of prostitution and bring it within the remit of labour, economic and administrative law. 



\section{Prostitution policy beyond trafficking: collaborative governance in prostitution}

\section{The challenges of prostitution policy revisited: harnessing a complex policy field}

Every policy domain imposes its own specific demands on the politicians and officials who bear responsibility for it. In Chapter Two we delineated five domain-specific challenges that face those officials who are entrusted with regulating prostitution. In Chapter Five we added the general challenge - a challenge that is not specific to prostitution policy, that every policy maker faces to a greater or lesser extent, but that constraints and shapes the capacity and possibilities for policymaking - that prostitution is a complex policy field.

The domain-specific challenges are the following. Prostitution is stigmatised. Trading sex for money is considered to be demeaning to women and involve the unacceptable commodification of female sexuality (Nussbaum, 1998; Radin, 2001). The stigma surrounding prostitution results in public condemnation, or at the very minimum, public distrust, lack of acceptance and a generalised anxiety about prostitution's effects on marriage and community. It also leads to sex work taking place at the margins of society, usually in designated urban spaces, undertaken by those such as low-income immigrants who are at a far remove from the general public, or by ordinary women working and living among us who conceal their work as a sex worker. Stigmatisation transforms female prostitution into an unspecified threat from an unknown other; a contagious activity that affects the morals of our daughters, sons and husbands and threatens public health, morality and the status of women (Corbin, 1990; Nussbaum, 1998, p 709; Chuang, 2010). This combination of fear, approbation and ignorance leads to an urge among authorities to control prostitution.

In addition to the stigmatised, covert nature of prostitution, and partly as a result of it, precise and reliable statistics are hard to obtain. Prostitution is an occupation that is characterised by, sometimes extreme, mobility, which makes it almost impossible to collect basic statistics 
such as the daily number of sex workers in a specific geographically bounded location. Another reason for the lack of reliable statistics is the difficulty of precisely defining core policy categories, in particular categories such as 'trafficking' and 'forced prostitution'. We return to this issue later in the chapter. The combination of cultural ignorance about prostitution and sex workers, and the lack of numbers, creates a situation in which, even in the best of circumstances, policy makers are 'sailing blind', without the solid base of evidence to guide their assessments and decisions that exists in many other policy domains, such as health, education and employment.

But these are not the best of circumstances. Prostitution policy is an archetypical case of morality politics. We spelled out the implications of this in Chapter Two. The topic of prostitution in society is engenders strong ideologies. As everyone considers morality their own provenance, morality politics is lay politics - everyone has an opinion about it. Morality politics occupies a peculiar position in relation to evidence: facts are instruments in the service of a moral argument; facts that contest the moral position are resisted, if necessary, adjusted, or in some instances, fabricated to fit the position (Weitzer, 2007; Doezema, 2010). This radically changes the perspective on the role of evidence in prostitution policy. Instead of a lack of facts, as suggested in the previous paragraph, evidence, with all the trappings of scientific and political authority, fulfils the function of a fantasy. Policy analysts speak in this regard of fantasmatic logic, a concept inspired by psychoanalysis to denote the need among policy makers and the general public to improve or complete an imperfect reality with utopian narratives of stability, repair and control (Schön, 1971; Stone, 1997; Glynos and Howarth, 2007; Mert, 2015). In the context of morality politics ignorance is an advantage and evidence an allure, a temptation to shape and bend policy towards some preconceived moral position. As we have seen, morality politics upsets the balance of stability and change in public policy. Where in normal circumstances stability comes from laws, constitutional structures and stable configurations of value and understanding, change is inspired by policy learning, a change of actors or strong exogenous shocks (Cairney, 2012, pp 208-9). All this is moot in the case of morality politics where fantasmatic logics induce both sudden, sharp changes in local rules and strategies and longitudinal drifts from policy goals. This is substantiated both by the frequent twists and turns in local prostitution policy and the wider regulatory drift away from legalisation towards a de facto repressive policy that attenuates and disowns the goals and assumptions of earlier policies. 
Prostitution policy is hard to disentangle from immigration policy. In this world of large population movements, and with most sex workers being immigrants, prostitution policy has a close political and legal association with immigration policy. This association has a predominantly restrictive character. Nations do not like poor immigrants; they certainly do not like poor immigrants who choose to work in prostitution. Despite the right to free movement of labour within the constitutional space of the EU, nation states still try to discourage and unsettle sex worker migrants from EU countries after they have habituated to the destination country. This dynamic is reinforced by the trafficking discourse. Vance rightly encourages the observer of contemporary prostitution policy to distinguish between 'law in the books' and 'law in action'. Where the first is clear about human rights, labour rights and the free movement of labour within the $\mathrm{EU}$, the second focuses on criminal codes relating to police borders, on the criminalisation of prostitution even in the licensed sector, on the fight against 'forced prostitution', and on labour laws that disempower immigrants.

The general challenge we identified is that prostitution policy has all the characteristics of a policy field. Policy fields are characterised by multiplicity, complexity, interdependency, emergence, uncertainty and unpredictability. From the vantage point of the policy maker who operates from within a policy field, the world looks messy and disordered. The dynamic complexity of policy fields has two important implications for policy makers. First, because emergence, the relational dynamics within the system, is the main 'engine' of the policy field; its behaviour is inherently unpredictable. That does not mean that the field lacks any regularity; interactions between elements can settle into regular patterns. For example, the exploitative business model of brothels that can be found in almost all countries is an example of such patterned regularity. However, because of the extensive nature of the field and its open boundaries, it is always prone to destabilising shocks that ripple through the system making it inherently unpredictable. The Sneep case that shook up Dutch policy makers in 2005 is an example of such a shock.

Second, dynamic complexity means that interventions result in unforeseen, unintended consequences. As we have seen over and over again in the preceding chapters, even well-meaning policy interventions in the domain of prostitution tend to result in, mostly negative, unintended consequences. In most cases these concern the human and civil rights of sex workers and immigrant women; in other cases they extend to the constitutional integrity of a legal code or governance 
system, or the social status of a group (clients of sex workers). It is not always easy to specify the causal link between policy intervention and unintended consequence. In some cases the ideological zeal of officials narrows their understanding of the possible consequences of their actions - one goal (control, the prevention of trafficking) trumps other considerations, such as privacy or fair treatment. In some cases unintended consequences (but how unintended were these really?) result from the deliberate selection of one set of interests (citizens' comfort, employers' freedom to act) over those of another (sex workers' rights to freedom of movement in the city and to change jobs). Perhaps the most common unintended consequence in prostitution is policy failure. The causal mechanism is a lack of information and understanding of the world of prostitution that results in measures that do not address the concerns or incentives of the parties affected, and that are easy to evade or counteract (Wagenaar, 1995).

What does all this add up to? We have observed that prostitution policy, although hotly debated at the national level in parliament and media, is realised at the local level. This means that local officials have been entrusted with the task of translating broad laws into workable programmes, selecting the policy instruments that give hands and feet to vague and unclear policy goals and statutory language, and above all interacting with the actors on the ground to induce them to be compliant with the law, to adjust their behaviour to conform to the goals and spirit of the law. Localism is an inherent quality of prostitution policy. We encapsulate the challenge faced by local policy officials dealing with prostitution regulation as follows: How can local officials design and implement an effective and humane prostitution policy that is cognisant of the global and moral forces that shape prostitution in contemporary society? Differently put, how can they steer free from the eroding influence that morality politics has on fairness, truth and human decency, accommodate the uncertainties and ambiguities created by the lack of evidence in this sector, understand and take a humane stance towards the global forces that compel scores of poor people to try their luck in other countries, and take the ineradicable stigma that is attached to prostitution into account in their mediation between sex workers and the larger society? How can policy makers effectively navigate a complex policy field?

We believe that these challenges are not confined to the two countries that were part of our research project, but that they apply to each and every country that attempts to regulate prostitution. Stigma, morality politics, lack of data, immigration, dynamic complexity and negative unintended consequences are forces that influence the sex 
trade everywhere, although perhaps not always with exactly the same potency, given the singularities of individual countries. Similarly, the national-local relationship is crucial to prostitution policy everywhere. National legislation has to be translated into local policy design to be implemented, but at the same time, as we have seen, the local exerts considerable discretion in shaping public policy. The literature on complex adaptive systems contains many suggestions for dealing with dynamic complexity, too many to discuss here in depth. One principle, however, underlies all this advice: complexity cannot be eliminated or denied. It also defies control. Control, as we have seen, is a governance fantasy. The best we can hope for in addressing these formidable challenges is to harness dynamic complexity, to take advantage of the opportunities it offers and use it for productive ends (Axelrod and Cohen, 2000, pp xi-xii), in other words '[S]eeking to improve but without being fully able to control' (Axelrod and Cohen, 2000, p xvi). Harnessing complexity boils down to three broad strategies: increasing variation, changing interaction and selecting and nurturing solutions that work (Axelrod and Cohen, 2000). By increasing variation we introduce new ideas, insights and experiences into a policy field that open up unproductive routines and stagnant problem solutions. By changing interaction we effectively create new relational dynamics and thus new emergent outcomes in the field (Wagenaar, 2007). By selecting and strengthening procedures and routines that work, we enhance the governance capacity of the field (Bourgon, 2011). In this chapter we focus on the variety and interaction pillars of this threepronged strategy. We suggest that policy makers need to organise the policy process in such a way that it provides space for the voice of the sex worker to be heard where it counts, and create operating routines to allow sex workers to influence policy design and implementation. The technical term for this form of policy design is collaborative governance. But we will also see in the next sections that in the real world of policymaking, enhancing governance capacity through variation, interaction and selection requires attention to essential additional factors such as building trust, enhancing self-organisation, managing emotions, and engaging in deliberative forms of communication.

\section{Introducing collaborative rationality in prostitution governance}

Before we describe and illustrate the possibilities of collaborative governance in prostitution, we need to discuss - and dismiss as inadequate - some 'common sense' reactions to the challenges described 
in the preceding section. The first would be to formulate clear national goals and make sure, through sufficient oversight and monitoring, that local policy makers adhere to this script. This is the impetus behind the new national prostitution law (WRP) in the Netherlands. The law is supposed to create uniformity among the welter of local licensing systems. Apart from the fact that this solution fails to address any of the challenges formulated earlier, there are theoretical and legal reasons why it is likely to falter on the localism that is inherent in prostitution policy. As we discussed in Chapter Five, policy formulation and policy implementation are not strictly demarcated phases of the policy process, but are, instead, continuous, consisting of overlapping competences, actors, activities and materialities. In practice national laws act as instructions, or rather suggestions or admonitions, to lower-level officials to draw on a set of administrative routines to transform the law into a more or less workable programme. Legally, in many countries, and this is certainly the case in Austria and the Netherlands, the local level has considerable constitutional autonomy in designated areas to raise taxes, design policy, and organise and deploy police capacity. Moreover, as the WPG shows, key concepts in the national law are often vaguely formulated and open to different interpretations. Local autonomy is in itself neither a good nor a bad thing. It depends on how it is deployed. But in a moral climate in which prostitution is considered synonymous with trafficking, regulations drift into ever more repressive measures in the Netherlands, or the Viennese police make autonomous decisions such as banishing street workers to ever more remote and dangerous areas of the city, the dangers of unchecked localism in prostitution policy are clear.

A second policy reaction would be to make a serious commitment to eradicating prostitution from society, as this moral blight and affront to women has no place in a highly developed, civilised society. We possess the legal and administrative tools - prohibition and the criminalisation of clients - and we must make sure that we deploy sufficient means and are serious in enforcing these prohibitions stringently. This solution addresses the morality dimension in prostitution policy. It would satisfy all those who perceive prostitution as morally unacceptable and degrading to women and it would send a signal to men to take gender equality more seriously. Moreover, by eradicating prostitution from society, it would solve most of the other challenges. Most, but not all. Apart from the considerable and probably insurmountable enforcement problems, prohibition does not address the issue of mass immigration. Nations, such as Italy, Spain and most countries in the Global South, that have long prohibited and criminalised prostitution 
still receive many immigrants from poor countries, some of whom choose to work in prostitution. ${ }^{142}$ The results are the well-known effects of driving women, whose social position is already precarious, into illegality where they are even more vulnerable to harm such as exploitation, dependency, indentured labour, and corruption by public officials. Dora's story at the beginning of this book is a stark reminder of that perverse dynamic. The problem is that, as far as we can see, no society has ever been able to completely eradicate prostitution. It is one of those utopias, one of those fantasmatic logics that, in one form or another, inhabit every policy domain. ${ }^{143}$

So, where does this leave us? As we argued in Chapter Three, policymaking is a practice. It is an ongoing and routinised accomplishment (Nicolini, 2012, p 3). Policymaking, in any domain, is a practical attempt to improve or accommodate a situation that is regarded as being in need of improvement. That means that policymaking is deeply embedded in the ideational-material world, to which we bring our competences, routines, habits and improvisations, our ideals and values, our worries and personalities (Wagenaar, 2004). The means we have at our disposal to deal with this ideationalmaterial world are equally commonplace: set up a meeting, write minutes, compose a report, have an informal talk with a colleague, assign a task to a junior associate, monitor agreements from an earlier meeting, visit a brothel for the monthly hygiene inspection, process an application for license - the list is as endless as it is tedious (Freeman, 2016; Rhodes, 2015). Somewhere in that everyday reality of public administration problems get solved, or not, and policy goals reached, or not. How does this humdrum take on policymaking address any of the formidable challenges formulated before? Through, what the practice theorist Pickering calls a 'dialectic of resistance and accommodation', where resistance denotes a temporary failure to capture the agency of an object or person and accommodation a response to this resistance (Pickering, 1995, p 22). From the perspective of the administrator the challenges that beset prostitution policy are shorthand for a bundle of

142 This includes indigenous women within the affluent countries of north-western Europe who, for a variety of reasons, exchange sexual services for money.

${ }^{143}$ Moreover, the prohibition solution does not address the sexual agency of women. Even in societies where gender relations are fairly equal, some women (and men) will decide, for financial or other reasons, to provide sexual services to men. Most countries, and certainly the countries that have prohibited prostitution, also harbour domestic sex workers, often at the higher end of the market, and frequented by the societal elite. In such societies the existence of this segment of the sex trade is a public secret that is shrouded in discretion. 
resistances as they manifest themselves 'on the ground': evasion tactics by brothel owners or sex workers, conflict with brothel owners or sex workers, a lack of coordination between different agencies, mutual misunderstanding between the main actors (often exacerbated by language and cultural differences), distrust, anger and anxiety on the part of the sex worker, aggressive media that are waiting to inflate small mistakes into major administrative embarrassments, conflicts with colleagues, a restless, angry public that demands to be heard (Wagenaar, 2006) - resistances that add up to a situation, common to much contemporary local governance, that the democratic theorist Mark Warren calls 'pluralized ungovernability' (Warren, 2014).

The literature also suggests accommodations to pluralised ungovernability that show remarkable similarities with the recommendations of fostering variability and interaction: governmentinitiated democratic participation. 'There is a lot of political work in today's societies,' Warren argues, 'that electoral democracy is unable to accomplish' (2014, p 45). This kind of participation, he continues, opens up a number of 'opportunities' to increase the governing capacity of local administrations. One is that it allows for the inclusion in decision making of those affected by an issue. The second is a more direct and specific form of empowerment of those affected. The second opportunity logically follows from the first, as inclusion without the actual capacity to influence decisions is hollow. ${ }^{144}$ The challenge is of course how to realise that empowerment. The third opportunity is trickier. It is about the capacity of the administration to build more effective forms of representation than electoral representation (which, given their precarious citizenship status, are ineffective for a large number of sex workers anyway) into the policymaking process. The strength and legitimacy of electoral representation is that it is based on equality; everyone has an equal vote. But that is also its weakness. The representative chain is not only weak but also largely unspecified. Local administrations are usually not elected because of their stance on the sex trade. Invited participation allows for more effective forms of representation. 'What matters most from the perspective of democratic representation,' Warren argues, 'is that the selection processes results in a body that includes the interests, values, views, and opinions of those potentially affected, as well as has the capacity for considered

144 Although many participatory schemes initiated by governments amount to exactly that: inclusion without decision-making influence. Think of the myriad information or consultation meetings, where participation is largely tokenistic and their purpose merely to placate the public (Arnstein, 1969). 
advice or decisions that represent the affected' (2014, p 55). More specifically, invited participation makes it possible for administrations to avoid advocacy-based representation (as in the Viennese case in which citizens captured the press and the police) and open up the policymaking process to influence by marginal or excluded groups.

In 2002 Wagenaar studied the implementation of the legalisation of brothels in the city of The Hague. What he, unexpectedly, found was an instance of government-initiated participation. It was imperfect (it was as much aimed at improving interagency coordination as including societal actors; it included only brothel owners and excluded sex workers and their advocates; there were such major conflicts and so much ill will on the part of the brothel owners that parties had to seek recourse to the courts) but in the end it did the trick: the city relatively quickly and painlessly introduced a licensing system for brothels and slowly and grudgingly a measure of mutual trust developed between city officials and brothel owners (Wagenaar, 2006). The example is important for the lessons it contains. Collaboration emerged out of an astute analysis of the situation at hand by the official in charge of the licensing project. He showed awareness of the sheer complexity of the situation (the licensing meant that the regulated tolerance of the preceding years had to be transformed into a coordinated administrative effort involving a dozen city agencies), as well as of the obstructive power of brothel owners. To avoid a long hard slug towards implementing a licensing system, and assure compliance with the system once it was in place, the official concluded that it was better to include the owners in the design of the licensing. The story of the, sometimes difficult, deliberations and negotiations demonstrates mutual learning (about the sex trade on the part of officials, about the desirability of closing times on the part of the owners, and about the importance of taking responsibility for your tasks on the part of all involved) (Wagenaar, 2006).

Let us call invited participation Solution CG, where CG stands for collaborative governance, and see how it stacks up against our list of challenges. First, in thoroughly pragmatic spirit, it takes the situation at hand as its starting point, not just in the sense that there is prostitution in a particular urban space and an imperative that the administration deal with it, but also that the only means that we have in our possession to deal with it consists of routine, unremarkable, practical, common sense. This answers both to the localism aspect that is inherent in prostitution policy and the intrinsic pragmatism of public policy. It is no coincidence, for example, that in their survey of collaborative governance, Ansell and Gash discovered that many of 
these collaborative local projects 'bubbled up', similar to the initiative in The Hague, in response to governance problems. As they observe:

Collaborative governance has emerged as a response to the failures of downstream implementation and to the high cost and politicization of regulation. It has developed as an alternative to the adversarialism of interest group pluralism and to the accountability failures of managerialism (especially as the authority of experts is challenged). (Ansell and Gash, 2008, p 544)

By including 'those affected by the issue', Solution CG answers to a number of other challenges to prostitution policy: lack of data, ignorance about the understanding of the immigration experience of poor women and the cultural distance created by the stigma on prostitution. Solution CG is especially strong on the problems of ignorance and lack of reliable and accurate data. Participating parties - sex workers and brothel owners - are able to contribute their experiential knowledge of the sex trade to assist in better policy design and criticise misguided or unworkable policy tools. Solution CG does not accommodate all ideological positions on prostitution, however. In the claustrophobic moral space of morality politics, pragmatism, with its conditional acceptance of prostitution, is itself an ideological position - as is every other policy approach to prostitution.

However, before we discuss the possibility of collaborative governance in prostitution policy, we need to address the question of who the partners are in such a collaborative relationship. In the The Hague case sex workers did not play a role in the deliberations over the design and introduction of a licensing system. In complexity terms, by not including sex workers the officials did not optimise the requisite variety in the policy field that is a condition for successful learning and adaptation. This deprives policy makers of the opportunity to be exposed, in a non-antagonistic setting, to knowledge, experiences, affects, personal histories and solutions that lie outside the reigning administrative frameworks. We are aware of the practical difficulties of involving sex workers in arrangements for policy design. Pervasive stigma and its sedimentation in law and implementation practices, results in mutual distrust, personal isolation and high mobility, and makes sex workers hard to reach. The experiences in Vienna with the design of the new Viennese Prostitution Act (Chapter Three) are case in point. A one-off hearing of individual sex workers by the authorities did not add up to a stable mechanism for securing the latter's input into the 
routines of policy design in Vienna. There was increased variation but at the system level the traditional interaction mechanisms did not change and there was insufficient selection of positive learning mechanisms to effectively counteract the usual interactions in the policy field between politicians, citizens and the media (Axelrod and Cohen, 2000, pp 1567). In the end the opportunity to learn from sex workers' experiences in designing a licensing system for brothels was limited. To benefit from the experiential knowledge of sex workers these collaborative relationships require the existence of stable, autonomous, self-assured partners. While most countries have sex worker organisations, we need to look more closely into the organisation and relational dynamics of such organisations to assess their capacity for collaborative governance.

\section{Sex worker advocacy and the state}

Governance scholars agree that societal interests participate most effectively in policy networks when they are organised. This understanding is partly theoretical and partly practical. Theoretically it derives from the sway that political pluralism holds over theories of the policy process. This, largely American, approach states that numerous interest groups attempt to influence the political agenda and decision-making process, while the state acts an arbiter between such groups. Practically, the internal dynamics of policy networks are easier to navigate when the participants represent organisations or organised interests (Rhodes, 1996).

Like most occupational groups sex workers organise themselves to exert influence to protect their rights and campaign for safe work conditions and sex workers' wellbeing. However, due to the stigmatised nature of prostitution, self-organisation in sex work differs from that in other occupations. Two events, both dating from the mid-1970s, mark the beginning of contemporary sex workers' self-organisation. In 1973 COYOTE (Call Off Your Own Tired Ethics), seen by many as the first contemporary sex worker advocacy group, was founded in San Francisco (Gall, 2014). COYOTE's strategy was a combination of political campaigning and the provision of services to sex workers. It supported the creation of many similar groups in other American cities. On 2 June 1975, around 100 sex workers in Lyon occupied the Saint Nizier church in the centre of the city. The occupation was a reaction to the prison sentences that 10 of their colleagues had received for soliciting, and the culmination of a period of protest and (unsuccessful) negotiations with the authorities about repressive policies, police harassment and corruption in the municipal administration regarding 
the governance of prostitution (Mathieu, 2001, p 108). The occupation received support from unions and political organisations in France, attracted widespread positive media coverage, and grew into a rallying point for sex worker rights organisations in France and abroad. Both COYOTE and the more loosely organised French groups were ignored, and in the French case repressed, by government authorities. However, both were successful as vehicles for consciousness raising and self-affirmation within the community of sex workers (Mathieu, 2001, p 122).

These early initiatives were followed by the foundation of the International Committee for Prostitutes' Rights, and the first international conference for sex workers in 1985 in Amsterdam. The HIV/AIDS crisis in the 1980s, although it identified sex workers as one of the sources of contagion, proved to be a window of opportunity for the formation of sex worker advocacy groups and the possibility of collaboration with government authorities. Protecting the health of their colleagues through the promulgation of safe sex practices became one of the main goals of many emerging sex worker advocacy groups. Long-standing, effective sex worker rights organisations such as the New Zealand Prostitutes' Collective (NZPC), the Scarlet Alliance in Australia and the Rode Draad (Red Thread) in the Netherlands (now defunct) were all founded in the 1980s. Similarly the fight against HIV/ AIDS initiated numerous advocacy organisations in Asian countries. At the same time public health authorities in several countries began to see that the involvement of community organisations, with their experiential knowledge of the work circumstances that increased and decreased the risk of HIV/AIDS and the means to design and support prevention measures, were a valuable ally in the fight against HIV/AIDS. Although the police attitude to prostitution scarcely changed, self-organisation and the positive experience of collaborating as a trusted partner with public health professionals proved to be an important form of self-definition and group affirmation (Beer and Tremblay, 2014, p 291).

Sex worker self-organisation is shaped by a number of characteristics in which prostitution differs from other occupations. Every occupation is to greater or lesser extent regulated, by state agencies that impose national regulation on the occupational group and through selfregulation by trade bodies or professional organisations. These regulations guarantee the quality of the product, organise appeal procedures in cases of conflict, specify sanctions in cases of dysfunctional or dishonest professionals, and in general promote adequate workplace conditions and labour rights. Because of the stigmatised, and in many 
cases criminalised, nature of prostitution, its regulation has a wholly different character from that of other policy fields. First, as we saw in the Chapter Five, regulation of prostitution is not about the quality of the service or the adequacy of workplace conditions. And, second, trade bodies and professional organisations do not play a role in the regulation of prostitution; prostitution is regulated by the state, and the policy instrument of choice is criminal law or authoritative forms of regulation (Gall, 2014, p 222). ${ }^{145}$ As we argued in Chapter Two, the legalisation of prostitution does not make the stigma go away. To improve the conditions under which they work sex workers are therefore forced to address the wider climate of hostility towards prostitution and sex workers. This almost automatically compels them to unite in sex work advocacy organisations that address the issues of stigma, criminalisation and the personal isolation that follows from that. That also suggests that social protest and pressure group tactics that aim to improve general civil, political and human rights are the strategy of choice for sex work advocacy groups (Gall, 2014, p 224).

Gall argues that unionisation, the route of choice for workers to create independent interest representation, is an inadequate strategy for sex workers. First, although improvement of workplace conditions is an important goal, the causes of substandard workplace conditions in prostitution do not lie solely with the 'employer', the brothel owner, but are also, if not largely, the result of the criminalisation of prostitution by the state. ${ }^{146}$ The combined effect of stigmatisation and criminalisation is that sex workers are relegated to an informal economy, where they work in isolation and in competition with each other, suffer precarious labour relations (with the attendant high mobility), and earn much of their income in the cash economy. Second, most sex workers are self-employed. This does not preclude unionisation per se, but, in combination with the other characteristics of sex work, makes it more difficult (Gall, 2014, p 222). Gall thinks that '[Sex workers'] "right to do business" as entrepreneurs and their view of themselves as individuals does not sit easily with the solidaristic and collectivist underpinnings of unionization' (Gall, 2014, p 223). We should add, third, that the fact that many sex workers are (recent) immigrants, who do often not master the language of the arrival country, and whose social bonds are mostly with family in the country of origin or the

${ }^{145}$ In the Netherlands brothel owners have set up a number of umbrella organisations. However, these do not regulate the business but act as advocacy groups, similar to employers' organisations.

${ }^{146}$ Moreover, not all sex workers work in brothels. 
community of nationals in the arrival country, augments the difficulties of collectivisation. Gall therefore concludes that:

[B]ecause of the difficulties and obstacles facing all sex worker organizations (including unions) and the need for any sex worker organization to confront the extraworkplace political and legal regimes that regulate sex work, both union and nonunion forms of sex worker collective self-organization in the workplace have coalesced around a form and modus operandi of extra-workplace pressuregroup activity that I call 'independent collectivism'. A key aspect of independent collectivism is that it is independent of operators, employers, the state and any other third parties. Thus, it is an organization composed of, by, and for sex workers only. (Gall, 2014, p 224; parentheses in original)

This is an important argument, well supported by empirical evidence. If it were true, it does not bode well for the possibilities for collaborative governance in prostitution policy. Collaborative governance requires an attitude of openness to the other party, a willingness to listen to the other's arguments. In theoretical terms, collaborative governance requires agonism instead of antagonism. Independent collectivism, with its disposition of independence, struggle, protest and resistance, sits closer to antagonism and resistance than to agonism. Yet, we also think that the argument overstates its case. First, solidarity and collectivism, just as well as individualism, protest and resistance, are not individual traits but dispositions and practices that are conditioned by the way situations are structured. The political climate in which sex workers operate determines the possibilities of constructive collaboration. Gall's own work bears this out. The cases of self-organisation from the US and Canada all involve advocacy groups, usually locally organised, in opposition to the political regime and the local police. In Australia the Scarlet Alliance rapidly managed to become a national group, recognised by federal and provincial governments, and was subsequently awarded contracts to provide health and education services to sex workers. The same story can be told about the NZPC (from interviews with Hendrik Wagenaar). The difference is that in the first two countries prostitution is criminalised, the social climate, fuelled by sensational media items, is hostile to prostitution, and the police, either hostile or indifferent to sex workers, are entrusted with the implementation of the law. In Australia and New Zealand on the other hand, prostitution is decriminalised, the political and social climate is more accepting of 
prostitution, and the police act more as a partner towards sex workers than as an enemy.

Second, research on sex worker organisations shows that they are able to combine advocacy and independence with a service provision task. It is widely observed that advocacy organisations operate in a perennial tension between services and politics. Members feel that the degree of formalisation that is required to fulfil service tasks, often funded by the state, conflicts with the broader goal of changing societal attitudes towards sex work and fighting police corruption. Also, formalisation implies some form of registration and record keeping, which members perceive as endangering their anonymity. Moreover a real danger exists of being co-opted by the state through subsidies and grants, where the conditions that are attached to the funding allow state agencies to impose their agenda on the advocacy group (Beer and Tremblay, 2014, p 299). Members of the NZPC trenchantly express this tension:

In the beginning, the NZPC resisted the formality of things such as group registration and membership lists because it wanted to create a more fluid movement that people could move in an out of easily. These kinds of formalities were seen as barriers to becoming part of a move for change, as many sex workers were reluctant to be formally identified as such. A flat structure was preferred where everyone would have a part to play and the idea of having formal meetings did not initially appeal to the group. (Healy et al, 2010, p 46)

However, evidence from Canada, the US, New Zealand and the Netherlands demonstrates that it is possible to establish a sufficient level of trust between the sex worker organisation and government agencies to establish a productive working relationship (Healy et al, 2010, p 47). The state is never a monolithic entity; while it might not be possible to develop trust with some agencies or officials, others prove to be more open and pragmatic in their relations with sex worker organisations. For example, while its relationship with the mayor of Amsterdam was openly antagonistic, the Rode Draad always had a cordial and reciprocal working relationship with officials from the tax authority and the Ministry of Social Affairs and Labour Relations (personal observation, Hendrik Wagenaar). Similarly, the NZPC established a good working relationship, which eventually included funding, with the New Zealand Ministry of Health (Healy et al, 2010, p 48). Since then the NZPC has managed large and complex public health contracts for the ministry (interviews with Hendrik Wagenaar). The latter is a 
splendid example of harnessing the complexity of a policy field: the introduction of the NZPC as a full partner increased variation, changed interaction patterns and created a new effective management routine that improved the delivery of public health services to sex workers in the fight against HIV/AIDS. Surveying evidence from Canada, Beer and Tremblay observed that sex worker organisations were able to develop both community and advocacy capacity: 'With stable funding, community-based nonprofit organizations both expand the arena of social service provision and act as potential sites of civic engagement' (Beer and Tremblay, 2014, p 300). In fact, in a political favourable climate the benefits of funding might outweigh its risks. As Beer and Tremblay conclude, 'research indicates that resources are central to social movement organizations sustaining themselves over the long term, and this longevity is necessary to mobilize an autonomous voice for disenfranchised populations in local and national politics' (Beer and Tremblay, 2014, p 301). The conclusion is that there is no necessary contradiction between state support and advocacy, and that in fact, the existence of a stable, politically recognised sex worker organisation might be a potent force in the battle for acceptance of prostitution as a legitimate occupation. However, does this mean that sex worker organisations and state agencies are able to jointly engage in the more demanding enterprise of collaborative governance? It is to this question that we turn in the next section.

\section{Governance capacity and collaborative governance}

The key word in modern theories of governance and public administration is capacity. The challenge of any governance system is to build and maintain effective governance capacity to tackle the numerous challenges that governments face. These challenges are such that the traditional management of societal sectors by hierarchically organised and siloed government bureaucracies that provide services to meet universal needs no longer suffices (Healey et al, 2003, p 60). Different authors describe these challenges in different ways, but they generally boil down to the following. The first relates to the increasing complexity and pluralisation of politics and social life. Political complexity, as we saw, is characterised by a general dispersion of power and a high degree of interdependence (Bourgon, 2011, p 21). The causes of political complexity are the globalisation of a range of issues such markets and trade, migration, urban development, environmental issues and security. These processes of globalisation reduce both the territorial effectiveness of public administration and, partly as a consequence, 
the democratic effectiveness of national or local electoral democracy (Ansell, 2011, p 4; Warren, 2014). A second challenge is what Warren calls the 'general post-modernization of culture' (Warren, 2014, p 47). This trend expresses itself in a less deferential attitude towards authority, a widespread disaffection with politics (Norris, 2011) and a tendency for civil society groups to create associations, parallel to the institutions of the state, that organise for purposes of advocacy, knowledge creation and self-government (Warren, 2001). When seen as a threat to traditional government this dense civil society environment results in highly adversarial politics (Ansell, 2011, p 4), but when regarded as a resource, it might open up new opportunities for political innovation (Bourgon, 2011, p 25; Wagenaar, 2014). The upshot of these trends is a state of 'institutional incapacity' (Warren, 2014, p 46); at all levels of government we witness disjunctions between government agencies' capacity to deliver on their political promises through traditional policy instruments, citizens' capacities to understand and govern their own social and physical environment, and the tendency of an increasingly beleaguered state to bear down on citizens with authoritative forms of regulation and surveillance (Norris, 2011).

The remedy for this institutional incapacity is generally seen as a form of government that actively involves citizens and communities (Healey et al, 2003, p 63; Ansell, 2011; Bourgon, 2011; Warren, 2014; Ansell and Torfing, 2016). Governing capacity is seen as residing in the ability of government institutions to leverage the problem-solving power of civic associations and effectively collaborate with stakeholders in identifying, framing and solving collective problems. This forms an alternative to three traditional forms of governance: adversarial politics, in which the party in power makes decisions by imposing its will on minority parties; coalition politics, where parties, none of which can expect to gain an outright majority, make decisions by bargaining among themselves; and managerial governance, in which management processes, often but not always outsourced to corporate actors, function as means for collective problem solving and service delivery.

What is collaborative governance? In broad-brush strokes collaborative governance is a mode of governance in which public agencies engage with various stakeholders to jointly deliberate about public problems (Ansell, 2011, p 167). Collaborative governance differs from the more generic term 'governance' in that it requires more stringent, more demanding standards of working together. Or, to put it differently, collaborative governance requires quite a bit of reflection on the design of the collaborative relationship. Just inviting people over and sitting around a table in a meeting room will not necessarily result 
in a productive exchange of ideas. Ansell and Gash express this in the following, more demanding definition of collaborative governance:

A governing arrangement where one or more public agencies directly engage non-state stakeholders in a collective decision-making process that is formal, consensus-oriented, and deliberative and that aims to make or implement public policy or manage public programs or assets. (Ansell and Gash, 2008, p 544)

This definition covers various types of collaborative arrangements, from conflict resolution platforms in which parties who are locked in intransigent conflict try to find mutually acceptable accommodations (Innes and Booher, 2010) to the kind of long-standing contractual relationships that the NZPC in New Zealand or the Scarlett Alliance in Australia holds with public health agencies (Healy et al, 2010; Gall, 2014). But whatever the nature of the arrangement, to designate it as collaborative, to allow it to build effective governing capacity, it needs to have the following characteristics.

First, it is essential that actors from civil society who are affected by the policy, who are stakeholders in other words, are involved in the governing arrangement. But this in itself is not sufficient. To infuse the collective problem-solving situation with genuinely new insights and knowledge, it is particularly important that peripheral, marginal or vulnerable groups are involved. Innes and Booher stress the importance of increasing variation in the stalled policy field. Contrarian and disadvantaged stakeholders are necessary to break open the unproductive understandings and dysfunctional policy arrangements that make collaborative governance necessary in the first place and to benefit from the reciprocity and creative potential of genuinely inclusive relationships (Innes and Booher, 2010, pp 101, 102). Inclusion of marginal groups is much more difficult and much less common than one may think, as the example from The Hague demonstrates. There are often good reasons to exclude these groups. They may be hard to find or to organise; they speak, dress, and behave differently from other stakeholders; there are often difficult language issues and cultural misunderstandings between groups; there may be well-founded mutual distrust; and often peripheral groups bring a long history of humiliation, marginalisation and pain to the negotiating table (Forester, 2009). Inclusiveness must be actively sought (Ansell and Gash, 2008, p 556). All these considerations apply to the inclusion of (immigrant) sex workers. But, as experience 
with collaborative governance and policy mediation suggests, these obstacles can be overcome (Forester, 2009; Innes and Booher, 2010). Inclusiveness is essential to securing legitimacy (this forum represents all stakeholders), diversity (a precondition for dealing with social and technical complexity (Axelrod and Cohen, 2000, p 32; Innes and Booher, 2010, p 36) and mutual recognition as genuine participants in the policy process. Recognition is particularly important for the most peripheral and vulnerable partners, as they feel isolated in their struggle to get heard.

Second, the collaborative arrangement needs to be authoritative that is, it must be aimed at, and have a mandate for, decision making. It must be exclusive in the sense that it cannot be a sideshow to the 'real' political process of decision making. The time and energy that participants put into the process must result in genuine influence. This will provide an incentive for sceptical or reluctant participants to join the collaborative forum (Ansell and Gash, 2008, p 557). Authority is also signalled through the membership and longevity of the collaborative arrangement. If participants with a true mandate to make decisions represent government, the administration signals to the outside world that it takes this forum seriously as a governance body. Similarly, the longer the collaborative forum is in operation, the more it will communicate that this is an important element of the administration's governing capacity.

Third, a condition for authority is that the collaborative arrangement has a formal and not a casual character. This implies a minimum of organisation and institutionalisation, such as agreeing on rules and procedures for meeting and decision making, a contractual arrangement with accountability procedures for situations where services are delivered, transparency (meetings are reported), an insistence on exclusivity (no forum hopping) and the sharing of resources. For example, marginal groups might need training in basic skills such as chairing a meeting, drawing up minutes or reading balance sheets (Fung, 2004). Sometimes governments decide to fund sex workers' organisations, not only to make it possible for them to spend time on working with government agencies, but also as a token of their recognition as valued partners in the desired governance arrangement.

So far, our description of design has been static, aimed at the proper structure and organisation of collaborative governance. But what is it that the parties in a collaborative arrangement actually do? The fourth, key element of collaborative process consists of engaging stakeholders in the twin processes of joint problem definition and joint-fact finding: exploring how each party perceives the central issues at hand and 
discovering the facts that the parties can agree about. This is more than just having each party state how they perceive the problem or list what they consider key evidence. In almost all policy conflicts, problems, definitions and relevant evidence are the most contested aspects in the adversarial relationship. The fact that parties are willing, with an attitude of sceptical acceptance, to listen to the other is itself a major achievement. By opening up, if ever so slightly, to the other's point of view, parties begin to discover what unites them as well as what divided them. They discover what worries, needs, values and goals they share. Joint problem definition has three effects. As an inquiry into the nature of an intrinsically complex problem it leads to a joint reconstruction of each stakeholder's conception of the problem (Ansell, 2011, p 172). When done well that experience can be transformative:

During the course of deliberation, people may discover new information and new perspectives about what is at stake in the decision before them. This may lead individuals not only to modify their choice of means for achieving ends, but to reconsider those ends. (Reich, 1985, quoted in Ansell, 2011, p 172)

Moreover, by jointly reflecting on the nature of the problem, the parties involved begin to own the transformed problem definition. Parties begin to see that the problem is too complex and unpredictable for any one party to fully comprehend, let alone, control. Participants discover - perhaps the better term is experience - their mutual dependency in harnessing the problem. This can also be seen as a form of social learning, in which the transformed understanding of the problem forms the basis for an inquiry into new ways of problem solving and reframed standards and criteria of what constitutes a successful solution. Joint problem definition also has important relational effects. Participants reframe their relationship away from a contest of emotionally held positions and preferences towards what Ansell calls a 'position of shared uncertainty' (Ansell, 2011, p 174). Joint problem definition is at the core of the process of breaking down stereotyping, the untested ascription of reprehensible views or negative character traits to opposing parties, and other barriers to communication that prevent exploration of mutual gains in the first place. It is at the heart of a process of building trust, mutual respect, shared understanding and commitment to the process. Put differently, in collaborative terms 'authentic dialogue' may begin to occur. 
Authentic dialogue is a technical term that signifies a process of communication that observes the requirements of accuracy, comprehensibility, sincerity and legitimacy (Innes and Booher, 2010, pp 97-9). Authentic dialogue can only be achieved in situations of face-to-face dialogue. It represents the hard-to-capture communicative process that forms the beating heart of every collaborative dialogue. It is a necessary condition for mutually learning new ways to think and act together. To get a sense of what the process of authentic dialogue entails in practice, it is perhaps useful to quote Innes and Booher at some length:

Authentic dialogue requires collaboratively adopted ground rules that will enable a productive dialogue. The rules typically include an injunction against criticism of others; acceptable ways of dealing with the press; avoiding repetition; and not dominating the conversation. Dialogue is apt also to require admonitions about listening respectfully. Many people come in with their own ideas and spend meeting time rehearsing to themselves what they want to say, rather than listening, much less keeping an open mind. Changing these habits might require training exercises.... $[\mathrm{S}]$ ome participants assume that since collaboration is about finding common ground, they should not bring up anything controversial. But without sincerity and without the questioning of given knowledge and assumptions, a dialogue cannot be collaboratively rational. It will not break through the socially constructed and often disempowering assumptions that may be the cause of the problem's intractability... There are nonetheless stakeholders who are confrontive [sic] and fight for positions rather than listen. Some are highly emotional and angry. While process managers need to try to get these individuals to speak in terms of interests rather than positions and avoid attacking others, it is equally important that they not gloss over the conflict. Sometimes managers may even have to surface and address hidden conflicts to assure the dialogue does not result in what many critics are concerned about $-\mathrm{a}$ lowest common denominator agreement, with peer pressure stifling unpopular voices.... Hidden differences can lead to an agreement that is thin and fragile rather than one that has engaged the deep issues and bound the stakeholders together in reciprocal arrangements. (Innes and Booher, 2010, p 100) 
When done properly the stakeholders in a process of collaborative governance may begin to reformulate how they understand the problem and in the process reformulate what they want to achieve. This often unleashes the creative potential that the combination of inclusiveness and authentic dialogue may bring to the collaborative forum. By learning to let go of favoured solutions and by opening themselves up to the knowledge and experiences of others, stakeholders may arrive at solutions that address shared interests. The most important part of this process is that this is a joint achievement. The learning about the issue at hand is shared: from each other and with each other. As Innes and Booher state: 'The goal of collaborative dialogue is not to choose who or what is right, not even what is true or best, but to find actions that all or most can support and that are workable ...' (2010, p 100).

Finally, fifth, successful collaborative governance requires leadership. In the literature on collaborative governance leadership is usually discussed in terms of facilitation. Facilitative leadership helps to navigate conflicting parties through the ups and downs of conflict resolution. Facilitative leaders engage in 'assisted negotiation' by mediating, or when the parties are stuck in a conflict and cannot reach a consensus, drafting a solution in non-binding arbitration (Ansell and Gash, 2007, p 554). 'Leadership is crucial for setting and maintaining clear ground rules, building trust, facilitating dialogue, and exploring mutual gains' (Ansell and Gash, 2007, p 554). In addition facilitative leadership is essential in empowering the weaker stakeholders in the collaborative platform, both to protect the democratic rights of the weaker parties to influence decisions that affect them, but also to guarantee the requisite diversity that is required to 'think outside the box' and arrive at genuinely creative solutions.

In a wider perspective of collaboration leadership is important in a different way. All newcomers in an established policy subsystem have to 'prove' themselves to the established stakeholders. They have to demonstrate that they are reliable, trustworthy, representative of their constituency, and that they possess resources that provide added value to the subsystem. This applies a fortiori to self-organisations of marginal groups who strive to find partners in the world of governance, in particular when that group also has to bridge the gender divide. Initially such advocacy groups, whose members dress and speak differently and are not able or willing to use the behavioural codes that guide the subsystem's interactions, are met with reserve if not downright suspicion. In such situations a leader who is able to communicate with a wide range of stakeholders is a huge asset. Such a leader creates the necessary bridging capital that is required for effective functioning in 
the subsystem. At the same time, while the advocacy group is opening up to the values and interests of other stakeholders, it is essential that the group recalibrates its balance between advocacy and accord. This can be a genuinely agonising process in which some members feel that the soul and identity of the organisation are at stake. In such a crucial phase of the advocacy organisation's development, effective leaders are able to reformulate the value commitments that fix the nature of the enterprise. They recommit the organisation to its distinctive aims, methods and role, both in the original community of stakeholders and in the wider policy subsystem. In terms of the advocacy organisation's position in the policy subsystem, the role of leaders is to 'develop a close alignment between meaning and action' by articulating an organizational mission around which the original members can unite (Ansell, 2011, p 67).

\section{Is collaborative governance in prostitution policy possible?}

Is collaborative governance, in the demanding sense as described above, possible in prostitution policy? And, if so, under what political or cultural conditions? At first blush the prospects are not hopeful. The case in The Hague excluded sex workers, and although it brought about a functioning licensing and monitoring system, and created a shared sense of what it takes to responsibly manage and govern commercial sex in a city and a modicum of trust between brothel owners and authorities, it was one of those 'thin and fragile' arrangements that are the result of a deficient collaboration process (Wagenaar, 2007). Moreover, the arrangement was exclusively focused on producing an administrative arrangement and ignored the workplace conditions of the sex workers. A study by Genevieve Fuji Johnson paints an even bleaker picture. The focus of her study was the 'governance capacity' of policy communities that dealt with prostitution policy across Canada. Fuji Johnson was particularly interested in the inclusion of 'organizations that support sex workers in terms of recognizing their agency, advancing their human rights, and responding to their needs/assets' (2015, p 1). The focus of the research was on how these organizations interact with each other and with municipal governments and police services (Fuji Johnson, 2015, p 2). Fuji Johnson distinguishes five types of interaction: collaborative, agonistic, siloed, antagonistic and emergent. In her careful description of policy communities in the domain of prostitution policy, she distinguishes between non-state and state organisations. Non-state organisations comprise support/ 
education/advocacy organisations by and for sex workers, service organisations, ally-support organisations and pragmatic prohibitionist organisations. State organisations consist of the various agencies of the municipal government and the police department. In addition she includes third sector agencies such as community mental health centres.

Fuji Johnson finds that there is a considerable amount of interaction between sex worker organisations both within and between municipalities, interactions 'that most closely approximate collaboration' (2015, p 3). However, she characterises none of the interactions between non-state and state organisations as collaborative. The best she found was a form of agonism, best described as a 'form of relational realism in the context of competing interests' (2015, $\mathrm{p}$ 14). These relationships are not based on trust and not aimed at consensus building, but display a form of pragmatism to respond to particular problems. Only in the city of Vancouver did Fuji Johnson find agonistic forms of interaction between municipal organisations and non-state actors. In all the other jurisdictions she studied she found relationships that were either siloed (mutual awareness but little interaction), antagonistic (open conflict and hostility between non-state and state actors, with the latter attempting to dominate the first), or emergent (nascent attempts at productive communication). Fuji Johnson's is a qualitative study, so we cannot draw any conclusions about the distribution of distrust in the population of local policy subsystems from it. Yet, the picture she paints is bleak indeed. State agencies and sex worker advocacy groups seem unable to engage in productive collaboration; implicitly at least, she attributes this state of affairs to the unwillingness of state actors to include sex worker organisations within their governance arrangements.

However, it would be wrong to dismiss the possibility of collaborative governance in prostitution policy out of hand on the basis of these examples. First, there are few examples of research into collaborative governance in prostitution policy and, as is the norm in this field (Ansell and Gash, 2008, p 544), these are all qualitative case studies. The problem with case studies is that the political-cultural context of the case is usually not considered. For example, a truncated form of collaboration was made possible in The Hague because of the consensual, coalition politics that characterises the political culture of the Netherlands, while Canada has a much more antagonistic, majoritarian system. We have also seen that in some cases sex worker-led organisations have entered into long-standing contractual relationships with state agencies to deliver essential services to the community of sex workers (Majic, 2013; Beer and Tremblay, 2014; 
Gall, 2014). For example, while city officials in The Hague were wrangling with brothel owners to implement a licensing system, the city of Rotterdam had invited the Rode Draad to provide policy advice to the city administration regarding municipal prostitution policy.

In 1999 the Rode Draad was invited to become a participant of the municipal Prostitution Advisory Commission in Rotterdam. Members of the commission, each representing an organisation with some authority and mandate in the domain of prostitution policy, came from the police, the tax authority, social work, public health, the city administration responsible for prostitution policy, and the Rode Draad. Council members did not participate in the commission for fear that they would impose their political agenda on its activities. The commission met once a month and its tasks were to formulate policy advice, to design policy solutions, to monitor the situation 'on the ground' in the city, and to signal instances of trafficking and exploitation. For example, the Rode Draad had observed that illegal, coerced prostitution took place in Turkish coffee houses in the city. This is an excellent example of what Bourgon calls 'adaptive capacity', the ability to react swiftly and effectively to unexpected emerging situations (Bourgon, 2011, p 60). Almost adventitiously the commission achieved a considerable amount of policy coordination, another instance of the adaptive and resilient capacity that such a collaborative arrangement brings to the governance system (Bourgon, 2011, p 60). The Rode Draad participated in the commission from 1999 to 2008. To make this possible it received a small subsidy and an office from the city administration. One of the contributions of the Rode Draad was to emphasise the privacy of sex workers in any situation in which sex workers were asked to report on the state of the field. Finally, the Rode Draad operated a low threshold information and support centre in the city that was managed by a sex worker (source: Sietske Altink). The arrangement was terminated when the Rode Draad lost its subsidy and had to close its operations. Municipal prostitution policy had by then taken a repressive turn as we saw in Chapter Five, and the commission was replaced by one of the chain management arrangements aimed at enforcing anti-trafficking measures. In hindsight the Rode Draad successfully managed the precarious balance between advocacy and service; the city did not always follows the advice of the Rode Draad, yet this did not affect the mutually respectful relationship in the commission.

Perhaps the most successful example of collaborative governance in prostitution policy concerns the NZPC in the prostitution policy subsystem in New Zealand. In the final section of this chapter we 
will discuss some elements of the collaborative relationship with state agencies and reflect on the contextual characteristics that make it possible. We admit that this is yet another qualitative case study, but such is the state of the art in this field, and the study hopefully generates insights that allow for more systematic testing. The NZPC was not only one of the driving forces in the passage of the 2003 Prostitution Reform Act that decriminalised prostitution in New Zealand, but in the late 1980s it was already involved as a provider of services and government adviser in New Zealand's fight against HIV/AIDS in the sex worker community. When the Prostitution Reform Act was passed by the New Zealand parliament the NZPC and its leadership were already well-known and trusted members of the policy community. It was therefore not a large step for government agencies to turn to the NZPC for advice and guidance. What follows is an observation by a public health officer, taken from a review of public authorities' experience of implementing the Prostitution Reform Act (Bruton, 2010). The interviewee in question, an occupational health nurse, was charged with monitoring brothels under the new legal regime, whereby inspectors receive information from the NZPC about possible infractions of hygiene or safe sex rules:

Most interviewees [public health inspectors] also highlighted the importance of the role of NZPC. Several alluded to the professional support for sex workers provided by NZPC and the assistance and information they provided to regulatory officers: 'Um, we've kept in contact with the NZPC and I've tended to feel that is probably the best way to go because I'm not an expert in the industry ... I think the NZPC are the people who have got an actual good grasp of what the realities are.' (Brunton, 2010, p 185)

What does this quotes illustrate? First, it shows that the NZPC managed to find and sustain the right balance between service delivery and advocacy. The NZPC has successfully held contracts with public agencies for the delivery of public health services since the late 1980s. Second, it demonstrates that government agencies and the NZPC have succeeded in building collective governance capacity, in which the former provide legitimacy and accountability and the latter credibility and effectiveness (Bourgon, 2011).

The organisation of the NZPC allows it to act as an advocate for sex workers while at the same time providing services and maintaining a working relationship with government agencies. With its head office 
in the nation's capital, the NZPC is set up as a dispersed organisation with local offices in every town in New Zealand that has a prostitution scene. The staff composition of the local offices reflects the ethnic composition of the local sex worker population. This guarantees that the organisation is representative of the sex worker population. The offices have low thresholds; as one of us (Hendrik Wagenaar) observed, sex workers can walk into the offices freely and spend time relaxing and chatting with others. The NZPC creates trust with its clientele by providing some essential services such as STD checks, general health advice, practical advice and representation in workplace disputes with brothel owners. New Zealand has a system of labour mediation boards; the NZPC represents sex workers who bring their case to the mediation board. The close ties between the NZPC and the sex worker population allows the NZPC to be informed about the situation 'on the ground' in the prostitution scene in New Zealand's towns and cities. This in turn has given it authority among government officials and brothel owners. But the role of the NZPC in New Zealand society goes much further than the capacity for governance and service delivery. The professionals and politicians we met were unanimous in their admiration about the moral leadership of the NZPC and its two directors, Catherine Healy and Calum Bennachie, in normalising the image of prostitution as work and of sex workers as regular citizens with the rights that accrue to all New Zealand citizens.

What have we learned from these examples? First, collaborative governance in the pragmatic sense as described here is probably more prevalent in prostitution than one might surmise from the current antagonistic atmosphere that prevails in the field. In fact, collaborative arrangements emerge precisely in situations of policy failure through the high costs of the politicisation of regulation and persistent implementation failures (Ansell and Gash, 2008, p 544). Policy failure is of course not a guarantee for the emergence of collaborative governance, but it creates the incentives and need among stakeholders to try something else. Second, the emergence of collaborative arrangements in prostitution policy is probably facilitated by the pre-existing political culture. Both the Netherlands and New Zealand have a culture of cooperation, striving for consensus and respect for minorities. ${ }^{147}$ Even if actors in these two countries are

147 Several of our interviewees in New Zealand pointed out the importance of the Treaty of Waitanga for shaping political culture in New Zealand. The treaty was signed by representatives of the British Crown and various Māori chiefs. It established British sovereignty over New Zealand but also recognised Māori 
locked in conflict, they have deeply ingrained cultural models available to suggest an alternative course of action. But more adversarial political cultures also contain local pockets of opportunity for setting up collaborative experiments. Fuji Johnson describes how in the deeply divided community of Downtown Eastside in Vancouver a spate of murders of sex workers, many of whom were members of ethnic minorities, acted as a catalyst for formerly antagonistic parties to enter into a more collaborative relationship. Fuji Johnson observes how the neighbourhood, for all its problems was also a 'nexus of strength, persistence and organization' that contributed to political mobilisation of residents and sex workers (Fuji Johnson, 2015, p 266). In addition, a Commission of Inquiry concluded among other things that 'a clear correlation [existed] between law enforcement strategies of displacement and containment and increased violence' (Fuji Johnson, 2015, p 267). The combined effect of community mobilisation and a report that condemned the police and the city administration for racist and counter-effective policies was that the authorities began to actively reach out to the community of women and sex workers in Downtown Eastside. Police, sex workers and advocacy groups were able to converge on a policy framework of harm reduction that resulted in various concrete policy measures, such as jointly negotiated Sex Work Enforcement Guidelines that emphasise safety, respect and dignity of sex workers, and a still fragile but nevertheless more positive relationship between sex workers and the police (Fuji Johnson, 2015, pp 267-9).

Finally, the examples also show that collaborative arrangements are fragile and reversible when political attitudes towards prostitution change. The repressive turn in local prostitution policy in the Netherlands led to the dissolution of the Prostitution Advisory Commission in Rotterdam and its replacement by an enforcement group. When the Rode Draad lost a major subsidy after it criticised

ownership of lands and forests and gave Māoris the same citizenship rights as British subjects. From its inception the treaty has been contested, with Māori and non-Māori New Zealanders attaching different interpretations to it. However, the treaty represents the recognition of minority rights and citizenship. In 1989 the government, spurred by several court cases and the recognition that the original treaty no longer applied very well to the conditions in contemporary New Zealand, recommitted the nation to an updated version of the treaty by adopting the Principles of Crown Action on the Treaty of Waitanga. In addition to principles of government, self-management and equality, a principle for cooperation was formulated that simultaneously acknowledged the existence of cultural duality and established the requirement for cooperation in good faith and common sense to attain a partnership between the peoples (https://en.wikipedia.org/wiki/ Principles_of_the_Treaty_of_Waitangi). 
the city administration of Amsterdam about its choice of advisers on prostitution policy, it had to close its doors after operating for 27 years as an internationally recognised centre of expertise on prostitution policy and advocacy for sex workers. Currently another advocacy group is trying to represent the interests of sex workers in the Netherlands. While the signs look promising (Amsterdam's city administration has indicated that it wants to talk and the Ministry of Justice has granted the group an annual subsidy), the city administration engages in blatant forum hopping, underhandedly exploring with the Minister of Justice the possibilities for sidestepping national privacy regulation to introduce a sweeping registration and information system for sex workers, the same type of system that has been rejected by the Dutch Senate as contrary to EU privacy regulations. ${ }^{148}$

148 The minister has recently declared that the city is free to introduce a registration system within the bounds of national privacy regulation. 



\section{SEVEN}

\section{Summary and conclusion}

The purpose of the book is to describe and analyse prostitution policy - how it is formulated, how it is implemented, and what outcomes it leads to. The analysis in this book departs from the presumption that in Europe, at least since the 19th century, prostitution has been a pressing concern for professional elites and nascent state institutions. Through feverish, almost obsessive, theorising - or perhaps it is more accurate to say, moralising - elites attempted to obtain cognitive and moral closure about the phenomenon, simultaneously mystifying, threatening and alluring, that women exchange sexual services for money, and thereby situate themselves outside the norms and boundaries that regulate sexual behaviour (Corbin, 1990). ${ }^{149}$ This concern was then translated into concerted attempts by state agencies to contain, redirect or eradicate prostitution. As a result, the organisation and manifest appearance of the sex trade, at least in Europe, has always been, directly and indirectly, the outcome of state involvement. If one likes it or not, every state, for better or worse, is deeply implicated in the sex trade through regulation (Jahnsen and Wagenaar, in press).

Despite the ubiquity of regulation, policymaking, as we argued in Chapter One, is underrepresented in the now voluminous literature on prostitution. This book is an attempt to close that gap. To this end we have compared prostitution policy in Austria and the Netherlands. Both countries make interesting objects of analysis. Contrary to the US, where from around 2000 onwards prostitution policy has been dictated by neo-abolitionism (Chuang, 2010), most western European countries have taken a more or less pragmatic approach to regulating prostitution. When the Netherlands decriminalised brothels in 1999 it was widely regarded as a vanguard of progressivism. Austria, although less in the limelight, has always had a tradition of societal acceptance, women's rights and administrative ethos when it comes to regulating prostitution. Yet, a fine-grained analysis of the formulation and implementation of prostitution policy in both countries reveals that under the surface the political forces opposing prostitution have found ways to undermine and eventually undo progressive policies. We

${ }^{149}$ Of course men also exchange sexual services for money, but that has somehow always raised less moral concern. 
think the analysis in this book led to two important conclusions. First, prostitution policy is fragile. Legitimisation and decriminalisation are easily reversed, and revert back to criminalisation and heavy-handed regulation and control. This is a complex process that largely occurs at the local level, thereby deviating from, and even undoing, national policymaking. Second, without a detailed exposition and analysis of the design and implementation of prostitution policy at different scales of governance, statements about its nature or outcomes remain necessarily superficial and are at worst misleading.

One of the aims of this book is to confront our data with insights from the policy sciences. However, although we bring the insights of policy theory to bear on prostitution policy, we want to do more than just 'apply' policy theory. We want to go beyond describing prostitution policy in terms of, for example, the advocacy coalition framework or interpreting its development as a punctuated equilibrium trajectory. Instead we have attempted as much as possible to take a pragmatic, practice-oriented stance in our analysis, that is, to analyse prostitution policy from the perspective of the politicians and officials who are charged with regulating prostitution in their country or municipality. Throughout the book the questions that guided our analysis were: What are the challenges that policy makers face when regulating prostitution? What does the world of prostitution look like from their perspective? How do they understand prostitution and what forces shape that understanding? What are the possibilities of and constraints on (local) policy makers to design effective and humane prostitution policy? Our empirical material consisted of quantitative and qualitative data on prostitution and its regulation in Austria and the Netherlands from roughly 2000. The Appendix describes the design of the research in greater detail.

What were the results of our inquiry? All politicians, professionals and administrators charged with the management of a particular societal domain will find that they face a set of specific challenges. These specific constellations of challenges issue from the nature of the problem at hand. They define the possibilities and constraints of state action. They are as it were the actionable 'fingerprint' of a particular policy domain. For the field of prostitution we identified five such challenges: the enduring stigma of prostitution; the highly moralised nature of prostitution and the ensuing fact that prostitution policy is morality politics; the high proportion of migrants in prostitution and the consequent confluence of prostitution policy with immigration policy; the lack of precise and reliable data on almost every aspect of 
the sex trade; and the circumstance that prostitution is largely a local phenomenon and that effectively its regulation occurs at the local level.

Chapters Three, Four and Five form the heart of the book. These three chapters describe what in effect is a tripartite policy system in prostitution, three intersecting, nested, levels of policymaking. In Chapter Three we described small groups of administrators who implement policy by designing and selecting policy instruments. Sometimes these groups are knitted together through advanced coordination technologies such as chain management or "enforcement protocols'; sometimes they operate in a loosely networked way, or are dominated by one agency that has captured the local implementation of prostitution policy. In many countries NGOs are an important part of these implementation communities, even though they often operate at arm's length from government agencies. The important insight is that these groups of administrators and professionals operate in relative autonomy from the national legal frameworks and institutions that formulate policy and make decisions, despite the fact that there is often considerable exchange at personnel level. In fact, in the two countries we studied local policy makers often deviated considerably from national policy goals. In the Netherlands, through a gradual accumulation of small, instrumental implementation decisions that are mostly taken under the political radar, a process we call regulatory drift, repressive policy goals have come to replace the more emancipatory goals of national law. In fact, local policymaking drives national policymaking, a situation that is now codified in the new national law that reverses some of the ideals of the repeal of the brothel ban. In Vienna the implementation of a new prostitution law that aimed to regulate all aspects of the sex trade was monopolised by the police and its effects were restricted to the removal of a relatively small number of outdoor sex workers from the city. The upshot of our analysis is that prostitution policy cannot be understood without a detailed understanding of local policymaking.

In Chapter Four we describe the national policy subsystems or policy networks where ideas are formulated and solutions designed and tested. These subsystems are loosely coupled to political decision-making bodies such as parliaments and state bureaucracies in which some of the actors involved occupy veto points. The actors in these subsystems proactively attempt to influence the national policy agenda, whereby those subsystems that are tied to the state bureaucracy are able to muster considerable influence. When through elections or an unexpected extraneous event a political opportunity arises, or, as Kingdon (1997) would put it, a policy window suddenly opens, the key actors in the 
subsystem are ready to act decisively. Conversely, when a subsystem, such as the policy network of progressive feminists in the Netherlands between 1980 and 2000, loses its perch in the bureaucracy, political influence diminishes immediately. The chapter also demonstrates another important dynamic in prostitution policy. In both Austria and the Netherlands additional national laws, such as immigration, labour, and fiscal law, and even laws regulating the use of information by government, have been applied to regulate prostitution and have had the effect of criminalising sex work. In other words, to understand how authorities regulate prostitution a focus on prostitution law is not sufficient and the analyst must take into account the full panoply of laws that are brought to bear on the sex trade.

In Chapter Five we described the wider policy field in which both local administrators and the national subsystems operate. The policy field has loose and shifting boundaries, and is geographically widely dispersed with often global dimensions. More importantly the key actors in the policy field are not only, or even exclusively, politicians or officials but ordinary people and opinion makers; equally important are the meanings these actors attach to their world, artefacts such as IT technology, travel and economic arrangements, and even trends and events, such as international treaties and economic developments. The aggregate of these 'actors' constitutes the extraneous effects that deeply influence national and local prostitution markets. For example, global economic inequalities in combination with easily available internet, mobile phone technology and low-cost travel opportunities have resulted in the migration streams that span the globe. We have described the policy field in almost ontological terms as characterised by complexity, interdependency, uncertainty and emergence. Both the local and national levels of policymaking are embedded in this complex adaptive field. In that sense it presents a sixth challenge to policy makers, but in this case the policy field presents the general challenge of dealing with dynamic complexity that policy makers in all domains of public policy have to face up to. The importance of the notion of a policy field is that it helps us to understand the predicaments of policy makers who attempt to regulate prostitution.

The policy field is also the level where public and political discourse emerges. It is hard to overestimate the importance of discourse for policymaking at all levels. Policy makers swim in a sea of images and narratives from which they have little opportunity to extract themselves. In particular we have seen how deeply the currently dominant discourse of abolitionism has influenced both local and national policymaking, how the abolitionist discourse was the 'glue' that bound the local and 
the national in prostitution policy, and how it functioned as an implicit coordination mechanism between a host of political, administrative and societal actors. ${ }^{150}$ This discourse - with its powerful imagery of sex workers as victims, clients as predators, prostitution as by definition forced, prostitution as a form of modern slavery, and thus an affront to women's rights, the crime of trafficking as the symbol of modernday prostitution, and the sex trade as a market in which the state can successfully intervene by persecuting clients and thus suppressing demand - originated in Sweden in the 1980s and has since spread around the world, capturing the hearts and minds of radical feminists and mainstream politicians and officials.

There is a direct connection between the nature of the policy field and the discourse that emanates from it. The policy field presents itself to the local (and national) policy maker as a bewildering world, an unknowable and uncontrollable forces. This results in an irresistible urge to simplify the mess by reducing it to clear, apprehensible policy narratives, moral schemata and fantasmatic control schemes. This is a universal dynamic that is not unique to prostitution policy, but because of the highly moralised nature of prostitution policy the dominant abolitionist narrative has effectively crowded out alternative policy narratives. This inevitably results in partial, misdirected policies that lead to persistent policy failure and negative unintended consequences. We have encountered many examples of this dynamic. For example, policy makers are irresistibly attracted to registration systems. The

150 The following anecdote illustrates our point. When we began the research the three participating Dutch cities argued for a comparative approach based on a most similar systems design. In other words, they preferred to compare the Netherlands with a country that had a comparable approach to regulating prostitution. Their argument for excluding countries such as Sweden in the comparison was that it was unlikely that client criminalisation would be introduced in the Netherlands any time soon. About six months into the project representatives of the three cities attended a seminar on client criminalisation organised by the Swedish Embassy. At the next project meeting the consensus was that the meeting had failed to convince them about client criminalisation: "It was mostly ideology with little evidence." Yet, in hindsight this was also about the time that the cities began to design and implement the 'enforcement arrangements' that dominated local policymaking for years to come. Two years later, at the end of the project, the cities experimented with registration, promoted the 'signals of trafficking approach' and vehemently argued for a national law that would introduce a national registration system and partial client criminalisation. A revised version of the law was passed in parliament on 21 June 2016. Somewhat similar to Finnish law, it proposes criminalising paid sex with non-registered sex workers. One of the fundamentalist Christian parties introduced client criminalisation in its policy platform in recent parliamentary elections. 
registration of sex workers, preferably in a system of national coverage, is considered to be an instrument of control. However, not only do such schemes violate European and national privacy regulation, but all the available evidence suggests that they are largely ineffective. Similarly, the criminalisation of sex workers (and their support system) undermines the human rights of the very group it purports to help. Similarly, the effort to police national borders by restricting the migrant sex workers' labour market closes off job opportunities and erodes the labour relations that would have helped them to establish themselves. In fact, as we observe, the framing of prostitution as 'trafficking' or 'slavery' has resulted in labour relations, and its corollary labour exploitation, in prostitution being excluded from the agenda of all the policymaking bodies we encountered in our research. The outcome of such policies, which are informed by one-sided, misdirected moral schemes, is that the stated goal of reducing the presence of prostitution in our society has not been reached and an already stigmatised group has been even further marginalised. In city after city and country after country the ideal of the regulation of prostitution repeatedly collides with reality (Jahnsen and Wagenaar, in press).

Prostitution policy is largely designed and executed at the local level, as we have seen. But what is a local official to do when the reality on the ground is determined and shaped by the emergent events in a widely dispersed, emergent and transnational policy field that is made up of a bewildering variety of human and non-human actors? It is not realistic to expect the official, or anybody for that matter, to have a comprehensive grasp of all that transpires in this dynamically complex system. What can policy makers do to negotiate the complexity and unpredictability of the policy field? The literature on complex adaptive systems is unanimous: instead of denying complexity policy makers should embrace it. Simplified policy narratives and control arrangements are forms of denying complexity. Embracing complexity means not to approach it as a liability but to make it productive. Stimulating variation, facilitating new communication lines and selecting and promoting solutions that work are general strategies for effectively navigating complexity. In Chapter Six we focused on collaborative governance with stakeholders, particularly sex workers, as a practical way of facilitating requisite variation and interaction in prostitution policy. Following the literature we defined collaborative governance as a governing arrangement where one or more public agencies directly engage non-state stakeholders in a collective decision-making process that is formal, consensus-oriented and deliberative, and seeks to make or implement public policy or 
manage public programmes. Collaborative governance is inclusive (it involves all stakeholders, particularly marginalised and contrarian groups) and authoritative (it has an official decision-making mandate from political authorities), and it proceeds by 'authentic dialogue'. Authentic dialogue is a particular form of face-to-face dialogue that observes the requirements of accuracy, comprehensibility, sincerity and legitimacy. While we identified a number of potential obstacles, we also discussed real opportunities, backed up by empirical evidence, for successful collaborative governance in prostitution policy. 



\section{Appendix: \\ research design and methodology}

\section{Goals of the project}

The research that forms the basis of this book was a collaboration between Platform 31 (a knowledge and network organisation in the area of urban policy), the Dutch cities of Rotterdam, Utrecht and The Hague, the Austrian city of Vienna, and the University of Leiden in the Netherlands. The Dutch partners contributed one third of the budget each; Vienna contributed a smaller amount. The research was designed to compare the implementation, outcomes and effects of prostitution policy in two countries, Austria and the Netherlands, that have a discernible and more or less coherent approach to regulating prostitution. The focus on policy implementation issues from the fact that in prostitution policy, as in most policies, a considerable gap exists between policy formulation and its actual implementation in the field, and that it is the actual delivery of public policy that determines the impact on the target group and on society at large. The main goal of this study is therefore to provide a detailed, in-depth analysis of the implementation of prostitution policy in the countries of study. A second goal of the study is to bring policy theory to bear on our data about prostitution policy, for the purpose of obtaining a better understanding of how such policies are designed and implemented.

\section{Research questions}

The project focused on the following research questions:

1. What is the size and state of the prostitution market in the Netherlands and Austria?

2. How is prostitution regulated in both countries at the implementation level? Which policy instruments are used? Which rationale is given for the use of different policy instruments? Are the policy instruments used in an effective and efficient manner? Which conditions have to be fulfilled (organisationally, financially, and from the perspective of political-administrative relationships) for the effective and efficient use of various instruments? Is the use of the mix of instruments consistent, effective and efficient? 
3. What are the effects of the mix of instruments in the prostitution field? Effects are based on the stated goals of the policy. We would also look for general effects such as public order, trafficking and illegal prostitution, labour rights, work conditions and human rights of sex workers, and unintended consequences such as transfer of prostitution to different areas (national or international) or impacts on the social position of sex workers.

4. What unintended consequences does the policy have? Here we think of increases or decreases in the number of sex workers or sex facilities, transfer effects, the disappearance of prostitution into an invisible underworld, or an increased risk for sex workers.

We want to emphasise that the participating cities were interested in the possibilities of effectively regulating prostitution. That implied that they were less interested - at the time at least (see Chapter Seven) - in a study of trafficking. ${ }^{151}$ Although trafficking was not the subject of the project, if it emerged in the course of the research as a topic that respondents were dealing with (for example, local policies that were designed to recognise and fight trafficking), we of course analysed it and integrated it in our conclusions.

\section{Design of the study}

The research was not designed as a formal outcome study with a controlled pre-test and post-test design. The complexity of the prostitution domain, in combination with the rapid developments in this field, prohibited, in our opinion, a formal, quasi-experimental design (Shadish et al, 2001). Such a design would provide us with a mere semblance of scientific control while the rigour of the design would result in missing out on most of the dynamic complexity that characterises this field. Moreover, authoritative knowledge about actual approaches to the regulation of prostitution is so scarce, that a mixedmethods, process-based research design seemed to be indicated. For this reason, we opted for a comparative case study design (Landman, 2000). A mixed-methods, comparative case study allowed us to map regulatory approaches, the societal and administrative context in which regulation operates, and the impact of regulation on the prostitution field. Policies are put into effect to remedy or alleviate a particular

151 Like all EU countries, the Netherlands and Austria have a National Rapporteur in Trafficking in Human Beings. This agency collects data on trafficking. The reports of the National Rapporteur have been used in our work. 
problematic situation. By studying the prostitution field in depth we aimed to obtain both an understanding of the societal origins and validity of the original problem formulation, the administrative context in which policy and regulation is designed and implemented, and the impact, or lack thereof, of policy measures that have been designed to address the problem. Policy effects are the intended and unintended consequences that follow from the implementation of a range of policy instruments with the goal of solving problems and/or attaining aspirations in the field of prostitution.

The main comparison was between the Netherlands and Austria. The participating Dutch cities (see below) expressed the desire for a most similar systems design (MSSD; Landman, 2000). The scientific rationale of a MSSD is that, when most independent variables are held constant, differences in the dependent variable are explained by those independent variables that do differ (Landman, 2000, p 71). An MSSD, as well as its counterpart, a most different systems design (MDSD), are strong designs that yield important comparative knowledge. One must distinguish between large $\mathrm{n}$ and small $\mathrm{n}$ comparative studies. Clearly this is a small $\mathrm{n}$ study: a comparison of two countries. Such a comparison does not allow the researcher to hold the independent variables constant, simply because there are too many of them; this is the problem of 'too few cases/too many variables' problem that dogs so much social science research (Goggin, 1986). The value of small $\mathrm{n}$ comparative studies must be sought in the rich contextual comparison. Or as Landman puts it: 'The comparison to the researcher's own country is either implicit or explicit, and the goal of contextual description is either more knowledge about the nation studied, about one's own political system, or both' (Landman, 2000, p 5). ${ }^{152}$

The cities' argument for an MSSD was that a comparison with a most different policy regime (in particular, one of client criminalisation, as in Sweden) would generate important information, but from a practical point of view it would be more useful to see what the policy implementation and effects are of a country with a similar regime. The cities thought it unlikely that the Netherlands would move towards a

152 Landman speaks of a trade-off in international comparative research between a design with a large $\mathrm{n}$, few variables, a high level of abstraction and rather robust conclusions versus a design with a small n, many dynamically interrelated variables, and detailed data and conclusions. Differently put, there is a trade-off between hard knowledge on a few, abstract variables versus less certain but more contextual, meaning-oriented and practical knowledge about the dynamics of everyday societal systems. Given the paucity of knowledge about prostitution policy, there are strong arguments to choose an in-depth comparison of a few countries. 
client criminalisation policy any time soon. On the other hand, we know so little of the effects of regulation (and decriminalisation) that it is expected that an in-depth comparison of such policy regimes would yield more interesting and relevant knowledge. Austria was selected for various reasons. Similar to the Netherlands prostitution is legal in Austria and in most provinces brothels are a more or less accepted part of society. Austria regulates prostitution. It has also experimented with decriminalisation-type policy measures, such as improving the working conditions of sex workers, sex workers' taxation and their eligibility for social security. Interesting to the Netherlands is that Austria has a long experience with the registration of sex workers. Similar to the Netherlands, Austria has a large number of migrant sex workers, mostly from eastern Europe. In an administrative sense the countries also show similarities. Each can be called a decentralised unitary state, although the Netherlands does not have a federalised structure such as Austria, and the Dutch cities are less autonomous than the Austrian Länder. Prostitution policy therefore shows more regional variation in Austria than in the Netherlands. Politically, both countries are governed by coalition governments in which, until recently at least, Christian Democrats and Social Democrats are the dominant forces. ${ }^{153}$ Both are relatively small and affluent; they do not have the extremes of poverty and degradation that are among the drivers of prostitution in other countries. Finally, there were various pragmatic reasons behind the choice of countries, such as language, available contacts and accessibility.

\section{Partnered research}

A major funding condition of Platform 31 was that the research team and the participating cities formed a consortium. As a result the research has been developed and executed in close collaboration with the three Dutch partner cities Rotterdam, The Hague and Utrecht; Platform 31 participated in an observing role. Soon after the start of the project the city of Vienna also joined the consortium. The three Dutch partner cities indicated that they would like to obtain policyrelevant information early on in the research and not at the end of the study. The study was therefore practice-oriented and designed and executed in close interaction between the research team and the partner cities. What did this co-production of research entail? As there are no blueprints or handbooks available that instruct researchers and partners

${ }^{153}$ In both countries' politics the grand postwar equilibrium has become destabilised by the increasing popularity of right-wing populist parties. 
how to engage in co-producing usable knowledge, the interactive design was developed 'in vitro' in the course of the research. In 2009 the research questions and research design were formulated in a series of meetings with the Dutch cities. At the meetings the participants jointly formulated questions that were practically relevant (that is, emerging from and speaking to practical concerns of policy makers) and scientifically feasible (meaning they can be researched in a scientifically adequate manner). In hindsight this resulted in a process of mutual learning and trust building. With regard to learning, the researchers obtained unique, 'hands-on' insight into the challenges and particulars of designing and implementing measures for regulating prostitution at the local level (shaped by national legislation and extraneous developments). For the representatives of the cities it meant a growing awareness of the possibilities and limitations of scientific research. The cities, aware of the lack of knowledge about the regulation of prostitution, were above all interested in more precise and reliable data about the size and nature of the sex industry, in learning about policy theory, and in general in obtaining a knowledge base for effective administrative action in regulating prostitution.

From the start of the project the research team and the Dutch partner cities met every three months. At the meetings a programme manager from Platform 31 was always present. A scientific advisory board was created to guarantee the scientific quality of the research. The board agreed to review all reports that were to be produced by the research team. The board consisted of Professor Joyce Outshoorn, emeritus professor of women's studies at Leiden University, Professor Ronald Weitzer, professor of sociology at George Washington University, and Dr Anton van Wijk, senior researcher at Beke, a research agency that has done extensive, policy-oriented, research on prostitution in Amsterdam.

\section{Data collection}

A key feature of the project is the way that data were collected. Data collection in prostitution research faces numerous threats to validity and is affected by numerous practical obstacles. A large proportion of sex workers are very mobile. Many migrant sex workers do not speak English. Because of the stigma attached to prostitution, sex workers protect their anonymity and are reluctant to be interviewed. Sex workers distrust government officials, as they expect nothing good to come from them. They also distrust researchers, as they believe that nothing is done with the results anyway. Given these challenges, data 
collection in prostitution research will always be a compromise between ambition and convenience, and results and conclusions of any study will be surrounded by uncertainty and problems of interpretation. In fact, only a series of carefully designed and executed studies comprising different policy contexts will gradually converge in more robust results and conclusions.

In this project the emphasis has thus been as much as possible on original data collection by field workers who are familiar with the local situation. Our insiders were outreach workers from local NGOs in Austria (some of them former sex workers), one of the authors (Sietske Altink, former worker of the Rode Draad) and an active sex worker in the Netherlands. The interviewers received training in qualitative interviewing. The advantages of using insiders over academic field workers are obvious. Insiders find it easier to gain trust and are in a better position to interpret the answers. In addition, insiders are in a unique position to obtain the serendipitous insights that come with moving about in the field. A risk of using insiders is that they share a context with their respondents and/or identify with them. In both cases this can compromise the quality of interview and observation data (Weiss, 1995). In general local researchers conducted the research in the two countries: Helga Amesberger in Austria and Hendrik Wagenaar and Sietske Altink in the Netherlands. Not only will local researchers have better access to national and local data sources, but they are also in a better position to situate what the respondents say in its proper political-cultural-historical context. ${ }^{154}$

Sampling turned out to be strongly dependent on the specific situation in the respective countries. Since 2000 the Dutch prostitution market has been the subject of a considerable number of research studies (Daalder, 2002, 2007 and Van Wijk et al, 2010 are the most well known, but numerous smaller studies have been conducted by local commercial research agencies). National and international researchers and journalists regularly approach Dutch field organisations for cooperation in gaining access to sex workers. Also, licensed sex facilities are subject to frequent inspections from various kinds of officials. In general the Dutch prostitution field is much more interconnected with

${ }^{154}$ One of the major problems of qualitative international comparative research that is conducted by one researcher is the problem of understanding the history and, often tacit, cultural understandings of a research site. In our opinion it is simply impossible to obtain a valid and solid grasp of the meaning of an issue by spending a limited time in a country, no matter how careful one is in selecting spokespeople. This problem is enhanced when researchers do not speak the language of the country where they are undertaking their research. 
official organisations than in most countries. Outreach work is largely done by municipal health and social work organisations that have longestablished, stable trust relationships with the prostitution field in their city. Professionals often feel that they put this trust relationship at risk by mediating for research access. In a relatively small market where many actors know each other personally, this has resulted in a certain research 'fatigue', a reluctance with field workers to mediate among sex workers to collaborate with researchers. In those cases where we did get access to sex workers we discovered that the interviews were not without risk to the sex worker. In at least one case the interviewee lost her job in the brothel where she worked after being interviewed by us. Although we could not establish a clear causal link, it nevertheless proved to be demoralising to our insider interviewer who felt guilty about this. The Austrian prostitution market on the other hand has been much less researched. In addition, outreach work is largely done by independent NGOs who have to go out and contact sex workers for purposes of providing information. Officials have a more arm's-length relationship with the field than in the Netherlands. Sex workers and outreach workers suffer less from research 'fatigue'; in fact we had the impression that our fieldwork was one of the first instances that Austrian sex work had been researched 'on the ground'. We found two major outreach organisations (LEFÖ and maiz) willing to conduct interviews with sex workers. For most interviews specific appointments were made; a few interviews were done in the course of outreach work.

The different situations in Austria and the Netherlands have led us to use different sampling and data-collection strategies, each with their own strengths and weaknesses. In the Netherlands the emphasis was on the use of insiders for recruiting respondents. In addition to interviewing, the two Dutch field workers engaged in extensive observations of management practices in sex facilities and of management-sex worker interactions. The two field workers hung out in clubs where possible and had numerous conversations - although short of a formal interview - with hostesses, bar personnel and clients. From this participant observation we learned a lot from actors' off-hand comments. The Dutch sex worker insider also kept a diary.

In the Netherlands we interviewed 44 sex workers, and six to eight administrators, professionals and police officials for every city, covering administration, public health and the police. Three of the sex workers had participated in the so-called B9 arrangement for victims of trafficking (a national referral system) and were therefore officially designated 'victims of trafficking'. Interviews were held in Dutch or English. Two of the authors (Sietske Altink and Hendrik Wagenaar) 
interviewed officials, administrators and police officers. In an earlier study (Wagenaar, 2006) Hendrik Wagenaar interviewed around 25 facility owners and over 50 municipal officials; we have drawn on those data in this study. In Austria we interviewed 85 sex workers (59 in Vienna, 26 in Oberösterreich), three facility owners, and 29 administrators, professionals (NGOs), politicians and police officers. Outreach workers from two NGOs, LEFÖ in Vienna and maiz in Oberösterreich, conducted the interviews with sex workers; our Austrian researcher (Helga Amesberger) did four additional interviews with Austrian sex workers. The interviews covered topics ranging from the pathway into prostitution to earnings and working hours. The Austrian interviewers were fluent in the languages the sex workers are speaking (Bulgarian, Romanian, Hungarian, Czech/Slovakian, Polish, Spanish, Russian, English and German). In both countries we paid the sex worker a fee of $€ 50$ for the interview. Table 1 gives an overview of the characteristics of the sex workers interviewed in both countries.

Table 1: Austrian and Dutch sex worker interviewees: main characteristics

\begin{tabular}{|c|c|c|c|}
\hline & & $\begin{array}{l}\text { Austria } \\
(\mathrm{n}=82)\end{array}$ & $\begin{array}{l}\text { The Netherlands } \\
(\mathrm{n}=44)\end{array}$ \\
\hline Gender & $\begin{array}{l}\text { Female } \\
\text { Male } \\
\text { Transgender }\end{array}$ & $\begin{array}{l}80 \\
0 \\
2 \\
\end{array}$ & $\begin{array}{l}38 \\
4 \\
2 \\
\end{array}$ \\
\hline Nationality & $\begin{array}{l}\text { Austria } \\
\text { Belarus } \\
\text { Bulgaria } \\
\text { Czech Republic } \\
\text { Hungary } \\
\text { Italy } \\
\text { Israel } \\
\text { Latvia } \\
\text { Moldavia } \\
\text { Nigeria } \\
\text { Poland } \\
\text { Portugal } \\
\text { Romania } \\
\text { Russia } \\
\text { Slovakia } \\
\text { Spain } \\
\text { The Netherlands } \\
\text { Ukraine } \\
\text { Meso- and South } \\
\text { America (Venezuela, } \\
\text { Cuba, Dominican } \\
\text { Republic, Chile, Jamaica) }\end{array}$ & $\begin{array}{l}8 \\
1 \\
15 \\
5 \\
11 \\
1 \\
0 \\
2 \\
0 \\
4 \\
1 \\
0 \\
15 \\
1 \\
6 \\
1 \\
1 \\
3 \\
7\end{array}$ & $\begin{array}{l}0 \\
0 \\
3 \\
0 \\
1 \\
0 \\
1 \\
0 \\
1 \\
0 \\
0 \\
1 \\
3 \\
0 \\
0 \\
0 \\
31 \\
1 \\
2\end{array}$ \\
\hline
\end{tabular}




\begin{tabular}{|c|c|c|c|}
\hline & & $\begin{array}{l}\text { Austria } \\
(n=82)\end{array}$ & $\begin{array}{l}\text { The Netherlands } \\
(n=44)\end{array}$ \\
\hline Work venue & $\begin{array}{l}\text { Brothel, (night)club } \\
\text { Studio, private club } \\
\text { Escort } \\
\text { Streetwalking } \\
\text { Window, Laufhaus } \\
\text { Massage parlour, sauna } \\
\text { From their own home } \\
\text { Mixture (more than one } \\
\text { work venue) } \\
\text { Others (hotel } \\
\text { prostitution, illegal } \\
\text { brothel/bar) }\end{array}$ & $\begin{array}{l}29 \\
11 \\
2 \\
9 \\
22 \\
4 \\
0 \\
6 \\
2\end{array}$ & $\begin{array}{l}5 \\
11 \\
1 \\
1 \\
4 \\
10 \\
5 \\
0 \\
7\end{array}$ \\
\hline $\begin{array}{l}\text { Age at the time } \\
\text { of interview }\end{array}$ & $\begin{array}{l}18-20 \\
21-29 \\
30-39 \\
40-49 \\
50+\end{array}$ & $\begin{array}{l}0 \\
39 \\
25 \\
14 \\
4\end{array}$ & $\begin{array}{l}2 \\
16 \\
12 \\
11 \\
3 \\
\end{array}$ \\
\hline Years in sex work & $\begin{array}{l}<1 \text { year } \\
1-5 \text { years } \\
6-10 \text { years } \\
11-15 \text { years } \\
16-20 \text { years } \\
>20 \text { years } \\
\text { Unknown }\end{array}$ & $\begin{array}{l}8 \\
34 \\
27 \\
7 \\
3 \\
1 \\
2 \\
\end{array}$ & $\begin{array}{l}5 \\
9 \\
10 \\
4 \\
4 \\
7 \\
5\end{array}$ \\
\hline $\begin{array}{l}\text { Age at the time } \\
\text { of commencing } \\
\text { sex work }\end{array}$ & $\begin{array}{l}15-17 \\
18-19 \\
20-24 \\
25-29 \\
30-39 \\
40-49 \\
>50 \\
\text { Unknown }\end{array}$ & $\begin{array}{l}4 \\
10 \\
27 \\
12 \\
18 \\
3 \\
3 \\
5\end{array}$ & $\begin{array}{l}0 \\
7 \\
12 \\
11 \\
4 \\
0 \\
0 \\
10\end{array}$ \\
\hline
\end{tabular}

Interviewers in both countries were equipped with the same interview guidelines. The interviews with sex workers took place at the workplace of the interviewee, in cafés or at the offices of the NGOs. One guiding principle for conducting the interviews was not to disturb the sex worker's business. That is, if the sex worker solicited a client during the interview, the interview was terminated. This happened in a few cases. The interviewers tried to speak alone with the sex worker, but sometimes colleagues and friends were present who also 
provided information. ${ }^{155}$ The interviewers took care that the manager or facility owner was not present during the interview - not an easy task as in one case the interviewers were requested to lower their voices because otherwise the owner could listen to the interview via the surveillance cameras.

Because of the growing importance of the internet as a platform for recruiting clients in the Netherlands, the cities asked us to do an analysis of internet prostitution. A major problem with monitoring internet prostitution is double-counting. From client forums we learned that sex workers only advertise when they are actually available; this offered us an opportunity to estimate the number of sex workers who are active on the internet per day. ${ }^{156}$ Sex workers provide the prospective client with one or more mobile numbers and ask him to call using the number recognition facility. Sex workers indicate that they will not react to text messages or emails. This led us to try to google mobile numbers. This turned out to be a successful method for tracing sex workers. As a mobile number is linked to the same person (or persons), it offers a good indication of the number of unique sex workers who are actively recruiting on a given day. We learned that the same number appears on the same site at successive times of the day. Sometimes the same number advertises on the same site with different ads (although the site managers discourage this). Less than half of the mobile numbers appeared on only one site. The conclusion is that the term 'doublecounting' is an understatement in internet prostitution. It was no exception to see numbers appear 200 to 300 times in one day (2011) when entered as a Google search, with some generating 2,000 hits or more. On 10 different days we counted the number of unique mobile numbers on a single sex site in the Netherlands. By double-checking two major sites on later days, we learned that the figure for unique numbers is quite stable. Figures can be an underestimate, as we cannot exclude the scenario where sex workers share a phone number.

We collected and analysed policy and administrative documents, and newspaper and other media reports on prostitution. As one of the main goals of the study consisted of conceptualising prostitution policy, we consistently used our empirical findings to confront the policy literature. Often the literature suggested insights and explanations of

155 When more than one sex worker participated in the interview, it was counted nevertheless as one interview.

156 This would apply in Austria more or less only to webcam sex. Internet ads are paid on a weekly or monthly basis, so they are on the website for the requisite amount of time. This does not necessarily mean the sex workers work each day. 
the data, but almost just as often the data suggested important revisions of the standard theory. Finally, Hendrik Wagenaar interviewed New Zealand politicians, officials, professionals, scholars and members of the New Zealand Prostitutes' Collective (NZPC) on two occasions (in 2013 and 2015) about the New Zealand Prostitution Act and the role of the NZPC in it.

\section{Generalisability}

While the data on which this book is based are collected in two relatively small European countries, we believe that their importance exceeds these two cases. Despite obvious differences in political culture and structure, both the prostitution markets and the policy dynamics surrounding prostitution in Austria and the Netherlands have a lot in common with those in other north-western European countries. Many countries in this area experience high rates of immigration, predominantly from eastern Europe, but also from Africa, southeast Asia and Latin America. Some of these immigrants end up in prostitution. In almost all countries in the north-western corner of Europe, prostitution occupies a prominent position on the political agenda. The Swedish approach of criminalising clients acts as strong beacon to pundits and politicians in many countries (including those in the EU), and leads to venomous public debates over the moral nature of prostitution and the direction of prostitution policy. Both Austria and the Netherlands have made concerted efforts to regulate prostitution with the stated purpose of reducing harm to sex workers and containing public nuisance that is caused by prostitution. To this end local policy makers in both countries deployed a range of policy instruments. These policies contain lessons for every nation or locality that tries to regulate prostitution in one way or another. The upshot is that Austria and the Netherlands are representative of the efforts of many affluent, highly developed countries to give prostitution and its direct stakeholders, sex workers and proprietors, a place in society morally, spatially and institutionally. 



\section{References}

Abel, G., Fitzgerald, L., Healy, C. and Taylor, A. (eds) (2010) Taking the Crime out of Sex Work. New Zealand's Sex Workers' Fight for Decriminalisation, Bristol: Policy Press.

AG Länderkompetenzen Prostitution (2012) Regelung der Prostitution in Österreich. Empfehlungen der Arbeitsgruppe 'Länderkompetenzen Prostitution', www.bmbf.gv.at/frauen/prostitution/prostitution_01_26159. pdf?4dz8a1.

AG Prostitution (2014) Prostitution - Regulation versus Legal Ban (on the Purchase of Sexual Services), Position Paper of the Working Group on Prostitution (November), www.bmbf.gv.at/frauen/prostitution/ positionpaper_wg_prostitution.pdf?50zga8.

AG Prostitution (2015) Regelung der Prostitution in Österreich. Empfehlungen der Arbeitsgruppe 'Prostitution', www.bmbf.gv.at/ frauen/prostitution/Bericht_der_Arbeitsgruppe_Prostitution_,_ Maerz_2015_\%28Kopie.pdf?4wlw29.

Agustín, L. (2008) 'Sex and the limits of enlightenment: the irrationality of legal regimes to control prostitution', Sexuality Research and Social Policy, 5: 73-86.

Altink, S. (1995) Handel in Hartstocht, Deventer: Waldorp Pers.

Altink, S. and Bokelman, S. (2006) Rechten van Prostituees..., Amsterdam: De Rode Draad.

Amara, N. (2014) 'Der Freier mit der Polizeimarke. Die Wiener Polizei hebt mit verdeckten Ermittlern Bordelle aus. Ein heikles Unterfangen', Kurier, 23 July, http://kurier.at/chronik/wien/derfreier-mit-der-polizeimarke/52.610.973.

Amesberger, H. (2014) Sexarbeit in Österreich. Ein Politikfeld zwischen Pragmatismus, Moralisierung und Resistenz, Vienna: new academic press. Amesberger, H. (2016) 'Sexarbeit in Wien. Von Regulierungsversuchen, Arbeitsbedingungen und Resistenz', in Wien Museum (ed) Sex in Wien. Lust. Kontrolle. Ungehorsam, Vienna: Metroverlag, pp 176-183. Amesberger, H., Halbmayr, B. and Liegl, B. (1999) Bedarfserhebung - Maßnahmen für weibliche Prostituierte in Wien, unpublished report, Stadt Wien/MA 57, Wien.

Amesberger, H., Caixeta, L., Greif, E. and Sauer, B. (in press) 'Prostitution policy in Austria', in S. Jahnsen and H. Wagenaar (eds) Prostitution Policy in Europe, Abingdon: Routledge (in press).

Anderson, J.E. (1984) Public Policy-Making: An Introduction, Boston, MA; Houghton Mifflin. 
Andeweg, R.B. and Irwin, G.A. (2002) Governance and Politics of the Netherlands, Basingstoke: Palgrave Macmillan.

Ansell, C. (2011) Pragmatist Democracy. Evolutionary Learning as Public Philosophy, Oxford: Oxford University Press.

Ansell, C.K. and Gash, A. (2008) 'Collaborative governance in theory and practice', Journal of Public Administration Theory and Practice, 18(4): 543-571.

Ansell, C. and Torfing J. (2016) 'Collaboration and design: new tools for public innovation', in C. Ansell, and J. Torfing (eds) Public Innovation Through Collaboration and Design, Basingstoke: Routledge, pp 1-18

Arnstein, S.R. (1969) 'A ladder of citizen participation,' Journal of the American Institute of Planners, 35(4): 216-224.

Asante, A. and Schaapman, K. (2005) Het Onzichtbare Zichtbaar Gemaakt. Prostitutie in Amsterdam anno 2005, Amsterdam: Partij van de Arbeid.

Andrijasevic, R. (2004) Trafficking in Women and the Politics of Mobility in Europe, Utrecht: University of Utrecht (doctoral thesis).

Axelrod, R. and Cohen, M.D. (2000) Harnessing Complexity. Organizational Implications of a Scientific Frontier, New York, NY: Basic Books.

Baptista and LEFÖ (2014) Executive Summary on Labour Exploitation, http://luciaprojekt.baptistaoktatas.hu/de/?page_id=433

Beer, S. and Tremblay, F. (2014) 'Sex workers' rights organizations and government funding in Canada', in C.R. Showden and S. Majic (eds) Negotiating Sex Work. Unintended Consequences of Policy and Activism, Minneapolis, MS: University of Minnesota Press.

Benoit, C., Atkinson, C., Casey, L., Jansson, M., Mccarthey, B., Philips, R., Shaver, F., Reimewr, B., Reist, D. and Smith, M. (2015) 'Sex industry workers and confidence in the police in Canada', Paper presented at the Second International Conference on Public Policy, Milan, Italy, 1-3 July.

Bernstein, E. (2007) Temporarily Yours: Intimacy, Authenticity and the Commerce of Sex, Chicago, IL: University of Chicago Press.

Bestuursinformatie, Gemeente Utrecht (2012) Evaluatie Breed Maatregelenpaket Barrierevormign Mensenhandel, Utrecht: Afdeling Openbaar Orde en Veiligheid.

Bevir, M. and Rhodes, R. (2008) Politics as Cultural Practice, http:// escholarship.org/uc/item/4cd2d9qk.

Bevir, M. and Rhodes, R.A.W. (2010) The State as Cultural Practice, Oxford: Oxford University Press. 
Biesma, S., van der Stoep, R., Naayer, H. and Bieleman, B. (2006) Verboden Bordelen. Evaluatie Opheffing Bordeelverbod Niet-Legale Prostitutie, Groningen: Intraval.

Bourgon, J. (2011) A New Synthesis of Public Administration. Serving in the 21st Century, Quebec: McGill-Queen's University Press.

Bovenkerk, F., van San, M. and Boone, M. (2006) Loverboys, of Modern Pooierschap, Amsterdam: Augustus.

Brants, C. (1998) 'The fine art of regulated tolerance: prostitution in Amsterdam', Journal of Law and Society, 25: 621-35.

Brodkin, E.Z. (2007) 'Bureaucracy redux: management, reformism and the welfare state', Journal of Public Administration, Research and Theory, 17(1): 1-17.

Brunton, C. (2010) 'Becoming inspectors of brothels: public health authorities' experience of implementing the Prostitution Reform Act', in G. Abel, L. Fitzgerald, C. Healy and A. Taylor (eds) Taking the Crime out of Sex Work. New Zealand's Sex Workers' Fight for Decriminalisation, Bristol: Policy Press.

Cairney, P. (2012) Understanding Public Policy. Theories and Issues, Basingstoke: Palgrave Macmillan.

Caixeta, L. (2005) 'Precarius labor et stuprum corporis. Prekarität und die bezahlte sexuelle Dienstleistung', in IG-Kultur (ed) Kulturrisse, http://kulturrisse.at/ausgaben/022005/oppositionen/precariuslabor-et-stuprum-corporis.-prekaritaet-und-die-bezahlte-sexuelledienstleistung

Chew, L. (2012) 'Reflections by an anti-trafficking activist', in K. Kempadoo (ed) Trafficking and Prostitution Reconsidered. New Perspectives on Migration, Sex Work, and Human Rights (2nd edn) Boulder, CO: Paradigm Publishers, pp 65-83.

Cho, S.Y., Dreher, A. and Neymayer, E. (2013) 'Does legalized prostitution increase human trafficking?', World Development, 41: 67-82.

Chuang, J.A. (2010) 'Rescuing trafficking from ideological capture: prostitution reform and anti-trafficking law and policy', University of Pennsylvania Law Review, 158(6), 1655-1728.

Cohen, M.D., March, J.G. and Olsen, J.P (1972) 'A garbage can model of organizational choice', Administrative Science Quarterly, 17(1): 1-25.

Cohen, S. (2011) Folk Devils and Moral Panics, Abingdon: Routledge.

Considine, M. (2005) Making Public Policy: Institutions, Actors, Strategies, Cambridge: Polity.

Corbin, A. (1990) Women for Hire. Prostitution and Sexuality in France after 1850, Cambridge, MA: Harvard University Press 
County Administrative Board of Stockholm, Mujaj E. and Netscher, A. (eds) (2015) Prostitution in Sweden 2014. The Extent and Development of Prostitution in Sweden, Report 2015:18, www.lansstyrelsen.se/ stockholm/SiteCollectionDocuments/Sv/publikationer/2015/ rapport-2015-18.pdf

Crowhurst, I. (2012) 'Approaches to the regulation and governance of prostitution in contemporary Italy', Sexuality Research and Social Policy, 9(3): 223-232.

Cruz, K. (2015) 'Centring the state in our critiques of trafficking', in P. Kotiswaran and S. Okyere (eds) State and the Law. Beyond Trafficking and Slavery Short Course, Volume 3, Open Democracy, pp 68-71, opendemocracy.net/beyondslavery.

Daalder, A.L. (2002) Het Bordeelverbod Opgeheven: Prostitutie in 20002001, The Hague: WODC.

Daalder, A.L. (2007) Prostitutie in Nederland na Opheffing van het Bordeelverbod, The Hague: WODC.

Daalder, A.L (2015) Prostitutie in Nederland anno 2014, Cahier 2015-1, The Hague: WODC.

Dean, M. (1999) Governmentality. Power and Rule in Modern Society, Thousand Oaks, CA: Sage.

Dearing, A. and Haller, B. (eds) (2005) Schutz vor Gewalt in der Familie. Das österreichische Gewaltschutzgesetz, Vienna: Verlag Österreich.

Dekker, H., Tap, R. and Homburg, G. (2006) Evaluatie Opheffing Bordeelverbod, De Sociale Positie van Prostituees, Amsterdam: Regioplan.

Ditmore, M. (2012) 'Trafficking in lives: how ideology shapes policy', in K. Kempadoo (ed) Trafficking and Prostitution Reconsidered. New Perspectives on Migration, Sex Work, and Human Rights (2nd edn), Boulder, CO: Paradigm Publishers, pp 107-27.

Ditmore, M. and Wijers, M. (2003) 'The negotiations on the UN Protocol on Trafficking in Persons', Nemesis, 4: 79-88.

Dodillet, S. and Östergren P. (2013) 'The Swedish Sex Purchase Act: claimed success and documented effects', in H. Wagenaar, S. Altink and H. Amesberger Final Report of the International Comparative Study of Prostitution Policy in the Netherlands, Austria and the Netherlands, The Hague: Platform 31, pp 107-130.

Doezema, J. (2010) Sex Slaves and Discourse Masters. The Construction of Trafficking, London: Zed Books.

Edelman, M. (1985) The Symbolic Uses of Politics, Urbana, IL: University of Illinois Press.

Edelman, M. (1988) Constructing the Political Spectacle, Chicago, IL: University of Chicago Press. 
Elmore, R.F. (1980) 'Backward mapping: implementation research and policy decisions', Political Science Quarterly, 94(4): 601-16.

El-Nagashi, F. (2010) “Weder Schuldige, noch Opfer". Ermächtigungsstrategien im Kontext von Migration und Sexarbeit', L'Homme, Z.F.G., 21(1): 75-83.

Engbersen, G., Snel, E. and Boom, J. de (2009) 'A van full of Poles. Liquid migration from Central and Eastern Europe', in R. Black, G. Engbersen, M. Okolski and C. Pantiru (eds) EU Enlargement and Labour Migration, Amsterdam: Amsterdam University Press.

Engeli, I., Green-Pedersen, C. and Larsen, L.T. (eds) (2012) Morality Politics in Western Europe: Parties, Agendas and Policy Choices, Basingstoke: Palgrave Macmillan.

ExpertInnenkreis "Prostitution" im Rahmen der Task Force Menschenhandel (2008) Prostitution in Österreich. Rechtslage, Auswirkungen, Empfehlungen. Maßnahmenkatalog für eine (arbeits- und sozial-)rechtliche Absicherung von Personen, die in der Prostitution arbeiten, www.bmbf.gv.at/frauen/prostitution/prostitution_02_26160. pdf?4dz8a1.

Fairclough, N. (2003) Analysing Discourse. Textual Analysis for Social Research, Abingdon: Routledge.

Fitzgerald, L. and Abel A. (2010) 'The media and the Prostitution Reform Act', in G. Abel, L., Fitzgerald, C., Healy and A. Taylor (eds) Taking the Crime out of Sex Work. New Zealand's Sex Workers' Fight for Decriminalisation, Bristol: Policy Press, 197-217.

Flight, S., Hulshof, P., van Soomeren, P. and Soorsma, P. (2006) Evaluatie Opheffing Bordeelverbod, Gemeentelijk Beleid, Amsterdam: DSP groep (in opdracht WODC).

Florin, O. (2012) 'A particular kind of violence: Swedish social policy puzzles of a multipurpose criminal law', Sexuality Politics and Social Policy, 9(3): 269-278.

Forester, J. (2009) Dealing with Differences. Dramas of Mediating Public Disputes, Oxford: Oxford University Press.

Foucault, M. (1983) Sexualität und Wahrheit. Der Wille zum Wissen, Frankfurt/Main: Suhrkamp.

Foucault, M. (1991) 'Governmentality. The Foucault effect', in G. Burchell, C. Gordon and P. Miller (eds) Studies in Governmentality, Chicago, IL: University Of Chicago Press, pp 87-104.

Freeman, R. (2016) 'Politics in practice: interaction and inscription', Paper presented at the ECPR General Conference, Charles University, Prague, 7-10 September. 
Fudge, M. (2015) 'The modern appeal of the anti-slavery paradigm', in P. Kotiswaran and S. Okyere (eds) State and the Law. Beyond Trafficking and Slavery Short Course, Volume 3, Open Democracy, pp 20-3, opendemocracy.net/beyondslavery.

Fuji Johnson, G. (2015) 'Governing sex work: an agonistic policy community and its relational dynamics', Critical Policy Studies, 9(3): 259-277.

Fung, A. (2004) Empowered Participation. Reinventing Urban Democracy, Princeton, NJ: Princeton University Press.

Gall, G. (2014) 'Collective interest organization among sex workers', in C.R. Showden and S. Majic (eds) Negotiating Sex Work. Unintended Consequences of Policy and Activism, Minneapolis, MS: University of Minnesota Press.

Gallagher, A. (2001) 'Human rights and the new UN Protocols on Trafficking and Migrant Smuggling: a preliminary analysis', Human Rights Quarterly, 23(4): 975-1004.

Geertz, C. (1973) The Interpretation of Cultures, New York, NY: Basic Books.

Gibson, M. (1986) Prostitution and the State in Italy, 1860-1915, New Brunswick, NJ: Rutgers University Press.

Giddens, A. (1984) The Constitution of Society. Outline of the Theory of Structuration, Cambridge: Polity Press.

Giner-Sorolla, R. (2006) 'Attitudes towards prostitution: sociopsychological', in M.H. Ditmore (ed) Encyclopedia of Prostitution and Sex Work, Volume 1, Portsmouth, NH: Greenwood, pp 49-50.

Glynos, J. and Howarth, D. (2007) Logics of Critical Explanation in Social and Political Theory, Abingdon: Routledge.

Goraj, J. (2012) 'The influence of media on society's perception of prostitution. Critical discourse analysis of the Dutch media on prostitution in the years 2011, 2009 and 2000', unpublished Master's thesis, University of Leiden, Department of Public Administration.

Goggin, M.L. (1986) 'The "too few cases/too many variables" problem in implementation research', Western Political Quarterly, 39(2): 328-347

Grün, H. (1907) Prostitution in Theorie und Wirklichkeit, Vienna/Leipzig: J. Deublers Verlag.

Gusfield, J. (1986) Symbolic Crusade: Status Politics and the American Temperance Movement, Champaign, IL: University of Illinois Press.

Hajer, M. (1993) 'Discourse coalitions and the institutionalization of practice. The case of acid rain in Britain', in F. Fischer and J. Forester (eds) The Argumentative Turn in Policy Analysis and Planning, Durham, NC: Duke University Press, pp 43-76. 
Hajer, M. (2003) 'A frame in the fields: policymaking and the reinvention of politics', in M. Hajer and H. Wagenaar (eds) Deliberative Policy Analysis. Understanding Governance in the Network Society, Cambridge: Cambridge University Press, pp 88-113.

Hamen, M. (2011) 'Framings von Sexarbeit im Kontext des Oberösterreichischen Sexualdienstleistungsgesetzes', unpublished diploma work, University of Vienna.

Hämmerle, K. (2015) 'Niederlage für Bordell-Werber. Verwaltungsgericht wies Beschwerde zurück. Freudenhaus aber noch nicht vom Tisch', Vorarlberger Nachrichten, 14 July, www. vorarlbergernachrichten.at/abend/2015/07/13/niederlage-fuerbordell-werber.vn\#registered.

Haveman, R. and and Wijers, M. (1993) 'Wetgeving. Vrouwenhandel en exploitatie van prostitutie', Nemesis, 2: 21-23.

Haveman, R. (1998) Voorwaarden voor de Strafbaarstelling van Vrouwenhandel, Gouda/Deventer: Quint.

Healey, P., de Magalhaes, C., Madanipour, A. and Pendelbury, J. (2003) 'Place, identity and local politics: analysing initiatives in deliberative governance', in M. Hajer and H. Wagenaar (eds) Deliberative Policy Analysis. Understanding Governce in the Network Society, Cambridge: Cambridge University Press, 60-87.

Healy, C., Bennachie, C. and Reed, A. (2010) 'History of the New Zealand Prostitutes' Collective', in G. Abel, L. Fitzgerald, C. Healy and A. Taylor (eds) Taking the Crime out of Sex Work. New Zealand's Sex Workers' Fight for Decriminalisation, Bristol: Policy Press, 45-57.

Hill, M. and and Hupe, P. (2014) Implementing Public Policy: An Introduction to the Study of Operational Governance (3rd edition), Thousand Oaks, CA: Sage Publications.

Hjern, B. and Porter, D.O. (1981) 'Implementation structures: a new unit of administrative analysis', Organization Studies, 2/3: 211-227.

Hogwood, B.W. and Gunn, L. (1984) Policy Analysis for the Real World, Oxford: Oxford University Press.

Honeyball, M. (2014) Report on Sexual Exploitation and Prostitution and its Impact on Gender Equality (2013/2103(INI)), Strasbourg: Committee on Women's Rights and Gender Equality, European Parliament.

Hood, C. (1986) The Tools of Government, Chatham: Chatham House Publishers.

Hood, C. and Dixon, R. (2015) A Government that Worked Better and Cost Less? Evaluating Three Decades of Reform and Change in UK Central Government, Oxford: Oxford University Press.

Hood, C. and Jackson, M. (1997) Administrative Argument, London: Dartmouth Publishing. 
Hooghe, L. and Marks, M. (2003) 'Unraveling the central state, but how? Types of multi-level governance', American Political Science Review, 97(2): 233-243.

Howlett, M. (2011) Designing Public Policies: Principles and Instruments, Abingdon: Routledge.

Howlett, M. and Ramesh, M. (2003) Studying Public Policy. Policy Cycles and Policy Subsystems (2nd edn), Oxford: Oxford University Press.

Howlett, M., Ramesh, M. and Perl, A. (2009) Studying Public Policy: Policy Cycles and Policy Subsystems, Ottawa: OUP Press.

Hrzeniak, M., Sauer, B. and Tertinegg, K. (2007) 'What's the problem with prostitution? Prostitution politics in Austria and Slovenia since the 1990s. A comparison of frames', in M. Verloo (ed) Multiple Meanings of Gender Equality. A Critical Frame Analysis of Gender Policies in Europe, Budapest/New York: CEU Press, pp 187-206.

Huijsman, R., Ahaus, K. and Rosendal, H. (2009) 'Samenhangende zorg in ketens en netwerken: de huidige stand en agenda voor vervolg', in H. Rosendal, K. Ahaus, R. Huijsman and C. Raad (eds) Ketenzorg. Praktijk in Perspectief, Maarssen: Elsevier Gezondheidszorg. Hupe, P., Hill, M. and Nangia, M. (2014) 'Studying implementation beyond deficit analysis: the top-down view reconsidered', Public Policy and Administration, 29(2): 145-163.

ICRSE (International Committee on the Rights of Sex Workers in Europe) (2015) Structural Violence. Social and Institutional Oppression Experienced by Sex Workers in Europe, Amsterdam: ICRSE, www. sexworkeurope.org/resources/community-guide-structuralviolence-2015.

ICRSE (2016) Exploitation. Unfair Labour Arrangements and Precarious Working Conditions in the Sex Industry, Amsterdam: ICRS, www. sexworkeurope.org/news/general-news/may-day-icrse-launchescommunity-report-exploitation-sex-industry.

Innes, J.I. and Booher, D.E. (2010) Planning with Complexity. An Introduction to Collaborative Rationality for Public Policy, Abingdon: Routledge.

Ison, R. (2010) Systems Practice: How to Act in a Climate-Change World, London: Springer.

Jahnsen, S.Ø. and Skilbrei, M.L. (in press) 'Norway', in S.Ø. Jahnsen and H. Wagenaar (eds) Prostitution Policy in Europe, Abingdon: Routledge.

Jahnsen, S.Ø. and Wagenaar, H. (in press) Prostitution Policy in Europe, Abingdon: Routledge. 
Jeffrey, L.A. (2015) 'Cave! Hic dragones: negotiating the contradictory pressures of sex work policy making: lessons for Canadian policymakers', Paper presented at the Second International Conference on Public Policy, Milan, Italy, 1-3 July.

John, P. (2012) Analyzing Public Policy, Abingdon: Routledge.

Jørgensen, M. and Phillips, L. (2002) Discourse Analysis as Theory and Method, Thousand Oaks, CA: Sage Publications.

Judt, T. (2005) Postwar: A History of Europe Since 1945, London: William Heinemann.

Kagan, R. (1978) Regulatory Justice: Implementing a Wage-Price Freeze, New York, NY: Russel-age Foundation.

Kapur, R. (2012) 'Cross-border movements and the law: renegotiating the boundaries of difference', in K. Kempadoo (ed) Trafficking and Prostitution Reconsidered. New Perspectives on Migration, Sex Work, and Human Rights (2nd edn), Boulder, CO: Paradigm Publishers, pp $25-42$.

Kempadoo, K. (2012a) 'Introduction. Abolitionism, criminal justice, and transnational feminism: twenty-first-century perspectives on human trafficking', in K. Kempadoo (ed) Trafficking and Prostitution Reconsidered. New Perspectives on Migration, Sex Work, and Human Rights (2nd edn), Boulder, CO: Paradigm Publishers, pp vii-xlii.

Kempadoo, K. (2012b) 'The anti-trafficking juggernaut rolls on', in K. Kempadoo (ed) Trafficking and Prostitution Reconsidered. New Perspectives on Migration, Sex Work, and Human Rights (2nd edn), Boulder, CO: Paradigm Publishers, pp 249-261.

Kingdon, J.W. (2011) Agendas, Alternatives, and Public Policies (2nd edn), Boston, MA: Longman.

KLPD (Korps Landelijke Politiediensten - Dienst Nationale Recherche) (2008) Schone Schijn. De Signalering van Mensenhandel in de Vergunde Prostitutiesector, Driebergen: KLPD.

Knight, D. (2010) 'The (continuing) regulation of prostitution by local authorities', in G. Abel, L. Fitzgerald and C. Healy (eds) Taking the Crime out of Sex Work. New Zealand's Sex Workers' Fight for Decriminalisation, Bristol: Policy Press, pp 141-159.

Kotiswaran, P. and Okyere, S. (2015) 'The role of the state and law in trafficking and modern slavery', in P. Kotiswaran and S. Okyere (eds) State and the Law. Beyond Trafficking and Slavery Short Course, Volume 3, Open Democracy, pp 8-13, opendemocracy.net/beyondslavery.

Krinsky, C. (2013) The Ashgate Research Companion to Moral Panics, Farnham: Ashgate.

Kulick, D. (2005) 'Four hundred thousand Swedish perverts', GLQ: A Journal of Lesbian and Gay Studies, 11(2): 205-235. 
Lakoff, G. (2014) The All New Don't Think of an Elephant!, White River Junction, VT: Chelsea Green Publishing.

Landman, T. (2000) Issues and Methods in Comparative Politics: An Introduction, Abingdon: Routledge.

Lane, J.E. (1987) 'Implementation, accountability and trust', European Journal of Political Research, 15(5): 527-546.

Le Breton, M. (2011) Sexarbeit als transnationale Zone der Prekarität. Migrierende Sexarbeiterinnen im Spannungsfeld von Gewalterfahrungen und Handlungsoptionen, Wiesbaden: Springer VS.

Lindblom, C.E. (1965) The Intelligence of Democracy. Decision Making Through Mutual Adjustment, New York, NY: Free Press.

Linder, S.H. and Peters, B.G. (1989) 'Instruments of government: perceptions and context', Journal of Public Policy, 9(1): 35-58.

Lowi, T. (1972) 'Four systems of policy, politics, and choice', Public Administration Review, 32: 298-310.

Mai, N. (2009) Migrant Workers in the UK Sex Industry, Economic and Social Research Council Report, RES-062-23-0137, Swindon: ESRC.

Majic, S. (2013) Sex Work Politics. From Protest To Service Provision, Philadelphia, PN: University of Pennsylvania Press.

Manin, B. (1997) The Principles of Representative Government, Cambridge: Cambridge University Press.

Marktler, T. (2012) 'Das Ö̈. Sexualdienstleistungsgesetz', in E. Greif (ed) SexWork(s). Verbieten - Erlauben - Schützen?, Linzer Schriften zur Frauenforschung 51, edited by U. Flossmann, Linz: Trauner Verlag, pp 9-48.

Mathieu, L. (2001) 'An unlikely mobilization: The occupation of Saint-Nizier church by the prostitutes of Lyon', Revue Française de Sociologie, annual English selection, 42: 107-131.

Maynard-Moody, M. and Musheno, M. (2003) Cops, Teachers, Counsellors. Stories from the Front-Line of Public Services, Ann Arbor, MI: University of Michigan Press.

Mert, A. (2015) Environmental Governance through Partnerships. A Discourse Theoretical Study, Cheltenham: Edward Elgar.

Merton, R.K. (1936) 'The unanticipated consequences of purposive social action', American Sociological Review, 1: 894-904.

Mitchell, S. and Herring M. (2006) 'Drifting away? Policy and regulatory drift in the Canadian health care system', Paper presented at the CPSA Annual Conference, York University, 1-3 June.

Mooney, C.S. (1999) 'The politics of morality policy: symposium editor's introduction', Policy Studies Journal, 27(4): 675-680. 
Mooney, C. S. (2001) 'The public clash of private values', in C.Z. Mooney (ed) The Public Clash of Private Values. The Politics of Morality Policy, New York, NY: Seven Bridges Press.

Moran, M. (2002) 'Review article: understanding the regulatory state', British Journal of Political Science, 32(2): 391-413.

Mosterd, M. (2008) Echte Mannen Eten Geen Kaas, Amsterdam: van Gennep.

Mouffe, C. (2000) The Democratic Paradox, London: Verso.

Nationaal Rapporteur Mensenhandel (2010) Mensenhandel - 10 jaar Nationaal Rapporteur Mensenhandel in Nederland - Achtste rapportage van de nationaal rapporteur, The Hague: BNRM.

Neuweg, S. (1990) 'Die andere Arbeit. Historische, soziologische und feministische Aspekte zur Prostitution', unpublished diploma work, Linz: Johannes Kepler Universität.

Nicolini, D. (2012) Practice Theory, Work and Organization. An Introduction, Oxford: Oxford University Press.

Norris, P. (2011) Democratic Deficit, Cambridge: Cambridge University Press.

Nussbaum, M.C. (1998) “'Whether from reason or prejudice”: taking money for bodily services', Journal of Legal Studies, 27 (January): 693-724.

Nussbaum, M.C. (2004) Hiding from Humanity. Disgust, Shame and the Law, Princeton, NJ: Princeton University Press.

O'Connell Davidson, J. (2006) 'Will the real sex slave please stand up', Feminist Review, 83: 4-22.

Oude Breuil, B.C. (2011) Almere Door een Rode Bril, Fenomeenonderzoek naar Seksuele Dienstverlening, Utrecht: Pompe Instituut.

Outshoorn, J.V. (2001) 'Debating prostitution in parliament: a feminist analysis', European Journal of Women's Studies, 8(4): 473-492.

Outshoorn, J.V. (2004a) 'Introduction: prostitution, women's movements and democratic politics', in J. Outshoorn (ed) The Politics of Prostitution: Women's Movements, Democratic States and the Globalisation of Sex Commerce, Cambridge: Cambridge University Press, pp 1-20. Outshoorn, J.V. (2004b) 'Voluntary and forced prostitution: the "realistic approach" of the Netherlands', in J. Outshoorn (ed) The Politics of Prostitution: Women's Movements, Democratic States and the Globalisation of Sex Commerce, Cambridge: Cambridge University Press, pp 185-204.

Outshoorn, J.V. (2012) 'Policy change in prostitution in the Netherlands: from legalization to strict control', Sexuality Research and Social Policy, 9: 233-243. 
Outshoorn, J.V. (2014) 'The contested citizenship of sex workers: the case of the Netherlands', in C.R. Showden and S. Majic (eds) Negotiating Sex Work. Unintended Consequences of Policy and Activism, Minneapolis, MS: University of Minnesota Press, pp 171-193.

Outshoorn, J. and Swiebel, J. (1998) 'Feminism and the state in the Netherlands', in G. Lycklama á Nijeholt, V. Vargas and S. Wieringa (eds) Women's Movements and Public Policy in Europe, Latin America and the Caribbbean, New York, NY: Garland, pp 143-166.

Pates, R. (2012) 'Liberal laws, punitive practices: logics of interference in the "most liberal sex work regime in the world"", Sexuality Research and Social Policy, 9: 212-222.

Peters, B.G. (2006) 'Concepts and theories of horizontal policy management', in B.G. Peters and J. Pierre (eds) Handbook of Public Policy, Thousand Oaks, CA: Sage, pp 115-138.

Pheterson, G. (1996) The Prostitution Prism, Amsterdam: Amsterdam University Press.

Phillips, N. (2015) 'What has forced labour to do with poverty?', in G. leBaron and L. Howard (eds) Forced Labour in the Global Economy Short Course, Volume 2, Open Democracy, pp 14-17, opendemocracy. net/beyondslavery.

Phoenix, J. (ed) (2009) Regulating Sex for Sale: Prostitution Policy Reform in the UK, Bristol: Policy Press.

Pickering, A. (1995) The Mangle of Practice. Time, Agency and Science, Chicago, IL: University of Chicago Press.

Prantner, M. (2006) 'Sexarbeit ... Frauenrechtsverletzung oder eine Arbeit wie jede andere? Eine kritische Analyse ausgewählter rechtlicher Regelungen in Europa', Master's thesis, Rosa-MayrederCollege, Vienna, http://v000702.vhost-vweb-02.sil.at/wp-content/ uploads/2008/07/sexarbeit-frauenrechtsverletzung-oder-eine-arbeitwie-jede-andere.pdf.

Presse- und Informationsdienst der Stadt Wien (2011) 'Rathauskorrespondenz 3 January 2011', www.wien.gv.at/rk/ index/daily.

Prior, P., Crofts, P. and Hubbard, P. (2013) 'Planning, law and sexuality: hiding immorality in plain view’, Geographical Research, 51(4): 354363.

Radin, M.J. (2001) Contested Commodities. The Trouble with Trade in Sex, Children, Body Parts, and Other Things, Cambridge, MA: Harvard University Press.

Rein, M. (1983a) 'Value-critical policy analysis', in D. Callahan and B. Jennings (eds) Ethics, the Social Sciences, and Policy Analysis, New York, NY: Plenum Press, pp 83-112. 
Rein, M. (1983b) 'The coordination of social services', in M. Rein (ed) Social Policy: Issues of Choice and Change, Armonk, NY: M.E. Sharpe, pp 103-137.

Rhodes, R. (1996) 'The new governance: governing without government', Political Studies, 44: 652-656.

Rhodes, R. (2015) Everday Life in British Government, Oxford: Oxford University Press.

Rittel, H.W. and Webber, M. (1973) 'Dilemmas in a general theory of planning', Policy Sciences, 4(2): 155-169.

Roberts, K. (2015) 'The Modern Slavery Bill: migrant domestic workers fall through the gaps', in P. Kotiswaran and S. Okyere (eds) State and the Law. Beyond Trafficking and Slavery Short Course, Volume 3, Open Democracy, pp 14-19, opendemocracy.net/beyondslavery. Robinson, C. (2015) 'Anti-slavery responses should offer solutions not benevolence', in P. Kotiswaran and S. Okyere (eds) State and the Law. Beyond Trafficking and Slavery Short Course, Volume 3, Open Democracy, pp 24-29, opendemocracy.net/beyondslavery.

Rode Draad (2012) Sekswerk in 2011, Trendrapport, Amsterdam: De Rode Draad.

Roessingh, M. and Ramesar, P. (2011) Slaven in de Polder: Hoe Sekswerkers, Schoonmakers and Seizoensarbeiders Worden Uitgebuit, Amsterdam: Uitgeverij Atlas.

Rose, N. and P. Miller (1992) 'Political power beyond the state: problematics of government', British Journal of Sociology, 43(2): 173205.

Rosendal, H., Ahaus, K., Huijsman, R. and C. Raad (eds) (2009) Ketenzorg. Praktijk in Perspectief, Maarssen: Elsevier Gezondheidszorg. Ruep, M. (2015) 'Salzburg geht mit Abschiebungen gegen Straßenstrich vor', Der Standard, 14 October, http://derstandard. at/2000023655654/Salzburg-geht-mit-Abschiebungen-gegenStrassenstrich-vor.

Sabitzer, W. (2000) 'Die Geschichte der Prostitution. Von unzüchtigen Weibspersonen', Öffentliche Sicherheit, edited by Bundesministerium für Inneres, Vienna, http://elib.at.

Salamon, L. and Lund, M.S. (2009) 'The tools approach: basic analytics', in L. Salamon (ed) Beyond Privatization: The Tools of Government Action, Washington DC: Uran Institute, pp 23-50.

Sanghere, J. (2012) 'Unpacking the trafficking discourse', in K. Kempadoo (ed) Trafficking and Prostitution Reconsidered. New Perspectives on Migration, Sex Work, and Human Rights (2nd edn), Boulder, CO: Paradigm Publishers, pp 3-24. 
Sassen, S. (2002) 'Women's burden: counter-geographies of globalization and the feminization of survival', Nordic Journal of International Law, 71(2): 255-274.

Sauer, B. (2003) 'Prostitutionspolitik in Wien (1975- 2002)', in cooperation with C. Brunner, unpublished report, Vienna.

Sauer, B. (2004) 'Taxes, rights and regimentation: discourses on prostitution in Austria', in J.V. Outshoorn (ed) The Politics of Prostitution: Women's Movements, Democratic States and the Globalisation of Sex Commerce, Cambridge: Cambridge University Press, pp 41-61.

Sautner, L. (2012) 'Prostitution in strafrechtlicher Perspektive. Impulsreferat zur österreichischen Rechtslage', in E. Greif (ed) SexWork(s). Verbieten - Erlauben - Schützen?, Linzer Schriften zur Frauenforschung 51, edited by U. Flossmann, Linz: Trauner Verlag, pp 1-8.

Sayer, A. (2000) Realism and Social Science, Thousand Oaks, CA: Sage Publications.

Schlesinger, W. (1868) Die Prostitution in Wien und Paris. Skizzen, Vienna: Verlag von Tendler \& Comp. (Julius Grosser).

Schmidt, V.A. and Radaelli, C. (2004) 'Policy change and discourse in Europe: conceptual and methodological issues', West European Politics, 27(2): 183-210.

Schön, D. (1971) Beyond the Stable State: Public and Private learning in a Changing Society, New York, NY: Random House.

Schön, D. and Rein, M. (1994) Frame Reflection. Towards the Resolution of Intractable Policy Controversies, New York, NY: Basic Books.

Scoular, J. (2010) 'What's law got to do with it? How and why law matters in the regulation of sex work', Journal of Law and Society, 37: 12-39.

Scoular, J. and O'Neill, M. (2007) 'Regulating prostitution. Social inclusion, responsibilization and the politics of prostitution reform', British Journal of Criminology, 47: 764-778.

Sexworker Forum Austria (2013) 'Discriminations against sex workers in the rights to work and to health', Information from Sex-Worker Forum of Vienna, Austria, to the UN Committee on Economic, Social and Cultural Rights of the United Nations High Commissioner for Human Rights, Vienna, 28 June.

Shadish, W.R., Cook, T.D. and Campbell, D.T. (2001) Experimental and Quasi-Experimental Designs for Generalised Causal Inference, Boston, MA: Houghton Mifflin. 
Sharma, N. (2015) 'Anti-trafficking: white-wash for anti-immigration programs', in P. Kotiswaran and S. Okyere (eds) State and the Law. Beyond Trafficking and Slavery Short Course, Volume 3, Open Democracy, pp 36-40, opendemocracy.net/beyondslavery.

Shove, E., Pantzar, M. and Watson, M. (2012) The Dynamics of Social Practice. Everyday Life and How It Changes, Thousand Oaks, CA: Sage Publications.

Sieber, S.D. (1981) Fatal Remedies. The Ironies of Social Intervention, New York, NY: Plenum Press.

Siegel, D. (2015) Het Zandpad: Closing Brothels or Closing Eyes: Utrechtse Sekswerkers na de Sluiting van het Zandpad, Meppel: Boom/Lemma.

Skilbrei, M.L. and Holmström, C. (2013) Prostitution Policy in the Nordic Region: Ambiguous Sympathies, Farnham: Ashgate.

Smith, H.M. (2011) 'Sex trafficking: trends, challenges and the limitations of international law', Human Rights Review, 12(3): 271286.

SOPHIE-mobil (2011) 'Interner Endbericht SOPHIE-mobil. 01.0630.11.2010', unpublished report, Vienna.

Sørensen, E. and J. Torfing, (2008) 'Introduction: governance network research: towards a second generation', in E. Sørensen and J. Torfing (eds) Theories of Democratic Network Governance, Basingstoke: Palgrave Macmillan.

Stella (2015) 'Third parties and the law', http://chezstella.org/wpcontent/uploads/2015/12/stella_thirdparties.pdflink.

Stone, D. (1997) Policy Paradox. The Art of Political Decision Making, New York, NY: W.W. Norton \& Company.

Sullivan, B. (2010) 'When (some) prostitution is legal: the impact of law reform on sex work in Australia', Journal of Law and Society, 37(1): 85-104.

Tampep International Foundation (2009) Sex Work in Europe. A Mapping of the Prostitution Scene in 25 European Countries, edited by L. Brussa, Amsterdam: Tampep International Foundation and TampepNetherlands.

Tampep International Foundation (2015) On the Situation of National and Migrant Sex Workers in Europe Today, Briefing paper, www.nswp. org/sites/nswp.org/files/TAMPEP\%20Briefing\%20\%20Paper\%20 2015.pdf.

Tatalovich, R., Smith, T.A. and Bobic, M.P. (1994) 'Moral conflict and the policy process', Policy Currents, 4(4): 3-6. 
Thalhammer, A. (2014) 'Stadt und Asfinag sperren Straßenstrich in Auhof $\mathrm{zu}^{\prime}$, heute, 6 August, www.heute.at/news/oesterreich/ wien/Stadt-und-Asfinag-sperren-Strassenstrich-in-Auhofzu;art23652,1051422.

Tonkens, E. (2011) 'De legalisering van prostitutie is een dekmantel voor seksuele slavernij', De Volkskrant, 2 November.

Tsebelis, G. (2002) Veto Players: How Political Institutions Work, Princeton, NJ: Princeton University Press.

van den Borne, A. and Kloosterboer, K. (2005) Inzicht in Uitbuiting, Handel in Minderjarigen in Nederland, Nader Onderzocht, Amsterdam: Ecpat Nederland, Defence for Children, Unicef Nederland en Plan Nederland.

van der Helm, T. and van Mens, L. (1999) 'Mobility. In prostitution in the Netherlands 1999-1998', unpublished report, Amsterdam.

van Rooijen, H. (2012) 'Beleidsinstrumenten in het prostitutiebeleid: reguleren of samenwerken?', unpublished Master's thesis, University of Leiden, Department of Public Administration.

van Wijk, A., Nieuwenhuis, A., van Tuyn, D., van Ham, T., Kuppens, J. and Ferwerda, H. (2010) Kwetsbaar Beroep: Een Onderzoek naar de Prostitutiebranche in Amsterdam, Arnhem: Bureau Beke.

van Wijk, A., van Ham, T., Hardeman, M and Bremmers B. (2015) Prostitutie in Nederlandse Gemeenten, een Onderzoek naar Aard en Omvang, Beleid, Toezicht en Handhaving in 2014, Beke Reeks, The Hague: WODC.

Vance, C.S. (2011) 'States of contradiction: twelve ways to do nothing about trafficking while pretending to', Social Research: An International Quarterly, 78(3): 933-948.

van der Zee, R. (2015) Mannen Die Seks Kopen, Amsterdam: Swp.

Vinzant, J.C. and Crothers, L. (1998) Street-Level Leadership: Discretion and Legitimacy in Front-Line Public Service, Washington, DC: Georgetown University Press.

Vos, J. and Wagenaar, H. (2014) 'The Münchhausen movement: improving collaboration between public institutions through the creation of a social movement', American Review of Public Administration, 44(4): 409-439.

Wagenaar, H. (1995) 'Het onbedoelde gebruik van beleid' [The Unintended Use of Public Policy], in L. Aarts, P. de Jong, R. van der Veen and H. Wagenaar (eds) Het Bedriff van de Verzorgingsstaat. Naar Nieuwe Verhoudingen tussen Staat en Burger, Meppel: Boom, pp 234-260.

Wagenaar, H. (2004) "“Knowing" the rules. Administrative work as practice', Public Administration Review, 64(6): 643-655. 
Wagenaar, H. (2006) 'Democracy and prostitution: deliberating the legalization of brothels in the Netherlands', Administration \& Society, 38(3): 198-235.

Wagenaar, H. (2007) 'Governance, complexity and democratic participation: how citizens and public officials harness the complexities of neighbourhood decline', American Review of Public Administration, 37(1): 17-50.

Wagenaar, H. (2011) Meaning in Action: Interpretation and Dialogue in Policy Analysis, Abingdon: Routledge.

Wagenaar, H. (2014) 'The agonistic experience: informality, hegemony and the prospects for democratic governance', in S. Griggs, A. Norval, and H. Wagenaar H. (eds) Practices of Freedom: Democracy, Conflict and Participation in Decentred Governance, Cambridge University Press, pp 217-248.

Wagenaar, H. (2015a) 'Governance-driven conflict: policy, reason of state and authoritarian governmentality', in E. Gualini, J. Mourato and M. Allegra (eds) Conflict in the City: Contested Urban Spaces and Local Democracy, Berlin: Jovis Verlag, pp 112-132.

Wagenaar, H. (2015b) 'Transforming perspectives: the critical functions of interpretive policy analysis', in F. Fischer, D. Torgerson, A. Durnova and M. Orsini (eds) Handbook of Critical Policy Studies, Cheltenham: Edward Elgar, pp 422-441.

Wagenaar, H. and Altink, S. (2012) 'Prostitution as morality politics or why it is exceedingly difficult to design and sustain effective prostitution policy', Sexuality Research and Social Policy, 9: 279-297.

Wagenaar, H., Altink, S. and Amesberger, H. (2013) Final Report of the International Comparative Study of Prostitution Policy: Austria and the Netherlands, The Hague: Platform 31.

Wagenaar, H., van Schijndel M. and Kruiter, H. (2010) Bewonersparticipatie en Veiligheid. Tussen Droom en Daad ... in een Complexe Bestuurlijke Context, The Hague: University of Leiden, The Hague campus.

Waldenberg, A. (2012) ““... wie andere auch!” Geschichte und Debatten der Hurenbewegung in Deutschland und Österreich von den 1970er Jahren bis 2011', diploma work, University of Vienna, http://othes.univie.ac.at/20344/1/2012-05-11_0305907.pdf.

Walkowitz, J.R. (1982) Prostitution and Victorian Society: Women, Class and the State, Cambridge: Cambridge University Press.

Walters, W. (2012) Governmentality. Critical Encounters, Abingdon: Routledge.

Warren, M.E. (2001) Democracy and Association, Princeton, NJ: Princeton University Press. 
Warren, M.E. (2014) 'Governance-driven democratization', in S. Griggs, A. Norval and H. Wagenaar (eds) Practices of Freedom: Democracy, Conflict and Participation in Decentred Governance, Cambridge: Cambridge University Press, pp 38-60.

Weiss, R.S. (1995) Learning from Strangers. The Art and Method of Qualitative Interview Studies, New York, NY: Free Press.

Weitzer, R. (2007) 'The social construction of sex trafficking: ideology and institutionalization of a moral crusade', Politics E Society, 35(3): 447-475.

Weitzer, R. (2012) Legalizing Prostitution: From Illicit Vice to Lawful Business, New York, NY: New York University Press.

Weitzer, R. (2015) 'Human trafficking and contemporary slavery', Annual Review of Sociology, 41: 223-242.

Werson, H. (2012) De Fuik. Achter de schermen van de Mensenhandel en Gedwongen Prostitutie in Nederland, Amsterdam: Carrera.

Yanow, D. (1996) How Does a Policy Mean? Interpreting Policy and Organizational Action, Washington, DC: Georgetown University Press. Zuidema, R., Aerts, M.C.M. and Boonstra, K. (2006) Arbeidsrecht voor Prostituees? De (on) Mogelijkheid van Toepassing in het Arbeidsrecht op Arbeidsverhoudingen in de Prostitutiebranche, Amsterdam: Hugo Sinzheimer Instituut. 


\section{Index}

A

abolitionism

coalition $34 \mathrm{n} 11$

and emotions $38,39,40,41$

and morality politics $10,34,36$

and national discourse 189

resistance to facts 43

use of redbaiting 42

accountability

and collaborative governance 236

democratic $66,77,78,86,108 \mathrm{n} 47$

and trust $138,141,142-3$

actor agency 5, 17, 112, 207, 225 , 233n143, 249

'adaptive capacity' 251

addiction see substance addiction

administrative bureaucracies 75,127

administrative law 75, 87, 109, 177, 217

'administrative measures' 106, 109-10, $118,135,142,167,170$

administrative reports $113,115,116$

advocacy 95, 139, 147, 252

agency capture 121, 136, 140, 190

agenda-setting 12, 128, 146, 147, 149, 192

Alkmaar 52n26, 97n42, 104, 169

Altink, S. and Bokelman, S. 213

Amesberger, H. 83

Amesberger, H. et al (in press) 176

Amsterdam

closure of toleration zones 102

conference for sex workers 238

forced prostitution 103

gentrification 117, 169

red-light district manager 89

registration systems 117

unreliable statistics $56 \mathrm{n} 28$

window prostitution $97 \mathrm{n} 42,104$, 110, 167, 169

Andeweg, R.B. and Irwin, G.A. 76 anger 38, 39n17, 40, 101

Ansell, C. 19, 49, 108n47, 109n47, 246, 249
Ansell, C. and Gash, A. 235, 236, 244, 248

anti-immigration ideology 27, 199

apartment prostitution 120, 130, 131

APV (General Local Ordinance) model 116, 117, 170

Arnhem 102

Asante, A. 160

Asante, A. and Schaapman, K. 161

Asscher, L. 161, 162

Association of Austrian Prostitutes see VdPÖ (Verband der Prostituierten Österreichs)

Association of Dutch Municipalities see VNG (Vereniging van Nederlandse Gemeenten)

asylum seekers 5, 52, 185, 186, 187

Australia 189, 190, 240

Austria

asylum seekers 186, 187

characteristics of sex workers $272-3 \mathrm{t}$

Criminal Code and Criminal

Law 119, 171

data registers 58, 59

Department of Criminal

Intelligence 59

Federal Constitutional Law 117

Freedom Party 176

gender equality 171

General Social Security 184, 185

Green Party 176

immigration 4, 185, 186-7

Länderkompetenzen Prostitution 172, 173

licensing 33

local governance $33,63,75,117-43$, 171-3, 183, 192

morality politics 175

National Action Plan against human

trafficking 172

national governance $170-87$

People's Party 176

policy implementation 75-6

policy network 171

policy subsystem 172 
regulation $118,177-8,179$

sex worker initiatives 173, 174

Sittenwidrigkeits clause 72, 178, 179, 184

Social Democratic Party 117, 125n62, 171, 176

Social Insurance Authority 182, $183 \mathrm{n} 113$

Social Law amendment 184

STD checks 179-82

Supreme Court of Justice 72, 178, 179

authentic dialogue 246, 247

authoritative instruments 81, 97, 109, 110, 119, 122-4

Axelrod, R. and Cohen, M.D. 231

B

Beer, S. and Tremblay, F. 242

Bernstein, E. 7, 56

Better Red Lights Than Blue Lights see Lieber Rotlicht statt Blaulicht

Bevir, M. and Rhodes, R. 17

Bindel, J. 200, 202n126, 205

border police $106 \mathrm{n} 45$

Bourgon, J. 251

Bovenkerk, F. et al (2006) 162

Bradley, K. 212

Brants, C. 89

Brodkin, E.Z. 77

brothels

building and safety regulations 89, 90

consultation with owners $78,83,91$, 153

decline of 97, 192

feminism and 150-1

and forced prostitution 141

inspections 98, 219, 252

legalisation 22, 52, 73-4, 84n38, 87, 92-116, 117, 120-3, 140, 154-9, 160-70, 213, 214, 235

licensing system 82, 128, 130, 131, 205, 237, 251

local regulation 65,76

'mortality' models 95

power of owners 52

prohibitionism 148

regulated tolerance of $88,89,188$

and taxation 183, 184

and veto 13

see also window prostitution

Bulgaria 4, 94, 101, 102, 103, 181, 186
C

Call Off Your Own Tired Ethics see COYOTE

Cambodia 55n 27

Canada 240, 241, 242, 249, 250

case study 1-3

'chain management' 79, 108, 109, 113, 191, 251

Chew, L. 4

Child Right 162

Christian Democrats 154, 156, 157, $160,164,167,268$

Christian fundamentalists 104, 139, 162, 163n90, 167, 261n150

Christian NGOs (non-governmental organisations) 176

Chuang, J.A. 10, 11, 31, 43

classification of sex workers 94

client criminalisation

feminist approach 176

local governance $65,125 \mathrm{n} 62$, 261n150, 267

and morality politics $44,62,71,232$

national governance $71,80,172$

and neo-abolitionism $12 \mathrm{n} 2$

and non-registered sex workers 116 , 117,169

tolerance zones 128, 129

cognitive-appreciative frameworks 54

co-governance 76

Cohen, J. 166

Cohen, M.D. et al (1972) 146

collaborative governance $231,232-55$

advocacy and the state 237-42

collaborative instruments 122,126

definition of 262

experiments with 191

and governance capacity 242-9

Comensha (NGO) 60

consociationalism 153

constructivist discourse analysis 12

consultation $83,90,92,126,127-8$, 152, 153

control and stigma 29-33

Convention for the Suppression of the Traffick in Persons and of the

Exploitation of the Prostitution of Others 194913

Corbin, A. 30n6

covenants 90, 153

COYOTE (Call Off Your Own Tired

Ethics) 237, 238 
criminal law

on exploitation 221

and legalisation 87, 171, 177

and modern slavery 212

as national 157, 158

and neo-abolitionism $11 \mathrm{n} 2$

and regulated tolerance 89

and sexual self-determination 185

and trafficking 53, 105

D

data registers 58-61

DCE (Directorate for Coordination of Emancipation Policy (Directie

Coördinatie Emancipatiebeleid) 149 , 150

debt 120, 205

deficit model 77

Dekker, H. et al (2006) 213, 214

democracy

and agonistic politics $35 \mathrm{n} 13,36$

experts and 20n5, 37n15

and facilitative leadership 248

and globalisation 243

and local governance $66,78,79$

and national governance 146, 192

and participation 234

detention centres 2

Directie Coördinatie Emancipatiebeleid

(Directorate for Coordination of

Emancipation Policy) see DCE

discourse analysis $11-12,13,15,136-8$

discourse coalition 139

disgust 38, 39n17, 40, 41

"displacement effects" 160

Dodillet, S. and Östergren, P. 36

domain-specific challenges 28, 29, 227-31

domestic workers, migrant 211, 212

Dortmund 64, 65

'double-counting' 274

drugs 88, 89, 94, 98, 133, 152, 160

Dutch Federation of National

Unions 165

DWP (Department for Work and Pensions) UK 43n20

\section{E}

Eastern European prostitutes exploitation of 94

local governance and 101-2 and migration 50, 198, 208, 275 national governance and 164, 175

tolerance zones 16

trafficking 55n27, 163 economic austerity 27

Edelman, M. 64n34

EEA (European Economic Area) 164, 185,209

eligibility 94

Elmore, R. 77

emergence 196, 197, 229

emotions 37, 38-42

enforcement

integrated 116

local governance 88-92, 100, 104, 105-6, 116, 122, 132, 140, 141

and police $53,128 \mathrm{n} 66$

and violence 254

'enforcement arrangements' 113, 167, $168,261 n 150$

Engeli, I. et al (2012) 34n12

entrapment 110, 113, 210

escort sector 93, 97n42, 160

essentialism 223

EU (European Union)

citizens 94, 102, 187

expansion of 94, 101, 164, 186

freedom of movement 209, 229

funding 119n55, 173n98

immigration law 210

privacy regulation 255

'third-country' nationals 187

European Convention on Human Rights 185

European Economic Area see EEA

Evangelische Omroep (Evangelical

Broadcasting) 162, 163n90

exogenous economic approaches 17

'experts'

and bureaucracy 117,118

challenges to 236

constructivism and 12

and democracy 20n5, 66

discourse analysis and 12

domain-specific 123

and institutional resistance 45

lay people as 36,37

and local governance 83, 123, 124 , 126

and national governance 146, 166, 172

'welfarism' and 15

exploitation

after registration 122

and control 51, 170

and immigration 4, 24, 53, 94, 101, 102, 103-6, 109, 195, 200-8, 211, 212, 213-25

and licensing system 98 
local governance 112, 116, 124

lower-end labour market 51, 52, 223 , 224

media generalisations on 37

prevalence of $115 \mathrm{n} 52$

and regulation 89

and tolerance zones 16

$\mathbf{F}$

facilitative leadership 248

fantasmatic logic 11, 46-9, 141, 228, 233

female sexuality 29, 30, 151

feminism

and local governance 104

and morality politics 36

and national governance $87,148-52$,

153, 154, 155, 158, 159, 160, 161,

$164,171,172,173,174,176$

neo-abolitionism 34n11, 222

radical 11, 22, 31, 261

'transnational feminist approach' 8

Feministischer Diskurs (Feminist

Discourse) 42n18

financial instruments 81,82

fines

by brothel owners 213

and local governance $81,82,110$, 111, 119, 120, 121n59, 122, 123, 128, 129, 130

First World Whore Congress

Amsterdam 1985149

forced (involuntary) prostitution

'evidence' for 84n38, 163

feminist view 160, 161

and identity $30 \mathrm{n} 7$

media and 177

and national governance 167,170

and pimps 204

and trafficking 51, 66, 103, 137, 141, 203, 204-7, 218, 221, 222, 229

and voluntary prostitution 87,150 , 151, 155-6

Foucauldian tradition 12

Foucault, M. 180

France 66

Frauenberger, S. 125, 126, 127n63

Freedom Party Austria 125n62, 133

Friedman, M. 44

Fudge, M. 212

Fuji Johnson, G. 249, 250, 254
G

Gall, G. 239, 240

Gallagher, A. 13

Gemeentewet (law on national and municipal governments) 157

gender relationships 29, 30, 175, 176, 179

General Local Ordinance model see APV

Germany 63, 66, 178n107

'gig economy' 224

Giner-Sorrolla, R. 38n17, 39n17

globalisation $8,50,53,242$

Glynos, J. and Howarth, D. 47

goal displacement 113, 114

Goggin, M.L. 267

governance

capacity $242-9$

collaborative $227-55$

concept of 19n4, 20-1

global regimes 7,10

human rights and 13

international 13

'legal governance' 126

local 71-143

national 145-93

and networks 20, 21

governmentality approach 14-15, 16

Groningen 52n26, 97n42, 117, 169

Grün, H. 179, 180, 181

H

Hamen, M. 176

Haveman, R. 151

healthcare

and brothel owners 96, 217

and deportation 187

funding for 45

and HIV/AIDS 222, 238, 242, 252

and institutional resistance 45

insurance 183

and licensing 93

and local governance 105, 107, 111, 112, 113, 117, 123

municipal public health 93, 94

and national governance 168, 174

social ambivalence and 190

STD prevention 85, 179-82, 190, 191

stigmatisation 227

Healy, C. et al (2010) 241 
Hells Angels 166

high-end enterprises 140, 166

HIV/AIDS 222, 238, 242, 252

Hohenems 65

home prostitution

administrative reports on 113

increase in 130, 131

lack of regulation 93, 94

prohibition of 33, 120, 167, 168, 169

Honeyball, M., Report on prostitution and sexual exploitation and its impact on gender equality 43

Howlett, M. 79, 80, 81, 82

Howlett, M. and Ramesh, M. 145

Howlett, M. et al (2009) 9, 10, 19

Hrzeniak, M. et al (2007) 176

human rights

and compulsory STD checks 181

Green Party and 176

and international governance 13, 18, 102

and legalisation 3

loss of $31,32,133,142,262$

and national governance 191, 192

to privacy 135

and Sex Worker Forum 174,

$181 \mathrm{n} 110$

and trafficking 51, 52, 53, 220

Hungary 103

Hupe, P. et al (2014) 72

I

ICRSE (International Committee

on the Rights of Sex Workers in

Europe) 31, 32, 215-16, 217

identity 30,47

ideology and morality policy 35,36

Idomeni 49, 50

'independency' 170

information

accuracy 43, 44, 54, 55-61, 227, 228, 274

collection 105

instruments 82, 110, 114

policies 124

Initiative for Whores (Initiative für Huren) 174

Inne, J.I. and Booher, D.E. 244, 247, 248

intake interviews 111

International Committee for Prostitutes' Rights 238

International Committee on the Rights of Sex Workers in Europe see ICRSE international protocols and agreements 9, 61, 62

internet prostitution and decline in sex facilities $97 \mathrm{n} 42$

and globalisation 6,53

governance of 110, 113

and home prostitution 168

and legalisation 101

statistics on 274

invited participation 234, 235

involuntary prostitution see forced prostitution

Ison, R. 196

Italy 2, 3, 16, 19n4, 66

J

Jahnsen, S. Ø. and Skilbrei, M.L. 71

Jeffrey, L.A. 32, 100

Jeffreys, S. 31

John, P. 146, 188

K

Kalayaan (charity) 211

Kempadoo, K. 8, 44, 50, 51

Kijkduin conference 1982 149, 150

Kingdon, J.W. 146, 147, 259

KLPD (Korps Landelijke Politiediensten - Dienst Nationale Recherche) 103, 104, 105

Kotiswaran, P. and Okyere, S. 199

Kreisky, B. 171

Krinsky, C. 161

L

La Strada (NGO) 171

Labour Inspection (Dutch agency) 218

labour rights

and civil law 95-6, 165-6

as goal of legalisation 87

lack of 205, 206

and local governance 93, 95-6

Modern Slavery Act 212

and morality politics 33

resistance to 33,84

Rode Draad report on 212, 213-18

Lakoff, G. 36n14

Landman, T. 267

Lane, J.E. 78, 142

language and moral position 33

Law for the Regulation of Prostitution and Suppression of Abuse in the Sex Industry see WRP

LEFÖ (NGO) 111, 112, 129, 133n75, 171, 173, 272

LEFÖ-Tampep (NGO) 59n32 
'legal governance' 126

licensing system $73,74-8,87,93$, 96-8, 104, 130-1

Lieber Rotlicht statt Blaulicht (Better Red Lights Than Blue Lights) 133n75

Lindblom, C. 147

Linder, S.H. and Peters, B.G. 83

local governance 71-143

Austria 117-43

importance of $61,62-8$

Netherlands 87-117, 142, 143

policy design 79,80

policy implementation 71-9

policy instruments $80,81-6$

and representation 234

and trafficking 230

'loverboys' 103n43, 161, 162

Lyon 237, 238

Lysbakken, A. 71

M

Mai, N. 206n127

maiz (NGO) 173n99, 272

male prostitution 50, 162, 257n149, $272 \mathrm{t}$

Man-Vrouw-Maatschappij (Man-WomanSociety) see MVM

mandatory identification requirements 164

Manin, B. 20n5

media, public 162-3

bias 37

on forced prostitution 163

on 'loverboys' 161, 162

and moral panics 161,162

and public discourse 176, 177

reports 124,125

resistance to facts 43

unreliable statistics 56

use by politicians 137

Mert, A. 48

migration 49, 50-4, 200-8, 229

classes of 209, 210

globalisation and 195

and labour exploitation 51, 52

law 2, 52, 157-8, 165, 210, 211-12

and national governance 164

rural to urban 50

and social networks 202, 207, 208

trends 8

MILENA (NGO) 171

minimum client age 153

Mitternachtsmission (charity) 64

mobility

causes of 214, 236, 239 impact of regulation $110,111,187$, 210

and migration 4, 6

and statistics 58, 60, 61, 227

'modern slavery' 208, 209-12

Modern Slavery Act 2015 UK 211, 212

Mooney, C.S. 36, 44

moral contagion 31

moral crusades 104

morality politics 33-49

emotional charge of $37,38-42$

fantasmatic logic $46-8$

as lay policy $36,37,228$

negative effect of 133,139, 158

resistance to facts $42,43-4$

and sudden change 45-6

Mouffe, C. 19, 35n13

MSSD (most similar systems design) 267

multi-agency collaboration 107, 108, 111

MVM (Man-Vrouw-Maatschappij) (ManWoman- Society) 149n80

\section{$\mathbf{N}$}

national governance 145-93

Austria 170-93

Netherlands 147, 148-70

National Rapporteur on Human

Trafficking 51, 59, 60, 62, 160, 266n151

needs assessments 65

'negative work notation' 106

neo-abolitionism 11, 22, 34n11

neoliberalism 15, 20, 212, 223

Netherlands

abolitionism 34, 159

administrative capacity $92-100$

authority-based measures 83

'backroom politics' 153

Bill 18202 151, 154, 158

Bill 21027 156, 157, 157-8

characteristics of sex workers 272-3t

Christian Democratic Party 154, 157, 164

coalition politics 153, 158, 160, 161, 167

collaboration 90, 91

Criminal Code 87, 158

cultural tolerance 88

data registers 59

Emancipation Council 159

expansion of sex industry 148, 151, 152 
Gemeentewet (Municipal Law) 66 information-based instruments 82 innovative administration 118 legalisation 9, 21, 22, 33, 52, 65, 76, 87-91, 94, 158, 163, 164

licensing and monitoring system $92-3$

local governance 87-116, 117

Morality Acts 1911148

national governance 147, 148-70

NGOs 152, 167, 171

'opting-in' arrangement 165-6

Penal Code 208, 211

progressivism 257

Raad van State 167

registration $80,86,88,89,96$

regulated tolerance $88,152,153$

religious media 159

Social Democratic party 149n80, $160,161,162$

statistics 56

tolerance zones 16

visa requirement 86

Wet Bibob 82, 97n42, 109, 110, 111, $166-7$

network approach 153

'network governance' 126

networks

instruments 82, 126, 127

tools 106,107

New Zealand

local regulation 63

Prostitution Reform Act 189, 252

self-organisation 240

Treaty of Waitanga 253n147

New Zealand Prostitutes' Collective see NZPC

NGOs (non-governmental

organisations)

Comensha 60

La Strada 171

LEFÖ 59n32, 111, 112, 129 ,

133n75, 171, 173, 272

and local governance 113, 124, 129, 130, 132, 173

maiz 173n99, 272

MILENA 171

and national governance 152, 167,

173, 174, 175, 183, 259

outreach work 124, 125, 129, 173, 271,272

and policy implementation 75

and policymaking $62,90,91,123$

Rode Draad 90, 98, 103, 149, 152, $166,212,213,241,251,254,255$ sex as work 176

SOPHIE 129, 173

SOPHIE-mobil 119n54

Tampep 59n32, 171, 196n123

on taxation 183

Nigeria 187, 208

Nordic model, client criminalisation 176

Norway 44n22, 71

Nussbaum, M.C. 39, 40, 41, 42

NZPC (New Zealand Prostitutes' Collective) 240, 241, 242, 251, 252-5

$\mathrm{O}$

O'Connell Davidson, J. 220

opting-in arrangement 102, 165-6

organisational instruments $81,124,126$

organised crime 88, 166

outreach work 271-2

and exploitation 101, 102

and interviews 201

NGOs and 124, 125, 129, 173, 271, 272

obstruction of 132

public health 96

Outshoorn, J.V. 9, 11, 46n25, 87, 150, 155n85, 156, 157, 160, 163, 167, 269

P

paternalism 29, 32, 173, 178

pedagogy and policy $12 \mathrm{n} 2,36,45$

personality disorder, prostitution as $30 \mathrm{n} 6$

Pheterson, G. 29, 30, 30n7, 38n16

Pickering, A. 232

pimps 51, 162, 202, 203-5

Platform 31 265, 268, 269

police

abuse by 16

corruption 2

influence on policy 128

loss of control 152

and migration 53

monitoring 105, 106

and regulation $93,96,121,135 \mathrm{n} 76$, 160

and street prostitution 134

Police Acts 75, 128n66

policy

complex fields 75, 195-200, 227 , $229,242,260-2$

design $13,21,36,71,79-80,82$, $100,125,127,130,231,236$ 
implementation $67,71,72-7,78$, 140

instruments $58,67,79-86,87$

networks 20-1, 68, 91-2, 145-7, 149, 150, 153, 155, 159, 237, 259, 260

regimes 3, 8, 9-12, 13, 62, 238

postcolonialism 8

'post-industrial' culture 7,8

poststructuralism 10

pragmatic approach

and collaborative governance 235

and regulated tolerance 89

state and non-state interaction 250

western European 22, 98, 154, 156, 188

Prior, P. et al (2013) 15

privatisation 20

procurement 82, 205-6

"progressive governance" 15

progressivism 22, 257

prohibition zones 119, 132, 174

prohibitionism 43, 54, 158

prohibitionist network 163

Prostitution Act see WPG

prostitution, definition of 57

Prostitution Information Centre

Amsterdam 32n9

prostitution-is-work frame 176

'protection' 95, 96

PROUD (advocacy organisation) 150, 207

public health services 96, 105, 122

public order 149

$\mathbf{R}$

Ramesar, P. 85n38

rape $1,11 \mathrm{n} 2,40,42 \mathrm{n} 18,150 \mathrm{n} 82,160$, 204

recursiveness $108 \mathrm{n} 47,109 \mathrm{n} 47$

redbaiting 42

red-light district manager 89

registration systems $80,86,111,121$, 122

regulated tolerance 89,90

regulatory drift $113,114,139$

Reich, R. 63, 64, 246

repression 114, 116, 134, 141-3, 192

research design and methodology 26575

residents and street prostitution

campaigns by $16,64,65,124,125$, 177

and expansion of sex industry 148

impact on 88 and local governance $119,132-4$

representation of 127

resistance

to evaluation 44

to facts 42

institutional 45, 46

and policymaking 233

and regulations 83

and stigma 100

Roberts, K. 211

Rode Draad (Red Thread) (NGO)

conferences $152 \mathrm{n} 83$

funding 149, 254, 255

and local governance 90

and Prostitution Advisory

Commission 251

and state 241

survey 98, 103, 212, 213

Roessingh, M. 85n38

Roessingh, M. and Ramesar, P., Slaves

in the Polder. How Sex Workers,

Cleaners, and Seasonal Laborers are

being Exploited 84n38, 94

Roma migrants 103, 181

Romania 101, 102, 181, 186

Rose, N. and Miller, P. 14

Rotterdam

administrative measures 110

chain management 108

closure toleration zones 102

Eros Centre 148

regulation 91

street prostitution 91

'toleration visas' $52 \mathrm{n} 26$

\section{$S$}

Sabitzer, W. 179

Salzburg 187

San Francisco 237

Sanghere, J. 205, 222

Sautner, L. 177

Sayer, A. 223n139

Scarlet Alliance, Australia 240

Schaapman, K. 160

Schaapman report 163

Schaffauser, T. 29

Schengen visas 187

Schlesinger, W., Prostitution in Wien und Paris (Prostitution in Vienna and Paris) 120,121

Schön, D. 46, 47

Schön, D. and Rein, M. 54, 64, 80

Scoular, J. and O'Neill, M. 14, 15

Segers, G.-J. 56n28, 162

self-employment 213, 239 
self-organisation $174,237-42,248$

sequential stage model of policymaking 146

sex clubs 101

'sex farms' 148n79

Sex Purchase Act (2009) Norway 71

Sex Purchase Act (2014) Sweden 44, 45

Sex Worker Forum 174

sexual violence 149,150

sexually transmitted diseases see STDs

Sexworker Forum 181n110

Sheridan, K. 38n17

Shove, E. et al (2012) 90

Siegel, D., Closing Brothels or Closing Eyes 116

Sneep case, human trafficking 103-4, 163

social media 53

social security insurance 182, 183

SOPHIE (NGO) 129, 173

SOPHIE-mobil (NGO) 119n54

"Stable State" (Schön) 46, 47, 48

the state $5,6-21,31-2,68$

statistics 54, 55-61, 227, 228, 274

Stavrakakis, Y. 48

STDs (sexually transmitted diseases) 31, 85, 96, 149, 179-82, 190, 191 see also HIV/AIDS

Stella $196 n 123$

stigmatisation 29-33

and compulsory STD checks 179, 181

and contamination 164

and control 29-33

and emotions 41

and exclusion 73

impact on policy 32

and local governance 100, 101-16, 117,118

and procurement 206

and regulation 170, 227

and policy intervention 94

and Sittenwidrigkeits clause 72

and threat to social norms 30,31

Stockholm 44n23, 76

Stone, D. 35, 48, 57, 83, 84, 85, 139

street prostitution $16,102,123,125$, 134

structural violence 31,32

STV (Stichting Tegen Vrouwenhandel)

(Foundation against Trafficking in Women) 149

substance addiction 16, 38n16, 102, 160
Sullivan, B. 189, 190

Sweden 44, 261

Sex Purchase Act 2014 36, 44, 45

Switzerland 178n107

\section{$\mathrm{T}$}

Tampep (NGO) 59n32, 171, 196n123

taxation 4, 5, 66, 140n78, 174, 182, 183-5

The Hague

authority-based measures 83

Chamber of Commerce 106n45, 107

'enforcement arrangement' 105, 106

legal definitions of brothel $92 \mathrm{n} 40$

information collection 105

intake interviews 111

legalisation 235

licensing system $73,74,76,77,78$, 82

loss of control 88

policy network 20, 21

registration systems 117

regulation 90, 91

window prostitution $97 \mathrm{n} 42$

tolerance zones 16, 101, 102, 127, $129 n 68$

'toleration visa' $52 \mathrm{n} 26$

trafficking

and asylum seekers 185, 186

Austrian Penal Code 177n106

'barrier model' 114, 115

increase in 160

labour sectors $50,51,52,71$

and legislation 53, 54, 172, 205

and local governance 93, 109,

111-16, 141-3

and media 51, 52, 162

migrant prostitution as $101,102,195$

national police networks 96

national governance 116, 150, 151,

153, 176, 189

Netherlands bill 154, 155-7

and registration 111

Sneep case 103-6

statistics $55 \mathrm{n} 27,138$

UN agreement 62

UN definition 208

transgender prostitution $174,272 \mathrm{t}$

'transnational feminist' approach 8

Trilling, D. 49, 50

trust

and collaboration 53, 235, 241, 246, 249, 253

and data collection $269,270,271$ 
and local governance 78, 85, 86, 109,

111, 116n53, 138, 141, 142

and national governance 145,150 , 153

\section{U}

UK (United Kingdom)

benefit sanctions $43 \mathrm{n} 20$

discourse 66

exploitation 206n127

Modern Slavery Act 2015 211-12, 218

national governance 188

National Referral Mechanism 211

UN Protocol to Prevent, Suppress and Punish Trafficking in Persons, Especially Women and Children 9, 10, 13, 62, 161, 208, 220, 221

unionisation 95, 165, 185n118, 217, 238, 239-40

unpaid 'internships' 224n141

urban gentrification 16, 27, 117, 119, 169

US (United States) 22, 34n11, 43, 240, 257

Utrecht

forced prostitution 103

registration 105, 112, 114, 115

tolerance zones 102

window prostitution $97 \mathrm{n} 42,103$, 104, 105, 114, 115, 116

\section{V}

Valkenburg case, Netherlands 38n17 van de Beer, M. 200, 205

van der Laan, E. 167

van Wijk, A. 269

van Wijk, A. et al (2010) 56n30

Vance, C.S. 51, 53, 222, 229

Vancouver 250, 254

veto, power of 13, 24, 129, 156, 158, 189,259

VdPÖ (Verband der Prostituierten

Österreichs) (Association of Austrian

Prostitutes) 174

Vienna

authoritative instruments 119

local governance 83, 117-34, 135

organisational instrument 81

police 121

prostitution and criminality 176

registration 111,112

regulation 118, 119-24

semi-formal legalisation of brothels 120 'seven-point plan' 125, 126

soliciting 119, 120

street prostitution 16, 119, 120

zones 129, 130-2

Viennese Police Act 118

Viennese Police Regulation for

Prostitution 1974119

Viennese Prostitution Act 2011 see WPG

violence $171,214-16$

visas

and accession countries 86

EU and EEA 209

non-EEA citizens 186

'prostitution visas' 3, 53, 187

Schengen visas 187

'toleration visas' $52 \mathrm{n} 26$

UK overseas workers 211

US 210n130

VNG (Vereniging van Nederlandse

Gemeenten) (Association of Dutch

Municipalities) 76, 93, 96, 116, 148,170

voluntary prostitution

as distinct from involuntary 87,89 , 98, 150, 154, 155-7, 207

prostitution as work 151, 158

and Sex Worker Forum 174

Vorarlberg, Austria 33, 65

Vorarlberg Police Act 65

\section{W}

Wagenaar, H. 43n21, 85n38, 98, 99, 162n89, 198

Wagenaar, H. and Altink, S. 33n10

Waldenberg, A. 174

Walters, W. 14

Warren, M.E. 21, 82, 234, 235, 243

'watch list' 106

Weitzer, R. 55n27, 104, 195, 269

'welfarism' approach 15, 16

Wet Arbeid Vreemdelingen (Law Regulating Work for Aliens) 164

Wet Bibob 82, 97n42, 109, 110, 111

Integrity Assessment Act 166-7

Wet Regulering Prostitution (Law for the Regulation of Prostitution) see WRP

window prostitution

closures 65, 97, 110, 116, 169

exploitation 103, 104, 106n46

forced 163

information $60,61,105$

tolerance to 148 
Index

WODC (Centre for Scientific Research and Documentation) 160

women's emancipation 149-51, 159

WPG (Viennese Prostitution Act 2011) and collaboration 236, 237

and local governance $74,82,119-20$, 122-5, 128-34, 141, 143

and national governance 175

WRP (Wet Regulering Prostitution)

(Law for the Regulation of

Prostitution) 116, 167-8, 232

Z

zero hour contracts $224 n 141$

Zola, É. 30n6

zoning laws and urban spaces 6,15 , $129,130-2$

Zuidema, R. et al (2006) 95, 95n41 


\section{"A splendid, evidence-based analysis of policies related to sexual commerce and labour migration in Europe. Scholars and policymakers will find the book's findings of tremendous value as they weigh alternative proposals for regulating commercial sex." \\ Ronald Weitzer, George Washington University, USA}

While the debate on regulating prostitution usually focuses on national policy, it is local policy measures that have the most impact on the ground. This book is the first to offer a detailed analysis of the design and implementation of prostitution policy at the local level and carefully situates local policy practices in national policymaking and transnational trends in labour migration and exploitation.

Based on detailed comparative research in Austria and the Netherlands, and bringing in experiences in countries such as New Zealand and Sweden, it analyses the policy instruments employed by local administrators to control prostitution and sex workers. Bridging the gap between theory and policy, emphasising the multilevel nature of prostitution policy, while also highlighting more effective policies on prostitution, migration and labour exploitation, this unique book fills a gap in the literature on this contentious and important social issue.

Hendrik Wagenaar is Professor of Urban Studies and Planning at the University of Sheffield. In 2013 he completed a 3-year international comparative study of prostitution policy. He is a founding member of the COST Action 'Comparing European Prostitution Policies'. He publishes in the areas of citizen participation, prostitution policy, practice theory and interpretive policy analysis.

Helga Amesberger is senior researcher at the Institute of Conflict Research in Vienna. Her main research topics are violence against women (current and historical), racism and prostitution policy and she has widely published on these subjects. Her book about sex work in Austria is regarded as standard reference. In 2012 she was awarded the Austrian Käthe Leichter Preis for her work on women's studies and the promotion of equality for women.

Sietske Altink has an MA in philosophy and was a researcher at the comparative study of prostitution policy. Since the 1980 s she has researched prostitution (for the ministry of social affairs in the Netherlands), worked with migrants at the Foundation against Trafficking in Women and managed the Dutch NGO "De Rode Draad" (Red Thread). She is a key figure in the prostitution debate in the Netherlands and is sought out for her wide knowledge of prostitution policy for lectures, presentations and media appearances.

PUBLIC POLICY / SOCIAL STUDIES

\section{Policy Press}

UNIVERSITY OF BRISTOL

www.policypress.co.uk
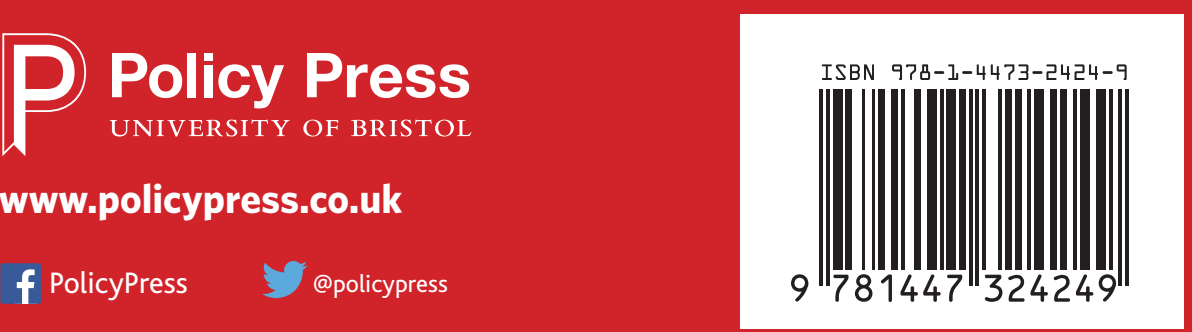